\title{
Catchment sediment dynamics and the role of deep-seated landslide-dams; Waipaoa catchment, Raukumara Peninsula, New Zealand.
}

Richard James Taylor

A thesis submitted to Victoria University Wellington in partial fulfilment of the requirements for the degree of Master of Science with Honours in Physical Geography

School of Geography, Environment and Earth Sciences

August 2011 


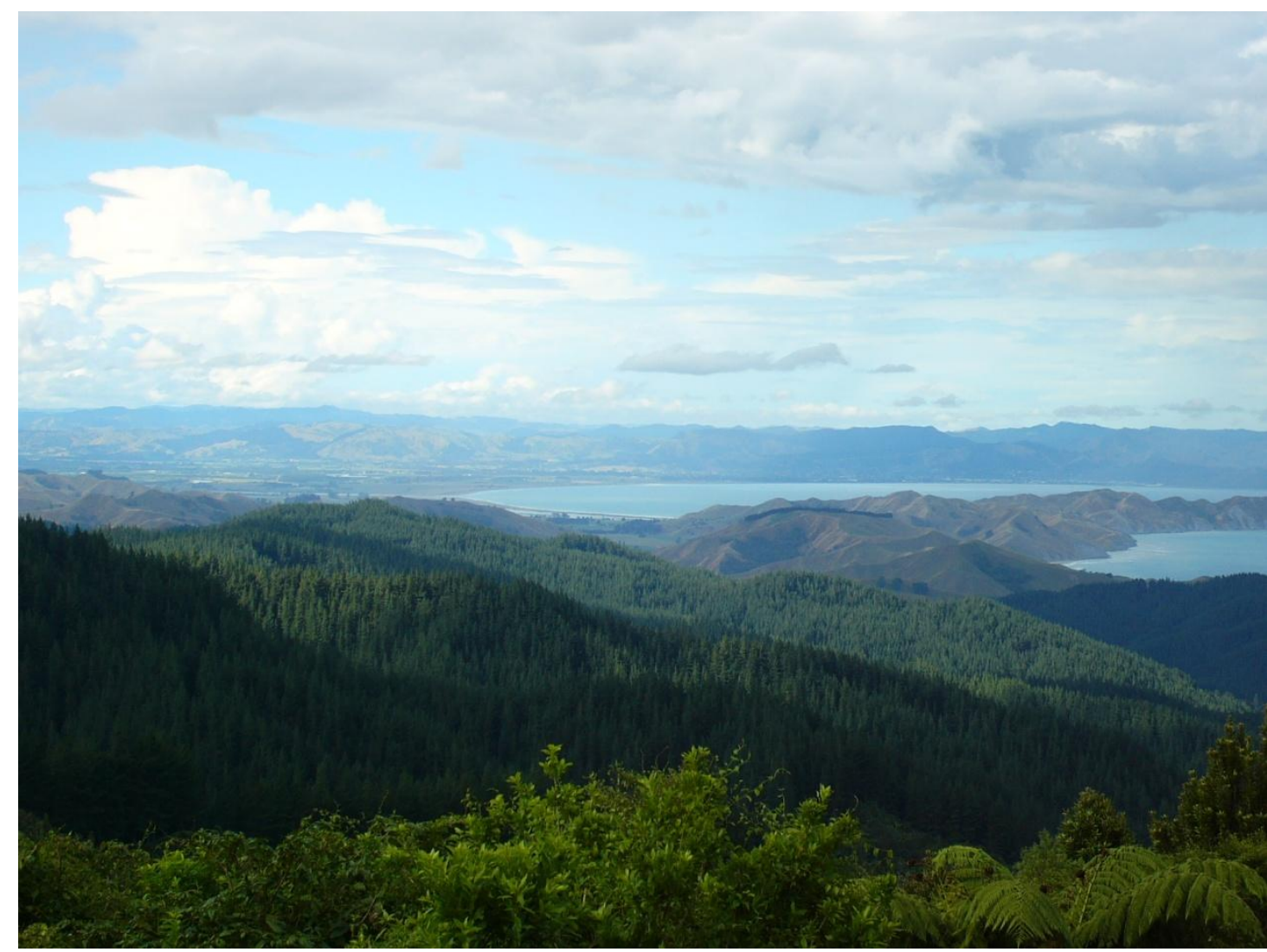

Looking north towards the Poverty Bay Flats and Young Nick's Head from the southern hills of the Waipaoa catchment.

"Let's think the unthinkable, let's do the undoable. Let us prepare to grapple with the ineffable itself, and see if we may not eff it after all." (Douglas Adams) 
Sediment volumes retained by landslide-dams of the Waipaoa are small at $1.85 \times 10^{6} \mathrm{~m}^{3}$ compared to the $24.5 \mathrm{~km}^{3}$ (Marden et al., 2008b) of sediment eroded in the landscape since the last glacial maximum. Landslide-dams do however represent a major perturbation to sediment transport, although due to their mainly short life span this disruption is discontinuous representing a pulsing in the transport network. The objective of this study is to investigate the sedimentary dynamics of the Waipaoa catchment by providing insights into the role that deep-seated landslides play and asks the questions: What is the impact on sediment transport imposed by the landslidedams of the Waipaoa catchment? and; What do the sediments impounded in landslidedammed lakes tell us about catchment sediment dynamics through time?

The Waipaoa River on the East Cape of New Zealand's North Island delivers volumes of sediment to the coast which are considered high by global standards. Catchment erosion is controlled by soft marine sediments, combined with a history of tectonic fracturing and frequent intense rain storms. Erosion events are driven by intense cyclonic systems rain storms which deliver $\geq 200 \mathrm{~mm} / 24 \mathrm{hr}$ rainfall and induce catchment wide gully erosion as well as shallow surficial landslides. Under current land covers gully erosion provides the dominant source of sediments, with high degrees of slope channel coupling and steep gradient river profiles providing for efficient delivery to the coast. Offshore in the Poverty Bay, sediments delivered by the Waipaoa River show considerable variability over a range of temporal scales.

Valley slopes within the Waipaoa catchment are also susceptible to large deep-seated landslide failures, with movement depths greater than 5 metres often on internal structural failure planes. These large slope movements can be produced by both extreme storm events $(\geq 300 \mathrm{~mm} / 24 \mathrm{hr}$ ) which occur on a return periods of 1 in 5 years and seismic ground shaking of 1 in 1000-2000 years. Where these large events block channels and are able to persist for long periods, sediments accumulated upstream to provide a unique record of the catchments sedimentary history. There have been some 1100 historic large scale features which have been identified within the Waipaoa region, with this study selecting seven that have shown evidence of channel blockage.

The project aims to provide insights into the age of a sample of deep-seated landslides that have dammed channels to determine how long landslide-dams survive in the landscape and quantify the volumes of sediment they have trapped. Further, the project aims to determine what the spatial and temporal distribution of these blockages has meant to sediment delivery and whether there have been changes in sediment dynamics in their upper catchments over time. The project uses the detailed mapping of the trapped body of sediments, GIS modelling of the palaeo and present landscapes and age control determinations provided by tephra and 14C dating to provide both volumes and rates of sediment delivery. 


\section{Acknowledgements}

This work is dedicated in memory of Dr Nick Preston, supervisor, mentor, role model and friend. It has largely been due to the support, encouragement and guidance that Nick provided throughout my undergraduate and then onto and including my postgraduate work which has motivated me in my research.

Without doubt, no academic thesis would be possible without good academic supervision. In this I have been privileged to be under the guidance of Professors Rewi Newnham and Brent Alloway, who have with patience and good humour supported and nurtured this project. While the project was outside their individual areas of specialisation and the supervision of my work was a last minute commitment, they nonetheless have been dedicated to the cause.

My scientific supervision and advisor on all things landslide has come from Mr Mike Page, who is a scientist I have looked up to throughout my short but intense academic carrier and whom I'm very proud and privileged to be able to work with. Throughout this project Mike has been a constant source of inspiration and has challenged my thinking and understanding of the landscapes of the Waipaoa.

I'm grateful for the financial backing from GNS science and the MARGINs project team who have made the project what it is. The direction of Dr Nicola Leitchfield as project leader from the principal mission has provided constant support in terms of project resources, funding and motivation to produce the best results possible. I'm grateful for the opportunity to be part of such an influential project at the cutting edge of research in landscape evolution.

Field assistance was provided by Hamish McCoy and John Ballinger who have each in their own way helped to shape this project. I also wish to acknowledge the help that John and the others from "The Undergraduates" who moved on to postgraduate study together have provided. As a close-nit team we have achieved a lot during the years of study together and have collectively developed into scientists. I wish you all well in your future careers.

Above all else I'm indebted to my lovely wife Kai, who has been my rock throughout what has been a difficult and sometimes frustrating journey of discovery. Without the unwavering support she has provided from beginning to end, from where there has been great hope and joy, through to the times when all was lost in the pit of despair, there would be no thesis. I'm indebted for her belief in my vision and in this journey and without her love and support none of this would have been possible. 


\section{Table of Contents}

Abstract .................................................................. iii

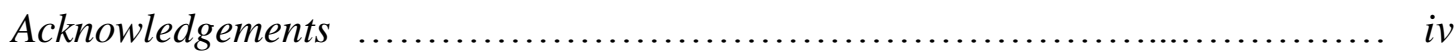

Table of Contents ....................................................... v

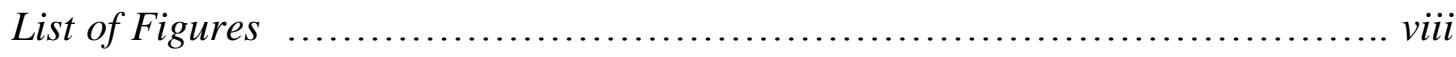

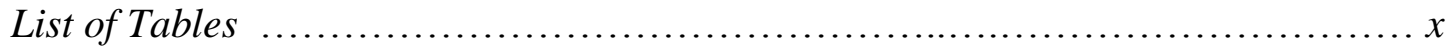

Chapter 1: A view of the changing landscapes of the Waipaoa

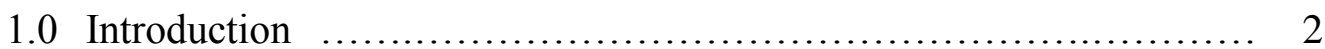

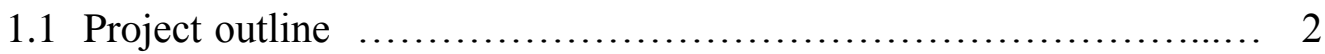

1.2 Justification: Source to sink and landscape connectivity .............. 4

1.3 New Zealand context and the 'MARGINS' project ............... 6

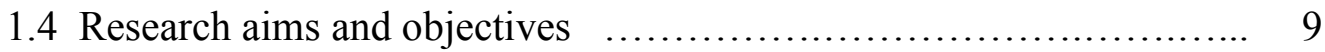

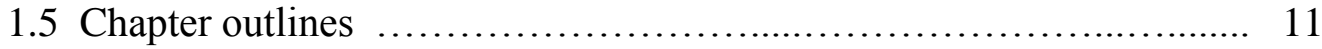

Chapter 2: Landslide-dams, sedimentation and landscape connectivity in review

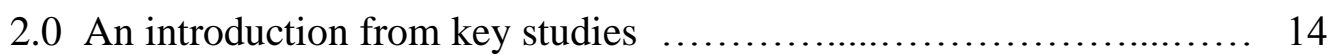

2.1 Geomorphology and the role of large landslides ...................... 14

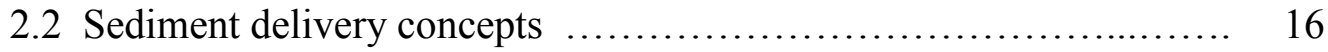

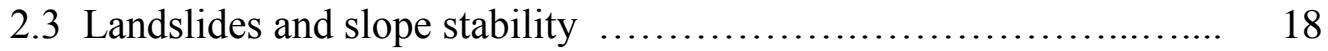

2.3.1 Landslide features, types and triggers $\ldots \ldots \ldots \ldots \ldots \ldots \ldots . \ldots$

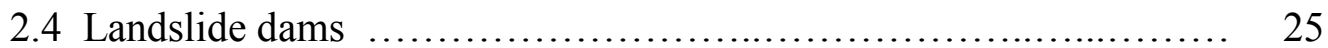

2.4.1 Dam longevity and modes of failure ................... 27

2.4.2 Large landslides and landslide dams .................... 28

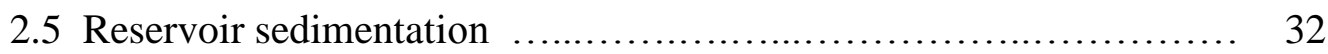

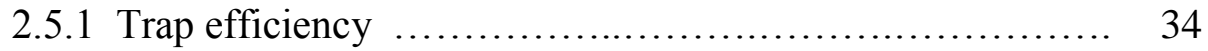

2.5.2 In justification of small reservoir studies .................. 37

2.6 Current and future research on sediment flux in the Waiapaoa .......... 38

2.6.1 The East Cape and Raukumara ranges f.................... 38

2.6.2 Totangi landslide-dam Gisborne .......................... 41

2.6.3 Current and ongoing studies $\ldots \ldots \ldots \ldots \ldots \ldots \ldots \ldots \ldots \ldots . \ldots \ldots \ldots$

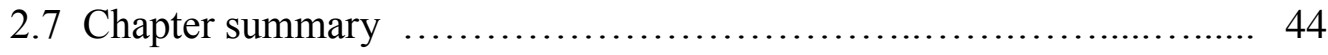


Chapter 3 Factors of control for landslide-dams and rates of sedimentation in the Waipaoa

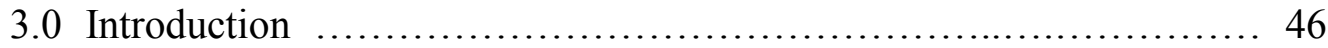

3.1 The Waipaoa River; a general setting .......................... 46

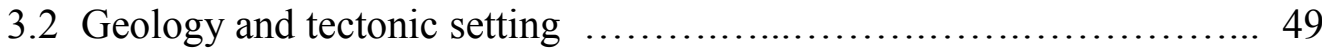

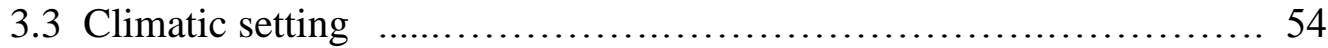

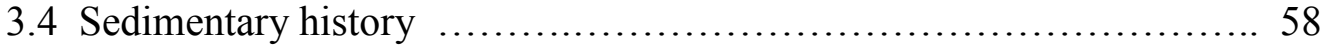

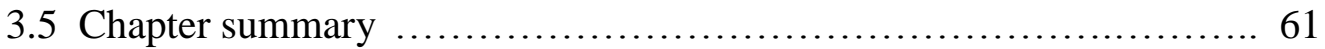

\section{Chapter 4 The Waipaoa; mapping, modelling and the study sites}

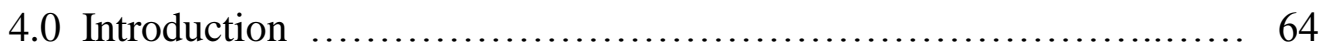

4.1 Large landslides database and the site selection process $\ldots \ldots \ldots \ldots \ldots 66$

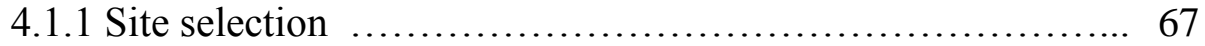

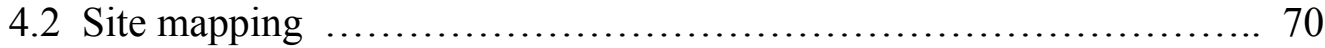

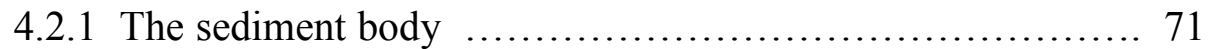

4.2.2 Differential GPS ........................................ 73

4.3 Coring and sediment body volume estimates ............... 74

4.3.1 Core site selection and coring methods ................... 75

4.3.2 Core sampling and bulk density $\ldots \ldots \ldots \ldots \ldots \ldots \ldots \ldots \ldots . \ldots . \ldots . \ldots 77$

4.4 Computer modelling ..................................... 79

4.4.1 DEM's and the palaeo-valley surface ...................... 82

4.4.2 The sediment body and volumetric calculations f............. 85

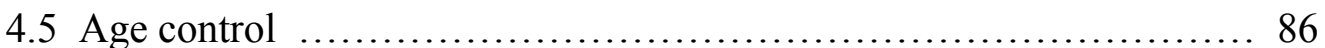

4.5.1 Radio Carbon (14C) dating ........................... 86

4.5.2 Tephra (Electron Micro Probe) ....................... 88

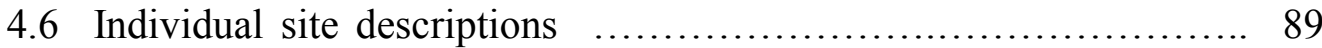

4.7 Estimates of and possible sources for error ..................... 99

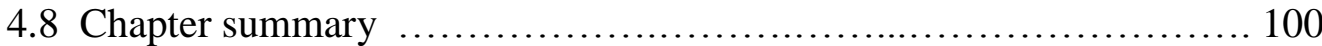

Chapter 5 Towards an understanding of the sediment dynamics of a large catchment

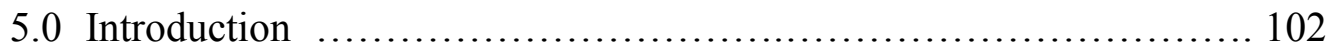

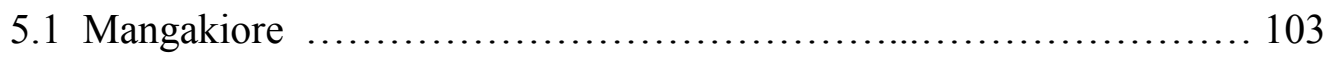

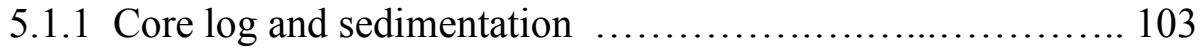




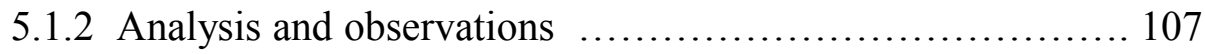

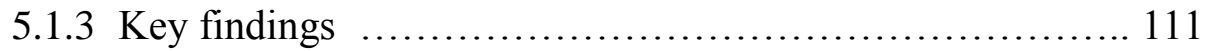

5.2 Kopaatuaki ............................................. 111

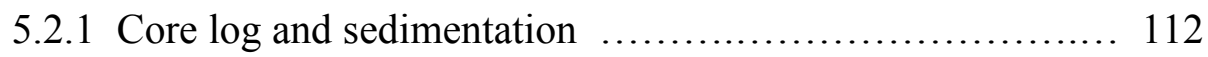

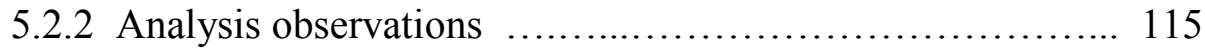

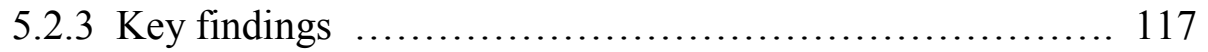

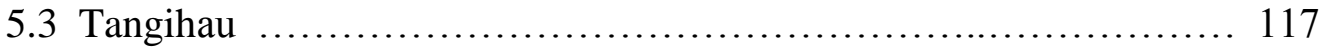

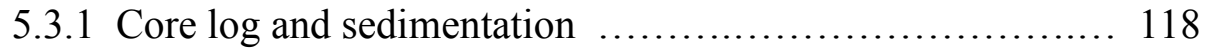

5.3.2 Analysis observations .................................. 121

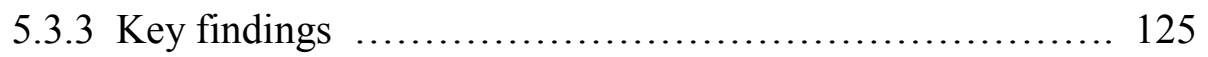

5.4 Monck Road ................................................ 126

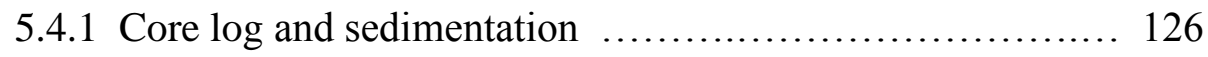

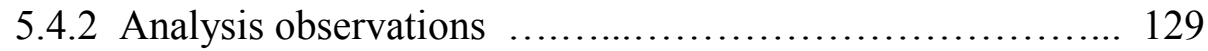

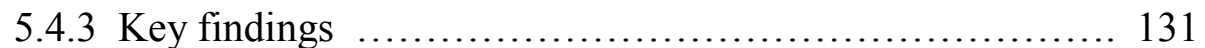

5.5 Maungahuri (...................................................... 132

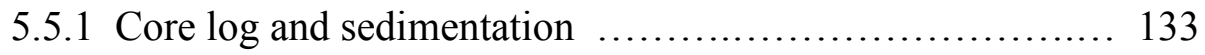

5.5.2 Analysis observations ................................. 135

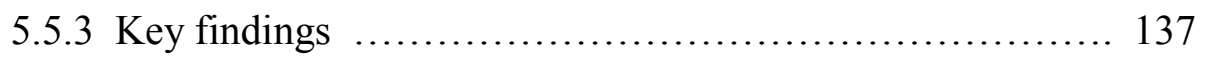

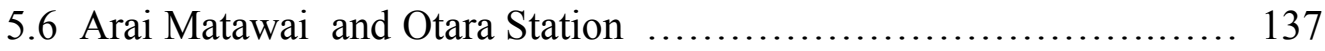

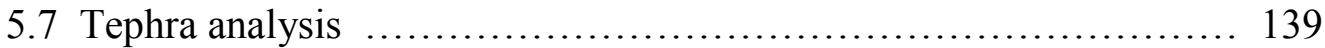

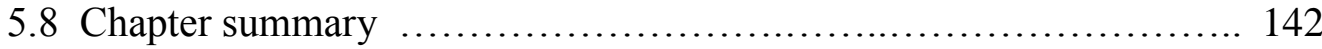

Chapter 6 The measure of control; landslide-dams and the Waipaoa regions sedimentary regime

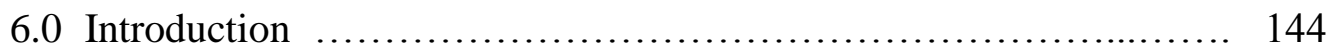

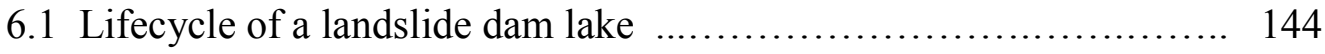

6.2 Quantifying sediment volumes and timing for landslide-dams f....... 147

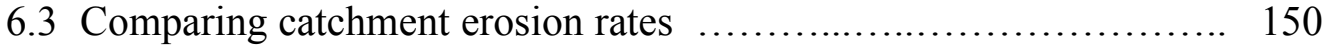

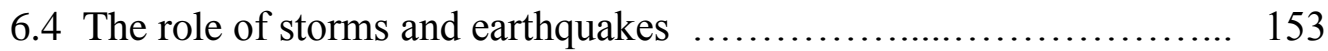

6.5 The spatial and temporal influence on sediment delivery $\ldots \ldots \ldots \ldots .156$

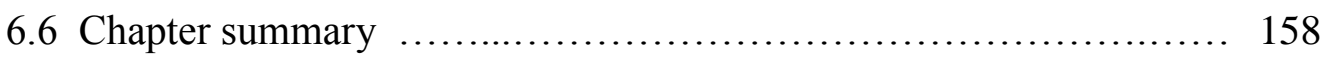


Chapter 7 Conclusions and reflections on landslide-dams lakes in palaeoenvironmental research

7.1 Conclusions of sedimentary significance $\ldots \ldots \ldots \ldots \ldots \ldots \ldots \ldots \ldots 1$

7.2 Musings, conjecture and future research $\ldots \ldots \ldots \ldots \ldots \ldots \ldots \ldots \ldots . \ldots \ldots$

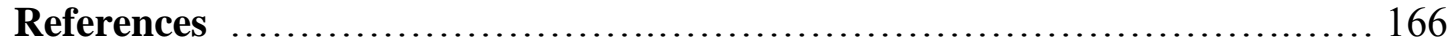

\section{Appendix}

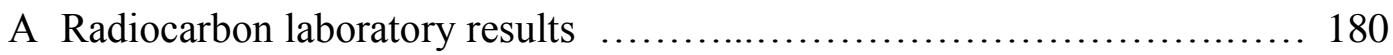

B Mangakiore rain gauge data ...................................... 204

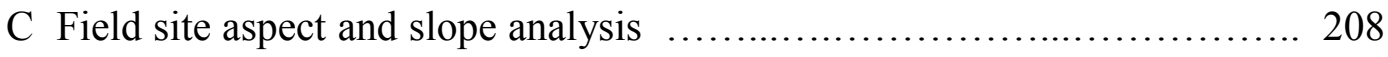

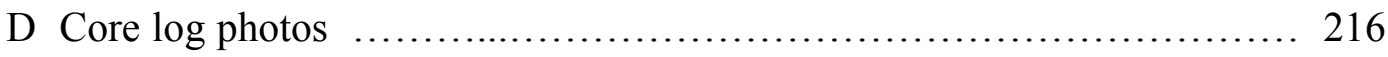

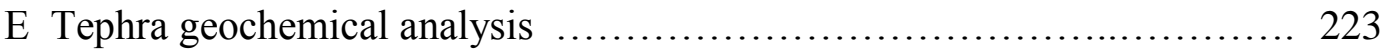

\section{List of figures}

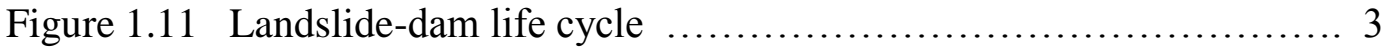

Figure 1.31 A simple model for an idealised sedimentary system ............ 7

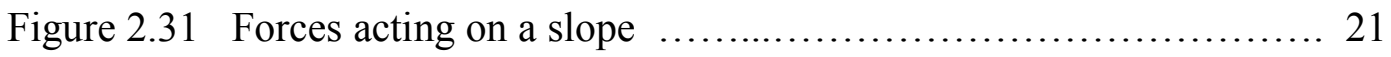

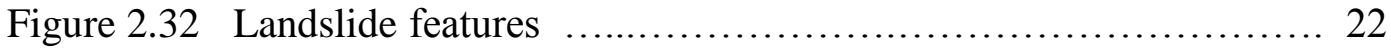

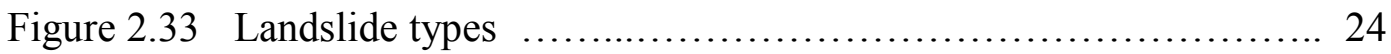

Figure 2.41 Geomorphic classification of landslide dam types $\ldots . \ldots \ldots \ldots \ldots . .26$

Figure 2.51 Factors that influence the trapping efficiency of reservoirs ...... 36

Figure 2.61 Long profile of a typical Waipaoa knickpoint .......................... 40

Figure 3.11 Key features for the Waipaoa sedimentary system $\ldots \ldots \ldots \ldots \ldots . \ldots 47$

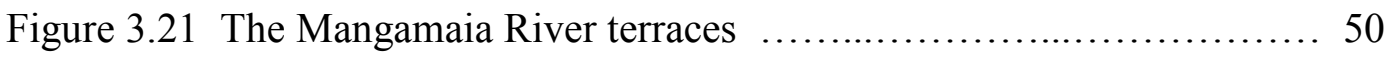

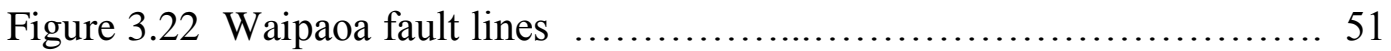

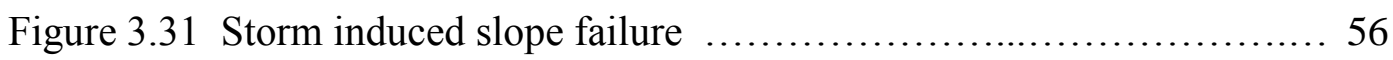

Figure 4.01 Flow diagram research objectives and the key task areas ....... 65

Figure 4.11 The large landslides database $\ldots \ldots \ldots \ldots \ldots \ldots \ldots \ldots \ldots \ldots \ldots . \ldots 6 . \ldots \ldots$

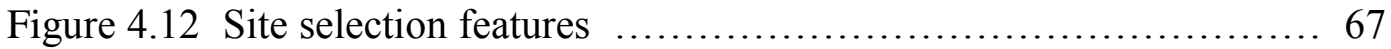

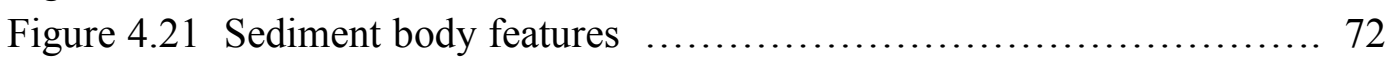

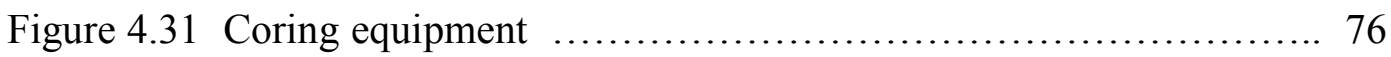

Figure 4.41 The GIS representation of reality $\ldots \ldots \ldots \ldots \ldots \ldots \ldots \ldots \ldots \ldots . \ldots . \ldots \ldots$

Figure 4.42 The vector and raster representation of the real world .......... 81 


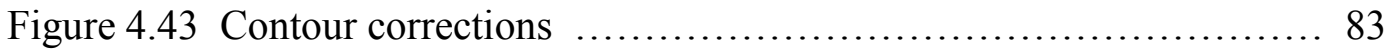

Figure 4.44 Contour adjustments to local scale ......................... 84

Figure 4.51 Radiocarbon sample preparation .......................... 87

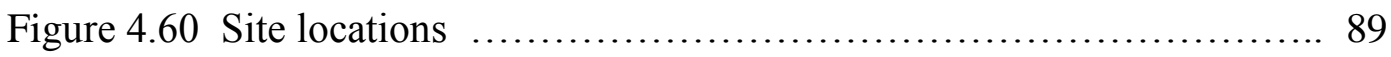

Figure 4.61. Mangakiore slope and aspect details $\ldots \ldots \ldots \ldots \ldots \ldots \ldots \ldots \ldots . \ldots 0$

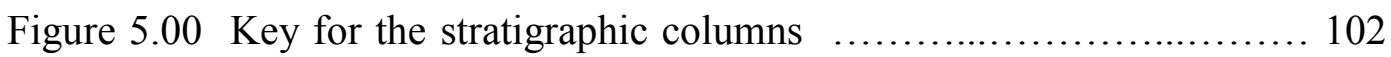

Figure 5.11 3D model of the Mangakiore landscape ....................... 103

Figure 5.12 Mangakiore site showing landslide and valley infill .............. 105

Figure 5.13 Core $\log$ for the Mangakiore field site ....................... 106

Figure 5.14 Sedimentation curves for the Mangakiore field site ............. 107

Figure 5.15 The Mangakiore landslide following the Cyclone Bola ......... 108

Figure 5.16 The Anaora Bay landslide ............................... 110

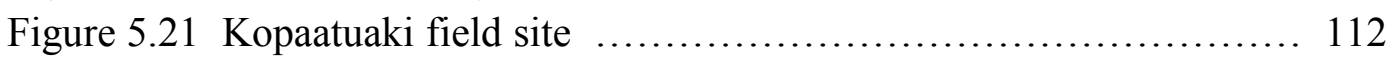

Figure 5.22 Kopaatuaki site showing landslides and valley infill ........... 113

Figure 5.23 Core log for the Kopaatuaki sediment body ................. 114

Figure 5.24 Sedimentation curves for the Kopaatuaki sediment body ....... 115

Figure 5.31 3D model of the Tangihau landscape ...................... 118

Figure 5.32 The Tangihau sedimentbody infill and distribution ............ 119

Figure 5.33 Core $\log$ for the Tangihau sediment body .................... 120

Figure 5.34 Sedimentation curves for the Tangihau sediment body .......... 123

Figure 5.35 Tangihau upper and lower sediment body profiles .............. 124

Figure 5.41 The Monck Road field site ................................. 126

Figure 5.42 3D model of the Monck Road landscape ...................... 127

Figure 5.43 Core $\log$ for the Monck Road sediment body ................. 128

Figure 5.44 Sedimentation curves for the Monck Road sediment body ....... 130

Figure 5.51 The sediment body terrace for the Maungahaumi field site .... 132

Figure 5.52 The Maungahaumi sediment body infill and distribution ......... 133

Figure 5.53 Core log for the Maungahaumi Sediment body ................ 134

Figure 5.54 Sedimentation curves for the Maungahaumi sediment body ...... 136

Figure 5.55 The bedrock protecting the Maungahaumi sediment body ....... 136

Figure 5.61 The Arai Matawai sediment body infill distribution ............ 137

Figure 5.62 The Otara station sediment body infill distribution ............. 138

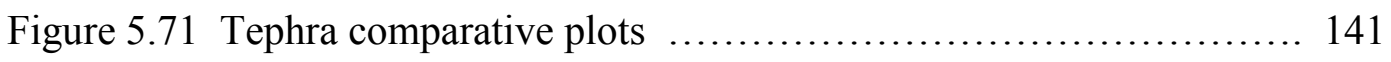

Figure 6.11 Landslide dam lake lifecycle $\ldots \ldots \ldots \ldots \ldots \ldots \ldots \ldots \ldots \ldots . \ldots \ldots$

Figure 6.31 Sedimentation curves for five of the study sites $\ldots \ldots \ldots \ldots \ldots \ldots 151$

Figure 6.41 Core log comparisons for the main sites .................... 154

Figure 6.42 Comparisons for erosion rates for Waipaoa core sites .......... 155 


\section{List of tables}

Table 2.31 An abbreviated classification of slope movements $\ldots \ldots \ldots \ldots \ldots . \ldots 18$

Table 2.32 Glossary for forming names of landslides .................... 19

Table 3.21 Recent regional earthquake data $\ldots \ldots \ldots \ldots \ldots \ldots \ldots \ldots \ldots \ldots . \ldots 2$

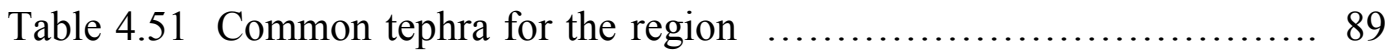

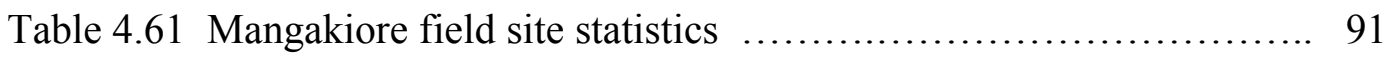

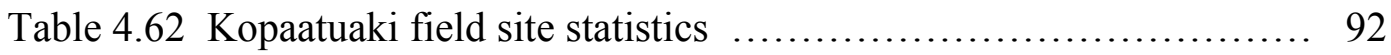

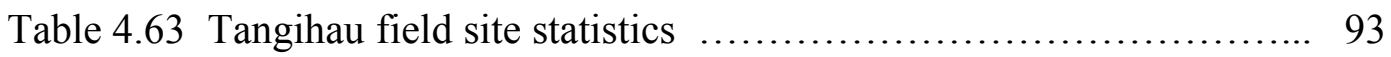

Table 4.64 Monck Road field site statistics ............................ 95

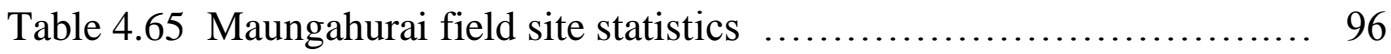

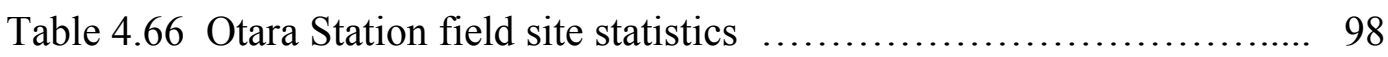

Table 4.67 Arai Matawai field site statistics ............................ 98

Table 5.11 Rainfall and soil moisture data for Mangakiore ............... 109

Table 5.12 Summary of key statistics for the Mangakiore landslide-dam .... 111

Table 5.21 Kopaatuaki core log age model .......................... 114

Table 5.22 Summary of key statistics for the Kopaatuaki landslide-dam ..... 116

Table 5.31 Tangihau core log age model ............................ 121

Table 5.32 key statistics for the Tangihau landslide-dam ................... 125

Table 5.33 Summary of key statistics for the upper Tangihau landslide-dam . 125

Table 5.41 Monck Road core log age model .......................... 128

Table 5.42 Key statistics for the Monck Road landslide-dam ................ 131

Table 5.51 Maungahurai core log age model ............................ 134

Table 5.52 Key statistics for the Maungahurai landslide-dam ............... 137

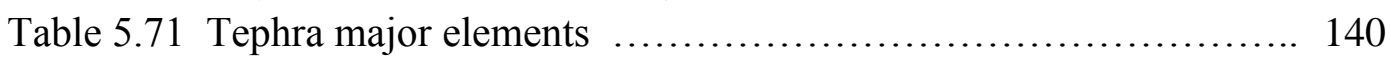

Table 6.21 Sediment volumes, ages for the landslide-dams ................ 148

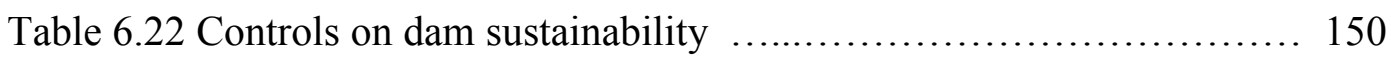

Table 6.31 Ranges in sedimentation rates f................................ 153

Table 6.51 Sediment volumes and projections $\ldots \ldots \ldots \ldots \ldots \ldots \ldots \ldots \ldots \ldots \ldots . \ldots \ldots$ 


\section{Chapter 1:}

\section{A view of the changing landscapes of the Waipaoa}




\subsection{Introduction}

The study of source to sink sediment progression and the investigation of sediment delivery ratios have become important tools for understanding catchment dynamics (Chorley and Kennedy, 1971). This however is not a straight forward process, as there are disruptions within the transport network in longitudinal, lateral or vertical direction which may operate over a range of timescales (Fryirs et al., 2007). This study aims to explore the spatial and temporal disruption to sediment transport caused by landslide-dams for a large catchment on the East coast New Zealand's North Island.

\subsection{Project outline}

Deep-seated landslides form a natural perturbation to sedimentary transport networks, and their occurrence in the Waipaoa catchment on the East Cape's Raukumara Ranges is not uncommon. When these large scale slope movements occur they may provide both a source and a barrier for sediments in transport networks. Where sediment pathways have been blocked by the onset of a large deep-seated landslide and this impediment to sediment transport has endured for long enough, there may be an accumulation of sediments upstream of the restriction. Figure 1.11 shows this accumulation of sediments and the study of these deposits provides a historical record of erosion and sediment transport within the landscape (Dearing and Foster, 1986, pp76). Whether at an individual site where accumulations have persisted to provide a long record of catchment dynamics or through the over lapping of multiple records, lake sediment derived sediment yields provide insights into palaeo-hydrological history of both environmental and human induced changes (Dearing and Foster, 1986, pp76; Verstraeten and Poesen, 2002).

This research project seeks to provide insights into environmental change within the greater Waipaoa catchment through understanding the spatial and temporal changes in sediment delivery. This can be done through the investigation of sediments impounded behind these landslide-dams. Dating the initiation of the onset for these large landslides may indicate large region wide disturbance events and understanding 
the rates of infill provides insights into catchment dynamics. Further, the geographic range as indicated by onset age, may provide an indication of a single event's magnitude. This prehistoric information has implications for the way modern erosion rates within the modern landscape are viewed and has implications for land management decisions.

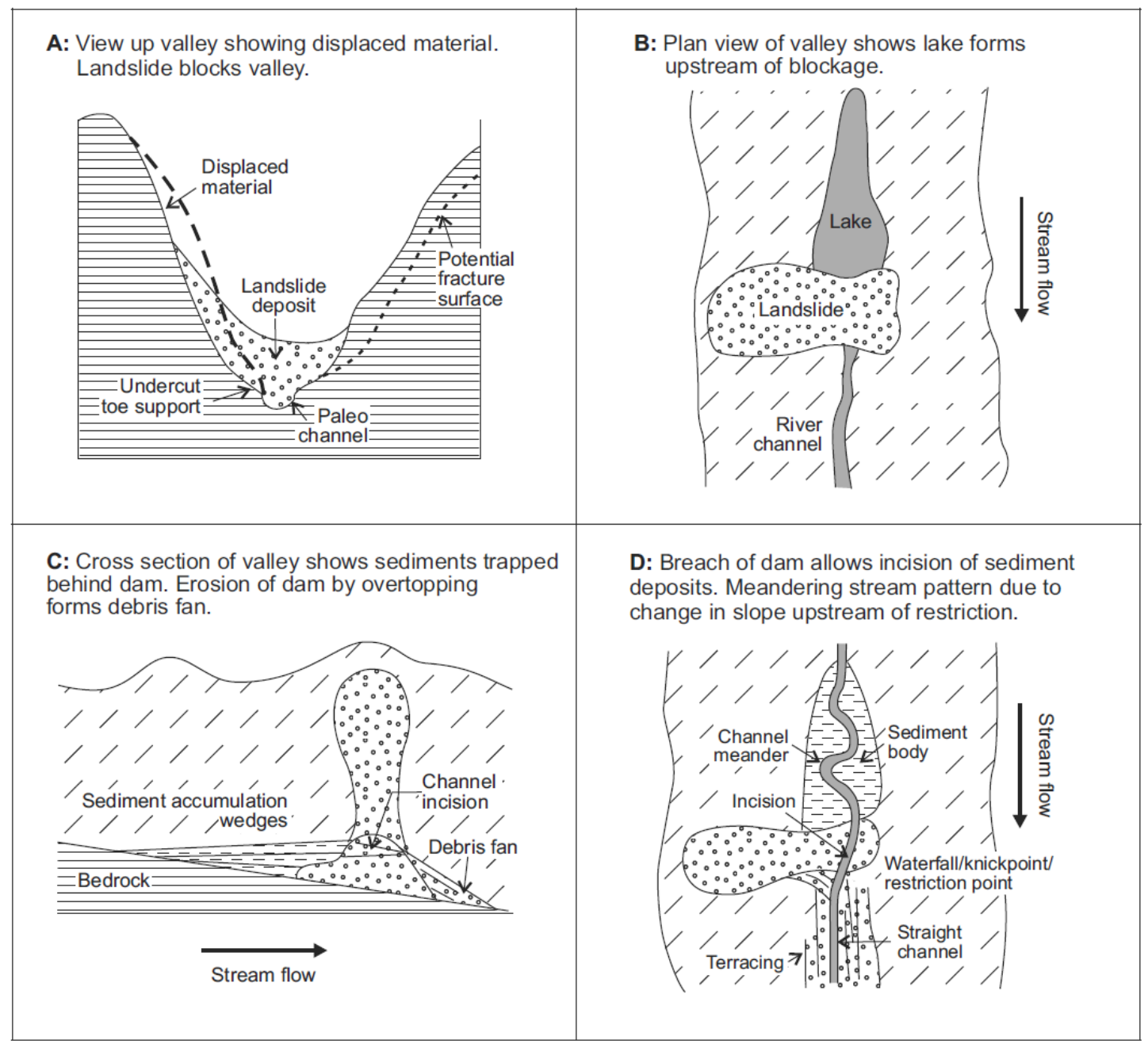

Figure 1.11. Landslide-dam life cycle. In image ' $A$ ' the damming of the valley due to a large deep-seated slope failure often due to slope priming from removal of toe support. Views 'B,C and D' show the infill and incision sequences of the lake and the impounded sediment body.

The following sections of this chapter are aimed at providing a framework for both the research question and the subject matter of the following chapters. This chapter introduces concepts and topics that are not fully formed and will be outlined in greater detail in following chapters. 


\subsection{Justification: Source-to-sink and landscape connectivity}

Source to sink describes the lifecycle of a sediment grain from uplift by tectonic processes, eroded in the landscape by mechanical and/or chemical processes and transported by fluvial networks to the depositional sedimentary basins. This journey however does not have a direct connection from mountain source, to ocean basin sink. It is well known that only a small faction of the sediments eroded in the landscape and transported within the fluvial system will find their way to be deposited in coastal sedimentary basins (Walling, 1983). Within the landscape there are impediments to transport where in-transport sediments may find storage compartments (traps) on hillslopes, floodplains, within the stream channel or behind drainage barriers such as landslide-dams (Fryirs et al., 2007). The sediments stored in the landscape provide a repository of material that may be redistributed at a later time and constitute a major contributor to the sediment flux. Within the landscape a cascade of these sediment stores influences both the rate and timing of sediment delivery to the sea. The cascade is in turn influenced by a combination of allogenic and autogenic mechanisms (Sømme et al., 2009). Therefore, the sediment loads transported by today's rivers, are not only a reflection of the contemporary land uses and climatic conditions, but also those of an inherited landscape (Bishop, 2007).

The overarching geomorphic landscape model for erosion is determined by a region's underlying geology, climatic setting and time. The erosion sub-system of the sourceto-sink network is reliant on hillslopes, where the supply of sufficient regolith is byand-large driven by the internal processes of weathering. The development of unconsolidated regolith overlaying the bedrock surfaces of the slope profile will strive to reach and maintain equilibrium depths with respect to slope, curvature and external influences of vegetation, climate and base level. These internal processes result in long timeframe down slope mass movement of regolith and adjustment of slope profile. These slope profiles are also responsive to external disturbance from tectonic and climatic signals on frequencies ranging from daily to millennial timescales. The response to these inputs is the patchwork down wasting of regolith where thresholds are exceeded creating the formation of gully networks and surface erosion patterns, which have positive feedbacks on erosion process (Schumm, 1977, Crozier and 
Pillans, 1991). Landscape response rates to change due to vertical movement provided by tectonics and base level occur over longer timescales, changes due to climatic inputs occur over shorter time frames although their affects are more widespread through the catchment. It has been suggested by Fernandes and Dietrich (1997) and Whipple (2001) this may be due to the time delays inherent to knickpoint retreat, as the base level signal propagates up the drainage network, while storm events are catchment wide. Even though there is a background of past climatic conditions which continue to influence the flux of sediment within the landscape sediment traps, it is the influence of more recent disturbance events such as cyclones and extreme storms that may transform form-process associations and sediment flux (Brierley, 2010).

Delivery of primary and reworked sediments to fluvial channels comes from the surface erosion processes of landslides, mass movement (slumping and debris flows) and gully complex incision. During storm events the most obvious and immediate source of these in transport sediments are surface erosion of weathered bedrock and the reworking of floodplain sediments due to channel widening or the undercutting and collapse of river bank deposits. With time, and in post event conditions, the influences of mass movement process on slopes will become the more dominant source of river borne sediments, where sediment delivery to the channel may continue on in the absence of the storm event. These mass movement failures result from delays in ground water saturation levels and where critical thresholds in slope stability are exceeded as a response to gully sidewall incision and channel relocation or widening. Sediments become stored in these deposits and gullies widen which serve to reduce channel-gully connectivity. This connectivity is strongest during the early incision dominated phase and reduces with increase of the mass movements, although the stored deposits will become reactivated in lower magnitude but higher frequency storms (Page et al., 2010). On a large scale, the undercutting of slopes and long periods of storminess may provide a slow preparatory factor for low frequency earthquake-triggered mass wasting events. Such as through the loss of slope toe support and maintained periods of elevated ground water levels or through providing a lubricant at bedding plane interfaces, slopes may become susceptible to failure. Earthquakes of a low magnitude may be able to produce large deep-seated landslides that fail on these bedding planes as translational/rotational failures, where other wise they may have been ineffectual at displacing the landslide block (Crozier et al., 1995; 
Korup, 2004). The affect on the sedimentary system of these deep-seated landslides is two fold, they may provide both a direct source of sediment to channels but may also serve to impede transport blocking sedimentary pathways over varying timescales.

Deep-seated landslides can contribute directly to the sediment budget over varying timescales through sediments supplied from mass movement processes and subsequent disaggregation of the landslide block. There are further direct contributions from undercutting and destabilisation of the hill slope toe, which may have been an important initial contributor to the destabilising of the slope (Crozier, 1986; Korup, 2002). Also the incision of the landslide material post failure and stream blockage provides a direct source of in-transport sediments. Indirect contributions come from the isolation of sediment above the blockage point and the disconnect that occurs to the upstream sediment transport network. Large deep-seated landslides, where the body of the movement remains intact or resistant to the river's erosive force may persist to dam the upstream flow of water. Where these landslide-dams are able to persist in the landscape for long enough, slope derived sediments that are in transit from upstream of the blockage may settle out in the low energy environment of pooled water upstream of the restriction point. This will allow the development of a body of fine-grained sediments, as the reservoir created by the restriction slowly in fills. Over time, the river will re-establish a channel and will start to incise through the landslide block. The rivers incision of the dam will cut down to the level of the sediment body infill, from this point on sedimentation will cease and transport pathways will be re-established (Costa and Schuster, 1988). In the low energy environment created by the low relief of the sediment body, the stream channel incision upstream of the blockage will slow creating a meandering channel form. Downstream from the restriction point there will be a steeper gradient and a straighter more deeply incised channel.

\subsection{New Zealand context and the 'MARGINS' project}

Estimates of the fluvial sediment flux discharged from steep, tectonically active margins have proven difficult to determine and are particularly sensitive to environmental change (Milliman and Syvitski, 1992 and Walling and Fang, 2003). Of an equal challenge has been the understanding of the factors that control and/or 
influence the erosion processes that operate in such catchments and their spatial and temporal variability (Fuller and Marden, 2008). A NZ Government-funded programme "Terrestrial Landscape Change: MARGINS Source-to-Sink New Zealand" is being carried out in the Waipaoa catchment to address these and other issues related to sediment transfer from terrestrial source to marine sink. This thesis contributes to the MARGINS programme by studying the impact of deep-seated landslides on long-term sediment flux.

The Waipaoa sedimentary system was chosen as an ideal natural laboratory to study as it contained the key macro-scale elements of source-to-sink in a closed system (refer Figure 1.31) (Carter et al. 2010). The Waipaoa's relatively small size, well defined sedimentary basins, its active tectonic and climatic drivers, and the large natural sediment delivery volume, combine to produce sedimentary and geomorphic records containing recognisable signals of the landscape response to these drivers, (catchment characteristics are discussed in more detail in chapter 3), while the proximity of the catchment to the Taupo volcanic centre provides volcanic ash for dating markers (discussed in chapter 4). The relatively recent arrival of humans and ensuing deforestation has resulted in erosion and sedimentation rates significantly greater than established natural Holocene background rates which may be used as an analogue for the non-forested conditions that prevailed during cooler periods following the last glacial maximum (LGM) (Litchfield et al., 2008). As large landslides may be triggered by both earthquakes and high intensity storm events, their study provides insights into both the tectonic and climatic forcing of the hillslope's adjustment to change in topographic relief and fluvial bedrock incision (Korup et al., 2007).

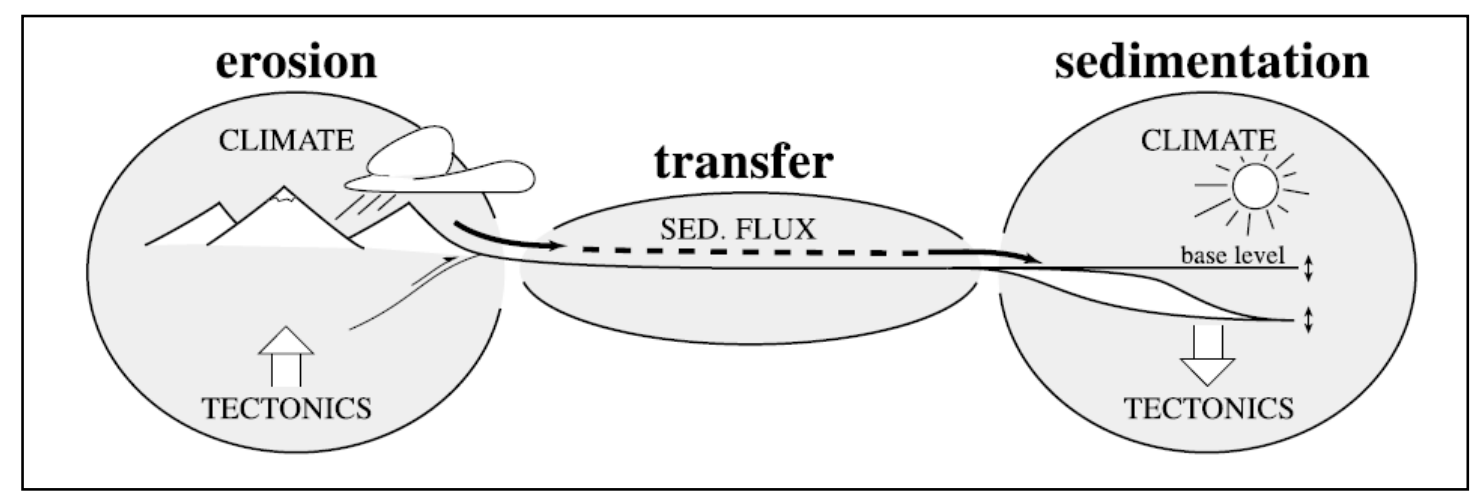

Figure 1.31: A simple model for an idealised sedimentary system (Castelltort and Van Den Driessche, 2003). 
The Waipaoa River provides the transport medium for the Waipaoa sedimentary system, with the uplifting Raukumara Ranges the source area and the subsiding continental shelf of the Poverty Bay and the Poverty Bay flats the sink (discussed further in chapter Three). As a non-glaciated catchment, the Waipaoa's landscape has still under gone rapid and dramatic change. These changes are driven by the influence on thresholds to sediment production and erosion related to the two primary influencing factors with the overprint of human interference during the late Holocene. The first factor is that of climate and the influence base level, regolith production/stability and vegetation cover created during the transitions from glacial to non glacial conditions. This climatic signal is recorded in the river terraces of the upper and middle sections of the Waipaoa river catchment which show an alternating cycle of aggradation and incision over the last $100 \mathrm{ka}$ (Berryman et al., 2000). The second factor, that of uplift due to tectonics, modulates the rate of incision and is evident in the spacing between aggradation terraces (Litchfield and Berryman, 2006).

On the Poverty Bay flats and the Poverty Bay shelf and slope, subsidence has resulted in the stacking of marine and fluvial deposits. These deposits document the initial marine transgression and the subsequent progradation of the shoreline which has occurred over the last $10 \mathrm{ka}$ (Wolinsky et al., 2010). Sediment budgets have been created through the combination of the onshore and offshore records and the reproduction of $\mathrm{W} 1$ surface which marked the extent of onshore aggradation at the end of the last glaciation (Litchfield et al., 2008). The rapid landscape change over the last $18 \mathrm{ka}$ to the Waipaoa River catchment has been encouraged by the region's young sedimentary bedrock geology. The geology is typically weak, highly fractured and consists of erodible late Cretaceous bedded sandstones and mudstones. Because of these offshore sediments, plus those of the floodplains and fluvial terracing, there is a robust record of landscape change in the Waipaoa catchment. These conditions provide an excellent location to study landscape evolution and to try to quantify the process of sediment movement through a fluvial system (Litchfield et al, 2009). While many of the contemporary aspects of the Waipaoa Sedimentary System have been studied in detail (Litchfield et al., 2008), the source for well over half of the total postglacial sediment delivered to on and off-shore sedimentary basins remains unquantified (Marden et al., 2008b). 
A number of studies in the Waipaoa catchment have focused on the sediment generation and delivery response to deforestation and to subsequent reforestation (Marden 2008b). The catchment is prone to erosion from storm events, and other studies have focused on the impact of storms on sediment delivery, intensity thresholds for shallow landsliding, buffering due to temporary in-channel sediment stores and connectivity of shallow landslides and fluvial channels post these events. Gullies and shallow landslides are the major source of sediments (Reid and Page, 2002; Fuller and Marden, 1010). Fuller and Marden (2010) suggest that sediment supplied from gully erosion is more constant than that generated by shallow storm generated landslides and gullies are more easily reactivated during smaller more frequent storm events. Many of these gullies are fluvio-mass movement complexes that show seasonality in sediment delivery through a process of cut and fill of fan deposits and through head cuts due to migration of knickpoints that respond to changes in rainfall intensities (Fuller and Marden, 2010). These sources account for the bulk of the offshore record and have been responsible for sediment delivery at different times throughout the post glacial period (Foster and Carter, 1997). For the period since the end of the Last Glacial Maximum until deforestation, less is known about sediment generation and the catchment's sensitivity to environmental change.

\subsection{Research aims and objectives}

Large landslides are influenced by and products of tectonic and climatic inputs. Additionally they provide both a source of sediment production and a restriction to delivery. Their study provides an opportunity to gain insights into aspects of sediment flux over a range of spatial and temporal scales. Deep-seated landslides are ubiquitous in the landscape of the Waipaoa river catchment (discussed further in chapter four) and mass-movement processes may account for a large proportion of the long term sediment flux from the catchment. Large landslides are not only a source of sediment generated in the catchment, they are also sediment regulators through changing slope profiles and channel blockages. Where sedimentary pathways have become blocked by landslides the sediments impounded may also provide insights into upstream catchment dynamics which will be discussed in following chapters. In addition, understanding how deep-seated landslides affect the landscape evolution of the 
Waipaoa catchment has implications for future land use, environmental and ecological planning in the region. This study has a particular focus on the short/medium timescale of tens to thousands of years and the impact that deep seated landslides have on the transport of sediments over this timescale.

\section{Project aim}

This project aims to investigate the spatial and temporal influence that channel blockages from large deep-seated landslides have on sediment delivery within the greater Waipaoa catchment and to quantify sediment volumes impounded by these large scale features. To achieve this aim the study asks the following questions:

$1 /$ What is the impact of landslide-dams on sediment transport in the Waipaoa catchment?

2/ What does the sediment record of lakes formed from landslide-dams tell us about subsequent changes in catchment sediment dynamics?

These questions may be answered through the pursuit of the project's objectives outlined below and volume estimates will be linked to other information for catchment-wide estimates within the MARGINS program.

\section{Project objectives}

1. For a representative sample of channel-blocking landslides provide minimum age estimates for the landslide event/onset of sedimentation and for dam breach/termination of sedimentation. This is achieved through the use of radio carbon dating of organics at the base of sediment cores taken from the impounded sediment or where possible debris which has been incorporated in the landslide matrix and exposed by river incision.

2. Quantify the sediment volumes impounded by these individual landslidedams. Using GPS mapping of the extent of sediments impounded and then through the creation of a three dimensional model of the sediment package using GIS software.

3. Establish rates of sedimentation for each catchment and any changes that may have occurred within the catchment over time. This will be achieved through 
the identification of boundary markers within stratigraphical columns and creating chronologies by using radio carbon and tephra markers within these columns.

\subsection{Chapter outlines}

This chapter has outlined the research topic, highlighting both the global context of sediment dynamics and the regional context of the MARGINS project's source-tosink studies. The chapter has indicated a research gap in the knowledge of sediment dynamics in terms of the influence of landslide-dams. The chapter concluded by setting up the research questions: 1 / What is the impact of landslide-dams on sediment transport in the Waipaoa catchment? 2/ What does the sediment record of lakes formed from landslide-dams tell us about subsequent changes in catchment sediment dynamics? It has also outlined the study objectives to answer these questions. The following chapters will provide the support to the claims made here and their outlines are listed below.

\section{Chapter 2 - Landslide-dams, sedimentation and landscape connectivity in review.}

This chapter provides a discussion of the current literature outlining the role of landslides as a geomorphic process, the use of sedimentary budgets to understand environmental change and the implications of landslide-dams in sediment delivery. The discussion will conceptualise the character and dynamics of sedimentary systems and will introduce current research in the New Zealand landscape.

\section{Chapter 3 - Factors of control for landslide-dams and rates of sedimentation in the Waipaoa.}

This chapter has an in-depth look at the Waipaoa Catchment and the factors that influence landsliding and sedimentation. It provides an outline of the regional setting for the East Cape and the Waipaoa catchment. 


\section{Chapter 4 - The Waipaoa; mapping, modelling and the study sites.}

The presentation of the overall project methodologies and techniques used in both lab and field data collection is the focus of this chapter. Methods used for the landslide identification and site selection process, mapping and 3D representation of landslides and sediment bodies using GIS computer technology, stratigraphical and age control techniques and the field methods involved of survey and coring of the sediment bodies are described. The chapter will also include the individual site descriptions.

\section{Chapter 5 - Towards an understanding of the sediment dynamics of a large catchment.}

A presentation of the results and findings from the work carried out in the field, laboratory and computer modelling.

Chapter 6 - The measure of control; landslide-dams and the Waipaoa region's sedimentary regime.

This chapter will draw together key remarks from the other chapters and will provide a discussion and thoughts around the results and findings of the study. The chapter will also put these findings into context with other studies highlighted in chapters two and three.

\section{Chapter 7 Conclusions and reflections on landslide-dams in palaeo- environmental research.}

This chapter will draw together key remarks from the other chapters and will provide the concluding thoughts around the results and findings of the study and the significance in light of the presented literature. It will also introduce topics for further study that may enhance the understanding around sediment transport and transport impediments. 


\section{Chapter 2:}

\section{Landslide-dams, sedimentation and landscape connectivity in review}




\subsection{An Introduction from key studies}

This chapter's aim is to examine landslide-dams in the broadest context in the New Zealand setting, their formation and breach and their controls on sediment dynamics, with a focus on the North Islands East Cape and the Waipaoa catchment. It has been argued that New Zealand provides an ideal location for the study of landscape evolution and the relative roles of factors that influence these processes. New Zealand is a young landscape where uplift is in general out-pacing that of erosion (Crozier, 2010). The evidence of the evolution of landforms has low levels of masking of human influence, due to their recent arrival. This chapter will show that the study of landslide-dams provides the opportunity to assess impacts that these natural features may have on fluvial systems and that their study may provide insights into catchment dynamics. The lags and buffers to sediment transport that landslide-dams provide are one end of the spectrum of possible impacts from such events, for example where sediments eroded in upper catchments become trapped due to alterations drainage network dynamics that these features provide (Korup, 2002). These in stream impoundments may be considered as events on geo(morpho)logical timescales which is due to their generally short preservation (Korup, 2002). However, over larger spatial and temporal scales the accumulative impacts of landslide-dams on sediment dynamics are unknown and may be considerable (Korup, 2002). This chapter will investigate examples in literature where spatial grouping in the formation of landslide-dams provides insights into the possible drivers of mass movements. Also highlighted will be examples where sedimentation of landslide-dams provides an insight in to catchment dynamics and, where these features are able to persist in the landscape for longer periods, that they may show changes over time.

\subsection{Geomorphology and the role of large landslides}

Occurrence of mass movement events on slopes in themselves form part of the geological rock cycle. Denudation is one of the four major groupings initially interpreted by $19^{\text {th }}$ century geologists as responsible for the wearing away of landmasses over geological time (Crozier, 1986). Denudation as defined by Davis (1903) in broad terms is the removal of regolith from steep slopes. In Davisian 
evolutionary theory of landscapes it is envisaged that landscapes uplifted by tectonic processes would with sufficient time be eroded though fluvial incision by rivers. Denudation of hillslopes through the weathering of bedrock and the slow transportational processes of surface wash from rainfall, the action of ground water, changes of temperature, freezing and thawing, chemical disintegration and hydration, the growth of plant roots, and the activities of burrowing animals would move material from slope to channel. The role of landsliding was not recognised (Crozier, 2010).

Wolman and Millar (1960) stated that fluvial work and landform development are related to high frequency stream discharge events and that large catastrophic events, while dramatic, were on too low a frequency to account for significant change. River channels will respond to climatic and tectonic forcing through changes in bed-form configuration, sediment yield, plan-form cross section or long profile. Guthrie and Evans (2007) expanded on this concept to suggest that this was also the case for slopes where landslides from low frequency events were responsible for the development and characteristics in a slopes form. This relationship Crozier (2010) suggests is however only possible where there is a direct coupling between slopes and fluvial channels which occurs only rarely and mainly in headwater catchments. Even in these low order catchments buffering from terracing and fluvial deposition is soon evident. The accumulation of these sediments at the toes of slopes and on the valley floor are the result of high frequency slope events and provide buffering to further transport. Guthrie and Evans (2007) suggest it requires a low frequency deep-seated landslide to clear these blockages and in most cases reconnecting systems and resetting slope and drainage networks. However it may be that the opposite is true especially in case of the occurrence of landslide-dams.

There have been many studies on the processes of sediment delivery from slopes to channels and many that have highlighted the importance of connectivity of channel and slope. Storm driven mass movements on slopes tended to be responsible for the failure of slopes on the lower to mid section of the slope surface due to elevated pore water pressures and would occur at high frequency. The lower frequency seismic driven slope failures tend to alter ridgelines and the upper sections of slopes (Dortch et al., 2009). These storm driven events tend to be shallow translational surface 
failures that displace material down slope, reducing the down slope profile while at the same time over steepening the up slope profile and destabilising the upper slope and changing slope hydrology (DeRose, 1996). Therefore repeated landsliding rarely occurs on previously failed surfaces. Instead, subsequent failures may migrate upslope or adjacent to the subsequent failure, where with time they form a mosaic pattern of varied failure scars and erosion thresholds (Miller et al., 2003). On a catchment wide scale this effect is exacerbated, with sub-catchments and slopes being in different phases and having different sensitivities to disturbance events (Reid and Page, 2002). The sediment flux from each sub-catchment (and slope) will have spatial and temporal variance in sediment delivery to the channel and will be reflected in catchment sediment yields.

\subsection{Sediment delivery concepts}

The use of sediment budgets is a fundamental approach in understanding catchment dynamics in geomorphology. Sediment budgets can be described as a quantitative statement within defined temporal and spatial boundaries of the generation, storage and discharge of sediment. In general, the sediment budget illustrates geomorphic work through quantifying landscape change and the distribution of sediments within the sediment stores. The magnitude of the sediment yield for a particular basin will be influenced by a large range of factors, both geomorphic and environmental. These factors include the degree of dissection in the upper catchment, drainage patterns, the availability and location of sediment sources, land cover and land use patterns, and soil textures (Walling, 1983). There are controlling factors such as catchment area and gradient, stream order and lithology which will influence the response rate and energy within the transport network (Fryirs et al., 2007; Phillips and Slattery, 2006). For sediment eroded in the upper catchment and entering the transport network, the question becomes what is the volumetric relationship to the sediment captured in the depositional sink? Roehl (1962) termed this the 'sediment delivery ratio' (D), the measured sediment volume eroded in the upper catchment (T), compared to the measured volume of deposited sediment $(\mathrm{Y})$, where $\mathrm{D}=\mathrm{Y} / \mathrm{T}$ and is often expressed as a percentage. For each of the field sites in this research project, the volume of sediment accumulated in the sediment bodies represents the yield of the quasi closed catchment upstream from the landslide blockage. Where there are variations in 
accumulation layers of these accumulated sediments stratigraphies or known time horizons within the stratigraphic column, an understanding of how yield and consequently the erosion processes of the catchment have varied throughout time (Boggs, 2006, pp 21-48).

Linking of process and landscape form is important for the comprehension of sediment transfer through fluvial systems (Schumm, 1977). This is due to transfers of sediment within the landscape are strongly influenced by scale, with sediment delivery firstly increasing then decreasing as the catchment area increases (Parsons et al., 2006). This is due to heterogeneity in both process and form increasing, and the connectivity within landscape systems decreasing with increasing catchment area. The identification of connectivity within source-to-sink sediment transport systems shows that there are spatial relationships for these sediment transfer mechanisms and that the degree of connection has an importance for morphological change (Hooke, 2003; Fryirs et al., 2007). For there to be a transfer of sediment from one zone or location to another, there must be sufficient connectivity between the zones. At the catchment scale it is the configuration and the connectivity between these sediment traps or stores that are important to the operation of the sediment transport through the landscape (Fryirs et al., 2007). Connectivity is also integral to how the landscape responds to differing frequency and magnitudes of disturbance events. The manner of connectivity affects the transfer of energy and matter between landscape compartments or within the sediment transport system as a whole. For a transfer of inputs from the head waters to be converted to the outputs at the basin mouth these connections within the landscape must be maintained (Hooke, 2003; Fryirs et al., 2007). Through the identification of potential sediment traps or storage within the landscape it is possible to quantify impediments to this process (Hooke, 2003).

Over longer timeframes it can generally be assumed that even coarse material can be transported through fluvial channel reaches, with the residence time of interim storage being dependent on the discharge regime of the catchment. When larger sediments cannot be transported, they are either broken down in situ or they are transported when channel morphology adjusts and the reach becomes more competent (Hooke, 2003). The fluvial system is an open system and a breakdown in connectivity can cause discontinuity of sediment transfer resulting in pulsing of sediment delivery from 
source to sink (Fryirs et al, 2007; Hoffmann et al., 2009). Sediment yield for a catchment describes the amount of sediment discharged over time and is expressed in terms of tonnes of sediment per square kilometre of catchment over time $\left(\mathrm{t} / \mathrm{km}^{2} / \mathrm{yr}\right)$ (Brown et al., 2009). This yield is a direct reflection of the erodibility of the bed rock within the catchment and the dominance of the erosion processes (Brown et al., 2009). Landslides are a dominant process in slope erosion and delivery of sediment to fluvial channels and will be the focus of discussions in this chapter.

\subsection{Landslides and slope stability}

This study topic has a focus on the consequences of deep-seated landslides on drainage networks, as opposed to a focus on the origin and mechanism of slope failures. However, it may be useful at this point to introduce a brief background on the principles of slope stability and the main landslide types including the nomenclature that will be employed throughout this and the following chapters.

\begin{tabular}{l|lll}
\hline \multirow{2}{*}{$\begin{array}{l}\text { Type of } \\
\text { Movement }\end{array}$} & Type of Material & \\
\cline { 2 - 4 } & Bedrock & Engineering soils & \\
\cline { 2 - 4 } & & $\begin{array}{l}\text { Predominantly } \\
\text { course }\end{array}$ & Predominantly fine \\
\hline Fall & Rock fall & Debris fall & Earth fall \\
Topple & Rock topple & Debris topple & Earth topple \\
Slide & Rock slide & Debris slide & Earth slide \\
Spread & Rock spread & Debris spread & Earth spread \\
Flow & Rock flow & Debris flow & Earth flow \\
\hline
\end{tabular}

Table 2.31: An abbreviated classification of slope movements (After Cruden and Varnes, 1996).

Classifications and definitions of slope movements are numerous and will reflect the particular aims and desired outcomes of the landslide investigator. Where some classifications may be focussed on passive tasks such as land use potential (housing, forestry, industrial, recreational etc), others may be interested in the assessment of active tasks such as slope stability analysis for assessment of hazard and risk prevention and avoidance (Crozier, 1986, pages 8-24). This project is concerned with the assessment of geomorphic activity and there are multiple objectives in terms of the study's requirements. The study has chosen to use the more generalised 
classifications of slope movements and definitions as proposed by Varnes (1958, 1978, and with Cruden, 1996) where the type of movement and the type of material is used to define the principle landslide group (refer table 2.31).

\begin{tabular}{llll}
\hline Activity & & & \\
\hline State & Distribution & Style & \\
\hline Active & Advancing & Complex & \\
Reactivated & Retrogressive & Composite & \\
Suspended & Widening & Multiple & \\
Inactive & Enlarging & Successive & \\
Dormant & Confined & Single & \\
Abandoned & Diminishing & & \\
Stabilised & Moving & & Type \\
Relict & & & Fall \\
\hline Description of First & Movement and subsequent movements described there after \\
\hline Rate & Water content & Material & Topple \\
\hline Extremely rapid & Dry & Rock & Slide \\
Very rapid & Moist & Soil & Spread \\
Moderate & Wet & Earth & Flow \\
Slow & Very wet & Debris & \\
Very slow & & & \\
Extremely slow & & &
\end{tabular}

Table 2.32. Glossary for forming names of landslides. Note, subsequent movements may be described by repeating the above descriptors as often as necessary (after, Cruden and Varnes, 1996).

Classification and description of any landslide can be done through defining firstly the dominant material involved and secondly the type of movement (Cruden and Varnes, 1996). The material involved in the landslide may be described as either rock, which Varnes (1978) defines as "a hard or form mass that was intact and in its natural place before initiation of the movement", or soil "an aggregate of solid particles, generally of minerals and rock, that either was transported or was formed by weathering of rock in place". Soils are further divided into earth and debris, where earth is defined in Varnes (1978) as a "material in which 80 percent or more of the particles are smaller than $2 \mathrm{~mm}$ " and debris "contains a significant portion of coarser material; 20 to 80 percent of particles are larger than $2 \mathrm{~mm}$ and the remainder less than $2 \mathrm{~mm}$ ”. Further refinement in describing the landslide can be done as more details are established on the movement. Descriptors (refer to table 2.32) of the time involved in the movement, 
style of activity and spatial location may be added in front of the landslide group to provide a progressive narrowing in focus (Cruden and Varnes, 1996).

Activity status of a landslide is considered over an annual season cycle, whereas inactive landslides can be considered as ones that have not moved during one annual cycle. Where the cause of the slope movement remains apparent i.e. a river eroding toe support, then the landslide may be considered dormant. Once the source of movement is removed such as when a river changes course, then the landslide is considered abandoned and if toe support is re-established it may be considered stabilised. The scars of a landslide are often visible in the landscape for thousands of years and these old restabilised landslides may be considered as fossil or ancient features. Where it can be determined that these ancient landslides were formed under different geomorphic conditions to the current, they may be considered relict. The rates of movement in landslides can be determined through distance of advance between surveys and the direction of the landslide's movement is related back to the surface of rupture (Cruden and Varnes, 1996). With the above as a base classification of a landslide feature, it is then important to understand the types and modes of movement. These will be covered in the following section.

\subsubsection{Landslide features, types and triggers}

Static stability of a detached mass on an inclined surface is described as a function of a maintained ratio between normal and shear stresses; where normal stress is derived from the gravitational vector normal to the slope and shear stress the vector in the direction of the inclined surface (refer figure 2.31). Resistance to the shear stress is provided by internal properties of cohesion and friction to which any changes in these conditions will alter the condition of static stability. Failure of slopes will occur where shear stress exceeds that of the forces that oppose it, shear strength and may be a result of changes to the intrinsic or extrinsic characteristics (Selby, 1982). There may be different types of movement that result from the slopes failure due to the material the slope may consist of and the way these materials influence the ratios of shear resistance and stress (Preston and Crozier, 1999). A hypothesis proposed by Montgomery and Brandon (2002) is that hillslopes in active mountain belts may find equilibrium between uplift rates and those of erosion through increasing rates of 
landsliding rather than progressive over steepening of slopes. This implies that regional relief will remain close to critical thresholds remaining independent of climatic, uplift and lithological controls and any small increases in slope angle will require substantial increases in the rates of erosion (Korup et al., 2007).

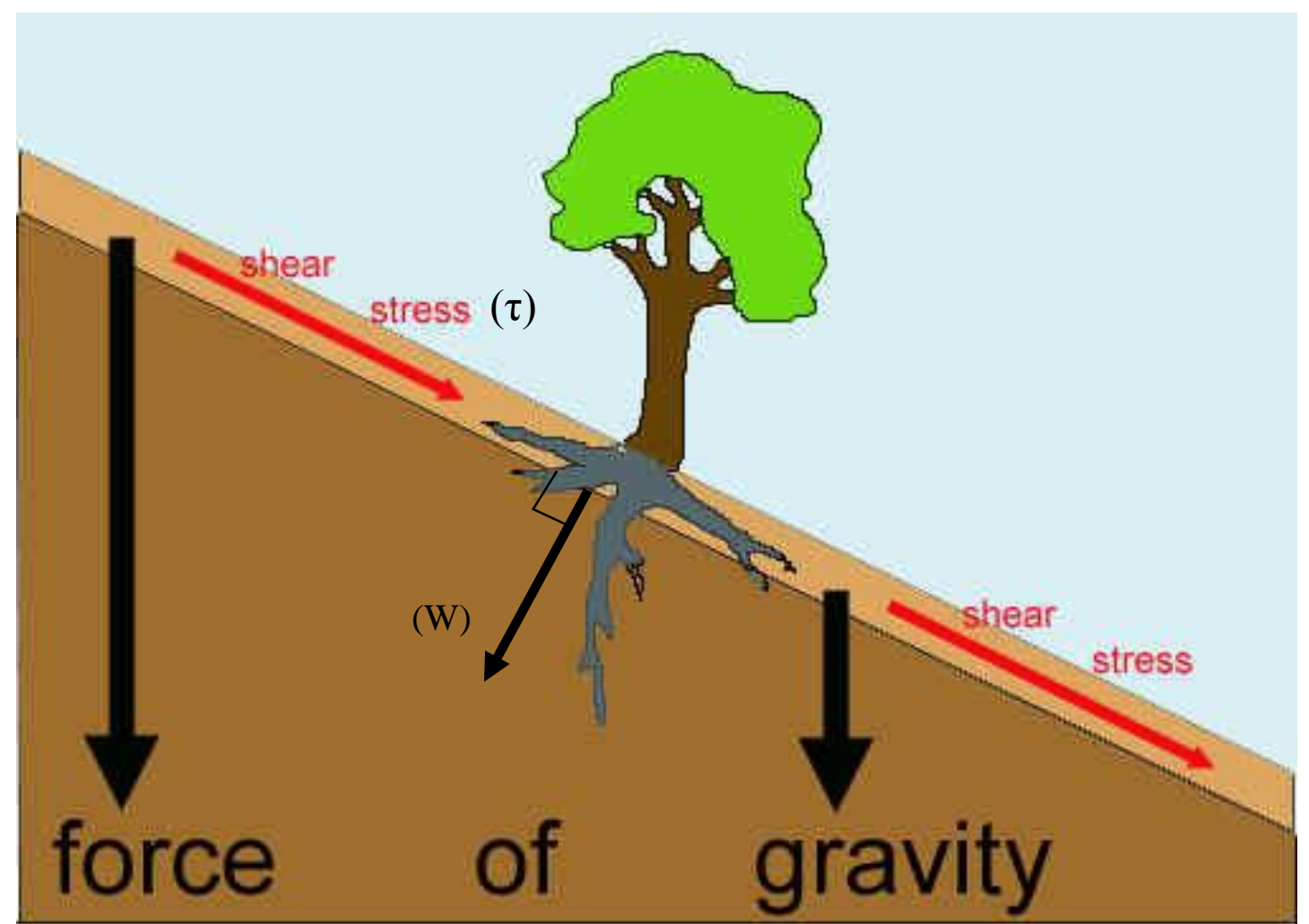

Figure 2.31, Forces acting on a slope. The image shows the vectors for gravity, normal (W) and shear $(\tau)$ stress on a hill slope. (After Varnes, 1978. Image courtesy of USGU, accessed on 23/09/1010).

The diagram in figure 2.32 shows the features of a complex earthslide-earthflow produced by Varnes (1978) and shows the terminology that will be employed by this study. This is a type of landslide that may form channel blockage which is why it is displayed here and the terminology employed is transferable to other landslide classes. It is important to note that the region of the land slide from the crown to the toe of surface rupture represents the zone of depletion and that this area of displaced material lies below the original surface. The region that extends from the toe of the surface rupture to the toe of the displaced material is known as the accumulation zone and is displaced material that lies above the original ground surface. The accumulated material can be expected to be larger than that of the volume of the depleted zone due to the tendency for displaced material to dilate during landsliding (Cruden and Varnes, 1996). 


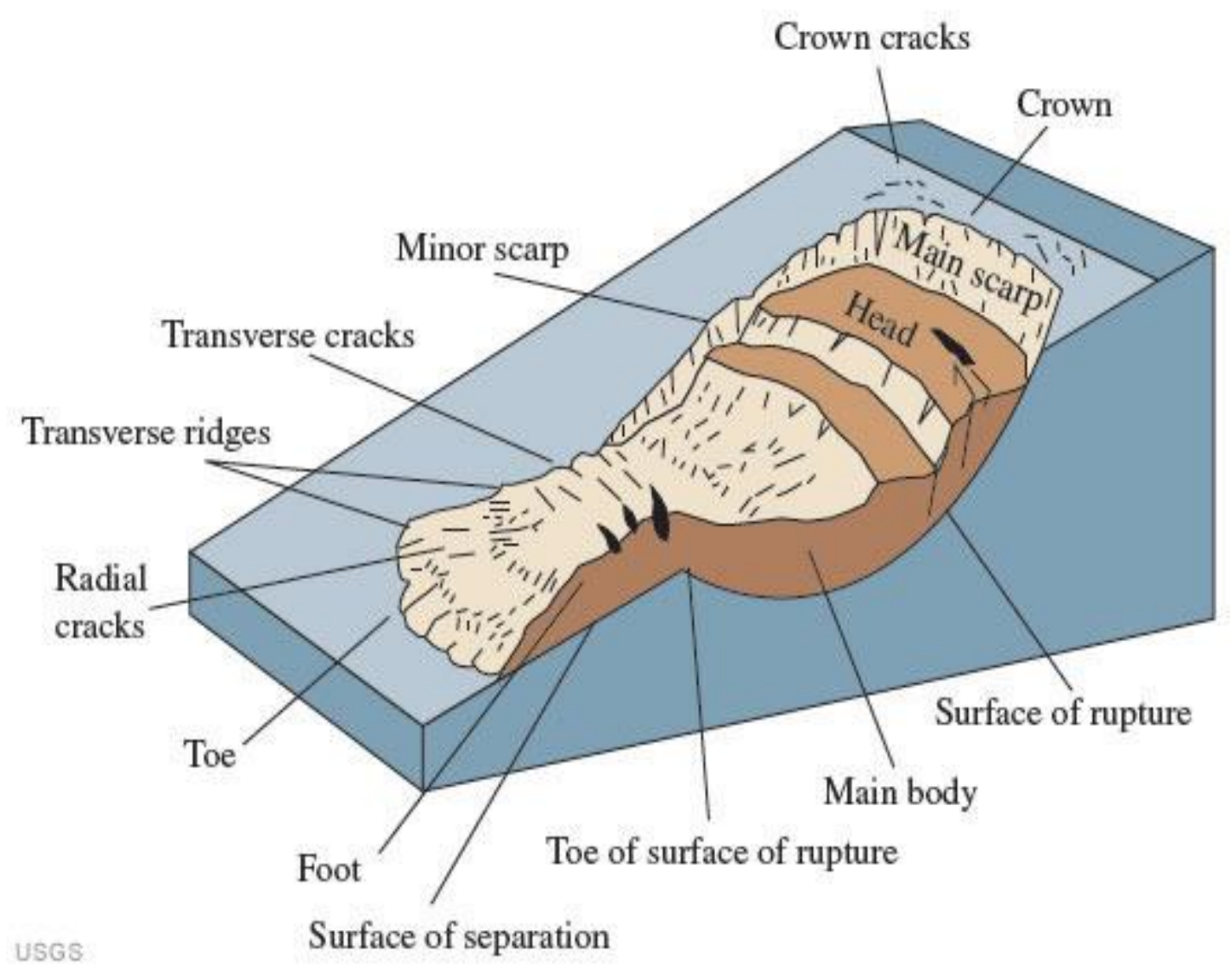

Figure 2.32. Landslide features. This illustrates and names the key features of a rotational landslide (After, Varnes, 1978).

The mechanisim of the displaced land mass forms one of the principal classification criteria, of which there are five distinct movement groups of fall, topple, slide, spread and flow. These groups are shown in figure 2.33 and each type has a number of common modes that are frequently encountered. These groups will be briefly described below with the letter indicating their pictorial location in figure 2.33. The following descriptions of movements are derived from definitions in the chapter by Cruden and Varnes (1996, pp 53-67) of landslide types and processes in landslides; investigation and mitigation edited by A.K. Turner and R.L. Schuster.

D. Falls; involve little or no shear displacement and occur on steep slope surfaces where once initiated the material descends mainly through the air by falling, bouncing or rolling. Movement is very rapid and forward motion is often sufficient to induce freefall if the slope angle below the mass is in excess of 76 degrees. 
E. Topples; the forward rotation out of the slope by the soil or rock mass that pivots on a point which is at or below the centre of gravity of the displaced masses. The movement will be initiated by the undermining or erosion of the toe of the material as it retrogrades backwards. This usually occurs in material with one preferred discontinuity system orientated to present a rock slope with semi-continuous cantilevered beams.

A. B. \& C. Slides; are a down slope movement of material that occurs at or over a relatively thin zone at the surface of rupture. The movement is not simultaneous over the surface of rupture but may often be first seen as cracking in the ground at what will become the head scarp. The volume of the displaced matter enlarges from an area of local failure and the displaced mass may slide beyond the toe of the rupture surface, extending over the original ground surface down slope. Modes of sliding are distinguished by the shape of the shear surface, with translational (B and C) slides being planar and rotational (A) slides being concave. Rotational slides commonly occur in homogeneous materials and are more frequent. With translational slides the displaced masses occur over planar or undulating surface. Planar sliding often follows discontinuities such as faults, joins or bedding surfaces and are usually shallower than rotational slides. With rotational slides, the movement restores the mass back to equilibrium, while translational slides may continue unchecked where slope length is sufficient. The displaced mass in a translational slide may break up as the slide develops and velocities or water content are increased, where the disrupted mass becomes a flow.

J. Spread; is the extension, fracturing and subsidence of a cohesive soil or rock mass into a softer underlying material and often results from liquefaction or flow of underlying material. This often results in an indefinable surface of rupture and the movements are often complex with disintegration, translation and rotation of the cohesive blocks. The soft underlying material is squeezed up into the cracks of the displaced cohesive material. These movements may be extensive and extending over many kilometres. 
F. G. \& H. Flow; is a spatially continuous movement were the surfaces of shear are short lived, closely spaced and usually not preserved. The displaced mass is usually strongly deformed and the internal velocities of the displaced material resemble that of a viscous liquid.

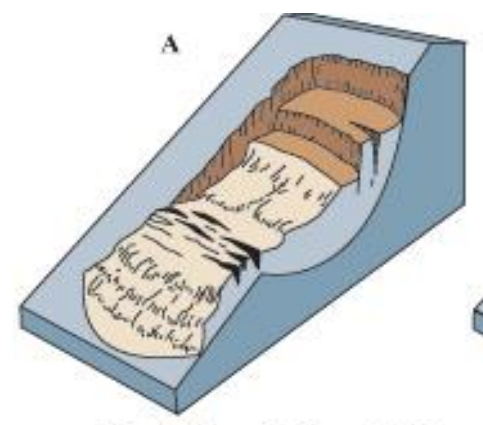

Rotational landslide

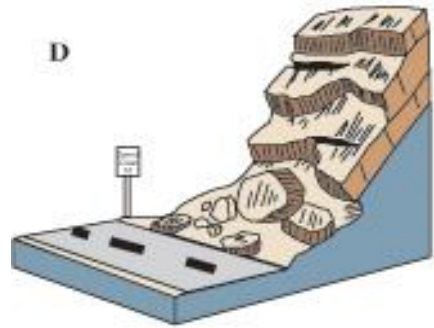

Rockfall

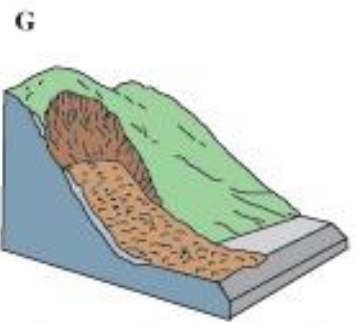

Debris avalanche

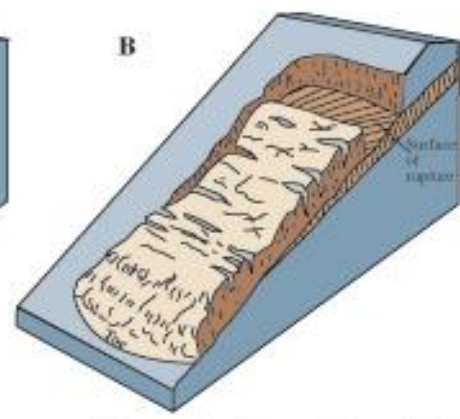

Translational landslide

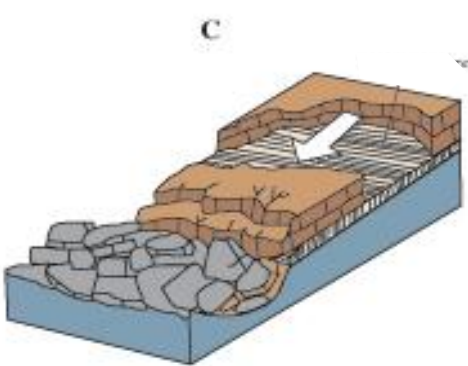

Block slide
E

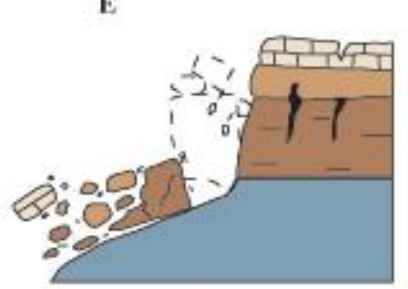

Topple

H

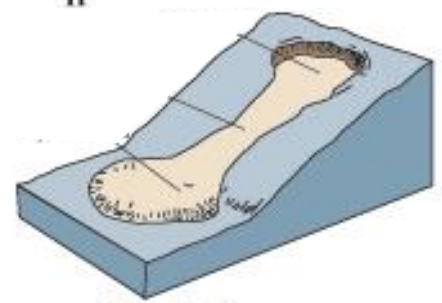

Earthflow

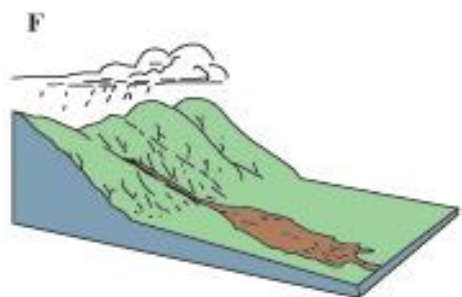

Debris flow

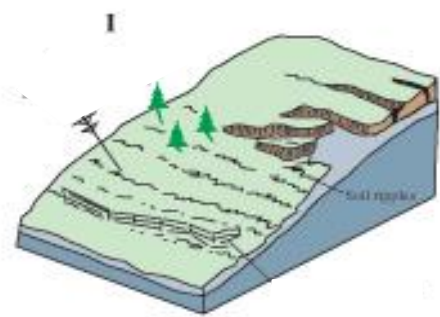

Creep

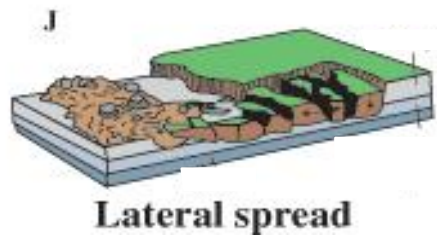

Figure 2.33. Landslide types. Modified from Varnes (1978) the image illustrates the landslide movement types.

The landslide movements described above can have several causes, including geological, morphological, physical and human, but they will have only one trigger. A trigger by definition is an external stimulus that causes a rapid increase in stress or 
reduction in strength resulting in a near immediate response in the form of a landslide (Wieczorek, 1996, pp76). The most common triggers of mass movement are those of an intense rain fall event, snow melt, water level changes, volcanic eruption and ground shacking during earthquakes. We will look briefly at the mechanisms of rainfall and earthquake triggers for landslides as these are the most common triggers associated with landsliding within the project setting.

During storm events of high intensity rainfall or sustained periods of lower intensity, thresholds of shear strength and stress within soil and regolith may be reached causing slope failure. These failures during rainfall events more commonly result in shallow surface failures, although dependent on the geo(morpho)logical conditions, deepseated failures are also possible. The most common mechanism attributed to rainfall events is the rapid infiltration and saturation of soils causing a temporary rise in porewater pressures (Brutsaert, 2005; Wieczorek, 1996, pp78). Ground shaking associated with earthquakes is able to trigger mass movements in many different geological and topographical settings. In terms of engineering geology the controls that are key to the slope's stability are those of material strength which is set by cohesion and internal friction, slope and discontinuity geometry and transient loads imposed by water and seismic ground acceleration (Schmidt and Montgomery, 1995). Deep-seated failures with ruptures on dipping bedding plains or non-conformities initiated by raised pore pressures due to extended periods of wet conditions in combination with earthquake triggers can cause fast moving translational slides. The material displaced in these slides may break up becoming a more complex movement with distance. Where fast moving landslide debris impacts with the slope on the opposite side of the valley, the landslide may block fluvial pathways forming natural dams (Costa and Schuster, 1986).

\subsection{Landslide-dams}

This section will look at the types of landslides that are likely to form channel blockages and the processes involved in the formation and failure of landslide-dams. Where possible there will be reference to current work in landslide-dam research and it will conclude with examples of landslide-dam research in New Zealand, proposing scope for this study and for future research. Large landslides forming lakes are 
common in many parts of the world and may form in a range of topographic settings and lithologies, but tend to form more often in narrow mountain valleys with impact sensitivity at all spatial and temporal scales (Costa and Schuster, 1988). The most likely mass movement processes that will result in landslide-dams are described by Costa and Schuster (1988) as "rock and debris avalanches, rock and soil slumps and slides and mud, debris and earth flows. The speed of the movement, the volume of material displaced and the area of the run-out zone are important contributors to the formation of landslide-dams. This is assisted where there may be the complete blockage of the stream before material removal can begin and is the best opportunity for dam formation (Costa and Schuster, 1988). The geomorphic classification of landslide-dams as suggested by Costa and Schuster (1988) can be done using the relationship of the dam feature to that of the valley floor and is shown in figure 2.41. At the local scale, large landslides have control on the longitudinal profile of the rivers and the spatial distribution of sediment stores, while at the catchment scale there are controls on sediment fluxes, transfers and storage. These controls have been well documented in studies of Himalayan (Hewitt, 1998; 2006) and New Zealand's South Island (Korup, 2002; 2004; 2005) alpine environments.
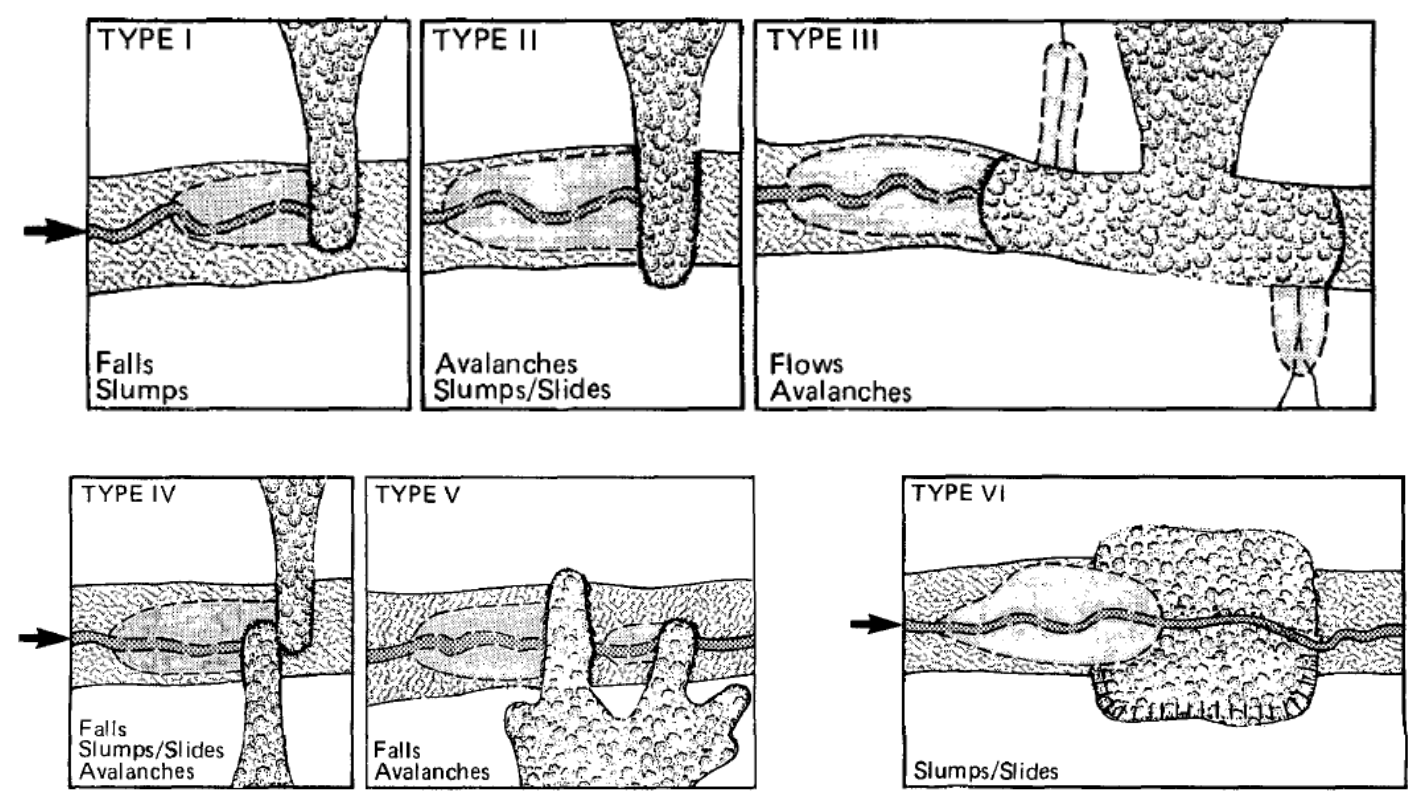

Figure 2.41. Geomorphic classification of landslide-dam types (After Costa and Schuster, 1988). Type I dams are smaller than the total width of the valley floor. Type II span the entire valley and deposit material on the opposite valley side. Type III fill the valley both up and down stream as well as full width. Type IV dams are formed by contemporaneous failure of both slopes. Type $\mathrm{V}$ dams are formed by landslide with multiple lobes. Type VI, one or more surface failures that extend under the stream. 


\subsubsection{Dam longevity and modes of failure}

The length of time that a landslide-dam can persist is dependent on the competency and permeability of the barrier material, the volume of the lake in relation to the volume of the barrier, and the rate of inflow as a function of slope and area of the upstream catchment (Adams, 1981; Costa and Schuster, 1988; Korup, 2004). Schuster (1993; 1995) argued that the composition of the dam material was an important control, with dams formed of large blocks, boulders and cohesive clays being less likely to fail. Natural dams, unlike engineered earth dams, are not privileged to have breach prevention mechanisms such as water barriers and filter zones to control porewater pressures and prevent piping, nor are they made of homogeneous consolidated materials (Costa and Schuster, 1988). They also lack channelised spillways and as a result have no control on water levels or flow paths, so natural dams tend to overtop, which is the most common cause of landslide-dam failure (Costa and Schuster, 1988; Korup, 2002).

This lack of outflow control however is suggested by Bromhead et al. (1996) to be of little importance where there is slight permeability in the dam matrix and the existence of natural bypass channels as factors that could improve dam stability for the long term. This theory however may be difficult to validate in the field due to difficulties in reconstructing the dams former particle size and distribution once breached (Korup, 2002). With process studies on natural dam failures being rare, Adams (1981) and Costa and Schuster (1998) point to overtopping being the primary mechanism of dam failure. Fluvial erosion from overtopping occurs as a head cut that starts at the toe of the landslide material at the downstream edge and migrates back upstream until it has reached the lake resulting in the breach of the dam. The breach then erodes down through the landslide material until reaching more competent material. This new channel level may not be at the former river channel, and is often higher due to displacement of the bed by the landslide and more competent landslide material armouring the stream bed (Costa and Schuster, 1988).

Other modes of failure for natural dams relate to the competency of the barrier's material. The heterogeneity and unconsolidated material in natural dams may result in a more porous material where piping of water through porous spaces and seepage 
through the dam may cause internal erosion and undermining. Also, slope failure on upstream and downstream faces as a result of high pore-water pressures may reduce the barrier crest height and result in overtopping and eventual breach, though both these causes are considered rare (Costa and Schuster, 1988; Korup 2002). In terms of geo(morpho)logical time, most landslide formed dams are discrete features where they may last for only a few minutes or as long as several thousand years (Costa and Schuster, 1988; Korup, 2002). In part, the stability of landslide-dams are controlled by the relative volumes of the dam and reservoir, with dams of less than or equal to their reservoirs being likely to fail (Perrin and Hancox, 1991). However, where landslidedam lakes persist for periods of time, they can have a large impact on the drainage and sediment transport networks both up and downstream of the restriction. To evaluate the impact these features have spatially and temporally, the longevity of the dam must be known (Cossart and Fort, 2008).

\subsubsection{Large landslides and landslide-dams}

Much of the work on large landslides both in New Zealand and abroad during the last 30 years has had a focus on the landslide's movement and the mechanisms involved in the slope's failure. Other studies have been case studies where the focus is on the hazard presented by large catastrophic landslides and landslide-dam breaches (Korup 2002). This section will highlight a few of the studies that have importance within the context of this current work such as Keefer (1984), where the spatial effects of seismic shock are explored and Pearce and Watson (1986), where the use of remote sensing is employed to trace the movement of sediment deposits. There has, in recent time been some redress to remedy the lack of qualitative studies with interest in the formation of natural dams, their sediment delivered to channel networks and palaeoenvironmental studies (Korup, 2002). Palaeo-environmental studies in New Zealand such as the Pettinga's (1987 a \& b) study on the Ponui (1987a) and Waipoapoa (1987b) landslides of the southern Hawke's Bay and the Crozier and Pillans (1991) and Crozier et al. (1995) studies of 100 deep-seated landslides and Quaternary evolution of the Taranaki region all highlight important aspects applicable to this current work. The most comprehensive local series of work on large landslide-dams has been carried out by Korup (2002; 2004; 2005; 2006 and Korup et al. 2007), as 
part of $\mathrm{PhD}$ and ongoing research into the impacts of large deep-seated landslides in New Zealand's Southern Alps.

The Ponui and Waipoapoa landslides are both large deep-seated rapid translational bedding plane failures, with planar areas of $25 \mathrm{ha}$ and 18 ha respectively. These landslides occurred in geographically distinct locations of the same region a few months apart from each other in the same year (1987). The focus of the study by Pettinga was on the detailed structural and geological settings and the modes and mechanisms of failure of the slopes. Of interest is that the studies highlighted that the probable trigger was related to elevated pore-water pressures as a result of extended wetter than usual weather conditions (5 years), although the movements were not fluid in nature. The study made reference that there was probable seismic preconditioning with the initial movement creating tension cracks observed after the 1931 Napier earthquake (Pettinga, 1987, a \& b). Although it may also be possible to relate the appearance of the tension cracks that were observed in 1931 to an intense tropical storm of the scale of Bola that occurred in the same year. The Ponui landslide also resulted in a channel blockage forming a lake and is also mentioned in the 1991 inventory of landslide-dams of Perrin and Hancox (1991).

In their inventory of large landslide-dammed lakes of New Zealand Perrin and Hancox (1991) identified 82 examples nation wide, of which they concluded most were the result of magnitude $M=6.2$ or greater earthquakes. They noted that the distribution of large landslide-dams also matched that of known shallow earthquakes of magnitude $M=6.2$ and greater. Additionally, the study also highlighted that four lakes were as a result of storm triggered landslides, which they describe as in the main being small features that result in ephemeral dams. All of these small storm induced landslide-dams occurred during the Bola storm event of 1988 in the East Cape region and one of these sites (Mangakiore) is a subject of this current study. Perrin and Hancox's 1991 study showed that for the North Island, landslides that formed dams almost entirely occurred in the softer Tertiary sedimentary rock of the East Coast and Wanganui Basin. The main movements of the landslide-dams were either rockslumps, rock-slides or complex combinations of block slides, debris flows and debris avalanches. Other landslide-dams of interest from the inventory, due to their ages and location in the East Coast region, are those of the large lakes of Waikaremoana (2200 
14C years BP) and Tutira (7200 cal. years BP) and the former lakes of Tiniroto (6500 14C years BP) and Ngatapa (Perrin and Hancox, 1991).

As large landslides may be triggered by earthquakes, the landslide record has the potential to establish palaeoseismisity for the region (Perrin and Hancox, 1991; Crozier et al., 1995), although to do so, it is requisite that other possible triggers may be eliminated (Crozier et al., 1995). In challenging the Davisian model of landscape evolution and how landscapes respond to disturbance events, the Crozier and Pillans (1991) study used examples from the Taranaki landscape to support the concepts proposed by Brunsden (1985) of equilibrium, environmental change, unsteady behaviour and episodic change. In a landscape experiencing tectonic uplift and climatic and seismic disturbance, uplifted terraces, fluvial erosion and large deepseated landslides showed that any one or combination of these concepts could hold. The deep-seated landslides were induced over the regional scale on a reoccurrence of 1 in $10 \mathrm{ka}$ on average and the local of 1 in 1000. Landslide generated topography was visible in the landscape for at least $30 \mathrm{ka}$ and represented residence to return ratio of 3:1 (Crozier and Pillans, 1991). This long residence time of the landslide features was used in the Crozier et al. (1995) study to determine the clustering and age distribution on landslide-dams in the Taranaki. Using the geomorphic indicators such as surface texture, boundary definition, surface drainage and incision and presence of absence of lakes in the valleys or head scarps they were able to determine age and clustering of landslides. By the elimination of other sources of possible trigger for landslide clusters through the use of four methods $1 /$ event synchronicity $2 /$ modern analogues 3/ spatial distribution in relation to identifiable fault traces and 4/ limiting equilibrium back analysis, they were able to determine that earthquakes were the likely triggering source. The Keefer (1984) study on the number, size, type and distribution of earthquake induced landslides also showed that earthquakes could be the triggering source for clustering of large deep-seated landslides.

Apart from the already mentioned studies where landslide-dams have been used as records of events, these features also have potential for recording changes in sediment flux at varying scale (Korup, 2002). Studies such as Pearce and Watson (1986) investigated the degree of sediment retention in a catchment prone to severe landsliding and a high number of landslide-dams. The interpretation of time series 
aerial photos following the 1929 Murchison earthquake enabled the investigation of the provenance of lithological marker sediments and the retracing of sediment deposit movements throughout the catchment. They showed that co-seismic sediments were resident within temporary sediment stores for longer periods than expected. This was especially the case for the larger fraction with pebbles and sand sized grains moving not more $10 \mathrm{~km}$ of source over a 50 year period (Pearce and Watson, 1986).

The analysis of sediment impounded by the Tutira landslide dam formed the basis of a series of studies by Page et al. $(1994 ; 1997 ; 2010)$ on changes in catchment dynamics, landscape erosion rates due to the influence of human arrival to the landscape and later the climatic variability and storm frequency of the Holocene. Sedimentary infill of the lake started post formation 7200 years cal. yr. BP from shallow translational landslides, and human arrival to the area was from 500 cal. yr. BP. The lake is a highly efficient sediment trap due to the unique configuration of the catchment and the out position for the lake making for a closed system. Land clearance practices of firstly Polynesian settlers and then later that of Europeans, altered catchment sediment budgets which left strong signals in the lacustrine deposits (Page and Trustrum, 1997). Because of the sensitivity of the catchment and the high trapping efficiency of the lake they were also able to assess short term budgets from a single high magnitude storm event to those of background sedimentation in the lake (Page et al. 1994). The sediment budget approach employs the conservation of mass to quantify the source to sink sediment pathways.

The latest in this series of studies has looked at the storm record for the last 7200 years, which will be discussed in more detail in the climate section of the regional setting chapter. A study by Cossart and Fort (2008) engaged the use of remote sensing and the creation of computer generated DTM's to assess the volumes of sediments detained by landslide dams in a mountainous catchment in the southern French Alps. The method involved the creation of a digital model of the valley floor prior to sediment infilling the valley, then comparing to the present day to create a model of the sediment package and derive a volume. They concluded that this is an efficient method of calculating sediment volumes in deposited sediments when compared to other methods available. They were however unsure of the precise 
calculation of trapped sediments especially the finer component which may be exported from the dam as suspended load (Cossart and Fort, 2008).

\subsection{Reservoir sedimentation}

The following section investigates the processes of reservoir sedimentation and the efficiency of small ponds and reservoirs to trap sediments. The section will highlight studies that have used sedimentation of small reservoirs to investigate environmental change. The methods of estimation of trap efficiency and the trap efficiencies for the studied reservoirs will be described in more detail in the methods chapter, later in this volume.

Stream power is dependent on catchment characteristics and will determine a river's ability to carry sediment, while rates of erosion from hillslopes will determine the sediment availability for streams to transport. Where erosion rates from slopes are less than the stream's ability to carry sediments, then the stream may erode sediment stores where available or it will be forced to carry reduced sediment loads (Crozier, 1986). The role performed by streams is often considered to be more important in the transport, rather than deposition of sediments. There are however certain conditions where river channel deposits may be preserved, such as in point bars in meanders of channels, natural levees and in overbank deposits on flood plains (Boggs, 2006, pp 251). Under normal conditions the stream will continue to carry the sediment load until stream power conditions change. This may occur due to changes in stream slope or profile or upon entering a larger body of water. Here the natural flow characteristics of a stream are disturbed and on entering a reservoir as flow depth and flow velocity are decreased. These flow changes reduce the sediment transport character of the stream causing the settling out of in transport sediments, with the coarser sediments settling out first (Julien, 1995, pp24-42).

There are three characteristic sedimentary deposit sequences which relate to the hydrology within lacustrine (lake) settings as described in Boggs (2006, pp 272-274). These are defined as overfill, balance-fill and underfill sequences. In an overfilled lake basin an open hydrological system dominates, which produces as progradational shoreline deposition sequence, with interbedded fluvial deposits being common. This 
system prevails where sediment supply and water flow is greater than the accommodation space for deposition in most conditions. For a balanced-fill system the basin will have an intermittently open hydrology allowing for fluctuations in lake level that result in a mixed progradational and aggradational sedimentary architecture. The sediment and water supply are in balance with the availability of accommodation space. Lastly there are underfill sequences which occur in reservoirs which are hydraulically closed, featuring a dominantly aggradational shore line and a complex stratigraphy associated with deposits in settings of high evaporation. The supply of accommodation space for sediment is constantly more than the water and sediment availability provided by the catchment. These generally occur in arid regions and are not applicable to reservoirs in this study.

The sedimentation processes for lakes can broadly be classified as primary and secondary processes. The primary processes refer to the initial deposition of sediments upon entering the reservoir and secondary are the reworking and redistribution of sediments (Shotbolt et al., 2005). Initially coarse sediments will be deposited in the head of the reservoir forming a delta, with delta morphology being described in terms of topset and foreset beds. In small reservoirs deltas are subject to periods of erosion due to fluctuations in water level resulting in a complex depositional architecture. Beyond the delta flow velocities decrease rapidly at a rate that increases with distance from the delta, fine particles are able to settle out of suspension (Shotbolt et al., 2005). Secondary sedimentation processes result in the resuspension of sediments and the deposition of them in deeper parts of the lake. This secondary sedimentation occurs where sheer stress overcomes cohesion of particles to the bottom and is primarily caused by wind waves and internal currents (Shotbolt et al., 2005).

Reservoir infill for the landslide-dam ponds of this study may be influenced by conditions that are best described as an open system early in their sedimentary infill and those of the balanced system later. This is due to both the incision of the barrier and the rapid initial infill of the reservoir post event and lowering pond water levels later in the infill sequence. Small reservoirs are however not very efficient sediment traps with sedimentation affected by turbulence in the water column created through both climatic and physical processes (Boggs, 2006, pp270-272). The physical 
disturbance of the water column is due to the limited volume and the short residence time of the inflowing water limiting stratification of the water column and limited reduction in water velocity and turbulence. Climatically, the influences from wind disturbance on the surface of the reservoir create wind waves and currents mixing of the water column and with solar radiation which produces thermal mixing currents. These all mean that the finest particles do not have time to settle out of the water column but are passing straight through the trap (Julien, 1995, pp 91-106). For reservoirs in ephemeral catchments where ponds may dry out altogether the channel may provide a connected flow in low flow conditions and during reservoir infill. Infill of small reservoirs is likely to be that of an overfill characteristic due to high catchment area to reservoir area ratios.

\subsubsection{Trap efficiency}

Trap efficiency describes the proportion of incoming sediment that is deposited or retained within the reservoir (Dendy, 1974). To achieve the purposes of this study it is required that sediments for a wide range of flow conditions are retained in reservoir therefore trap efficiencies should be high. In general due to the smaller hydrological size of valley reservoirs, such as those formed behind natural landslide-dams the low reservoir to catchment area ratio results in a lesser proportion of fine suspended sediments being deposited than could be expected in larger water bodies where flow distances and water retention times are longer (Shotbolt et al., 2005). Therefore in smaller reservoirs under estimations in catchment sediment yield may result and should be corrected for (Verstraeten and Poesen, 2000). There are many processes and parameters that may affect the efficiency of the reservoir to trap sediments (Brune, 1953), however as trap efficiency is a reflection on the amount of sediment deposited, the factors that effect sedimentation are most important (refer to figure 2.51).

Particle size distribution of the incoming sediments will form a control on trap efficiency in relation to retention time, with coarser and denser particles having higher settling velocity and requiring less time to settle out. The controls on grainsize are dependent on catchment lithology and sediment delivery processes (Verstraeten and Poesen, 2000). Retention time is also influenced by the characteristics of the inflow hydrograph and reservoir's geometric character. Reservoir shape, surface area, storage 
capacity and outlet typology are controls on reservoir flow characteristic. Lower runoff values will result in a larger retention time and higher trapping efficiency, with high intensity flow events reducing retention time. The position and distances of inlet and outlet channels and reservoir shape also have control on retention times. With larger distances between inlet and outlet channels there will be an increase in residence time, while the height and size of the outlet at the embankment will control water column mixing (Brune, 1953). Permanent ponds as opposed to ponds that dry out also control average retention time and water chemistry may affect flocculation through altering particle size. Vegetation on the reservoir floor will affect sedimentation processes and should also be considered (Verstraeten and Poesen, 2000). 


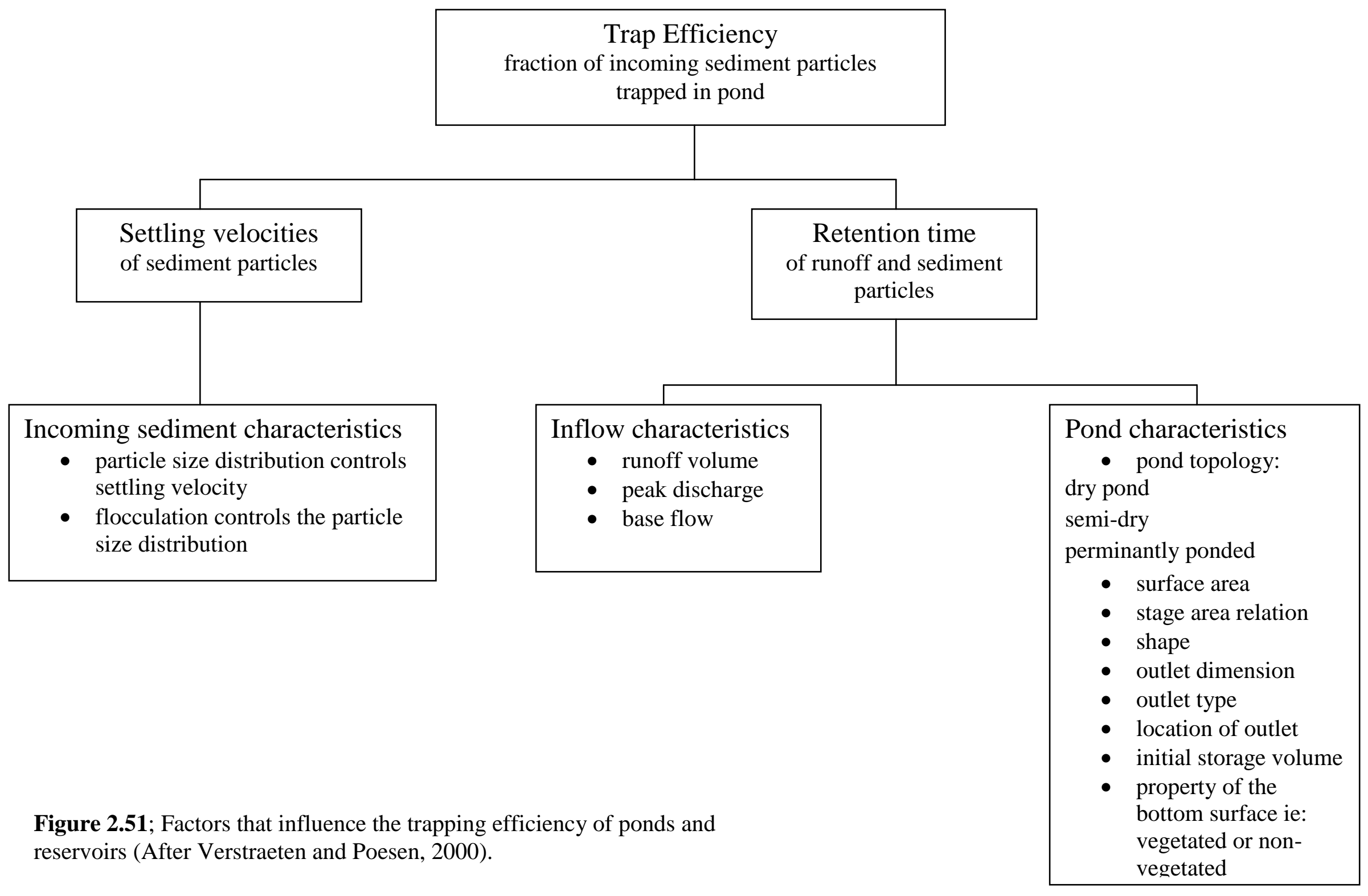




\subsubsection{In justification of small reservoir studies}

Studies such as those of Verstraeten and Poesen (2002) and Koi et al. (2008) have shown the worth of small reservoirs in the assessment of sediment yields and the interpretation of spatial and temporal environmental dynamics. These studies have also shown that they may produce results that are useful even over large areas and short timeframes. For an earthquake and high intensity rain storm prone catchment in central Japan's Tanzawan region, a study conducted by Koi et al. (2008) has investigated the relationship between sediment discharge and landslide occurrence at the catchment scale. As has been demonstrated in earlier sections of this chapter, both high intensity storms and earthquakes can be triggers for landslides and landslides are a major source of sediment delivery to river channels. Earthquakes occur only periodically and Koi et al. (2008) suggest that the sediment derived from these events can remain active in the landscape for decades. Koi et al.'s (2008) study aimed to understand the long-term effects of co-seismic landslides on sediment discharge in terms of hazard and basin management. The study investigated landslide distribution, catchment wide sediment discharge and the spatial distribution of sediment yields from 15 flood control check dam sub-catchments. The study was able to establish baseline sedimentation rates for both the catchment as a whole and the subcatchments of the check dams, through the analysis of the sediment deposits within the check dams. The study was able to conclude that the sediments delivered by the 1923 Kanto earthquake were still active within the catchment some 80 years later and were contained within recent sediment discharges (Koi et al., 2008).

In a study that investigated the link of sediment sources within small catchments and sediment transport through larger river networks Verstraeten and Poesen (2002) expand on the problem of up-scaling box plot soil erosion data to the sediment delivery ratio for larger catchments. Using data derived from 21 ponds in central Belgium the study compared 3 methods of estimating sediment yield for a large area and making inter-catchment comparisons. The study found, that when investigating spatial variations in sediment yields over large areas, the data derived from ponded sediments in small reservoirs produced acceptable results for annual and longer timescales. For the event response the results of the same reservoirs was questionable due to the sediment layers being too thin. This was due to the reduced trapping 
efficiency of small reservoirs during large events especially where storage capacity was low when compared to runoff volumes (Verstraeten and Poesen, 2002).

While it is understood that sediment volumes captured in small reservoirs are highly disposed to fluctuation and may constitute incomplete records, these errors may be constrained when site specific trapping efficiencies and sediment dry bulk densities are understood (Verstraeten and Poesen, 2000). Studies on trap efficiency of small reservoirs such as Dendy (1974) and later Heinemann (1981) have shown, that for suspended sediment content $80-95 \%$ of sediment may be retained and that this was independent of reservoir shape and catchment configuration. The exception to this was where extreme conditions affected flow and sediment volumes, in which case efficiency to trap sediments was greatly reduced due to overtopping of outflow embankments and reduced residence time of incoming sediments (Dendy, 1974). This current study does not require a high resolution record and is interested in the mean conditions of sedimentation. So the study of the sediment bodies which have developed in the small ponds upstream of these landslide features are nevertheless able to provide sufficient insight into the changing dynamics within the catchment on an inter-decadal timescale and enable inter-catchment comparisons.

\subsection{Current and future research on sediment flux in the Waipaoa}

As demonstrated in the previous discussions there has been a significant amount of work around landslide studies and sediment dynamics. This next section will focus on the East Cape region of New Zealand and in particular the Waipaoa catchment highlighting the work undertaken through the MARGINS project and related studies and will to draw attention to the research gap that this current study will address.

\subsubsection{The East Cape and Raukumara Ranges}

The East Coast of New Zealand's North Island is a climatic and seismically active region, with this history to be discussed in more detail in following chapters. The region experiences annually a large number of landslides most of which are surface failures and attributed to storm events. A number of studies on the landslide 
contribution to sediment budgets have been carried out within the Waipaoa catchment. Larger deep-seated landslides, defined as regolith displacement depths greater than $5 \mathrm{~m}$, while less common are also less well studied. Current frequency (last 20 years), is approximately 1 landslide every 2 years (Page and Lukovic, 2011). They can be triggered by both high intensity storm events and seismic events (Hicks et al., 2000; Reid and Page, 2002). Earthquakes are frequent (discussed further in following chapters) and are generated through both subduction zone seismicity and the active faults within the associated deformation zone (Litchfield et al., 2009b).

A number of the prehistoric landslides in the region have been attributed to earthquakes by authors such as Adams, 1981; Pettinga, 1987a, 1987b; Perrin and Hancox, 1991; Reid et al., 1991 and Korup, 2002. As part of the work involved in the set up of the GNS large landslide database for the Gisborne region, Page (2011) has identified and compiled a list of 1026 large deep-seated landslides within the greater Waipaoa catchment. These landslides have been categorised in terms of their type and in relation to sub-catchment, area, location on the slope, slope angle and orientation, geology and current activity status. These landslides have also been described in terms of their relationship to river channels, such as channel incision and channel blockage. The vast majority of landslides (704) involved channel incision and only a small number (33) of landslides showed evidence of current or historic channel blockage (Page and Lukovic, 2011). Of the landslides that showed evidence of channel blockage as evident in observation of stereo aerial images, most were in higher order catchments where the combination of small catchment area and narrow valleys combine to enable dam stability. While the triggering of large deep-seated landslides in the Waipaoa catchment is often attributed to earthquakes, the importance of the preparatory factors may be just as significant and can be attributed to climatic variables. Climatically-driven river incision and knickpoint retreat has led to destabilisation of slopes through over steepening and removal of toe support (Marden, 2008b). Climatic fluctuations, such as those post last glaciation, can have dramatic effect on sediment flux through changes in vegetation cover, and altered stream power resulting from changes in mean precipitation, storm frequency and magnitude, and base level (Litchfield and Berryman, 2005). 
Within the landscape, these changes are evident in the Waipaoa 1 (W1) high aggradational terraces laid down during glacial conditions and their deep incision post termination and transition into the more stabile conditions of the Holocene. The flux of sediment due to this post-glacial incision (Marden et al., 2008b) when compared to deposition on the Poverty Bay continental shelf (Orpin et al., 2006) showed that volumes of sediment removed account for only $25 \%$ of deposition. This indicated other on-shore sources of stored sediment or deliveries are responsible for the remaining sediments. The triggering of landslides through slope destabilisation resulting from the changes imposed by post-glacial incision is suggested as a possible mechanism for this (Marden et al., 2008a). Litchfield and Berryman (2005) through their work in eight Waipaoa tributary catchments were also able to determine that this incision of the W1 terrace was due to climatically-induced changes of base level and stream power rather tectonic uplift.

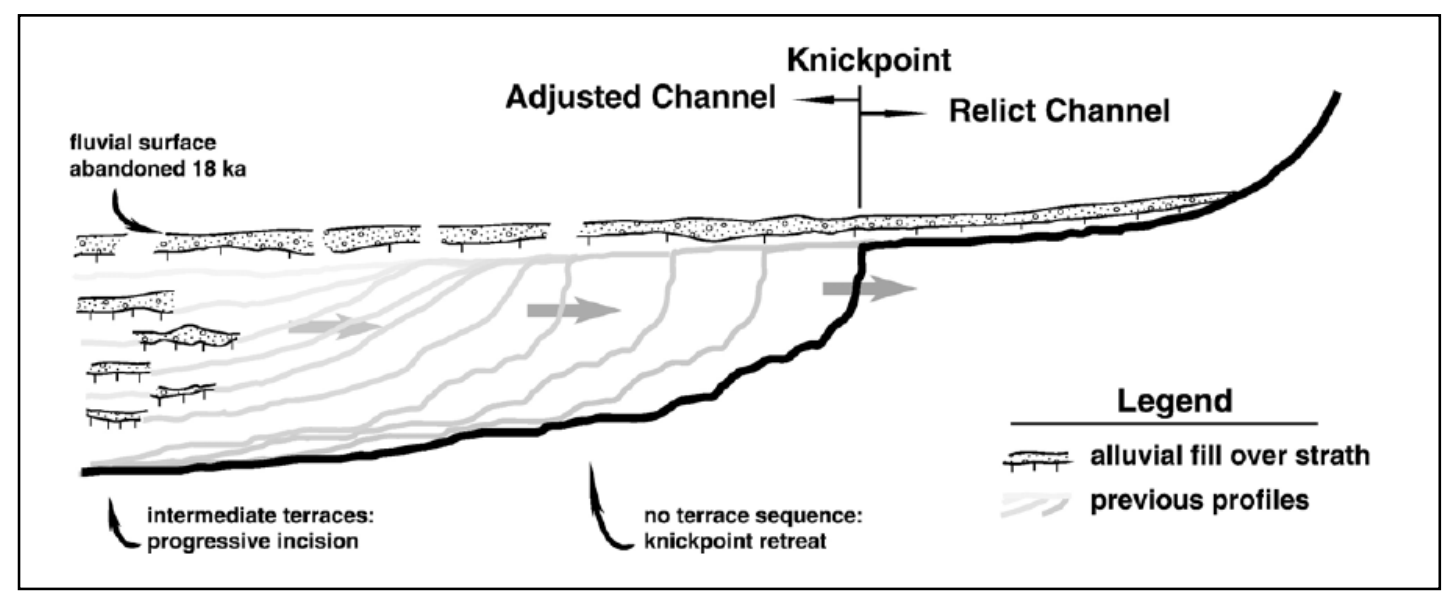

Figure 2.61, Long profile of a typical Waipaoa knickpoint. Illustrating the relation ship of the relict $18 \mathrm{ka} \mathrm{BP}$ channel surface to the propagation of base level induced channel adjustment. No scale is intended (Crosby and Whipple, 2006).

The longitudinal profile of a river (both alluvial and bedrock) will tend toward a form that will best facilitate sediment transport of bed load and erosion of the riverbed (Crosby and Whipple, 2006, and references therein). The changes in boundary conditions will tend to alter the stream's efficiencies in sediment transport or erosion, causing the channel to adjust and find a new form more appropriate to the new conditions. These boundary condition changes may be both regional and local, with landscapes over geological timeframes being in a constant state of adjustment. Knickpoints are described in Crosby and Whipple (2006) as defining the mobile 
boundary between relict and adjusting portions of fluvial channels and a typical profile for a Waipaoa tributary is shown in figure 2.61.

Research by Crosby and Whipple (2006) and Berryman et al. (2010) in the Waipaoa both point to knickpoint initiation being a result of post-glacial incision. Crosby and Whipple (2006) mapped 236 active knickpoints often occurring as waterfalls through out the Waipaoa. While Berryman et al. (2010) reconstructed the post-glacial downcutting history for a section of the Waihuka, which is a tributary to the Waipaoa. The identification of knickpoints identifies the boundary between landscapes that are in the process of adjusting to post-glacial conditions and those of relict landscapes. Berryman et al. (2010) suggested response to base level change was ongoing in the Waihuka with different parts of the landscape in either phases of aggradation or degradation and consequently sediment transport. The retreat of the knickpoint is estimated at a rate of approximately $2 \mathrm{~km} / \mathrm{yr}$ meaning landscapes below the knickpoint have several thousand years ago adjusted to post-glacial conditions. The understanding of these changes in the spatial and temporal distribution of sediment from the terrestrial sources to marine compartments is one of the goals of the MARGINS source-to-sink project. The links of large landslides to knickpoints in terms of both a source and disruption to sediment transport will be a large part in the understanding of these interactions. The current large landslide study follows on from and enhances the earlier terrestrial and offshore work mentioned in the MARGINS section of the previous chapter.

\subsubsection{Totangi landslide-dam Gisborne}

The mechanisms and timing in the formation and breach for two palaeo-landslide-dam lakes associated with complex series of landslide failures were part of a study carried out by Pere (2003). This study showed that there were three main landslides which combined to block the Ngatapa valley forming a large landslide-dammed lake. The Ngatapa valley is located in a western sub-catchment of the Waipaoa. The first of the failures, the Sunworth complex is described as a $4.1 \mathrm{~km}^{2}$ defect controlled deep-seated wedge failure that slid and blocked the southern end of the Ngatapa valley. This event was accompanied by the translational failure of Karaka A $\left(135000 \mathrm{~m}^{2}\right)$ and Karaka B $\left(30,000 \mathrm{~m}^{2}\right)$ (Pere, 2003). These movements were associated with bedding plain 
failures in alternating sandstone and mudstone successions of the Late Miocene age Tolaga group, which typically are dipping southeast in this region. Triggering of the landslides was considered to be by a large magnitude seismic event and the failure having been preconditioned through valley incision destabilising slopes and the fragmentation of bed rock by earthquakes. This complex failure caused the blockage and temporary isolation of the Ngatapa valley from the Waipaoa and the formation of two lakes as a result of a single triggering event.

The main lake of Totangi formed in the blocked valley and had an area of $2.35 \mathrm{~km}^{2}$, while the smaller lake, Karaka $\left(0.3 \mathrm{~km}^{2}\right)$, formed in the Sunworth landslide head scarp. Through the use of tephra chronologies and constrained by radiocarbon ages Pere (2003) established that these lakes were formed approximately 28ka Cal year BP and persisted for a $13 \mathrm{ka}$ period. It was considered that during the formation of the Totangi dam the initial flush of sediments was contained within the dam complex and that these sediments were then progressively released following the dam's breach. Post closure of the Ngatapa valley the catchment was considered to be a closed system with all surface water draining into the lake and no surface flow of water out of the catchment. During the period that the dam was able to persist, it provided an effective barrier to sediment transport from the $6.15 \mathrm{~km}^{2}$ upper catchment. This resulted in the net accumulation of $35.5 \mathrm{~m}$ of sediment depth, that was evident through the preservation of terraces above the dam post dam breach. Mapping of the terraces enabled the calculation of a total volume of $59,251,488 \mathrm{~m}^{3}$, which represents an average sediment yield of $1479 \mathrm{t} / \mathrm{km}^{2} / \mathrm{yr}$ for the catchment. Through calculating sediment volumes over discrete periods within the infill sequence, a range of sediment yields (700-3800 t/km²/yr) in response to climatic change was suggested, with the peak of $3800 \mathrm{t} / \mathrm{km}^{2} / \mathrm{yr}$ at $22 \mathrm{kyr} \mathrm{BP}$ which coincided with the W1 aggradational terrace phase (Pere, 2003).

Sedimentation of Lake Totangi was eventually responsible for bringing the lake level to the crest of the dam and enabling overtopping to start incision and finally dam breach (Pere, 2003). Once breach occurred the poorly consolidated sediments of the lake floor were easily entrained and transported within the drainage network, with only $17 \%$ of the material remaining in the Ngatapa valley. Removal of the dam material and the incisions into lake sediments occurred at variable rates over an 
estimated 2330 years, with the material being transported via the Waikakariki River to rejoin the Waipaoa. Pere (2003) considered that the majority of the material eroded was then deposited by the Waikakriki in a fan formation where the valley meets the Poverty Bay flats. Pere (2003) considered that while landslide-dams of the scale of Ngatapa provided perturbations to sediment flux, the impact to sediment yield on the greater Waipaoa catchment over the longer timescale was insignificant. The study suggested that there would need to be a number of similar dams in multiple catchments throughout the region to show any measurable impact. At the time of the study there were no further landslide-dams known to the author on which to base further calculations. Since this study, work on forming the large landslide inventory within the Waipaoa as part of the MARGINS project by Page (2011) has identified that there are over 1000 large landslides, of which there are 33 that have formed channel blockages. It is these 33 landslides that formed the basis and starting point for this current study, and part of the MARGINS large landslide objective.

\subsubsection{Current and ongoing studies}

Investigations in the spatial and temporal distributions of large deep-seated landslides and volumes of sediment contributed by these events to the Waipaoa sedimentary system is the focus of an ongoing study by Bilderback (Canterbury University). Focusing on two northern catchments of the Waipaoa the study aims to quantify sediment volumes delivered directly to the sedimentary system by large landslide events. The Bilderback study aims to provide minimum age estimates of the landslides and their spatial distribution in the northern Waipaoa catchments. This is done through the use of tephra chronologies. The study then aims to provide estimates of sediment volume contributed by these events to the Waipaoa sedimentary system. The hypothesis is that deep-seated landslides will be abundant in areas of the landscape where the fluvial channel has already responded to post-glacial incision, with landscapes above the knickpoint's retreat being in relict form and more stable. The spatial distribution of ages may provide insights into possible triggering mechanism, such as large seismic events or knickpoint retreat up-river channel profiles. 
In a similar study to that of Pere (2003) Butler (Massey University) is investigating the formation and evolution Lake Ngamarua in the south western Te Arai catchment, also a tributary to the Waipaoa. The aim of the study is to provide an age estimate for the formation of Lake Ngamarua which formed in the head scarp of a large landslide, and to identify sedimentation rates and associated environmental changes from sediment core anlaysis.

\subsection{Chapter summary}

This chapter has introduced the key concepts that are central to the current study and has introduced examples from national and international work that are influential. The current study is furthering and drawing on the work carried out by Pere, introducing the recommendations that were made to include the study of additional sites to better estimate the effect of landslide dams on sediment dispersal. This study also, through the dating of landslides, will combine with the Bilderback study to enhance our understanding in the spatial and temporal distribution of triggering events for large landslides and the regions climatic and tectonic history. Where this current study departs from those described above is in regards to the sedimentary systems, where this study will be looking at sediments that are removed from the sedimentary system rather than added to it. An outcome of this study may be to further support the use of landslide-dammed lakes and the sediment packages of former impoundments as an event recorder for palaeo-environmental studies. The current study may also go some way to answering some of the questions around landslide-dams, such as what are the spatial and temporal distribution of these features in the environment and what impact do they have on the downstream transfer of sediments. 


\section{Chapter 3:}

\section{Factors of control for landslide- dams and rates of sedimentation in the Waipaoa}




\subsection{Introduction}

In this chapter the regional setting for the greater Waipaoa catchment will be outlined in terms of the geographic location of the catchment and its relationship to key features of geomorphic interest. The chapter will also present a literature review on what is known of the region's seismic, climatic and sedimentary histories. The aim of this chapter is to provide a background on the conditions within the region that are responsible for the formation of natural landslide-dams and for the sedimentary behaviour of the region's catchments.

\subsection{The Waipaoa River; a general setting}

Situated in the East Cape region of New Zealand's North Island, the Waipaoa is the largest of three catchments draining to the east of the Raukumara Ranges. The Waipaoa catchment extends from Poverty Bay at the eastern boundary and exit point for the Waipaoa River to the catchment headwaters high in the Raukumara Ranges in the west (Hicks et al., 2000). As discussed in more detail later this chapter, for this study the greater Waipaoa catchment includes the smaller Waimata catchment. The individual catchment's outlines are shown in figure 3.11 and the two catchments cover a combined area of $2500 \mathrm{~km}^{2}$ (Marden et al., 2008b).

Rugged and deeply dissected, the Raukumara Ranges reach a maximum elevation of $1752 \mathrm{~m}$ at Mt. Hikurangi summit and comprise a zone of ranges and basins which are associated with the forearc crumple zone of the Hikurangi subduction margin (Litchfield \& Berryman, 2005). The Raukumara Ranges may be divided into two subgroups, firstly lying in a northeast-southwest direction and forming the backbone of the peninsula are the bedrock frontal ridge ranges, with an average elevation of $1300 \mathrm{~m}$. This group of ranges forms the north-eastern extension of the North Island's axial range and provide a major topographic divide between the east and west coast. The second subgroup and the main group for this study are the lower elevation eastern ranges from which the Waipaoa River descends. It is the central and southern section of the East Cape peninsula which contains the Waipaoa catchment and the eastern ranges of the second sub group have peaks which rarely rise above the $1000 \mathrm{~m}$ mean elevation (Mazengarb \& Spaden, 2000; Litchfield \& Berryman, 2005). Roughly round 
in shape, the catchment of the Waipaoa has major tributaries of the Mangatu, Waingaromia, Wharekopae, Waihuka, Waihora and Te Arai Rivers which drain the ranges and coastal lowland hills. The Te Arai under the Waipaoa catchment's current configuration is the southern most tributary joining at the southern end of the Poverty Bay flats as the Waipaoa River reaches the sea.

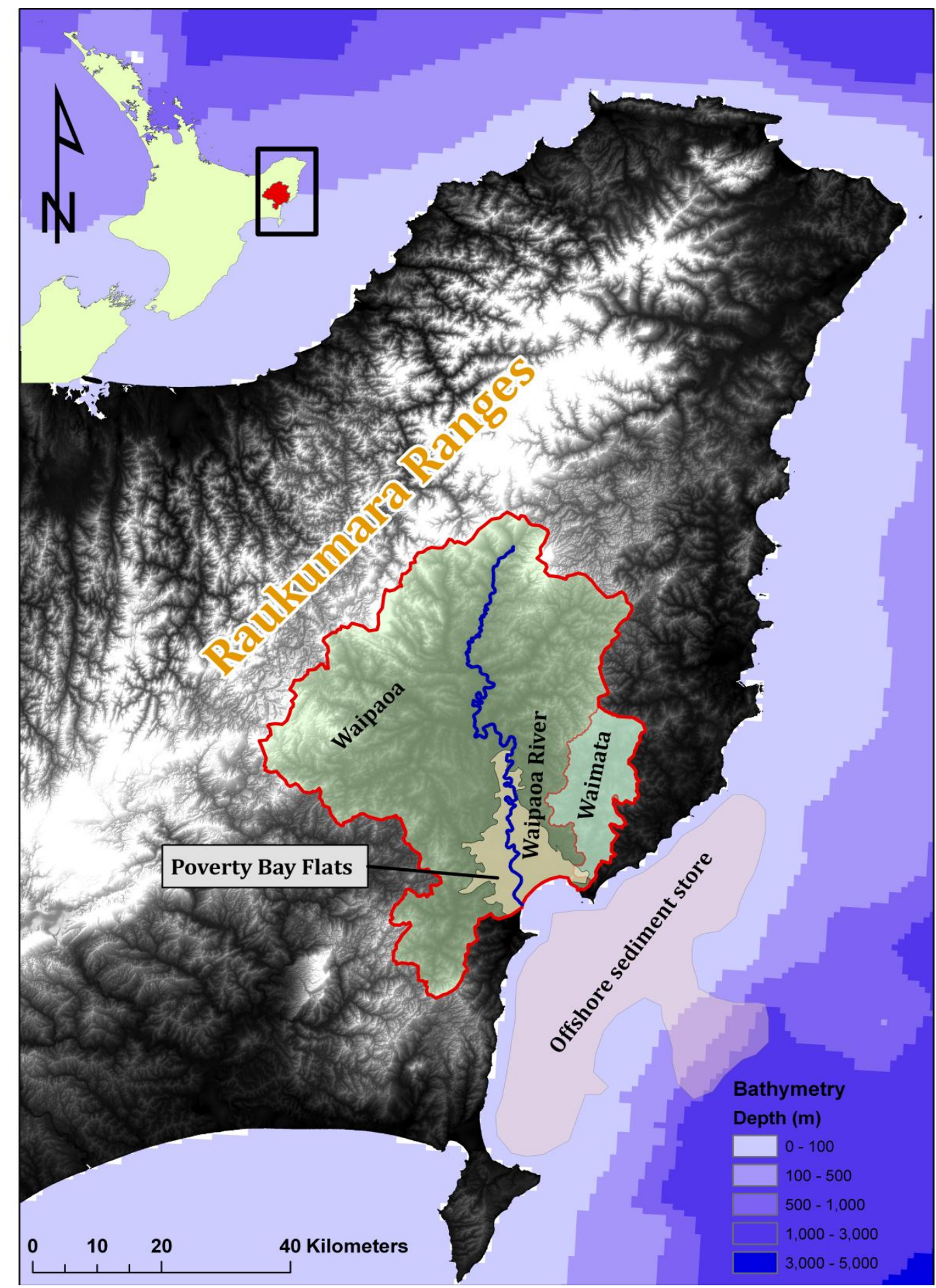

Figure 3.11; Key features for the Waipaoa sedimentary system. This figure shows the locational setting for the Waipaoa catchment and illustrates key feature of the Waipaoa sedimentary system. 
The back country of the East Cape today is densely covered in native podocarpbroadleaf rainforest and it is these forests which would have been dominant for the last 15 thousand years (ka) as suggested in pollen evidence such as that by Allsop (1973). The podocarp-broadleaf forests would have also covered the lower coastal ranges and even the coastal plains during the warmest periods of the Holocene and prior to human settlement (Eden et al., 2001). While the region's climate has had a large effect on vegetation cover, with shrub and grasslands being dominant in cold glacial conditions and full forest cover during the Holocene optimum (McGlone et al, 1984), recent human land use changes have had a larger influence on vegetation cover. It was the coastal and lowland regions that were those first to be influenced by anthropogenic activities. Evidence for the clearance of forest was firstly associated with the Polynesian arrivals which have been estimated to have occurred from as early as 1200 AD (Higham and Hogg, 1997). Maori are known to have cleared large sections of the native lowland podocarp forest for hunting and cropping purposes and to have maintained these clearings as bracken and scrub through periodic burnings (McGlone and Wilmshurst, 1999). These forest clearances would have been principally located close to the main centres of habitation (McGlone, 1989), which were dominantly in the south-west and lower reaches of the catchment (Jones, 1988). Later, clearance of forest is indicated to have occurred in the inland ranges and high back country. Evidence of these clearances is shown in pollen records taken from Lake Waikaremoana by Newnham et al. (1998) and may have been coincident with a warmer period during the Holocene. There has been no evidence in the Waipaoa of inland and high country clearances and coastal hill country clearances were probably not maintained.

Following the periodic slash and burn clearance of relatively small areas of forested land by Maori were the large scale clearance practices associated with European settlement. Clearance of the lower reaches of the Waipaoa and the coastal plains and hills first occurred around the 1820s (McKay, 1982). The basin wide clearance of forest and conversion into pasture for agricultural farming occurred between 18801920. These forest clearances left only an estimated $2.5 \%$ of native forest cover on land that was steep or remote (Gomez et al., 1999). This wholesale land clearance produced an immediate geomorphic response, with increases in erosion (discussed later this chapter) and flood peak response of rivers. This landscape response was of 
great concern to those farming on the Poverty Bay Flats and also local iwi, due to not only the high levels of investment in both agriculture and settlement in the lowland areas, but also the rates of change that were occurring in the landscape. These landscape changes in response to the land clearances became the focus of many studies on erosion and catchment dynamics to provide strategies to mitigate these adverse effects. It was thanks largely to the decline in the economic viability of pastoral farming in this high erosion prone landscape, and the downstream effects from flooding and sedimentation on the Poverty Bay Flats, that there has been a reconversion of land to plantation forest in more recent years. The conversion of steep hill country pasture to plantation forestry was begun by the New Zealand Forest Service during the 1960s and head water areas were replanted to help control erosion. Plantation forests now cover $20 \%$ of the catchment and indigenous forest $6 \%$, with the remainder remaining in pasture (Page and Trustrum, 1997). Gisborne is the major settlement of the region, located on the north-eastern Poverty Bay Flats and provides the infrastructural support for the region's industry which consists of mostly agricultural and forestry exports.

\subsection{Geology and tectonic setting}

Uplift of the Raukumara Ranges results from the subduction of the Pacific tectonic plate beneath the Australasian plate at the Hikurangi subduction zone which lies $90 \mathrm{~km}$ off the coast to the east of the ranges (Barnes et al., 2002). The eastern slopes of the ranges show the resultant deformation of the slip-strike plate motion as a folded and seaward directed thrusting landscape in the forearc region (Crosby and Whipple, 2006). The Waipaoa catchment is underlain by marine rocks and sediments ranging in age from the Cretaceous to recent, and the region's geological structure is complex. In general terms there are three sedimentary suites which are broadly associated with landforms from the head waters to the coast (Berryman et al., 2000). The first suite, in the catchment head waters, is dominated by highly fractured Cretaceous and Tertiary sedimentary marine rocks of strongly jointed sandstones, siliceous argillites and smectitic mudstones, marl and limestones. The combination of Miocene to recent normal faulting and the presence of the smectitic clays provide for a highly unstable landscape predisposed to high rates of slope disturbance such as earthflows, slumps 
and gully erosion (Berryman et al., 2000; Gage and Black, 1979 cited in Marden et al., 2008b). The second sedimentary suite is associated with the more competent sandstone/mudstone and mudstones of Miocene-Pliocene age in the mid to upper reaches of the catchment and adjacent to axial ranges. These sediments support steeper slopes, where on these gentler rolling landforms, hillsides have become steeply incised. These landscapes are highly unstable and subject to widespread landslide, gully and slump erosion. The mid to lower reaches make up the third suit and represent the smallest area, consisting of Quaternary sediments of lacustrine, fluvial and lagoon deposits. These younger, less competent deposits are highly prone to large scale slumping and surface erosion (Mazengarb \& Spaden, 2000). This geologic setting and tectonic history result in the highly erodible Waipaoa landscape that it is sensitive to the region's extreme seismic and climatic inputs.

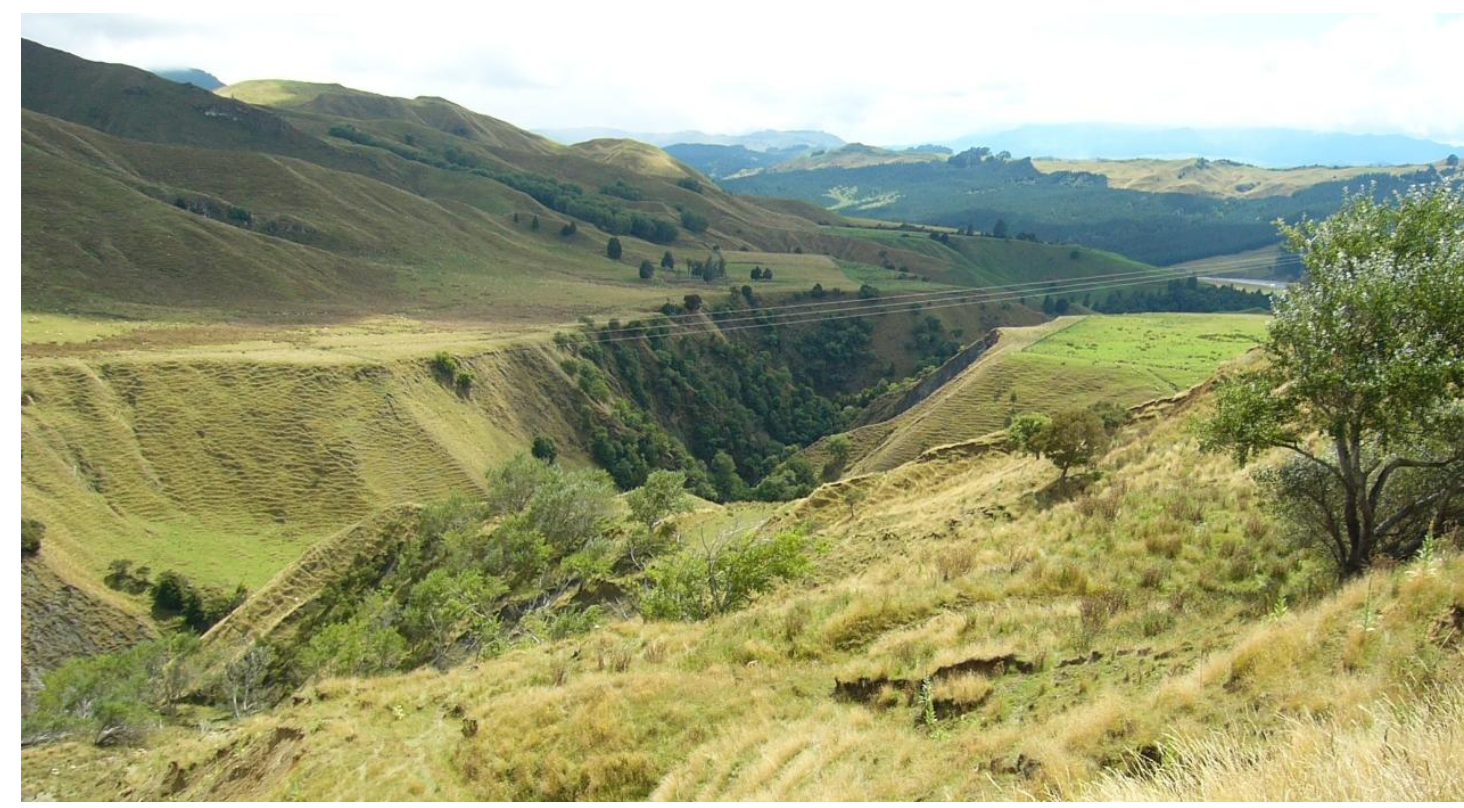

Figure 3.21; The Mangamaia river terraces. In the Mangatu catchment viewed from the top of an active landslide and looking downstream, evidence of an older landslide can be seen in the left of the picture below the far terrace (Photo R. Taylor 2010).

The tectonic and seismic record for the region is little known, but the landscape shows evidence of the response to tectonic forces. Such changes include variations in base level which have resulted in the deposition and erosion of terrace sequences such as those on the Waipaoa River and its tributaries (Figure 3.21). Spatially, the response to tectonic inputs across the region varies widely. Estimated mean uplift rates range from $0.5-0.9 \mathrm{~mm} / \mathrm{yr}$ in the middle and eastern catchment, through to $1.1 \mathrm{~mm} / \mathrm{yr}$ closer to the coast and up to $3-4 \mathrm{~mm} / \mathrm{yr}$ in the headwaters of the upper catchment (Berryman et al., 2000; Litchfield and Berryman, 2006). In a study of uplift rates on the Waihuka 
River, a north-western tributary of the Waipaoa River, Berryman et al. (2010) showed that while rates of uplift are similar to that of the main channel, there is considerable variation in the timing. The timing variations across the catchment result from the deep-seated processes related to three broad groups of active faulting structures that have been recognised (Litchfield, Smith and Berryman, 2009b): (1) the strike slip faults, which are the westward extension of the North Island Dextral Fault Belt that forms the axial mountain ranges extending from Wellington through to the Bay of Plenty; (2) the west-east trending normal faults in the eastern uplifted forearc region of the Raukumara Ranges, which are generally short in length and not considered to contribute significantly to deformation; (3) the offshore thrust faults, which are part of the actively deforming forearc in the northern Hikurangi Margin where there are high convergence rates (55mm/yr) (Wallace et al., 2004 in Litchfield et al., 2009b)). It is movement of these faults (refer figure 3.22) that produce the moderate to large ground shaking-events that are capable of triggering of large deep-seated landslides in the Waipaoa catchment (Litchfield and Berryman, 2005).

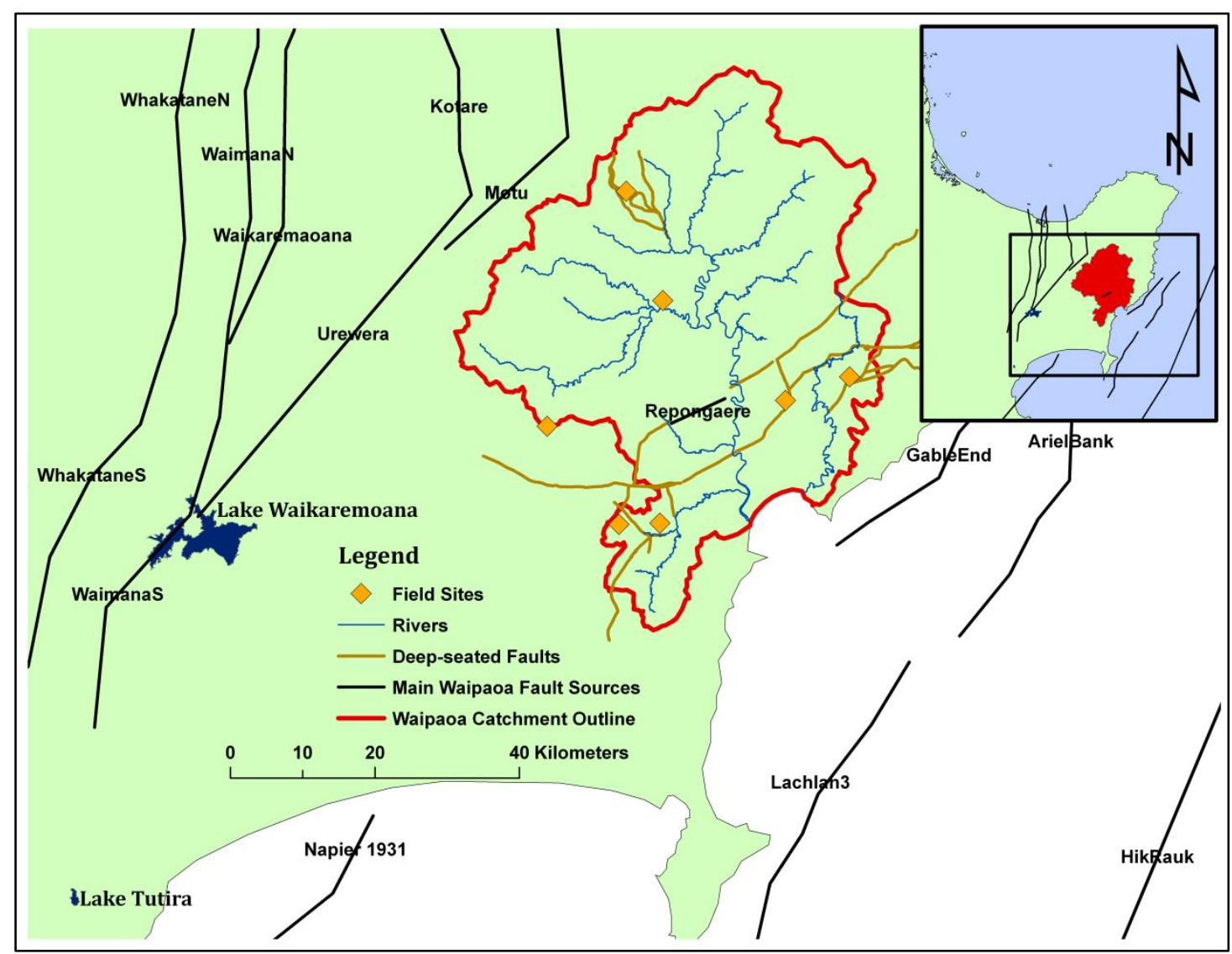

Figure 3.22; Waipaoa fault lines. The main faults likely to be responsible for both, deep-seated and shallow landsliding, as they relate to the study sites and the region's other major landslide-dam lakes. (After Litchfield et al. 2009b). 


\begin{tabular}{|c|c|c|c|c|c|}
\hline Year & Name & Description & Mechanism & $\begin{array}{l}\text { MMI at } \\
\text { Gisborne }\end{array}$ & $\begin{array}{l}\text { Occurrence } \\
\text { of landslides }\end{array}$ \\
\hline 1914 & $\begin{array}{l}\text { East Cape } \\
\text { Earthquakes }\end{array}$ & $\begin{array}{l}\text { Two earthquakes } \\
21 \text { days apart, of } \\
\text { moderate size, } \\
\text { recorded off } \\
\text { northern } \\
\text { Raukumara } \\
\text { Peninsular }\end{array}$ & $\begin{array}{l}\text { Shallow } \\
\text { earthquake with } \\
\text { epicentre } \\
\text { offshore at } \\
\text { Waipiro Bay } \\
\text { northeast of } \\
\text { Cape Runaway }\end{array}$ & MM9 & $\begin{array}{l}\text { Both } \\
\text { earthquakes } \\
\text { caused } \\
\text { landslides } \\
\text { throughout the } \\
\text { Raukumara } \\
\text { Range }\end{array}$ \\
\hline 1914 & $\begin{array}{l}\text { Bay of } \\
\text { Plenty } \\
\text { earthquake }\end{array}$ & $\begin{array}{l}\text { Deep-seated } \\
\text { earthquake felt } \\
\text { over a large area }\end{array}$ & $\begin{array}{l}\text { Earthquake } \\
\text { located in the } \\
\text { subduction slab } \\
\text { at a depth of } \\
\text { 300km }\end{array}$ & MM7-8 & $\begin{array}{l}\text { No reported } \\
\text { landslides }\end{array}$ \\
\hline 1921 & $\begin{array}{l}\text { Hawkes Bay } \\
\text { earthquake }\end{array}$ & $\begin{array}{l}\text { Deep-seated } \\
\text { earthquake felt } \\
\text { widely within } \\
\text { the Napier to } \\
\text { Gisborne regions }\end{array}$ & $\begin{array}{l}\text { Earthquake } \\
\text { located offshore } \\
\text { at a depth of } \\
80 \mathrm{~km} \text { occurred } \\
\text { on a normal } \\
\text { fault within the } \\
\text { subduction slab. }\end{array}$ & MM7 & $\begin{array}{l}\text { No reported } \\
\text { landslides }\end{array}$ \\
\hline 1931 & $\begin{array}{l}\text { Hawkes Bay } \\
\text { earthquake }\end{array}$ & $\begin{array}{l}\text { The largest } \\
\text { historical } \\
\text { earthquake for } \\
\text { the east coast of } \\
\text { the North Island } \\
\text { region followed } \\
\text { by numerous } \\
\text { after shocks. }\end{array}$ & $\begin{array}{l}\text { Rupture of } \\
\text { dextral reverse } \\
\text { fault south west } \\
\text { of Hastings in } \\
\text { the Hawkes } \\
\text { Bay. }\end{array}$ & MM7+ & $\begin{array}{l}\text { Caused } \\
\text { moderate } \\
\text { landsliding over } \\
\text { a } 470 \mathrm{~km}^{2} \text { region } \\
\text { with large } \\
\text { landslides in the } \\
\text { Hawkes Bay } \\
\text { region. }\end{array}$ \\
\hline 1932 & $\begin{array}{l}\text { Wairoa } \\
\text { earthquake }\end{array}$ & $\begin{array}{l}\text { Strong ground } \\
\text { shaking } \\
\text { experienced in } \\
\text { Gisborne }\end{array}$ & $\begin{array}{l}\text { Mechanism not } \\
\text { well determined }\end{array}$ & MM8 & $\begin{array}{l}\text { Significant } \\
\text { landsliding over } \\
\text { a large area } \\
\text { between Wairoa } \\
\text { and Tiniroto }\end{array}$ \\
\hline 1966 & $\begin{array}{l}\text { Gisborne } \\
\text { earthquake }\end{array}$ & $\begin{array}{l}\text { Shallow } \\
\text { earthquake } \\
(18 \mathrm{~km})\end{array}$ & $\begin{array}{l}\text { Occurred on the } \\
\text { Hikurangi } \\
\text { subduction } \\
\text { interface }\end{array}$ & MM7-8 & $\begin{array}{l}\text { No reported } \\
\text { landslides }\end{array}$ \\
\hline 1993 & $\begin{array}{l}\text { Ormond } \\
\text { earthquake }\end{array}$ & $\begin{array}{l}\text { Centred } \\
\text { northwest of } \\
\text { Ormand at a } \\
\text { depth of } 37^{2}\end{array}$ & $\begin{array}{l}\text { Occurred in the } \\
\text { mantle of the } \\
\text { subducted } \\
\text { Pacific Plate. }\end{array}$ & MM7 & $\begin{array}{l}\text { Shallow } \\
\text { landslides }(<5 \mathrm{~m}) \\
\text { in mudstone hill } \\
\text { country }\end{array}$ \\
\hline 2007 & $\begin{array}{l}\text { Gisborne } \\
\text { earthquake }\end{array}$ & $\begin{array}{l}\text { Situated } 64 \mathrm{~km} \text { to } \\
\text { the southeast of } \\
\text { Gisborne } \\
\text { offshore at } 44 \mathrm{~km} \\
\text { depth. }\end{array}$ & $\begin{array}{l}\text { A slow slip was } \\
\text { triggered on a } \\
\text { normal fault } \\
\text { within the } \\
\text { mantle of the } \\
\text { subducted } \\
\text { Pacific Plate. }\end{array}$ & MM8 & $\begin{array}{l}\text { Some landslides } \\
\text { throughout the } \\
\text { Waipaoa } \\
\text { catchment }\end{array}$ \\
\hline
\end{tabular}

Table 3.21. Recent regional earthquake data. A summary of details for the recent earthquakes to affect the Gisborne region (Data from Litchfield et al. 2009b). 
Intensities in ground-shaking required to produce landsliding in New Zealand have been shown by Hancox et al. $(1997,2002)$ to be a minimum on the Modified Mercalli Intensity (MMI) scale of MM6 with a minimum moment magnitude $\left(\mathrm{M}_{\mathrm{w}}\right)$ of $\mathrm{M}_{\mathrm{w}} 6$. For the East Cape region estimates of return intervals and the mean strengths for strong ground-shaking of the strike slip faults of the Dextral Belt decrease from west to east. The western strand with its longer Whakatane, Waimana and Waikaremoana faults have shorter return times of 1100-1800 years with $\sim \mathrm{M}_{\mathrm{w}} 7.4, \sim \mathrm{M}_{\mathrm{w}} 7.5$ and $\sim \mathrm{M}_{\mathrm{w}} 7.5$ respectively. While in contrast, the eastern sources of the Urawera, Kotare and Motu faults are slightly smaller at $\sim \mathrm{M}_{\mathrm{w}} 7.3, \sim \mathrm{M}_{\mathrm{w}} 7.1$ and $\sim \mathrm{M}_{\mathrm{w}} 7.1$ respectively with return times of 3500-5200 years. The Repongaere fault in the central forearc region and a group 2 fault, has a calculated mean strength of $\sim \mathrm{M}_{\mathrm{w}} 6.3$ and with a return interval of $\sim 5500$ years and can be considered representative of all small faults in the central forearc region. The faults of this region are likely to produce a ground-shaking magnitude of MM7 over more than two thirds of the Waipaoa catchment. The last group, the offshore faults, have a calculated mean of $\sim \mathrm{M}_{\mathrm{w}} 7.2-7.6$, which is similar to that of the Dextral Belt faults and produce the largest ground-shaking events of MM79, covering much of the Waipaoa catchment. These faults are also the most active and have return intervals of $\sim 630-930$ years (Litchfield et al. 2009b).

Documentary records provide a 160 year history of major earthquakes in the North Island. During this period there have been, according to Litchfield et al. (2009b), eight historic earthquakes $\geq$ MM 7.0 in the Gisborne region and these events are listed in table 3.21. The large magnitude events that are likely to be responsible for the deep-seated landslides that form landslide-dams and are usually linked to movements of the active faults mentioned above and are considered to have return times of 10005200 yrs. The most recent of these large earthquakes has been the 2007 Gisborne earthquake, which reached a maximum ground-shaking intensity of MM8 and was responsible for a number of landslides in the local region (Litchfield et al. 2009b). Smaller earthquakes of $\leq$ MM7 occur on a relatively high frequency. These smaller events are generally deep-seated $(30-60 \mathrm{~km})$ and have a return period of $\sim 26$ years (Litchfield et al., 2009b). Earthquakes of this lesser magnitude may also produce both shallow and deep-seated landsliding, although generally over a smaller area. It is most likely however, that these smaller magnitude events are more often responsible for surface failures of $<3 \mathrm{~m}$ depth and not capable of producing the deep-seated 
movements that are required to form landslide-dams. These lesser magnitude events can still have a significant impact on sedimentary systems where they may produce shallow surface failures even on slopes under forest cover. Sediment is then available for mobilisation and delivery to stream channels by storm events.

Not all of the earthquakes in recent history have had landslide movements associated with them and this is likely due to the type of movement and the location of the associated faults. Litchfield et al. (2009) concluded that it is movement of the offshore thrust faults and those of the subduction interface which were the most important source of large deep-seated landslide producing events for the Waipaoa (figure 3.22). Work on recurrence times for the Lachlan Fault, one of the offshore faults in the northern Hawke Bay, seen in figure 3.22 by Cochran et al. (2006), showed a frequency of 1000-2000 years for the large events and 600-1000 years for the lesser events. There are direct relationships between these faults in the northern Hawke Bay and those offshore on the Gisborne coast and they are able to provide an analogue for offshore fault movement frequency and earthquake size in the Waipaoa region (Litchfield et al., 2010). The Cochran et al. (2006) study also recorded major events ( $\left.\sim \mathrm{M}_{\mathrm{w}} 7.9\right)$ which occurred at 7100 and 5500 calendar years before present and which could have resulted in the formation of the Tutira and Waikaremoana landslidedam lakes. Return times for these events is rather longer than expected and could mean that other trigger, such as climate, need also be considered for deep-seated landslides and perturbations of the sedimentary system.

\subsection{Climatic setting}

Climatic influences for the Waipaoa catchment are strongly related to the region's geographic setting, at a latitude of $40^{\circ}$ south on the east coast in the mountainous East Cape region of New Zealand's North Island. The region's climatic conditions are dominated by the frontal weather systems of the westerly wind belt that are common for this latitude. The East Cape region experiences a temperate, though lively maritime climate, which can fluctuate markedly between the polar and sub tropical influences. The Waipaoa catchment is in the eastern most part of the East Cape and in the lee of the substantial Axial Ranges (see figure 3.11) which provide a barrier to prevailing westerly tracking weather systems. It is the combination of these influences 
which provide for a high rainfall gradient east to west, where mean annual rainfall in the ranges reaches $3000 \mathrm{~mm}$ and falls to $1000 \mathrm{~mm}$ at the coast (Smith, 1977). The net effect of the barrier provided by the Raukumara Ranges for Gisborne is that the weather in general offers mild temperatures with warm dry light foehn winds and hot dry summers.

These mild conditions prevail throughout the Waipaoa catchment. However, these conditions are punctuated periodically by the appearance of the high humidity air masses of subtropical and ex-subtropical cyclones which drive strong onshore winds from the southeast through to the northeast. These cyclonic systems which swirl in from the north-eastern Pacific and can deliver rainstorm events of high intensity which are then amplified by the orographic effect of the terrain resulting in high region-wide rainfall. While these storm events affect the region as a whole, more intense pockets of rainfall occur at the local scale influenced by local topographic conditions in relation to wind direct. In generalised terms these marauding storm events occur on an average frequency of 3-5 per year although there is large variability in intensity which is associated with the cyclone's path (Marden et al. 2008a). The most intense of these storm events in recent decades was the 1988 Cyclone Bola event, which delivered a total rainfall over the three day duration ranging from $900 \mathrm{~mm}$ in the northeast of the Waipaoa catchment to $300 \mathrm{~mm}$ in Gisborne with a peak $24 \mathrm{hr}$ intensity reaching over $300 \mathrm{~mm}$.

Events of the scale and magnitude of the Bola storm are highly destructive and may cause region-wide shallow landsliding as seen in figure 3.31. This shallow landsliding is typically regolith failures that move as debris flows, although the more intense events can also cause deep-seated landslides. The occurrence of deep-seated slope failure producing events is usually strongly correlated with rainfall distribution and peak intensities, especially when storm rainfall totals approach or exceed the $200 \mathrm{~mm}$ in 2-3 days, the threshold for surface failure (Page et al., 1999). These extreme cyclonic events are considered to be rare. Events on the scale of Bola are said to have an estimated return period of 1 in a 70 years (report by Peacock D H Ltd. John Philpott and Associates Ltd, 2009). Even so, the region still regularly experiences smaller though more frequent cyclones (rainfall $\sim 200 \mathrm{~mm} / 24 \mathrm{hr}$ ), which can have a significant and region-wide influence on geomorphic processes. Interestingly, the 
historic record shows that events of Bola size (rainfall $\geq 300 \mathrm{~mm} / 24 \mathrm{hr}$ ) for the region have occurred three times since the instrumental records began, 1924, 1938 and the Bola event of 1988 (Orpin et al., 2010). There is no direct record of storm events from within the catchment to support this storm frequency record that predate European arrivals. However, a storm record taken from a sediment core retrieved from Lake Tutira in northern Hawke's Bay can be considered indicative of storm inputs for the Waipaoa catchment (Orpin et al., 2010; Page et al., 2010). Conditions conducive to the formation and preservation of laminated sediments have produced a highresolution record of lacustrine organic productivity, normal and severe rainfall, earthquakes and volcanism from Lake Tutira's formation 7200 cal. years BP. The Tutira record uses sediment accumulation at the centre of the lake as a proxy for storm event inputs and the thickness of the deposit as an indication of the rainfall intensity (Orpin et al., 2010).

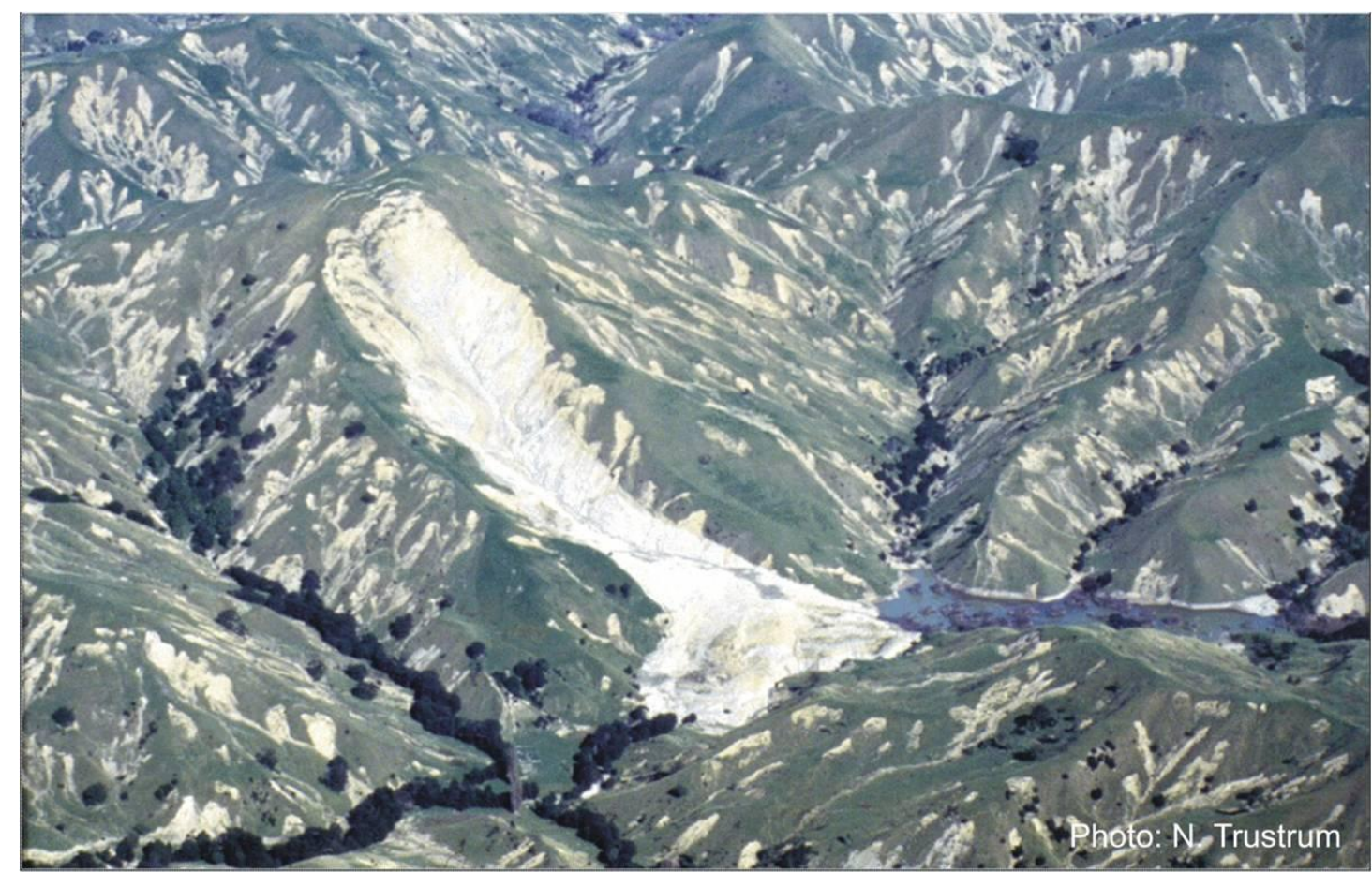

Figure 3.31. Storm induced slope failure. Shallow and deep-seated landsliding at the Mangakiore field site following the Bola event 1988 (Photo Trustrum 1988).

The storm record in the Tutira core has shown that on average, a storm frequency of one major storm in five years for all storm sizes throughout the 7200 year core history for eastern New Zealand (Page et al., 2010). Throughout the record however, there is considerable variability in both the intensity of these storms and in the return frequency for them. Page et al. (2010) and Gomez et al. (in press) have suggested this 
variability is likely a muted response to the El-Niño Southern Oscillation (ENSO) and the Southern Annular Mode (SAM) phenomena, the two leading modes of climatic variability of New Zealand. The Page et al. (2010) study however was able to identify and categorise 1400 individual storm layers within the record. Of these storm layers there were 54 events estimated to be of approximately Bola size ( $\geq 270 \mathrm{~mm} / 24 \mathrm{hr})$ and a further 7 catastrophic storm events where indicated rainfalls were $\geq 500 \mathrm{~mm} / 24 \mathrm{hr}$ (Orpin et al., 2010). The occurrences of storms in this record also clustered to show periods where storm events occurred with greater magnitude/frequency. There are 10 major periods in the Tutira record that indicated more activity in intense storm occurrence. In addition to the European period record, these occur at about 500-700, 1100-1250, 1850-2100, 2850-3200, 3600-4000, 4300-4500, 4700-4900, 5700-5900 and 6850-6900 cal. years BP (Page et al. 2010).

These periods of increased storm activity lasted for tens of years to several hundred years and the onset and cessation of these stormy periods was often abrupt. Transition from a period of increased storm activity to a period of more normal activity occurred on a scale of years to decades. Of particular interest within this storm record are two periods which centred on periods 2000 and 4000 years ago, where both the intensity and frequency of storms were greater than for other periods. Throughout the Tutira record, there are also periods which show lower occurrences of storm activity. These occurrences of periods of increased/decreased activity have also been identified by using other proxies, such as pollens, speleothems and chironomids sourced in other records throughout the eastern North Island region such as Newnham et al 1998; McGlone, 2002; Gomez et al. 2007 and Philips and Gomez 2007 (Page et al, 2010). This record of storm activity from Tutira can therefore be used to provide an analogue for the Waipaoa catchment and the East Cape region in general. And it is the links with these other records which gives confidence of the validity in the Tutira record as an indication of storm frequency and intensity, and storm impacts within the Waipaoa sedimentary system. 


\subsection{Sedimentary history}

For large catchments such as the Waipaoa, the sediment yield over the longer term is buffered due to the number of storage sites along the transport network being stored in secondary sites (Phillips and Gomez, 2007). Where influxes of sediment to channels are high, there is a tendency for transport of sediment to be overwhelmed. Where high inputs of sediment persist, this reduction of sediment transport will cause the active channel to widen from a single thread to that of a more braided form. Pre-historic evidence of sustained high influxes of sediment are seen in the terrace formations of the Waipaoa and tributaries, which formed during glaciations, where less forest cover and changing climatic patterns resulted in high rates of upland erosion (Berryman et al., 2000; Marden et al. 2008b). The sedimentary history of the Waipaoa switched from the state of sediment supply excess, or aggradation, to one of sediment transport excess and incision around 8ka cal. years BP (Berryman et al., 2000). Stabilisation of the slopes of the upper catchment through the establishment of forest cover, and increased stream discharges of a wetter and warming post glacial climate, caused the Waipaoa River and its headwater tributaries to incise into the terraces they had laid down throughout the last glacial. Litchfield and Berryman (2006) have calculated that the incision rates have outpaced uplift rates in the catchment by 1.5 times on average and with the period of incision being continuous until recent anthropogenic changes in the catchment (Phillips and Gomez, 2007; Marden et al., 2008b).

The Waipaoa River is predominantly a gravel bed river over most of its length and takes a $104 \mathrm{~km}$ journey from the headwaters where the channel has a more braided form, falling $1.2 \mathrm{~km}$ to cross the alluvial plains of the Poverty Bay flats. When reaching the Poverty Bay Flats, the Waipaoa changes to a single mainly meandering channel before exiting at the coast (Wolinsky et al., 2010). The coastal alluvial plain of the Poverty Bay Flats has been a repository (trap) for sediments eroded from the ranges and lowland hills and has been prograding seaward throughout the mid-late Holocene. Wolinsky et al. (2010) were able to determine that the rates of deposition on the plains remained constant throughout the Holocene due to propagation and subsidence. The Wolinsky et al. (2010) study also determined that the fine fraction of eroded sediments delivered to the coast plain remained a constant at $\sim 2.0$ million metric tonnes per year (Mt/yr). The sediment delivery to the coast by the Waipaoa 
River has been estimated by Gomez et al. (2007) at $15 \mathrm{Mt} / \mathrm{yr}$ of which the majority $(85 \%)$ is fine muds and $0.15 \mathrm{Mt} /$ year of coarser bed load. The Poverty Bay Flats are predominantly made up of the coarse fraction with the fine muds mainly being deposited in overbanking events and are estimated at $16 \%$ of suspended load (Wolinsky et al. 2010). These fine muds form a major onshore part of the sedimentary system sediment accumulation, which is causing the coast line to prograde. The coast has moved seaward a distance of some $12 \mathrm{~km}$ since the Holocene Climatic Optimum, to reach the current shoreline position (Carter et al., 2010).

The Poverty Bay Flats have been the main deposition centre for much of the erosion in the Waipaoa catchment, with only the Bola event producing enough sediment to be a recognisable individual event in the offshore sediment store record (Brackley et al. 2010). The volume of sediment delivery to the coast by Cyclone Bola was calculated by Hicks et al. (2004) at 32-36 million tonnes. This volume is higher than equivalent sized storm events which occurred when the landscape was in forest and is due to the high erosion rates under modern land covers. Also, the more direct connection of the Waipaoa River due to channelization form flood protection stop banks that have stopped deposition of sediment by overbanking onto the Poverty Bay Flats (Marsaglia et al., 2010). Under these modern conditions, the dispersal of the fine sediments to the shelf is normally by hypopycnal surface plumes and reworking by wave action, with hyperpycnal plumes only forming when sediment concentrations exceed $\sim 40,000$ $\mathrm{mgL}^{-1}$ such as during cyclone Bola. For the conditions that prevailed prior to human development, dispersal by plumes is unlikely due to lower erosion rates in upper catchments under forested conditions and lower connectivity within the fluvial system (Kettner et al., 2009; Foster and Carter, 1997). In the offshore record and for the last $18 \mathrm{ka}$ Cal years BP a total of $17.9 \mathrm{~km}^{3}$ of sediment which has been eroded within the Waipaoa catchment has been delivered to the sediment store of the continental shelf. The volume of sediment retained in the Poverty Bay Flats is estimated to be $6.6 \mathrm{~km}^{3}$ making up a total store of sediment from the catchment of $24.5 \mathrm{~km}^{3}$ (Marden et al., 2008b). Terrigenous sediments delivered to the coast by the Waipaoa River throughout most of the Holocene have been described by Philips and Gomez (2007) as showing little variability even when subject to high magnitude low frequency disturbance events, with buffering of sediment delivery likely due to fluxes in sediment storage. Under contemporary land covers post forest clearance of the 1800's 
$\mathrm{AD}$, delivery rates have shown the system to be sensitive and highly responsive to hillslope destabilisation (Phillips and Gomez, 2007).

The physical weathering of slopes through shallow landsliding and gully erosion are important denudation processes for the Waipaoa catchment (Philips and Gomez, 2007). The occurrence of shallow landslides on slopes influences the resistance to further instability and landsliding of the slope, with Crozier and Preston (1998) showing that upslope of a shallow failure there was a positive relationship between regolith depth and weathering rates. A study of sediment discharge from tributaries within the Waipaoa catchment by Hicks et al. (2000), showed that rainfall thresholds for sediment discharge are lower where gully processes dominate. Sediment delivery by gullies is proportional to their area, irrespective of the land cover type (Marden et al. 2008a), while delivery from shallow landsliding is strongly related to slope/channel coupling and timing of the landslide to peak rainfall intensity (Preston, 2008). In the Waipaoa catchment gully erosion dominates in the headwater catchments, structurally weakened Cretaceous lithologies of the Mangatu and in areas not dominated by forest cover (Marden et al. 2008a). Parkner et al. 2007 have shown that gully systems will occur under forest cover in the region, although they occur in over steepened regions. These slopes also often susceptible to shallow landsliding and the occurrence of gullies in forested catchments are often a primer for landsliding on slopes (Parkner et al. 2007). The downcutting and changes of profile from rivers have the affect of destabilising hillslopes through over steepening of slopes and the loss of toe support, which primes slopes to mass failure from large infrequent disturbance events. These large slope failures can change the coupling relationships between landscape compartments and differing transport responses to the influx of sediments result from these disturbance events (Kasai et al. 2006). Under forested cover landslides dominate as the erosion type, while under grassland cover gully processes are responsible for the majority of sediment delivered to channels (Kasai et al. 2005).

A study post cyclone Bola by Page et al. (1999) looked at the importance of landslides to total event sediment yield in the Waipaoa catchment. An estimated 50\% of landslide material mobilised on slopes entered the stream channel, with landslide location in relation to channel being a major influence on delivery. During the Bola event, landslides contributed $20.5 \times 10^{6}$ tonnes or $64 \%$ of the total estimated catchment 
suspended sediment yield of $32 \times 10^{6}$ tonnes (Page et al., 1999). There was considerable variation in contributions from individual sub-catchments. During storm events of the last 20 years and including the Bola event large deep-seated landslides have also been produced. For the total catchment the remaining 36\% of the event suspended sediment load was from gully, sheetwash, rill, stream bank, earthflow, tunnel gully erosion and bedrock failures (Page et al., 1999). These deep-seated movements have not only displaced considerable volumes of material which have entered the transport network, but have also blocked river channels, forming lakes and impounding sediments already in transit. The variability between catchments is dependant on sediment types and whether the slopes are predisposed to landsliding as the dominant erosion process, or more towards other erosion types (Hicks et al, 2000). A study by Jones as part of MSc thesis work on contemporary sediment delivery ratios in the Te Arai sub-catchment, also a study site of this project, calculated the load delivered to a local stream from landslides for the Bola event. Using aerial photos of the catchment to map landslide scars and using the depth ratio of 0.5 , an estimated $129.0 \times 10^{3} \mathrm{~m}^{3}$ of sediment was delivered to the channel as suspended load for the event (Jones, unpublished MSc thesis, 2009).

\subsection{Chapter summary}

- The Waipaoa catchment is a high sediment yielding catchment due to its geological setting and its exposure to disturbance events from tectonic, climatic and anthropogenic sources. Sub-catchments of the Waipaoa have differing responses to disturbance inputs due to lithology and configuration. Studies of modern sediment dynamics (post-deforestation), including the impact of large storms such as Cyclone Bola, may provide insights into how the catchment responded under cooler climatic, grassland-dominated conditions following the last glacial maximum.

- Earthquakes provide disturbance events which are a source of slope failure and sediment movement in the Waipaoa catchment. Small ground-shaking events of $\leq$ MM7 occur at a high frequency of $\sim 26$ years and can have a widespread impact. These smaller events are capable of producing regionwide shallow landslides even under forested catchments. The larger ground- 
shaking events of $\geq \mathrm{MM} 7$ are associated with the movements of the offshore faults and occur at a lower frequency with return intervals of $\sim 630-930$ years. It is these events that are most likely responsible for the deep-seated slope failures and formation of landslide-dam lakes within the catchment.

- Storms, often generated in the tropical Pacific deliver a highly charged impact to the region which is enhanced by the orographic effect of the catchment's topography. These storms cause widespread surface failures at a catchment scale which mobilise large volumes of sediment. At the sub-catchment scale localised extreme rainfall volumes can cause deep-seated failure of slopes, especially where slopes are primed by elevated pore-water pressures brought on by extended wet periods. The Tutira record from northern Hawke's Bay provides a record of storm frequency and intensity for the Holocene and shows 10 major periods of intense storm activity.

- Changes in catchment configuration that result from deep-seated landslides affect sediment yields at the catchment scale through the trapping of sediments delivered to the channels in the sub-catchments where sediments are then released over longer timescales. While the 1988 Bola event was distinguishable in the continental shelf sediments due to its high sediment yield, prehistoric events of similar size are not. These records are found in overbank sediments on the Poverty Bay Flats and in river terraces and impoundments/sediments accumulated upstream of large landslide-dams. Under grassland conditions in the Waipaoa catchment, shallow landslides are the dominant source of sediment during large storms such as Bola and can be responsible for up to $64 \%$ of total suspended sediment generated, although other sources of erosion such as gullies are dominant during lesser magnitude storms and under forest cover. 


\section{Chapter 4}

\section{The Waipaoa; mapping, modelling and the study sites}




\subsection{Introduction}

This chapter will explore the methodologies used to achieve the project's aim of providing insights into the sediment dynamics of the Waipaoa and the role that deepseated landslides have as spatial and temporal regulators in sediment delivery. The project sets out to resolve the three objectives as defined in section 1.3 Research Aims and Objectives. In principle there are four key areas of undertaking that have been identified as necessary to complete these objectives (refer figure 4.01). These key tasks areas are:

- Site identification. The identification of landslide-dams suitable to the study by examining features from aerial photos and details provided in the GNS large landslides database;

- Mapping sites. The detailed mapping of the sediment bodies impounded behind the landslide-dams;

- Coring and stratigraphy. The creation of site specific stratigraphies and chronologies from sediment cores and the provision of age estimates for dam formation and breach. Also through identifying tephra in the cores, it may be possible to link the sites to make inter-site comparisons possible;

- Computer modelling. The development of three dimensional digital terrain models (DEMs) of the palaeo-landscape and the modern sediment body surface to provide for volume estimates of impounded sediments and accumulation rates of sediments trapped to be calculated.

The following chapter will focus on outlining the procedures employed in each of these task areas used to achieve the project objectives and will enable justifications for the decisions made. The chapter will also include a brief description of the individual sites which were selected for the study. 


\section{Flow diagram research objectives and the key task areas.}

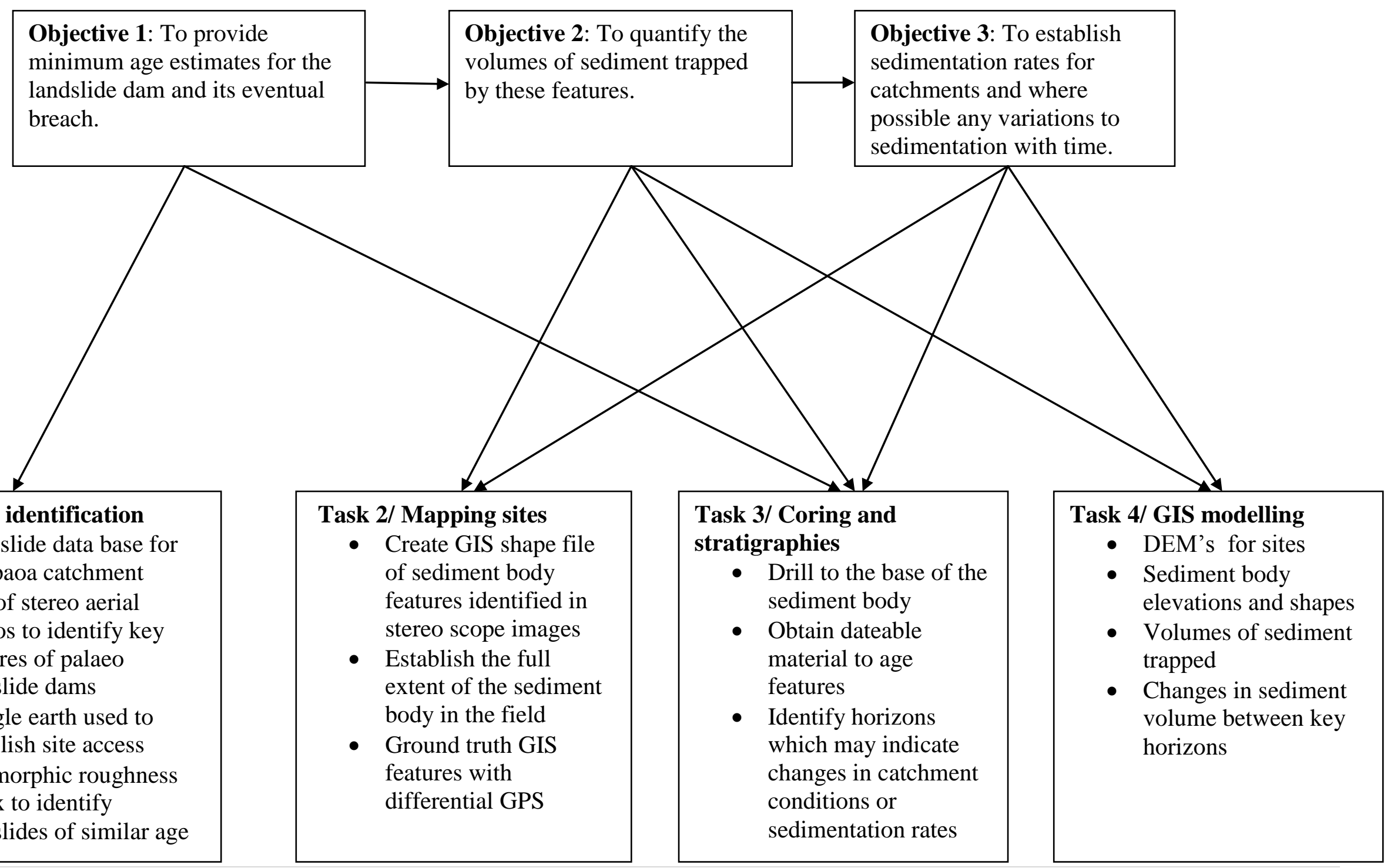

\section{Task 1/ Site identification}

- Landslide data base for Waipaoa catchment

- Use of stereo aerial photos to identify key features of palaeo landslide dams

- Google earth used to establish site access

- Geomorphic roughness landslides of similar age
- Create GIS shape file of sediment body features identified in scope images extent of the sediment features with differential GPS conditions or

sedimentation rates
Objective 3: To establish sedimentation with time. 


\subsection{Large landslide database and the site selection process}

Large deep-seated landslides are pervasive in the study area. A database has been compiled by GNS listing a total of 1026 large deep-seated landslides within the greater Waipaoa catchment. These landsides are representative in the landscape across all lithologies, slope angles and aspects and activity class, where these large deepseated features often involve the movement of the entire slope surface (Page and Lukovic, 2011). The database shows that the vast majority of landslides documented (799) occur in the younger and more erodible Tolaga group marine mudstones. These sedimentary rocks were formed during the late Tertiary and are underlying approximately $70 \%$ of the total catchment (Page, unpublished work).

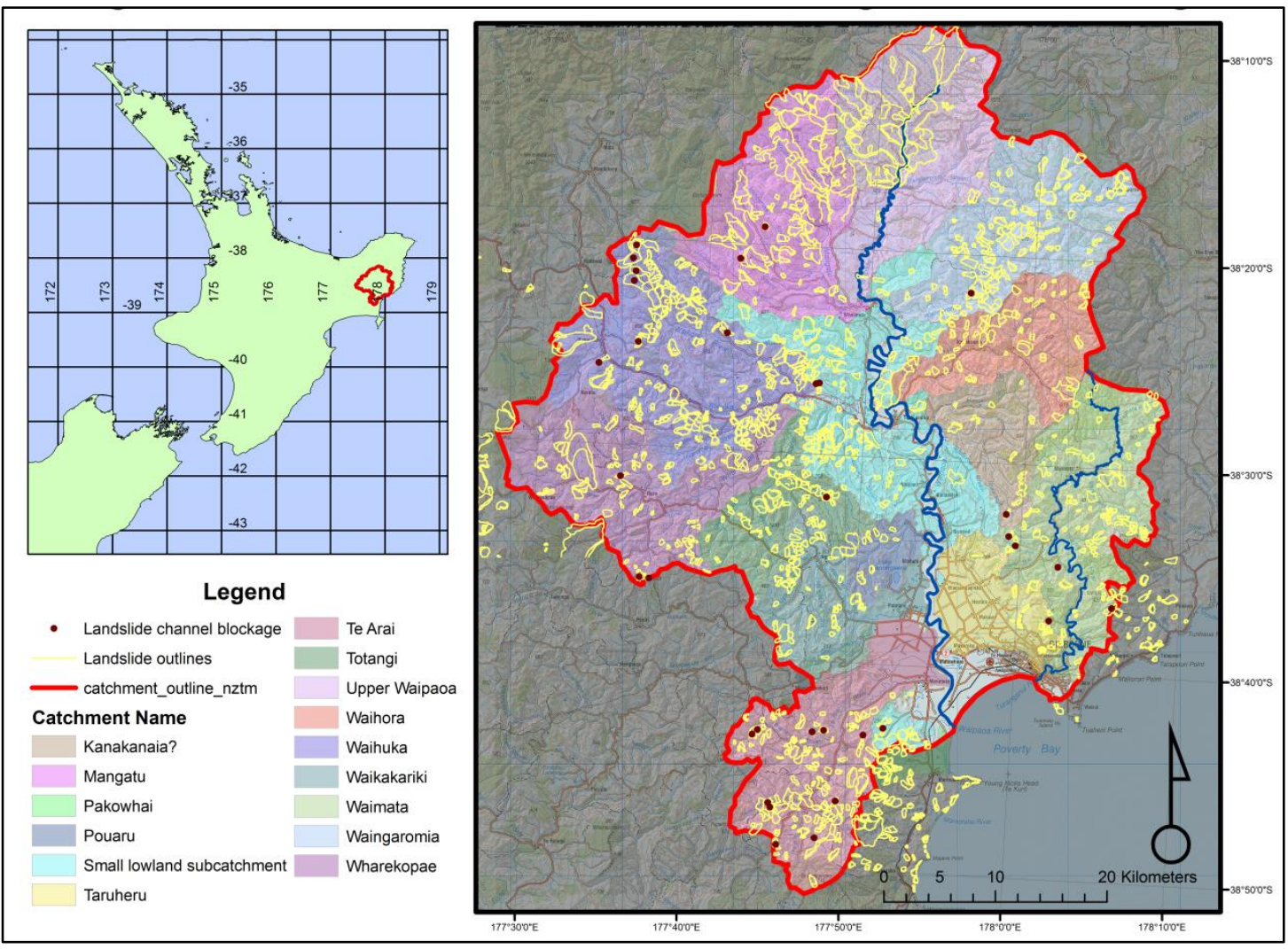

Figure 4.11. The large landslides database. Image shows the locations of the landsides that have interacted with the channel as yellow outlines and those with evidence of channel blockage as red dots.

The initial identification of the landslides detailed in this database has been primarily through the use of stereo-scope aerial photography. When viewed through the stereoscope, features of the landslide scars become clearly visible and may be mapped and provisional details such as area, volume and primary movement type can also be 
described. Evidence gathered by the above mentioned method has shown that a total of 851 landslides have interacted at some level with the stream of its valley floor. Although of these, only 33 showed any evidence of a full channel blockage. The initial sites of interest for this study have been selected from the 33 landslides which have been identified as having formed a channel blockage that.

\subsubsection{Site selection}

The co-ordinates for the 33 large landslides of interest to the study were entered into Google Earth ${ }^{\circledR}$ where the sites could be viewed as a satellite image. The images were able to be magnified, rotated and tilted to oblique views to help with site evaluation. The use of Google Earth and the stereo imagery for the individual sites was necessary to identify the key features deemed important for the study. These key features formed the selection criteria and involved both physical and practical elements. These are discussed in detail below and can been seen in figure 4.12 .

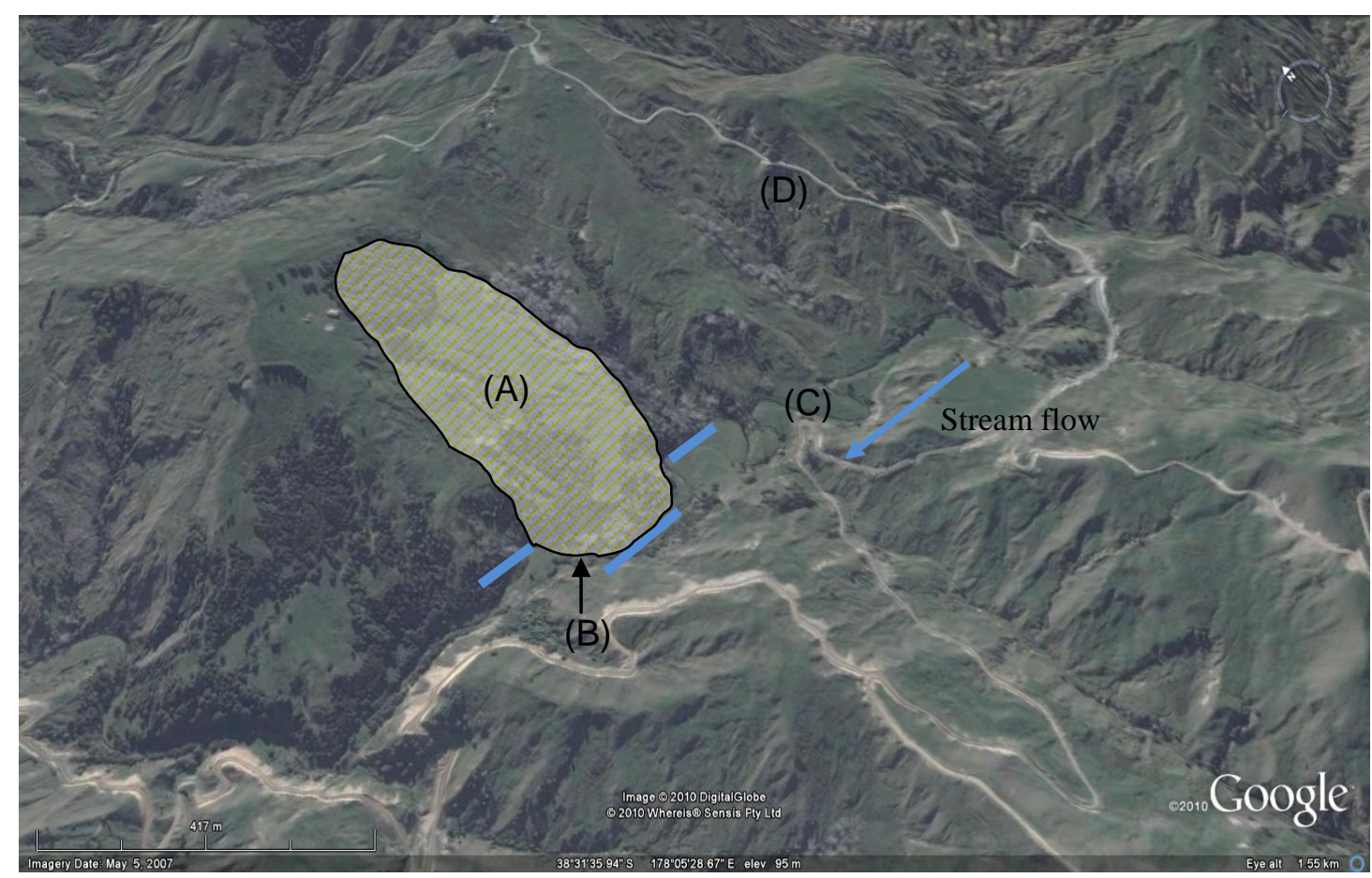

Figure 4.12. Site selection features. A "Google Earth" image of the Monck Road field site is used to highlight the features that were important in the site selection process. (A) The shaded area defines the landslide body. (B) Incision through the landslide by the river, with the blue bars showing stream displacement. (C) River incision into sediment body and meandering channel form. (D) Site access road, in this case a farm track. (Image modified from, Google Earth, 2010.) 
The physical criteria for site selection involved two main features;

A. The landslide body. Clear evidence of the landslide having formed a full blockage of the river channel was required. Further, evidence that this blockage had persisted long enough for there to have been signs of significant disruption to the sediment transport network was necessary. The blockage was apparent through landslide debris being evident across the valley and up on the opposing valley slope. The evidence that the blockage persisted for a period of time was derived from the flat valley form of impounded sediments upstream of the landslide blockage. The river's incision of the landslide body would occur at some point in time after the channel was blocked and drained the lake which would have formed. This is seen in the aerial and satellite images in the immediate profile of the upstream valley floor, which would be flatter and broader than that of the downstream profile and there would be a sharp elevation change at the point of the blockage in the downstream direction.

The river's incision of the landslide material was evident by the steep change in gradient of the river channel and can be seen in the images as a straight section of the river channel, often with a waterfall. These details were considered as clear evidence that there had been a channel blockage which had persisted for a long period of time and was also an easily identifiable geomorphic feature, clearly seen in both the stereo aerial photos and also on Google Earth ${ }^{\circledR}$ images. When the landslide has blocked the valley, it has also changed the shape of the valley floor by raising it and the stream channel may have been displaced sideways. This displacement of the channel is shown in figure 4.12 by the blue bars and is also an identification feature that assists initial site selection.

B. The sediment body. During the period of time that the channel blockage persisted, the valley would infill with sediments eroded in the upper catchment. Subsequently at some point, the river could start to incise into the sediment it previously deposited as the sediment body. Evidence that the river was cutting through infill sediments was indicated by changes in the energy environment of the stream. This could be seen as a flat floored valley infill and was 
distinguishable from river terracing by a meandering river section upstream of the restriction point (C) as shown in figure 4.12. This meandering was due to the shallowing of channel gradient provided by the sediment infill post formation of the original valley.

It was important that there were remnants of a sediment body so that elevations and dimensions of the sediment infill could be determined to provide the data required in the modelling process. Depth estimates for the sediment infill would require the coring of the sediment package. Further supporting depth measurement could be taken, if there was sufficient incision by the river to establish the palaeo-valley base of the palaeo-river thalweg. River incision and coring would also help by providing dateable material for determining the formation and breach of the landslide-dam. This dateable material collected from the sediment body could provide indirect aging of the landslide where it was not possible to date the landslide feature directly through other means. The strata observed in the cores and the river incision could also help by providing a reference across the entire sediment body, especially where tephra were present.

The sites selection and suitability to the study was also conditional on some practical and logistical considerations;

1. Road and vehicle access to the site. Having the ability for drive-on-access to the sediment body was important as many of the equipment components used to drill the cores in the sediment body are heavy, bulky and awkward to carry by hand, requiring vehicle transport. An example of the type of minimum road access required can be seen in figure 4.12 as a farm track for the Monck Road site (D).

2. Composition of the sediment body. The impounded sediments needed to be made up of fine-grained material able to be retrieved by the coring system. While this would not always be known from the aerial photos, the grade of the material in the river channel could be used as a guideline, with coarse base rocky river channels being more likely to mean coarse sediment supply for 
infill. Consolidated material with maximum particle size no larger than a granule or $<-2 \varphi$ on the Wentworth scale would be expected to be suitable for drilling.

Further to the site selection criteria identified above, it was necessary, where possible, to have a range and number of sites sufficiently representative of the diversity in the greater catchment. In terms of lithologies, slope angles, slope orientation and length, valley size and orientation and sub-catchment configuration and characteristics. A representative selection would need to consider the number of sites that could reasonably be investigated within the timeframe of this project. The project would also consider the Waimata catchment in the Greater Waipaoa, as objective four of the project is the consideration for sediment delivery over the period since the last glaciation (LGM). During these 18 thousand years or so post LGM the Waimata River would have had periods where it joined with the Waipaoa River, both due to lower sea levels and also river migration across the Poverty Bay Flats.

From the initial set of 33 landslides identified in the large landslides database, 11 sites closely fitted the above mentioned criteria and hence were selected for initial evaluation by field reconnaissance. These sites were physically inspected on the ground to confirm that the features observed from the aerial photographs and satellite images were as they appeared. Following the field reconnaissance trip conducted in late February 2010, the number of sites chosen for this study was reduced to seven. The main reason for unsuitability of sites was the limited access in some of the remoter and steeper terrain of the greater Waipaoa.

\subsection{Site mapping}

The sediment bodies which have been identified and described in the site selection process were mapped as the first step in the process of achieving objective two, to quantify the volumes of trapped sediments. The mapping process involved two stages. The first stage involved the digitising of the features as observed in the aerial imagery. The second step of the mapping process involved determination of the true extent of the features on the ground and making comparison to what has been observed in the stereo aerial photos and satellite images. This process is known as "ground truthing" 
and the following section will describe in detail both the term and the procedure involved in the "ground truthing" of these features. This mapping forms the basis which provides the necessary data for the computer modelling process and there are cross-overs between both processes. This section will describe the physical methods involved with the site mapping on location. More details on both the tools and methodologies for the computer digitising of the features and modelling are described in depth in the computer modelling section (4.4) of this chapter.

\subsubsection{The sediment body}

From the stereo aerial photographs and ortho-rectified aerial images, the visual extent of the main site features, as described in the site selection earlier (4.11), were digitised as a point, line or polygon shape file in ESRI-ARCmap® GIS program. Those shape files could then be transferred to handheld Trimble GPS units to be used as a reference when identifying the site's key features on location. Determining the point where the sediment body began and the slope ended on site was in generalised terms representative as a break in slope and flattening of the terrain in the valley floor. This could be viewed as a terrace extending upstream of the restriction point, as shown in figure 4.21. To map the true extent of the sediment body's main features, this generalisation needed to be further clarified. This was achieved through the use of a hand auger to check the soil profiles for where the slope stopped and infill sediments started. Transects were taken at stepped intervals upstream from the restriction point. The auger cores also enabled determination of common features in stratigraphy across the sediment body profile. This process enabled more accurate determination of boundaries between lacustrine sediments, laid down in the ponded environment of the landslide-dam, and the colluvial sediments from contemporary slope processes and post dam aerial environment.

Three to four transects were set across the sediment body at evenly spaced intervals for the full length of the sediment body. Auger cores were drilled at stepped intervals across the sediment body profile for each transect. Once the transition point from ponded sediments to the contemporary soil development processes had been identified, it was then necessary to confirm the break in slope feature on the ground. The process of identifying the extent of the infill sediments was also important in the 
upstream direction to determine where the sediment body tapered out to the river bed. The task of determining the longitudinal extent of the ponded sediments was helped by the river's incision of the sediment body. For all of the sites in this study, the stream restrictions had been breached and river downcutting had begun to greater or lesser extents.

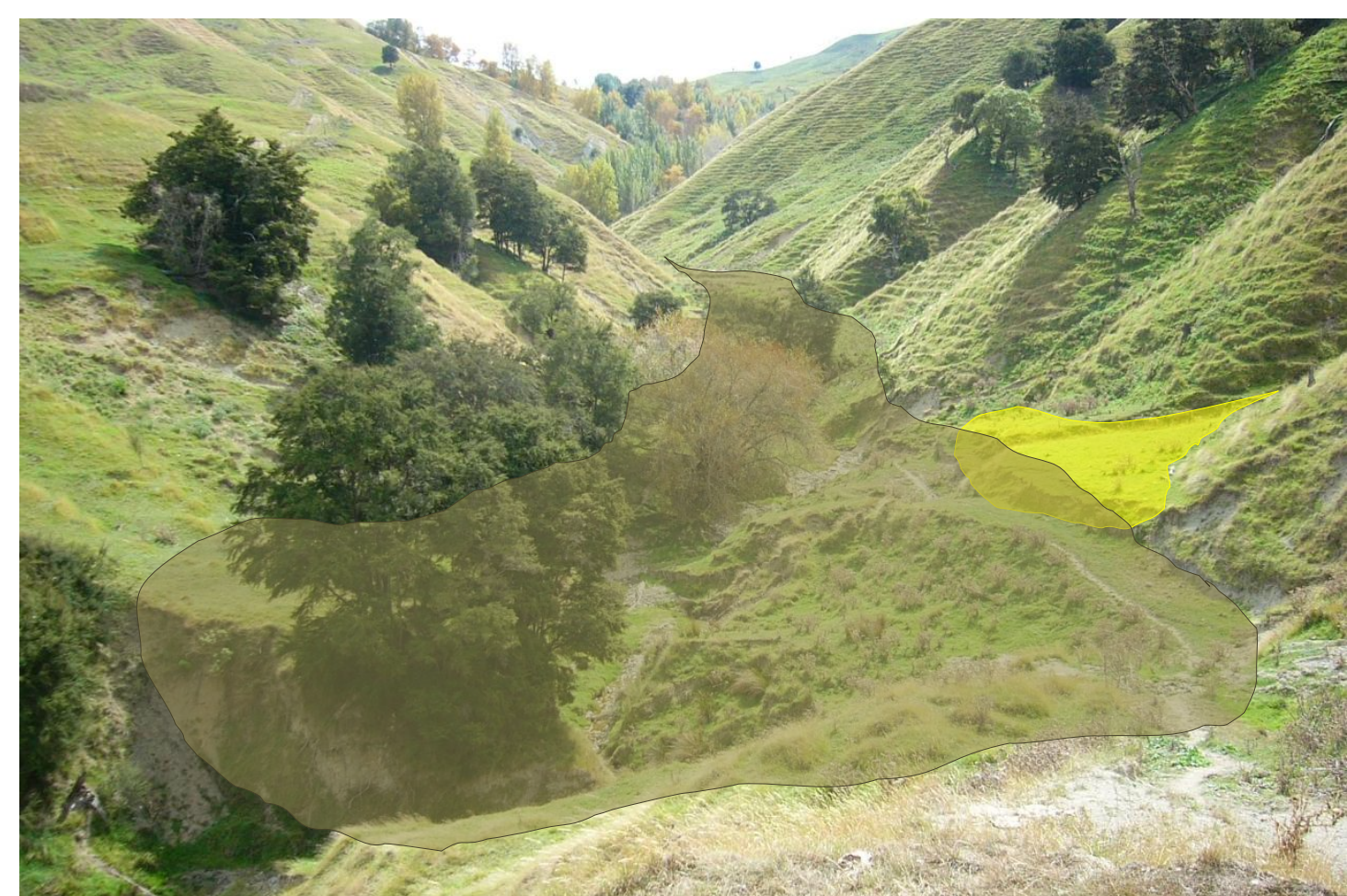

Figure 4.21. Sediment body features. A view upstream at the Otara Station field site provides perspective of the sediment body features, which can be seen as terracing, shaded in brown. The yellow shape shows a debris fan extending from a gully which is a more recent feature that covers and disguises the extent of the sediment body (image R. Taylor, 2010).

To some extent the identification of these features may be arbitrary. It is possible that during the period after the dam breach and prior to the river's incision of the sediment body, the river may have meandered across the top of the infill sediments. In doing so, some of the more recent and less consolidated material which had been deposited late in the infilling process, could have been eroded. The removal of this material would represent a loss in the sedimentary system and is identified as a source of error in the volume estimations. Also, the colluvial slope processes that have occurred post sediment infill and up to modern times may have masked to some extent the true edge of the sediment body. These more contemporary features can be seen as indicated in the image of figure 4.21, through the presence of a debris fan. However, within the 
context of this study, it was considered that the errors relating to those influences mentioned above would be minor enough to be acceptable. It was considered that the volumes of sediment lost would be well within the margins of error and the accuracies of the global positioning system (GPS) measuring system employed as well as within the margins of error of the other methods used in volume estimation in the study.

\subsubsection{Differential GPS}

Once the physical extent of the sediment body had been determined for each site, the process of mapping or 'ground truthing' the original GIS shape files that were made of the sediment bodies from the aerial photos, could be undertaken. 'Ground truthing' is the calibration of remotely sensed data, in this case the location of the outlines of the sediment bodies created in the GIS program. This 'ground truthing' enabled the accurate projected of the sediment bodies in relation to other geographically referenced data in GIS to create the three dimensional models that are used for the volume estimates. This calibration was achieved by exporting the outline waypoints to a hand held GPS unit, then walking the parameter of the actual sediment body outline as determined in the previous section. The GPS records a waypoint track of the spatial information in three dimensions that can then be imported to the GIS to accurately update the sediment body shape files. Other methods that could be employed to acquire the spatial information for the sediment bodies would be to survey the site by either ground survey methods such as the use of Real Time Kinematic (RTK) or with aerial survey such as LiDAR (Light Detection And Ranging). While both these techniques would have produced a more accurate representation of the sites, the costs and time involved in these methods was prohibitive to the project and the added accuracy gained was considered to be of lesser importance.

The GPS system used in this process was the hand held Trimble ${ }^{\circledR}$ differential GPS, which has an accuracy of within two metres in a moving situation and considerably better $(<1$ metre) when creating a stationary waypoint. The differential GPS achieves the sub metre accuracy by using two GPS receiving units. The first unit is the hand held roving unit, which takes waypoints and tracks (lines) by using the triangulation of incoming satellite signals and the accurate internal time keeping as with a traditional GPS receiver. The second unit is a base station, which is set up at a 
geographically referenced maker, such as a trig point and collects the same incoming satellite signals at the same time as the hand set. This second unit, because it is located at a geographically known point on the earth, can be used to correct for any anomalies in the positioning provided by disturbance to the incoming satellite signals due to changing atmospheric conditions and other effects. The base station does not need to be located where the handset is being operated, but is most accurate if located within a $20 \mathrm{~km}$ radius of its operation. Within the Gisborne region, Land Information New Zealand (LINZ) operate and maintain a number of geodetic survey base station sites which of which the one closest to the field site being mapped was used. The waypoint data collected by the two units is combined in the computer operating program for the Trimble ${ }^{\circledR}$ GPS system and any possible errors in the signal that the handset receives are rectified. This approach increases the accuracy to a plus or minus error of 0.2 metres (Trimble, 2011). The corrected waypoint data is then ready for export to the GIS program where the waypoints are projected as vector layers and form the base data for the model making process. For this project, the GPS was used continuously when in the field, with waypoints taken not only in 'ground truthing' the sediment body, but also when transects were taken across the sediment body and in the position of auger and coring sites.

\subsection{Coring and sediment body volumetric estimates}

The second step in the process to achieve objective two requires that there is an indication of the depth for the sediment infill so that volume estimates for the sediment body may be established. The study used two methods for determining the depth measurements, firstly where river incision was sufficient to determine base level and secondly by coring. The study also considered the use of ground penetrating radar to give a continuous profile across the sediment body. This method was discarded as being too time consuming to set up, calibrate and operate for seven sites within the project's time frame. Coring of the sites was considered beneficial as it:

1/ Helps to provide an estimate of sediment body depth for volume calculations; 
2/ Enables dateable material to be retrieved so that age estimates for the landslide can be determined;

3/ Provides an insight into the sedimentary environment formed behind the landslide-dam.

The second method to estimate depth can be through obtaining data from the GPS elevation measurements taken of river channel incision. Where the incision was to bedrock, these depths were used as further control points in the terrain modelling process.

Cores of the sediment bodies were taken using a percussion boring tool and the details of the methods used will be outlined in the following section. The percussion coring method was chosen above other possible methods due to the speed, power and portability of the coring unit. The percussion corer could drill to the anticipated maximum depth required for the project and operate in the grade of material that would be encountered and provide minimal disturbance to the sediments in the core. It was also equipment that was readily available at the University and the operation costs associated are low. This section on coring and sediment body volume estimates will also discuss the core sampling strategy and the method used for determining the bulk density of the sediments.

\subsubsection{Core site selection and coring methods}

Before coring at a site could begin, a suitable location to drill needed to be established. Selecting a suitable coring site on location required that the following three main criteria were met;

1/ The site needed to be undisturbed as best as could be determined. This meant, the core site elevation should be the same or similar to that of the perimeter of the sediment body. Consequently, there would be no evidence of material removal due to stream meander during the dam breach phase, or excessive deposition due to overbanking. 
2/ The drilling site needed to be clear of tributary gullies joining at the sides of the sediment body to ensure that sediments would be as little disturbed as possible and a core representative of the lacustrine depositional environment could be retrieved.

3/ The drilling point would need to be towards the centre of the valley and yet back from the restriction point. The reasoning here was twofold: (1) there was less likely to be landside and colluvial slope material in the core and (2) the core depth might show the best possible representation of sediment body maximum depth.

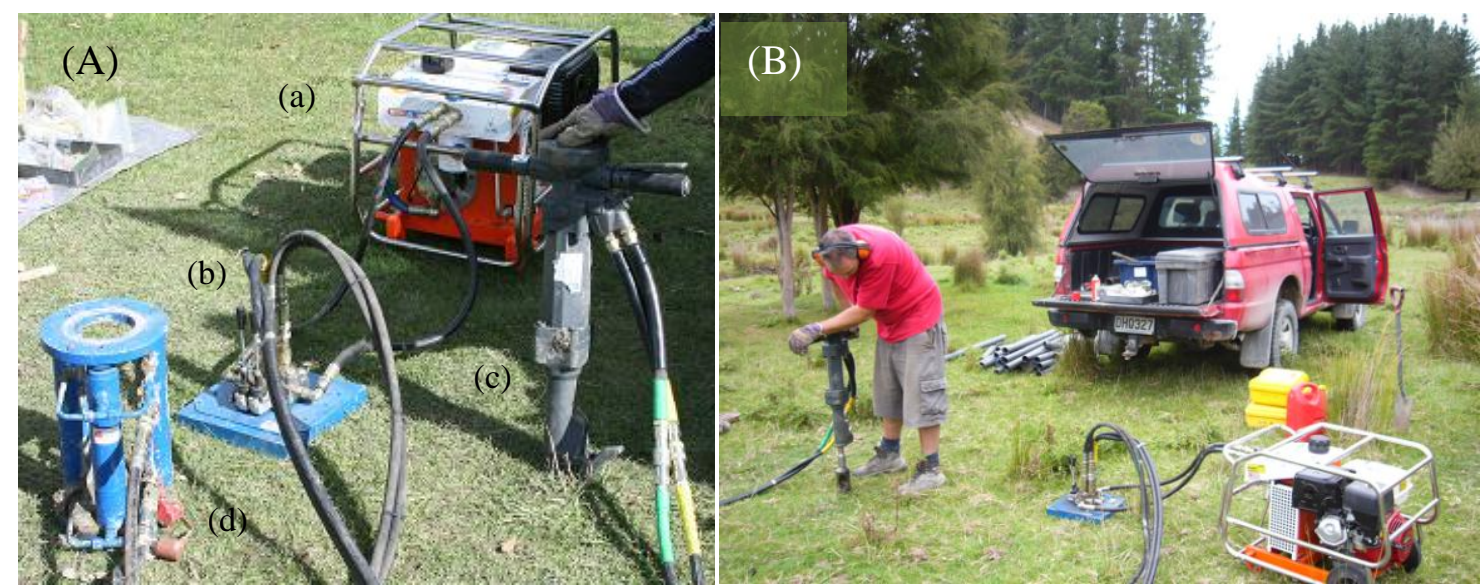

Figure 4.31. Coring equipment. Image ' $A$ ' shows the main component features of the coring tool which are, a/ the hydraulic pump, b/ the hydraulic switch unit, c/ the percussion hammer and $\mathrm{d} /$ the extraction unit. The percussion coring tool has two coring attachments that may be driven into the ground with a pneumatic hammer action. The core lengths retrieved are 1 metre sections, with one coring attachment having an open window for viewing the core profile in the field. (B) showing the author and the coring tool in action at the Mangakiore field site. The enclosed coring tube is being used and spare core liners are seen stacked by the left rear of the vehicle. (Images courtesy of, (A) R. Boys, 2008. \& (B) J. Ballinger, 2010).

The drilling method used was that of percussion coring. It met the project's requirements of being portable, suitable for coring to the depths anticipated, suitable for fine-grained sediments and the extraction of an undisturbed core. An other important feature of this tool is that it has an enclosed core tube, which incorporates a replaceable inner sleeve so that the extracted core is preserved for observation off site. The percussion coring tool uses no twisting action, so there is only minimal disturbance to the sediment. This disturbance is restricted to the outer edge of the core and is due to friction where the sediment comes in contact with the liner. There can be 
some compaction of the sediment if the sediments are poorly consolidated due to the hammering action, which means there may be some distortions in layer depths (Glew et al. 2001). This however was not the case for the sites selected for this project and there was minimal compaction for each section of core. When the coring tool is driven to its full depth it is then extracted and the filled core liner removed and another liner inserted. The core tool is then redeployed in the same hole to get the next section of core. Extensions are then attached to the coring tool as the core depth is increased and the coring process is continued until an impenetrable layer is met (Glew et al. 2001).

The cores taken throughout this project were done using the enclosed coring tool. The cores were taken back to the laboratory where they were split open using a bench saw to cut the outer case length wise. To separate the sediment a fine wire was drawn through from end to end dividing the sediment core into two half round halves. Splitting the core allowed for a basic description of the core characteristics such as texture, colour (Munsell colour chart), horizons, inclusions and stratigraphic units to be recorded. One half of the core was used for this purpose and was also the source for the samples for radiocarbon dating, bulk density analysis and samples for grain size analysis. The second half of the core was sealed airtight and stored in the cool store intact and undisturbed. This second half could then be used for any further analysis such as pollen analysis if deemed necessary at a later stage or in case of the first half of the core became damaged. Retrieval of enclosed cores in the field had the disadvantage of not knowing whether there was suitable material in the core to work with until some time after the field work was completed. The advantage of having an intact record of the depositional sedimentary stratigraphies was considered more important.

\subsubsection{Core sampling and bulk density}

Descriptions of individual cores will be discussed in the results section. This section will detail the sampling and bulk density methods employed. Sampling within the core was to provide material for radiocarbon dating of the landslide-dam formation, its breach and any event horizons within the core. Either a continuous or a discrete method of sampling could be employed. A continuous method could allow for a more full representation of sedimentary history for each site, but would be vastly time 
consuming and costly. Also, as there was disturbance within some of layers within the cores, there would be inconsistencies between the disturbed and undisturbed layers. It was considered that a more coarse sampling strategy was more appropriate. As the cores and in-situ profiles exhibited event type stratigraphies, it was decided a discrete sampling method would be employed to best represent the important details within the individual event layers of interest to the study.

Where possible, large organic samples such as sections of tree branch, that the core tool had cut through or thick organic deposits, that were continuous and represented a layer in themselves, were retrieved to use for radiocarbon dating samples. These samples were taken at the core base and top to date the onset and termination of the landslide-dam. The on set of the dam would show as homogonous sedimentation due to deposition under ponded conditions, overlaying a palaeo-sol or blocky landslide debris layer. The termination was seen in the core usually as an abrupt change in the sediment characteristics of texture, grain size and colour. At this point there had been a change in the deposition regime which had occurred due to the sediment body going from sub-aerial to aerial feature. This change point would indicate that sedimentation had altered from a more regular deposition that occurs during the ponding phase, to that of less frequent event deposition from overbank deposits. Deposition of all grain sizes would occur due to big storm events but regular flow events would result in the fine grain sizes remaining in transport within the channel flow. Within these extremes for sites, where there was clear stratigraphic horizons showing changes in the sedimentation regime, organic samples were taken at or very near the event horizon to provide time lines. Between horizons, sediments were characterised as being uniform in texture and colour, where colour was defined in terms of the Munsel colour chart. The sediments within these horizons were then sampled for bulk density. It was considered unnecessary to do grain size sampling, as the source material and the sediments distance travelled would be constant for the period of sediment infill.

Bulk density samples were taken at 10,20 or 50 centimetre intervals, with the frequency being determined by the thickness of the layer being sampled in relation to the total core length and homogeneity of the individual layer. The bulk density of a soil is not an intrinsic property and depends greatly on the physical make up of the soil and the degree of compaction. The study used a direct measurement of sample 
mass and volume by use of a core sample to convert to density after Lutz 1947 and Jamison et al. 1950 to calculate bulk density. This method works well where the soil sample is at or near field capacity and the soil is soft and cohesive, using cores of $2 \mathrm{~cm}$ or larger in diameter. This gives less disturbance of the core sample although there is no gain in disturbance reduction by diameter from cores over $3 \mathrm{~cm}$ (Campbell and Henshall, 2000). The procedure requires that a known volume of sample is retrieved and its wet mass taken. The sample is then dried in an oven at $110^{\circ} \mathrm{C}$ for 24 hours and its dry mass recorded. This gives the dry bulk density as mass per unit volume and is inversely proportional to porosity. The more pore space within the soil the lower the bulk density, expressed in $\mathrm{g} / \mathrm{cm}^{3}$. Thus bulk density = mass of oven dry soil / core volume (Berglund, 1986. pp 425-27).

This project used a modified version of the bulk density method described above and in Berglund 1986 pages 425-427. Small metal core tubes of thin wall section were manufactured which had an internal volume of 7.603 cubic centimetres. The weights for the individual tubes were measured to three decimal places and recorded. These core tubes were inserted by gently pressing them squarely into the sediment of split core section using the sampling regime described earlier. A fine wire was then inserted on the outside of the tube down to the base of the core and dragged across the base to separate the sediment. The core tube was extracted and the ends trimmed flush with a scalpel. The sediment and the core tube were weighed to three decimal places to give wet weight and then dried in a $110{ }^{\circ} \mathrm{C}$ oven for twenty four hours. The tubes and sediment were then weighed dry and the dried sediment was then pressed out of the tube into a mortar so the sediment could be ground and grain size analysis done. Sources of error are often due to compaction of soil when driving in the core, or cracking of soil if the soil it is too dry. These errors can be reduced by taking care and pressing rather than driving in a core tube and trimming the protruding ends flush (Grossman and Reinsch, 2002).

\subsection{Computer modelling}

A computer model of the landscape for each of the field sites was generated, using the geographical program Arc-GIS ${ }^{\circ}$ by Esri ${ }^{\circledR}$. This program was also the primary tool for the calculation of the sediment volumes contained behind the landslide-dams. The 
GIS or Geographic Information System is a computer based program that incorporates the use of hardware, software and data, to capture, map, analyse and present geographically referenced information. The program is used to group similar themes (houses, roads, postcodes) or landscape based topographical features such as rivers, contours and remote sensing data (i.e. from a GPS) in individual layers and projects them to where they are referenced in space via a common projection co-ordinate system (refer to figure 4.41). The data for the individual or multiple layers can then be analysed and manipulated as required by the operator using the geo-processing tool to derive a desired answer or outcome and this manipulation results in a new data set (Heywood, Cornelius and Carver, 2002).

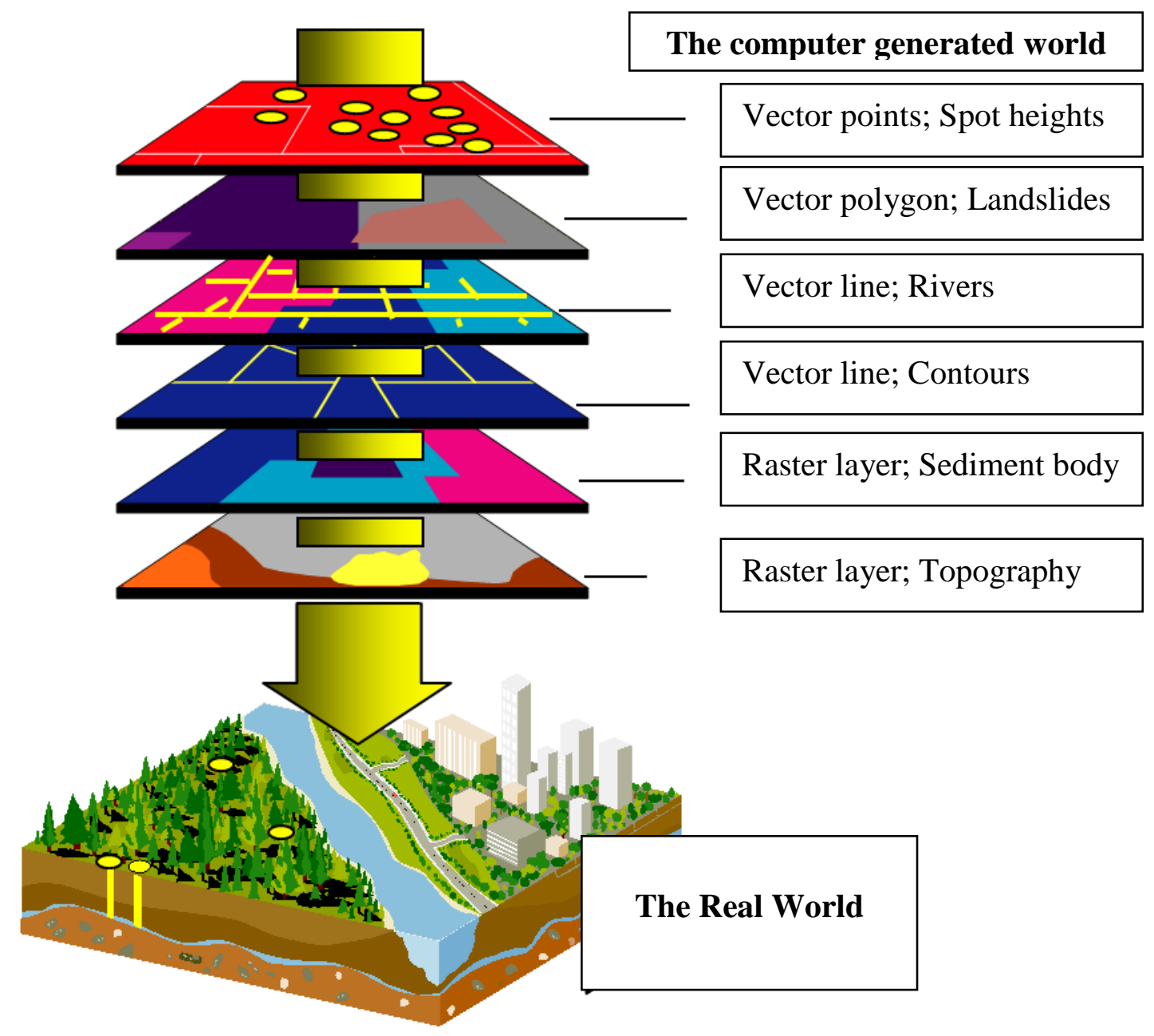

Figure 4.41. The GIS representation of reality (Image adapted from, CRFS 2011).

GIS data are presented in two forms (refer, figure 4.42), one, a grid based raster format where the grids may take on any dimension but store only one value per cell and is the base for representing landscapes in three dimensions. The other format is 
vector, where features such as roads, houses contours, fields, trig points, etc. can be represented as points, lines or polygons (Esri®, 2008). The geo-processing tools are able to convert one format to the other. The remote sensing data from the GPS and the contour data from LINZ are vector layers that can be used to create the hydraulically correct three dimensional (3D) digital elevation models (DEM) in the raster format. The DEMs for this study were based on a 1x1 metre grid, projected in NZGD 2000 transverse mercator and each of the grids are assigned to an elevation value to the third decimal place. There are a number of GIS systems that are available and suitable for this project. For this project the Esri ${ }^{\circledR}$ Arc-GIS ${ }^{\circledR}$ program was used, as it is commonly available at the university and GNS.
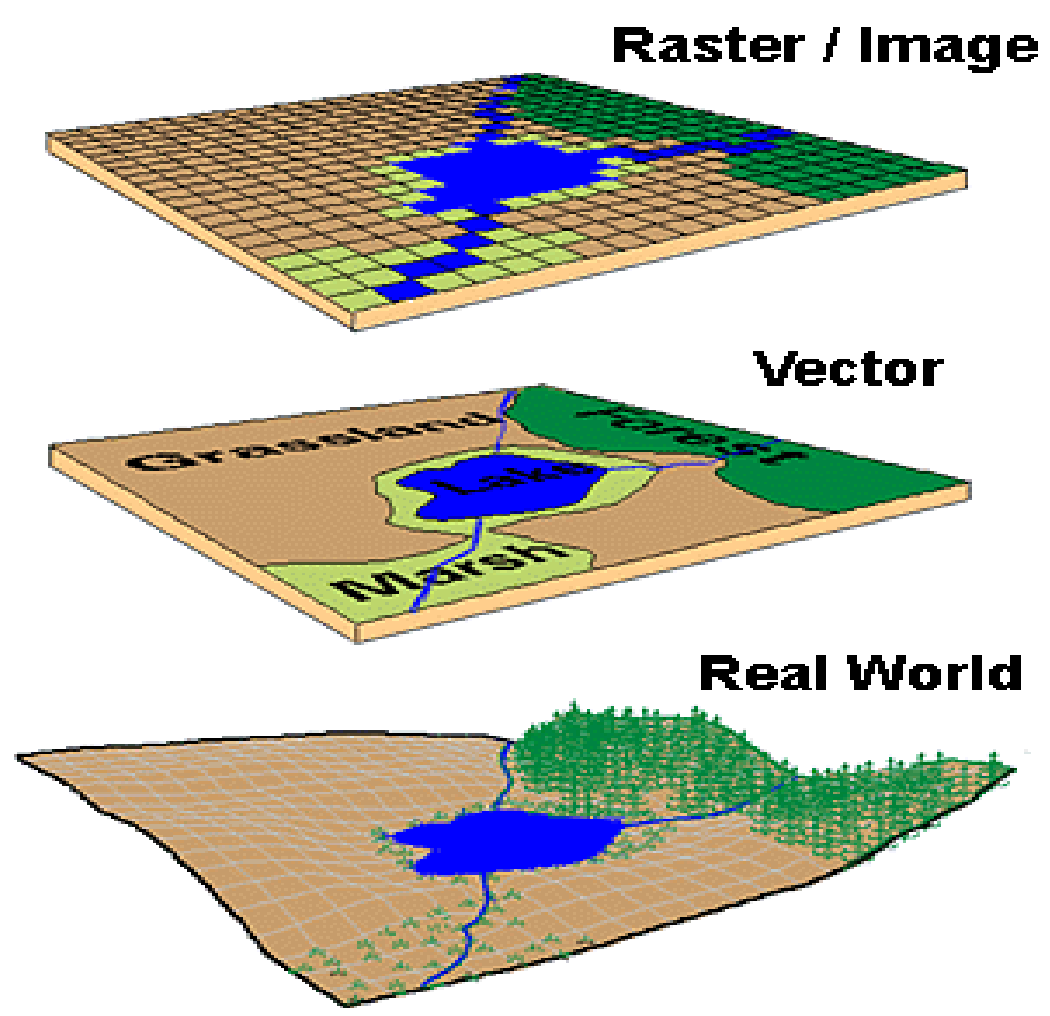

Figure 4.42. The vector and raster representation of the real world (Image from; Google images, 2011).

The process of estimating the sediment volumes involved three primary steps;

1/ Creation of a 3D representation of the palaeo-valley;

2/ Reconstruction of the sediment body maximum infill surface;

3/ Volume calculations. 
The modelling methods in this study are based on those used in previous sediment volume based landscape studies, such as that of Schrott et al. (2003), Cossart and Fort (2008) and Otto et al. (2009). The above mentioned studies all used the geoprocessing algorithms of GIS based programs to develop hydraulically correct landscape models using valley floor data derived from point measurements that were collected in the field by various means. They then used the computer generated 3D models made of the palaeo-valley form and that of the current valley to calculate sediment volumes for the infill, using the GIS based analyst and statistics tools. The same modelling process was applied in this study.

\subsubsection{DEMs and the palaeo-valley surface}

The first step in the recreation of the palaeo-valley surface required the development of digital elevation models (DEMs) which use altitude data as the main input source in the form of contours and spot height elevations. Contour and spot height data for each of the sites were obtained from the Land Information New Zealand (LINZ) national topographic database and from remote sensing data collected in the field via the GPS. The contour data were taken from the LINZ topo50 topographic data which is based on 20 metre grids in NZGD 2000 transverse mercator projection and has a vertical accuracy of $\pm 10 \mathrm{~m}$. While the error of the contour data at this national scale is quite large, at the local scale these errors are at least consistent within catchments and can be corrected for. The spot height data from LINZ is from trig stations which have accuracy in the $x / y$ coordinates of $0.05-0.5 \mathrm{~m}$ and a vertical accuracy of $0.05-0.35 \mathrm{~m}$ depending on the order of the trig station. Accuracy of the GPS data has been described earlier and this data was used as both, a primary point source for the DEM and to help in correcting the contour data at the local scale.

High resolution $(0.6 \times 0.6 \mathrm{~m})$ ortho-rectifed digital aerial photographs projected in NZGD 2000 transverse mercator for each of the study sites were overlaid with the vector data of contours and spot heights from both, LINZ and remote sensing. These data layers were then checked for accuracy of alignment to the aerial photos and then corrected as required. The left image in figure 4.43 shows the result of misalignment of the contour data, where the orange contour lines are those clipped from the national data set for the local site. The misalignment of the contours can be seen clearly in the 
valley floors, where they are not centrally aligned to the river channel and the lower contours of the opposing valley slopes are not of equal elevation. The contour layers were adjusted where necessary to conform to the aerial image and corrections to this misalignment were helped with point elevations taken in the field and local site knowledge. Once the contours fitted the landscape projected in the aerial photo, work could begin on the reconstruction of the valley contours immediately preceding the landslide event and the subsequent channel blockage. This involved identifying the landslide barrier in the contours and creating an upstream and downstream interpretation of the landscape, seen in the right image of figure 4.43.

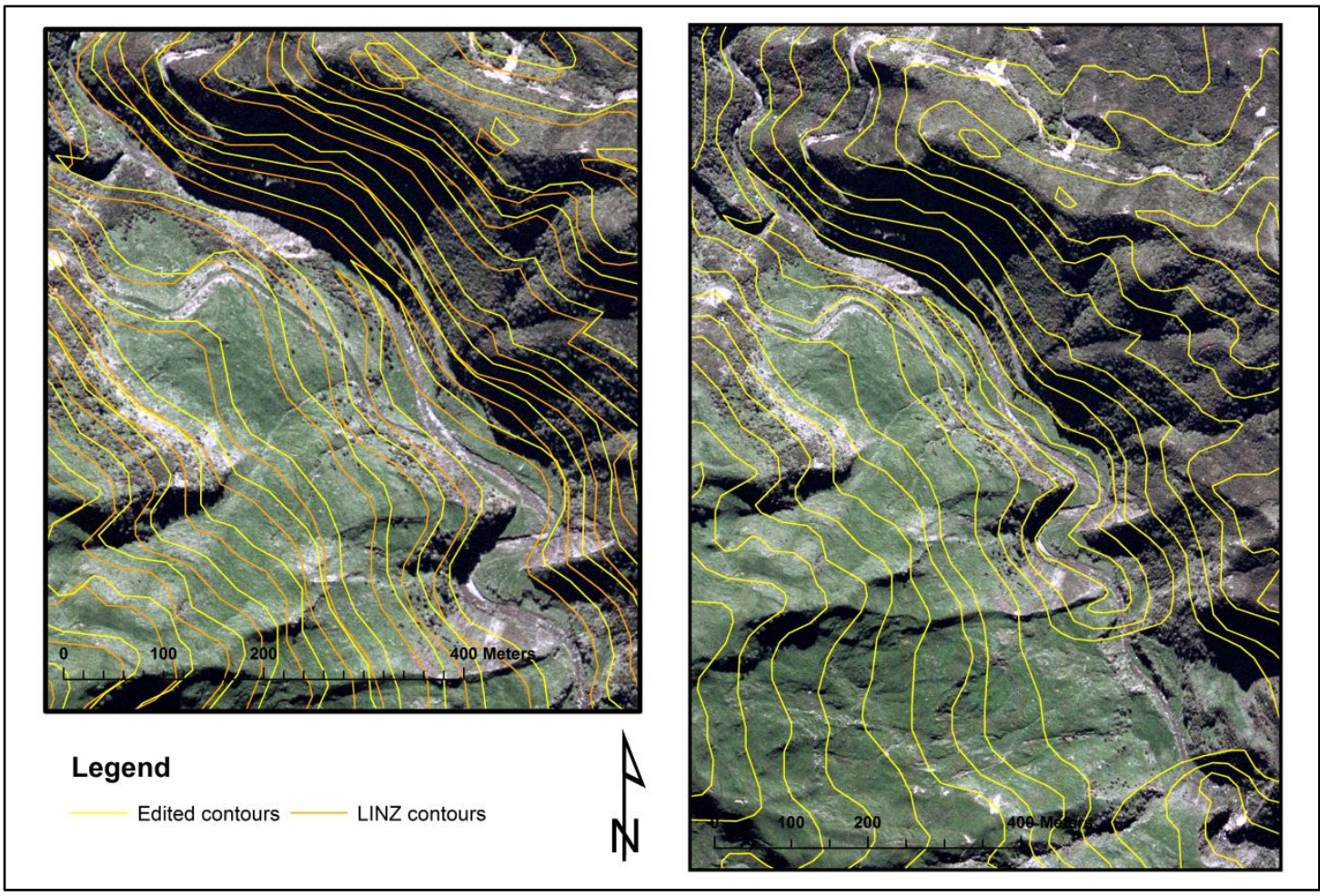

Figure 4.43. Contour corrections. The above figure shows the correction of the base contour data for the Maungahuri field site. In the left image the contour layer is reprojected to match the landscape. In the right image the contours are manipulated to represent the landscape following the landslide event.

Of course the slope and contour of the valley prior to the landslide is not known with complete accuracy. It can however be assumed, that today's landscape reflects that of the past. Major change in the landscape from uplift and weathering over the time frame of this study is assumed to have had negligible impact. There may be small areas identified, where the contours are formed around small slope movements, but these are considered to have occurred in relatively recent times. The contours therefore were required to be readjusted to a form that represents the slope prior to 
that minor slope failure. There are also features in the landscape that at the local scale are not represented at the national scale and not indicated by the contours, such as the spur in the centre of the images in figure 4.44.

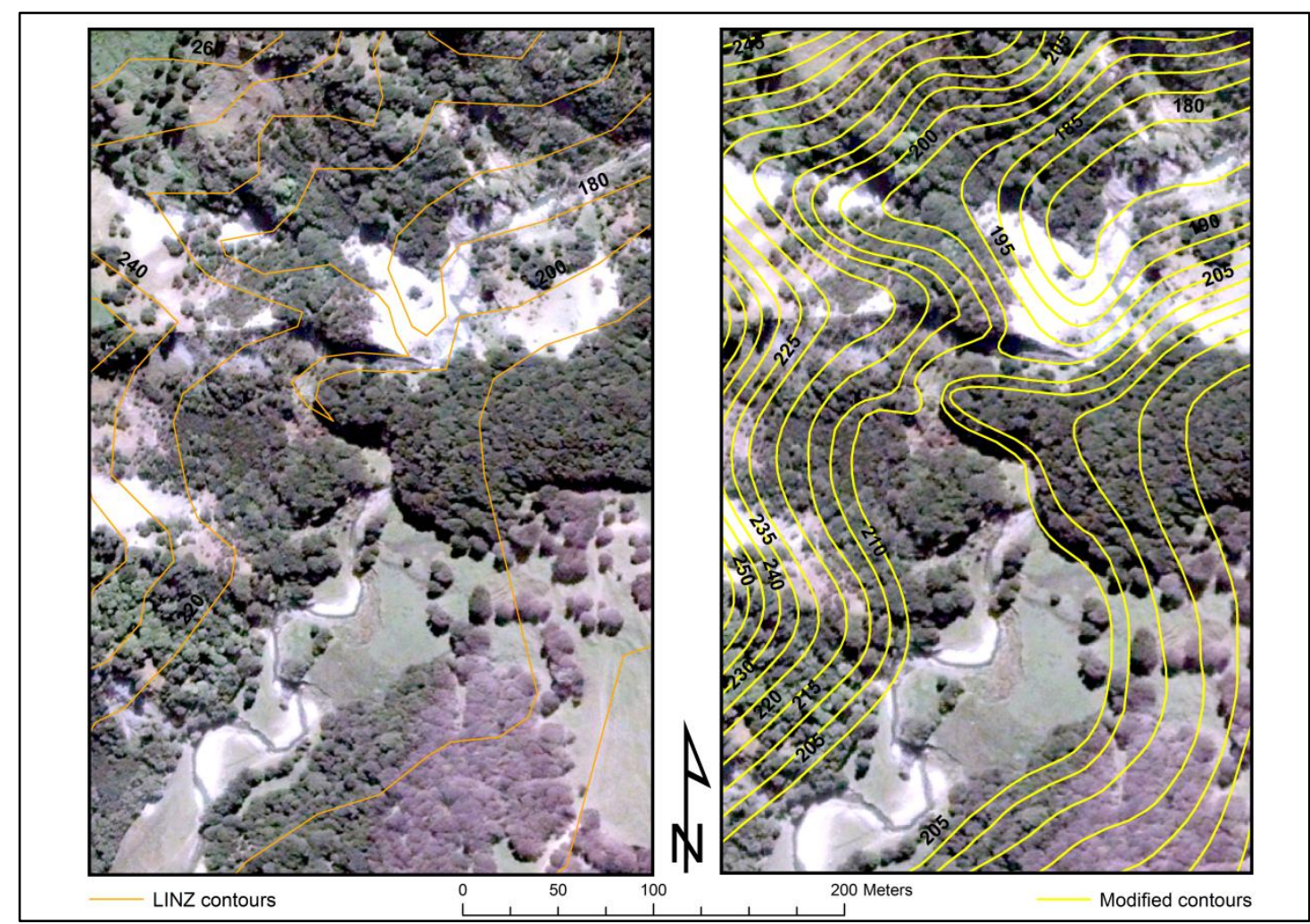

Figure 4.44. Contour adjustments to local scale. The above image shows the differences between the LINZ national contours and the adjustments made to better fit the actual local landscape.

Where these missing features are likely to affect the projection of the slopes below the level of the sediment infill, these features were required to be included in the contour data. Adjustments were made to the contours to reflect what is physically seen in the landscape and in the aerial photos but not represented in the contour data. This is most important for the contours close to the level of the sediment body, so that the 'ground truthed' shape files fit the modelled landscape. Figure 4.44 shows adjustments made to the contours at the Arai Matawai field site were the LINZ contours have left out a spur and have not followed well the outline of the sediment body. It is these contours that are close to the mapped and 'ground truthed' outline of the sediment body that need to be adjusted to closely fit the actual landscape. The contours which are further up slope will have little impact on the way the computer modelling program will respond in the lower valley and receive only minor adjustments. 
The study makes the assumption that the contours below the infilled sediment body in the valley floor prior to the landslide can be represented by projecting trends seen in the contours of similar valley slopes in both, the up and downstream valley profiles. New contours projecting below the current surface are created to represent the valley profile before the infill by using the editing tools of the GIS to copying the contours parallel. The spacing of the new contours is adjusted to give the desired slope profile and the palaeo-valley floor its shape. The progressive widening of the spacing between the contours will give a reducing gradient and a shallower slope and vice versa. These new contours which are made for the sediment body profile and the point elevations of the palaeo-river channel thalwegs, slope and depth from the remote sensing data, provide the critical data points that constrain the DEM modelling of the valley floor. These data points are derived from field data where river incision through the infill has cut back to bedrock, from projection of the slope between points taken upstream and downstream of the landslide and the core base depth.

\subsubsection{The sediment body and volume calculations}

For the calculations of volume to be made, a model of the surface of the sediment body was required. This surface was created as a $1 \times 1 \mathrm{~m}$ raster grid, equal to the DEM's grid, and was derived from the elevation data collected when 'ground truthing' the outline of the sediment body and from spot elevations taken from transects across it. An assumption was made that the surface of the sediment body was close to a plain and that the sediments settling out under water were evenly distributed across the sediment profile at any given point downstream. This assumption was made to simplify the modelling process and is reasonable for small reservoirs considering the redistribution and working of sediments as highlighted the section on small reservoir studies in chapter 2 . There were also a number of instances where much of the sediment body for a field site had been removed by erosion, post dam breach and sediment body incision and the elevations could not always be recorded for the inner stretches of all sediment bodies.

Due to all surface layers using the common NZGD transverse mercator projection in the raster grid based system, it means that all grid squares for each layer will be aligned in both the horizontal and vertical directions and that the projection system 
gives each grid square a known dimension. The GIS calculation program can equate the numbers of grid squares for the surface of the sediment body to give an area from the known dimensions of each square. By using a small grid square, the over and under steps are small and more or less cancel each other out. For calculating the volume, the surfaces of the sediment body and the palaeo-valley are referred to and the numbers of squares that are common to both, give a volume. Surface areas for three dimensional surfaces can also be calculated for the other important surfaces, such as the catchment, by providing the GIS program with a shape file that can control the boundaries for calculation within the DEM. Due to the coring and dating strategy that was employed in the project and will be discussed in the following section, it was possible to subdivide the vertical projection into sections or horizons. This has meant that there are known time lines within the sediment infill sequence and each of these time segments has a known depth. An accurate estimate of the volume for the sediment between these time lines can be calculated by knowing the volume difference between each depth. This understanding of volume and time can provide for rates of infill per catchment and there can be comparisons made within and between sites.

\subsection{Age control}

Objective one seeks to determine the age for onset of the landslide-dams in this study, while objective three seeks to define sedimentation rates for the catchments (refer figure 4.0). The key tools for achieving both of these objectives are ${ }^{14} \mathrm{C}$ radiocarbon dating and the use of volcanic tephra markings in the stratigraphic columns of the cores for each of the sites. This section will provide a brief outline of the principles of both these age control mechanisms and describe how they are used in the context of this study.

\subsubsection{Radiocarbon $\left({ }^{14} C\right)$ dating}

The technique of radiocarbon dating was developed in the 1940s and is based on the proportions of the three naturally occurring isotopes of carbon in the atmosphere of

${ }^{12} \mathrm{C},{ }^{13} \mathrm{C}$ and ${ }^{14} \mathrm{C}$ that are incorporated in any organic substance. These isotopes of carbon exist in known ratios, with the ${ }^{13} \mathrm{C}$ and ${ }^{14} \mathrm{C}$ isotope existing at only trace levels. 
The ${ }^{14} \mathrm{C}$ isotope is radio actively unstable and has a decay half life of 5730 years, giving a dating range of from present time to 55,000 years before present (Godwin, 1962). ${ }^{14} \mathrm{C}$ is formed in the upper atmosphere and remains relatively constant over time. Organisms incorporate carbon in their structure through respiration and combustion and the carbon in their structure maintains the same isotopic ratio of the atmosphere that they live in. When the organism dies, the exchange of carbon with the atmosphere stops and the radio active ${ }^{14} \mathrm{C}$ isotope begins to reduce in abundance at its half life. Therefore, measuring ${ }^{14} \mathrm{C}$ provides an age estimate since the time the organism ceased the exchange of ${ }^{14} \mathrm{C}$ with that in the atmosphere (Prior, 2010).

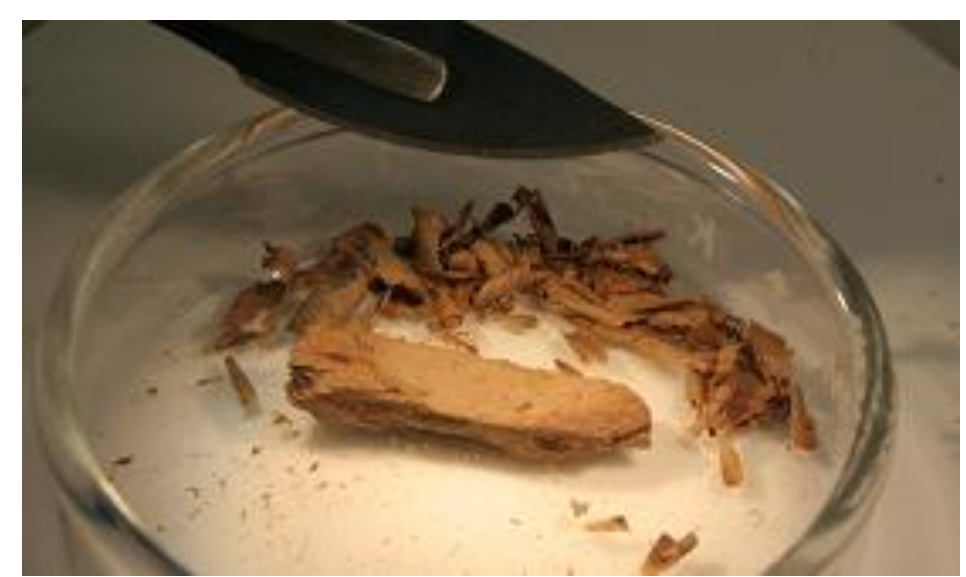

Figure 4.51. Radiocarbon sample preparation. Image shows a well preserved wood fragment and shavings taken from a large sample removed from a core at $\sim 5.20 \mathrm{~m}$ depth in the WT1 core before grinding and cellulose extraction (Image courtesy of R. Boys, 2008).

There are two methods for measuring radiocarbon, either directly counting the decay of the ${ }^{14} \mathrm{C}$ atom, or by counting all the isotopes of carbon and determining the ratio of ${ }^{14} \mathrm{C}$ to ${ }^{12} \mathrm{C}$ and ${ }^{13} \mathrm{C}$. This project uses the latter, the Accelerator Mass Spectrometry (AMS) technique. Due to the way the AMS technique works, it has the advantage of requiring much smaller sample sizes to get an accurate result (Prior, 2010). For this study the AMS method was chosen as some of the samples would be small amounts of organic material taken from bulk soils, so the ability of AMS to work with smaller samples was an advantage. Where possible, large samples were sought for dating, but where there was no large organic sample, plant microfossils in sediments were used. The photo in figure 4.51 shows a wood sample during the physical treatment process which is the stage prior to the chemical treatment and cellulose extraction phases in preparation for combustion to carbon and dating. Radiocarbon dating provides the 
primary method for age control in this study and is supported by the use of tephras and tephra chronologies as described in the following section.

\subsubsection{Tephra}

The Waipaoa catchment lies in the down wind arc of the Taupo Volcanic Centre (TVC) which includes the calderas of Taupo, Tongariro, Ngauruhoe and Ruapehu, the major sources of volcanic tephras in the Gisborne region. The Gisborne and Waipaoa region also receives tephra deposits from the other major volcanic centres of the North Island of New Zealand, including White Island to the North East, making tephra a useful chronological tool in the region (Lowe et al., 2008). Tephra is the general term for all material erupted explosively from a volcano and includes material ranging in size from ash to car sized blocks. For the current study, tephra have two important features:

1. Their fallout occurs over a short time span, generally hours to days;

2. They are widespread, forming a blanket over the area of fallout that represents the same age wherever they occur.

For the Waipaoa catchment area tephra are significant, as there have been a large number of studies that have provided ages and characteristics for each of these tephra, enabling the continuous linking of stratigraphies and the transfer of ages through these tephra tie points (Alloway et al., 2006). Tephra identified in the field and in the cores are described by appearance and position in the stratigraphic column. They are assigned a provenance and age from literature of known tephra for the Gisborne region and through the relationship to radiocarbon dated horizons in the core. This is then transferred to tephra in other cores through the use of geochemical markers and electron microprobe analysis (EPMA) to link the sites in time. The tephra that are likely to be encountered by this study and their ages are listed in the table 4.51 . 


\begin{tabular}{|l|l|l|l|l|}
\hline Tephra Name & Source & $\begin{array}{l}\text { Carbon Age } \\
\text { Calibrated } \\
(\mathbf{y r} \text { BP) }\end{array}$ & $\begin{array}{l}\text { Calender } \\
\text { Years } \\
(\text { AD/BC) }\end{array}$ & Reference \\
\hline Kaharoa & Tarawera & $1314 \pm 12$ & $636 \pm 12$ & Wilson (1993) \\
\hline Taupo & Taupo volcano & $1717 \pm 13$ & $233 \pm 12$ & Wilson (1993) \\
\hline Whakaipo & Taupo volcano & $2960 \pm 190$ & $1010 \pm 190$ & Wilson (1993) \\
\hline Waimahia & Taupo volcano & $3410 \pm 40$ & $1460 \pm 60$ & Wilson (1993) \\
\hline Whakatane & Haroharo & $5530 \pm 60$ & $3580 \pm 60$ & Hajdas et al. (2006) \\
\hline Mamaku & Haroharo & $8005 \pm 45$ & $6055 \pm 45$ & Hajdas et al. (2006) \\
\hline
\end{tabular}

Table 4.51. Common tephra for the region. The provenance, name, ages and reference source for tephra likely to be encountered in the cores.

\subsection{Individual site descriptions}

The following section is a brief description of the individual sites that where selected for the study using the methods described in this chapter. Individual geographical and site specific details will be discussed. The names of the sites are derived from named local features such as a road, river or the operating property name.

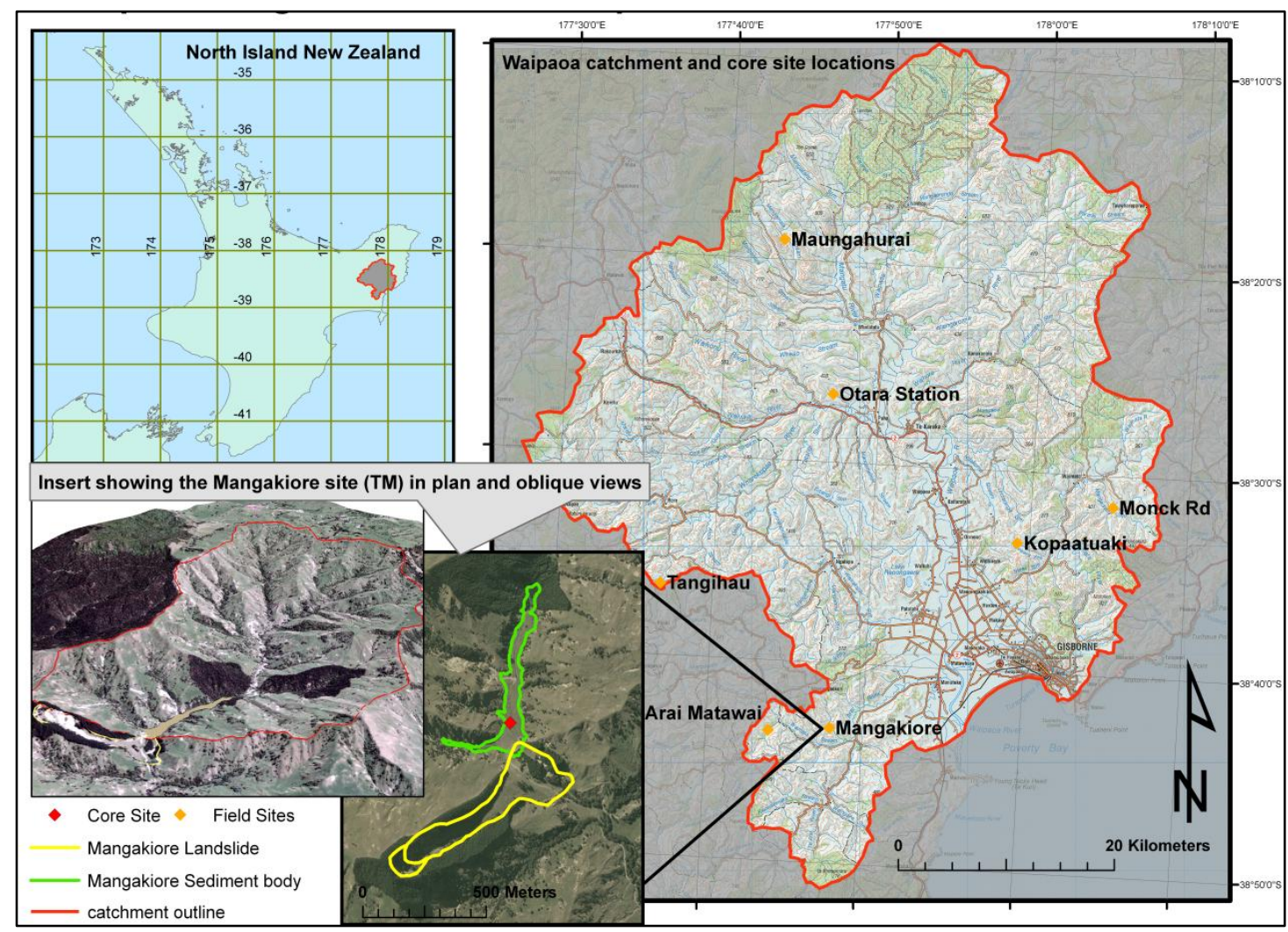

Figure 4.60. Site locations. From the selection process mentioned throughout this chapter, 7 sites were chosen. Their locations are shown in the above image as is an example of one of the sites and the layout of the main features of interest to this study. 


\section{Mangakiore}

The Mangakiore site is a lowland coastal site with an elevation of $53 \mathrm{~m}$ above mean sea level (AMSL) at the sediment body coring location. This site is at the lowest altitude of all the sites in this study. The catchment area of 697.16 Hectares (ha) is long and narrow with many short steep tributaries leading to a wide open main channel. The main channel is a $3^{\text {rd }}$ order stream which flows southeast and has a low gradient. From below the channel blockage to where it drains into the Waimata Stream and into the lower stretches of the Waipaoa River, the channel is almost at the coast and meanders in its alluvial valley. The catchment slopes are mainly of low angle and short length, with a maximum slope angle of $68^{\circ}$ and a mean angle of $20^{\circ}$ where the majority of slope angles cluster (refer figure 4.61). The northern headwater ridgelines are at $300 \mathrm{~m}$ elevation with peaks of $350 \mathrm{~m}$ AMSL, while the slopes in the lower catchment where the landslide blockage occurred are approximately $180 \mathrm{~m}$ with peaks of 300m AMSL. The region's lithology is early-middle Miocene Tologa group mudstone or possibly Tunanui formation mudstones (Mazengarb and Speden, 2000). The landslide is described as a translational slide having a north-easterly aspect and an area of $1.5 \mathrm{ha}$, the smallest landslide in the study.

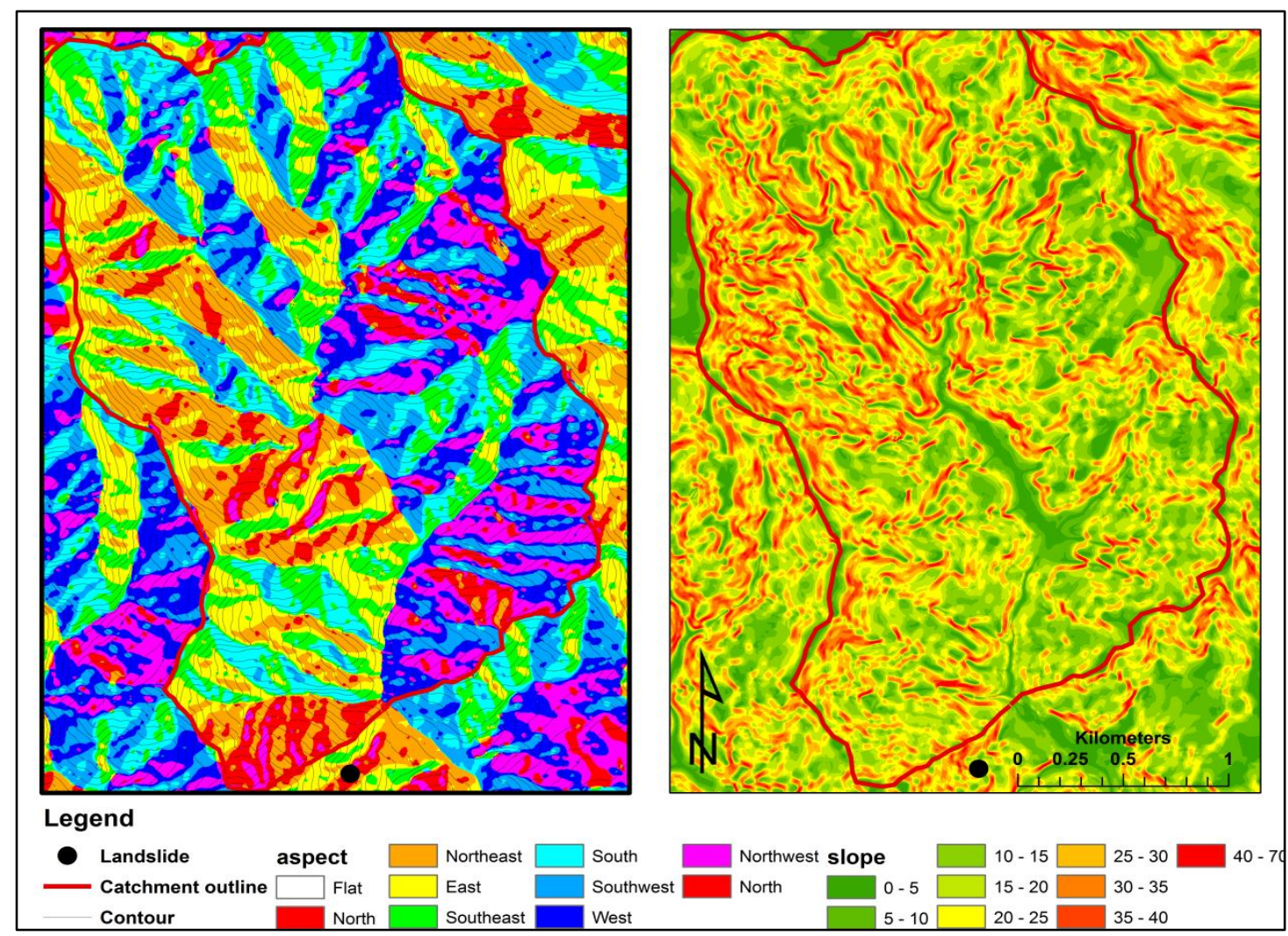

Figure 4.61. Mangakiore slope and aspect details. For all other sites refer Appendix C. 
The Mangakiore landslide is described in the landslide database as a translational slide/flow complex which has occurred in Miocene-Pliocene aged mudstone lithology. This type of landslide is the most common for the Waipaoa catchment and occur in all sub-catchments with a total of 452 landslide recorded. They are however less common and occur in lower numbers in the upper Waipaoa and Mangatu catchments. The statistics for the Mangakiore landslide are outlined in the following table (table 4.61) and this type of landslide are most common to the Te Arai catchment due to the lithology. Where they occur in other catchments which are dominated by similar mudstone lithology they tend to be the smaller of the large landslide classes. When this type of landslide blocks valleys forming lakes they tend to be short lived (10s of years) as outlined in the section on landslide-dams in chapter 2 .

\begin{tabular}{|c|c|c|c|c|c|}
\hline $\begin{array}{l}\text { Catchment } \\
\text { area (ha) }\end{array}$ & Orientation & $\begin{array}{l}\text { Channel } \\
\text { length (m) }\end{array}$ & $\begin{array}{l}\text { Max/Min } \\
\text { elevation } \\
\text { (m AMSL) }\end{array}$ & $\begin{array}{l}\text { Gradient } \\
\text { ( } \Delta \text { elevation } \\
\text { /channel } \\
\text { length) }\end{array}$ & $\begin{array}{l}\text { Channel } \\
\text { configuration } \\
\text { and drainage } \\
\text { density }\end{array}$ \\
\hline 697.16 & South & $4,444.16$ & $380 / 80$ & 0.07 & $\begin{array}{l}3^{\text {rd }} \text { order } \\
\text { Elongated } \\
\text { catchment with } \\
6.37 \text { drainage } \\
\text { density }\end{array}$ \\
\hline
\end{tabular}

Table 4.61. Mangakiore field site statistics.

\section{Kopaatuaki}

The Kopaatuaki catchment feeds the Horoweka Stream. Draining east-southeast it is a tributary to the Waimata River in the west of the catchment. The Kopaatuaki site is the furthest east and more lowland of the Waimata field sites and the sediment body infill is at an elevation of $120 \mathrm{~m}$ AMSL. The landslide blocked the Horoweka stream at the confluence of three tributary catchment streams which drain the surrounding rolling lowland country hills, reaching maximum elevations of $310 \mathrm{~m}$ AMSL, with mean ridgelines elevations of approximately $200 \mathrm{~m}$ AMSL. The tributary catchments drain southwest, southeast and northeast to the confluence with a mean slope angle for the catchments of $15^{\circ}$. The majority of slopes have an angle of less than $36^{\circ}$ with a maximum slope for the catchment of $44^{\circ}$ (refer figure in Appendix C). The catchment is underlain by early Pliocene Mangahea group sandy, fossiliferous mudstones of decimetre bedding in a south east dipping landscape (Mazengarb and Speden, 2000). 
The Kopaatuaki landslide shows evidence of two slope movements. The first and largest landslide was a translational slide along the bedding surface and has a southerly aspect. The second was a smaller reactivation within the original landslide which would have occurred some time later as a result of the undercutting of the slope post dam breach. The original landslide (LSN-228) displaced a large volume of material that represented most of the south facing slope, blocking the channel and impounding a lake that would have reached a maximum depth of approximately 15$18 \mathrm{~m}$. There are 100 large landslides recorded for the Waimata catchment, with three in this sub-catchment showing evidence of channel blockage. The large landslide database lists this landslide as a translational slide/flow complex that has occurred in the Tologa Group Miocene mudstones and it is listed as inactive. Table 4.62 lists the catchment and main landslide features for the larger of the two landslides which is the main landslide for this site. This landslide type is dominant in the Waimata catchment and occurs in both sand and mudstone lithologies, with the ones that occur in the sandstone generally being much large than those that occur in the mudstone.

\begin{tabular}{|c|c|c|c|c|c|}
\hline $\begin{array}{l}\text { Catchment } \\
\text { area (ha) }\end{array}$ & Orientation & $\begin{array}{l}\text { Channel } \\
\text { length } \\
\text { (m) }\end{array}$ & $\begin{array}{l}\text { Max/Min } \\
\text { elevation } \\
\text { (m } \\
\text { AMSL) }\end{array}$ & $\begin{array}{l}\text { Gradient } \\
\text { ( } \Delta \text { elevation/c } \\
\text { hannel } \\
\text { length) }\end{array}$ & $\begin{array}{l}\text { Channel } \\
\text { configuration } \\
\text { and drainage } \\
\text { density }\end{array}$ \\
\hline 168.46 & $\begin{array}{l}\text { east- } \\
\text { southeast }\end{array}$ & $1,307.19$ & $220 / 110$ & 0.08 & $\begin{array}{l}2^{\text {nd }} \text { order } \\
\text { Short wide } \\
\text { catchment with } \\
7.76 \text { drainage } \\
\text { density }\end{array}$ \\
\hline
\end{tabular}

Table 4.62. Kopaatuaki field site statistics.

\section{Tangihau}

The Tangihau field site is midway between the Poverty Bay coast and the Raukumara ranges in the Wharekopae catchment. Tangihau is the western most field site and is on the far western boundary of the Waipaoa catchment. The Tangihau sub-catchment drains to the south east and is underlain by early Miocene, Tolaga group sediments of alternating beds of sandstone and mudstones (Mazengarb and Speden, 2000). The landscape dips to the southwest with a southeast strike. Eastern and western sides of the catchment valley are distinctly different. The eastern segment of the catchment is characterised by gently graded $\left(5-20^{\circ}\right)$ south and southwest facing slopes. The slopes 
of the eastern section of the catchment accounts for a little over half (53\%) of the drainage basin. While the western side of the valley consists of very steep (30-70 $)$ north to northeast facing slopes. These western slopes expose the profile of the massive bedded sand and mudstone units and contribute to the remainder of the catchment surface. The total catchment area is 398.1 ha and $28.7 \%$ of the catchment slope angle is greater than $40^{\circ}$, with a north facing aspect. The palaeo-lake base level is at $420 \mathrm{~m}$ AMSL with the highest site elevations being $645 \mathrm{~m}$ AMSL, occurring on the steep southern slopes that run as a north-south orientated ridgeline. The gentler grade of the southeast facing slopes drains down from a northeast-southwest ridgeline that reaches an elevation of $610 \mathrm{~m}$ AMSL.

The large landslides database recognises a total of 88 landslides in the Wharekopae catchment and $33 \%$ of the landslides are of the same type and class as the Tangihau landslide (3a). Landslides in this type in the Wharekopae catchment typically involve the movement of the whole slope with undercutting and removal of toe support by river incision being the main preparatory factor. This type of landslide is common in the area of the Tologa Group mudstones and they are typically large slope movements. The landslide movement is described as a rotational slide/slump and has moved southeast on a bedding surface failure. The landslide has a total area of 15.84 ha, with an estimated volume of material displaced of 4,530,960 $\mathrm{m}^{3}$ and formed a total blockage of the stream valley. The lake impounded by this dam would have had a maximum depth of approximately $20 \mathrm{~m}$ and would have been drained by seepage through the landslide material and overtopping during storm events. There is evidence of a smaller slope failure upstream from the main blockage which, if concurrent with the main failure, could be responsible for reducing sediment delivery to the sediment body for a period of time. Details for the catchment are listed in the following table.

\begin{tabular}{|l|l|l|l|l|l|}
\hline $\begin{array}{l}\text { Catchment } \\
\text { area (ha) }\end{array}$ & Orientation & $\begin{array}{l}\text { Channel } \\
\text { length }(\mathbf{m})\end{array}$ & $\begin{array}{l}\text { Max/Min } \\
\text { elevation } \\
\text { (m AMSL) }\end{array}$ & $\begin{array}{l}\text { Gradient } \\
\text { (Aelevation } \\
\text { /channel } \\
\text { length) }\end{array}$ & $\begin{array}{l}\text { Channel } \\
\text { configuration } \\
\text { and drainage } \\
\text { density }\end{array}$ \\
\hline 398.12 & Northeast & $1,336.12$ & $580 / 430$ & 0.11 & $\begin{array}{l}2^{\text {nd }} \text { order } \\
\text { Catchment } \\
\text { with } 12.86 \\
\text { drainage } \\
\text { density }\end{array}$ \\
\hline
\end{tabular}

Table 4.63. Tangihau field site statistics. 


\section{Monck Road}

The Monck Road field site is in the northeastern Waimata catchment and is the eastern most site in the study, located on the eastern boundary for the Waipaoa catchment. The catchment has an area of 2103.89 ha which drains northwest via the $3^{\text {rd }}$ order (Strahler scale) Mangaorangi Stream into the Waimata River. The longest stream channel starts in the eastern hills, but these hills are not the highest within the catchment. The catchment is underlain by the late Tertiary sediments of the Tolaga Group, with centimetre to decimetre bedded fine to medium grain sandstones and mudstones. The bedding dips to the southwest and the landslide that formed the blockage at the Monck Road site has a southwest aspect (Mazengarb and Speden, 2000). The maximum slope angle for the catchment is $62^{\circ}$ with a mean slope angle for the catchment of less than $15^{\circ}$ and the majority of the slopes are in the lower quartile (refer to Appendix C). The Monck Road site is characterised as a wide open valley with long shallow slopes and a low stream channel gradient for the main channel, which is $5.5 \mathrm{~km}$ long from headwaters to restriction point.

The surrounding hills have a mean elevation of approximately $200 \mathrm{~m}$ AMSL, with peaks up to $380 \mathrm{~m}$ AMSL in the far eastern headwaters. The highest parts of the landscape are in the south and east of the catchment. The drill site on the sediment body was at an elevation of $90 \mathrm{~m}$ AMSL and it is anticipated that the lake level would have reached a maximum depth of 10-12 $\mathrm{m}$ at a surface elevation of approximately 95 $\mathrm{m}$ AMSL. The landslide has an area of 20.03 ha and is of an unknown total volume, but shows signs of periodic reactivation and may still be an active slope. First generation native vegetation that grows at the head of the landslide scar and in the head scarp shows no signs of deformation due to slope movement. Thus, it would appear that the upper slope at least is stable over the last few hundred years and any creep may be confined to the lower and shallower slope only. Any reactivation of the lower slope is due to stream migration and the progressive removal of toe support. The landslide movement for the Monck Road landslide is described as a large translational slide/flow complex and is of a type that is common for the large landslide features that occur in the mudstone lithology. 


\begin{tabular}{|l|l|l|l|l|l|}
\hline $\begin{array}{l}\text { Catchment } \\
\text { area (ha) }\end{array}$ & Orientation & $\begin{array}{l}\text { Channel } \\
\text { length } \\
(\mathbf{m})\end{array}$ & $\begin{array}{l}\text { Max/Min } \\
\text { elevation } \\
\text { (m AMSL) }\end{array}$ & $\begin{array}{l}\text { Gradient } \\
\text { ( } \begin{array}{l}\Delta \text { elevation } \\
\text { /channel } \\
\text { length) }\end{array}\end{array}$ & $\begin{array}{l}\text { Channel } \\
\text { configuration } \\
\text { and drainage } \\
\text { density }\end{array}$ \\
\hline 2130.89 & Northwest & $6,363.08$ & $280 / 100$ & 0.03 & $\begin{array}{l}3^{\text {rd }} \text { order } \\
\text { Round } \\
\text { catchment with } \\
2.99 \text { drainage } \\
\text { density }\end{array}$ \\
\hline
\end{tabular}

Table 4.64. Monck Road field site statistics.

\section{Maungahaumi}

The Maungahaumi field site is the highest elevation site in Mangatu, the northern most catchment, and has a total catchment area of 1180.43 ha. This site is characterised by its extreme slopes, narrow valleys and its ruggedness and high energy environment. The catchment is drained by the $2^{\text {nd }}$ order Mangamaia Steam which is fed by tributaries and finds its source in the headwaters of the Raukumara ranges with ridges of $950 \mathrm{~m}$ plus AMSL elevation and peaks of over $1000 \mathrm{~m}$. The longest channel drains from the highest terrain which is in the north-western corner of the catchment. The valley slopes are long and steep and plunge dramatically to the drainage line. Valley slopes face west and east and the slope lengths from floor to ridge are over $1200 \mathrm{~m}$. The sediment body in the valley floor has its surface elevation at approximately $427 \mathrm{~m}$ and the estimated maximum lake depth was $40 \mathrm{~m}$ with a lake surface elevation of $460 \mathrm{~m}$. The geology of the region is of the much older poorly bedded green-gray calcareous mudstones and sandstones of the Wanstead formation in the Mangatu group of Eocene age (Mazengarb and Speden, 2000).

The slopes in the Mangatu catchment are highly prone to deep-seated landslide failures and there is evidence of two at this site, which could be responsible for the blockage. It is hard if not impossible from the field evidence to attribute the remnant of the sediment body to one landslide or the other. It is also possible that both were active at the same time. The preferred interpretation however is that the landslide of the western slope (LSN-23) with an area of 8.64 ha followed the landslide on the eastern slope (LSN-24), which has an area of 16.97 ha. It is interpreted here that the landslide of the western slope resulted from the undercutting of toe support post dam breach and stream incision of the landslide debris and may still be periodically active. 
The bedding surface dips northeast and the landslide of the western slope, being the larger of the two, is a translational slide on that bedding plain. The landslide of the western slope is a smaller failure and cuts down across the bedding plains. It is interpreted as being associated with a localised fracture due to seismic activity. Very little of the sediment body remains and it is only due to a hard outcrop of a spur across the drainage line that has protected what little remains of the sediment body. What is preserved shows a continuous and undisturbed sequence of infill which does not suggest that there had been two separate blockages. This may be due however to the extremely high energy of the environment and the rapid removal of material from the valley floor, so it is a remnant of the last event only that is still surviving. The landslides that caused the channel blockage are described in the large landslides database as rotational slumps that are slow to moderate in motion and occur exclusively in the older bedded lithologies of the upper Waipaoa, Waihuka and the Mangatu catchments. There are a total of 63 landslides listed in the landslides database of the type at the Maungahuarai field site.

\begin{tabular}{|l|l|l|l|l|l|}
\hline $\begin{array}{l}\text { Catchment } \\
\text { area (ha) }\end{array}$ & Orientation & $\begin{array}{l}\text { Channel } \\
\text { length } \\
\text { (m) }\end{array}$ & $\begin{array}{l}\text { Max/Min } \\
\text { elevation } \\
\text { (m AMSL) }\end{array}$ & $\begin{array}{l}\text { Gradient } \\
\text { (Aelevation } \\
\text { /channel } \\
\text { length) }\end{array}$ & $\begin{array}{l}\text { Channel } \\
\text { configuration } \\
\text { and drainage } \\
\text { density }\end{array}$ \\
\hline 1180.43 & Southeast & $7,255.74$ & $1040 / 420$ & 0.09 & $\begin{array}{l}3^{\text {rd }} \text { order } \\
\text { elongated } \\
\text { catchment } 6.15 \\
\text { drainage } \\
\text { density }\end{array}$ \\
\hline
\end{tabular}

Table 4.65. Maungahaumi field site statistics.

\section{Otara Station}

The Otara field site is located in a small catchment at the head of the Poverty Bay Flats. The stream channel for the Otara site is a $1^{\text {st }}$ order channel and drains a small low lying catchment (168.09 ha) in the middle of the Waipaoa catchment and at the head of the Poverty Bay alluvial plain. The slopes of the Otara Station site are, like with the Maungahuri site, highly unstable and there are scars of many deep-seated landslides visible in the landscape. There are two rotational landslide slumps that have occurred on opposing slopes that could be responsible for the channel blockage. The western landslide (LSN-103) on the north-eastern facing slope is the larger at 19.38 ha 
and the eastern slope failure of 5.17 ha is on a slope of south-western aspect. The landslides are described in the large landslides batabase as rotational slumps and are of a type (3a) that are the second highest occurring type in the Waipaoa catchment at a total of 306 landslides. For this site the preferred sequence of events is that the larger landslide occurred first, blocking the channel that then began to be incised by the stream which caused toe support loss from bank under cutting of the eastern slope, triggering the smaller slope failure. This smaller failure is continually being under cut and reactivating and evidence of this is seen by repetitive erosion and deposition phases in the grain size changes of the profile. The material from the previous blockages is not completely removed prior to the next failure and the deposition sequence begins on top of an unconformity.

The region's geology is mudstone of the early Pleistocene sediments of the Mangetuna group which are the youngest sediments of the study when landslides have formed (Mazengarb and Speden, 2000). The channel length to the restriction point is approximately $1000 \mathrm{~m}$ and becomes ephemeral where it forks at the head. Ridgelines are oriented northwest-southeast and step down from east to west. The eastern slope of south west aspect has a ridgeline at $340 \mathrm{~m}$ and a peak elevation of $428 \mathrm{~m}$ AMSL. The slope is steeper and longer than the opposite slope with slope angles of $25-35^{\circ}$ (refer figure in Appendix C). The western or north-eastern aspect slope has ridgelines at $250 \mathrm{~m}$ and a maximum elevation of $340 \mathrm{~m}$ AMSL. These slopes are shorter and steeper with slope length of $400 \mathrm{~m}$ and slope angles of $20-30^{\circ}$. The valley floor at the lowest point at the restriction is at $115 \mathrm{~m}$ and the maximum depth of the lake is estimated at $15 \mathrm{~m}$ or $130 \mathrm{~m}$ AMSL, with the reoccurring failures of the western slope and the smaller landslide being some $5 \mathrm{~m}$ lower in both maximums. The river has incised deeply into the lower valley, forming a very narrow steep sided valley and the upper valley slopes are attempting to regain equilibrium with the rate of downcutting of the river. This means the environment is one of high energy and continual change and this is displayed in the profile of the sediment body. 


\begin{tabular}{|l|l|l|l|l|l|}
\hline $\begin{array}{l}\text { Catchment } \\
\text { area (ha) }\end{array}$ & Orientation & $\begin{array}{l}\text { Channel } \\
\text { length }(\mathbf{m})\end{array}$ & $\begin{array}{l}\text { Max/Min } \\
\text { elevation } \\
\text { (m AMSL) }\end{array}$ & $\begin{array}{l}\text { Gradient } \\
\text { (Aelevation } \\
\text { /channel } \\
\text { length) }\end{array}$ & $\begin{array}{l}\text { Channel } \\
\text { configuration } \\
\text { and drainage } \\
\text { density }\end{array}$ \\
\hline 168.09 & $\begin{array}{l}\text { South- } \\
\text { southeast }\end{array}$ & $1,779.21$ & $380 / 120$ & 0.15 & $\begin{array}{l}2^{\text {nd }} \text { order } \\
\text { Elongated } \\
\text { catchment with } \\
10.58 \text { drainage } \\
\text { density }\end{array}$ \\
\hline
\end{tabular}

Figure 4.66. Otara Station field site statistics.

\section{Arai Matawai}

Arai Matawai (figure 4.67) is the last site of the study. It is a highly dissected catchment in the Te Arai catchment and forms the headwaters of the Waimata Stream that flows northeast. The main channel is a 3rd order channel and has many $2^{\text {nd }}$ order tributaries. The catchment area is 746.60 ha and has $600 \mathrm{~m}$ elevations in the headwaters with peaks of over $700 \mathrm{~m}$ and the longest channel flows for $3819 \mathrm{~m}$ to the waterfall at restriction point. The region's geology is the northwest dipping, centimetre to decimetre bedded calcareous Tolaga group sandstones and mudstones of the early Miocene (Mazengarb and Speden, 2000). The catchment has gentle (5-15 $)$ northwest facing slopes and much steeper $\left(30-40^{\circ}\right)$ east-southeast facing slopes. The landslide that blocked the valley occurred in the direction of the dip plain on the northwest facing slope and has a total area of 49.61 ha. The blockage of the valley is described as a very rapid translational slide/flow complex and is common in the bedded sandstone/mudstone lithologies. A total of 42 of this type of landslide are reordered in the large landslides database. At the restriction point the river channel was raised to $200 \mathrm{~m}$ AMSL from approximately $175 \mathrm{~m}$ and is seen now as a waterfall. The height of the sediment body is at $209 \mathrm{~m}$ at the blockage giving a depth of sediment at that point of $9 \mathrm{~m}$, with a maximum lake level that would have been at 215 m AMSL.

\begin{tabular}{|c|c|c|c|c|c|}
\hline $\begin{array}{l}\text { Catchment } \\
\text { area (ha) }\end{array}$ & Orientation & $\begin{array}{l}\text { Channel } \\
\text { length (m) }\end{array}$ & $\begin{array}{l}\text { Max/Min } \\
\text { elevation } \\
\text { (m AMSL) }\end{array}$ & $\begin{array}{l}\text { Gradient } \\
\text { ( } \Delta \text { elevation } \\
\text { /channel } \\
\text { length) }\end{array}$ & $\begin{array}{l}\text { Channel } \\
\text { configuration } \\
\text { and drainage } \\
\text { density }\end{array}$ \\
\hline 764.59 & Northeast & $4,383.89$ & $580 / 180$ & 0.09 & $\begin{array}{l}3^{\text {rd }} \text { order } \\
\text { elongated } \\
\text { catchment } \\
\text { drainage } 6\end{array}$ \\
\hline
\end{tabular}

Figure 4.67. Arai Matawai field site statistics. 


\subsection{Estimates of and possible sources for error}

The quantification of error is difficult for this study as there are many stages that rely on assumptions. Also the GIS surface modelling software will not always honour the input data. For instance, the creation of the contours for the palaeo-valley form below the current topography assumes a continuation down-slope on a trend as indicated by the current up-slope surface and there are few measured subsurface data points to constrain the model. The contour dataset stems from the Land Information 1:50 000 topographic map series with a spatial accuracy from well located features of $+/-30 \mathrm{~m}$, with vertical variability dependent on ground cover. These errors, while quite large, are consistent over the small scale of these sites, meaning relative heights are acceptable. The use of contour data to extrapolate subsurface topography is subject to significant error as it is based on few measured data points and modelling the valley floors becomes a problem for the software due to the lack of data to constrain shape.

Errors in the modelling stage in principle may stem from four areas:

1. The $20 \times 20$ metre scale of the national topographic data and the errors in the making of this data set.

2. The corrections to the national data set to better represent the smaller local scale features as observed on current geo-referenced aerial images and those of the point data taken in the field.

3. Assumptions of valley form just post landslide and prior to infill and to what extent was the intrusion from the landslide debris into the valley upstream.

4. The depth of the sediment body as taken from one single core combined with the above assumptions in valley profile and form and the form of the sediment body surface i.e. flat or concaved.

Errors in age estimates will primarily come from the sampling of material supplied for radiocarbon dating. The primary error source will be where there has been redeposition of sample material within the column, or the introduction of older/modern material from an external source. To minimise the possible error in sampling, samples were taken from regions of the core profile that were identified as periods of low disturbance. A sampling regime of taking samples of wood from large 
branches or material that extended across the full width of the core and through which the coring tool had cut when drilling were considered to have been less likely to have been reworked within the sediment profile. Also, samples of similar material were used where possible for each core so that radiocarbon ages were based on the same source and by organisms that metabolised carbon in the same way.

\subsection{Chapter summary}

This chapter has shown the methods that have been employed to achieve the study's aims and objectives as set out in chapter 1 . For this study the primary consideration in the methods selection process has been that of portability. Many of the field sites in this study are in remote locations with access being a limiting factor. This chapter has shown that for each of the task areas there has been consideration made to alternate methods, with a justification provided for each of the methods chosen. Following the application of these methods, the resulting data collected will be presented in the next chapter, "Towards an understanding of sediment dynamics at the sub-catchment scale". 
Chapter 5

Towards an understanding of the sediment dynamics of a large catchment 


\subsection{Introduction}

This chapter details the findings that result from the application of the field, laboratory and modelling methods discussed in the previous chapter and presents analysis of these findings for each site. The contemporary surface of the sediment body at each field site is used as the datum for all depth measurements, with the surface depth being recorded as zero. Where cores have not bottomed out, depths and ages are back calculated using the sedimentation rates and the modelled computer landscapes as reference. All ages expressed in this section are in calibrated radiocarbon years before present (cal. years BP) using the Southern Hemisphere calibration curve (McCormac et al., 2004), except for the modern site of Mangakiore, which is in calendar years. Where the ages are sourced from other reference material such as tephra, they are quoted in the terms of that reference. Where the ages are derived as part of this study, they are the mid point of the $95 \%$ confidence interval and cover a minimum of $70 \%$ of the area giving an error of \pm 20 years. A key for the stratigraphical columns is provided in figure 5.0. In many instances there is more information than can be presented in this chapter and for this and the background data sets that inform the summary data presented, refer to the appendix section.

\section{Key}

$\square$ Dark organic soil

$\therefore$ Sand/Tephra

$\Delta \Delta_{\Delta \Delta}^{\Delta}$ Lapilli

$\square$ Stratified organic-rich sediment,

$\triangle$ Lacustrine sediments, slow regular sediment deposition

VA Aerial deposition from overbank deposits

$\therefore$ Weathered bedrock

Q Bedrock

$\because \because$ Landslide/slope deposits

$\multimap$ Radiocarbon sample

Wood fragments

Figure 5.0. Key for the stratigraphic columns. 


\subsection{Mangakiore}

With the advantage of well defined timelines for the onset and termination of the channel blockage and both instrumental and observational records, the Mangakiore field site (figure 5.11) provides the opportunity to analyse catchment sedimentary response to a single event, and to quantify event sediment delivery for a catchment under grassland conditions. Further, analysis of the core data from the Mangakiore sediment body provides insights into the event sediment dynamics of landslide-dams.

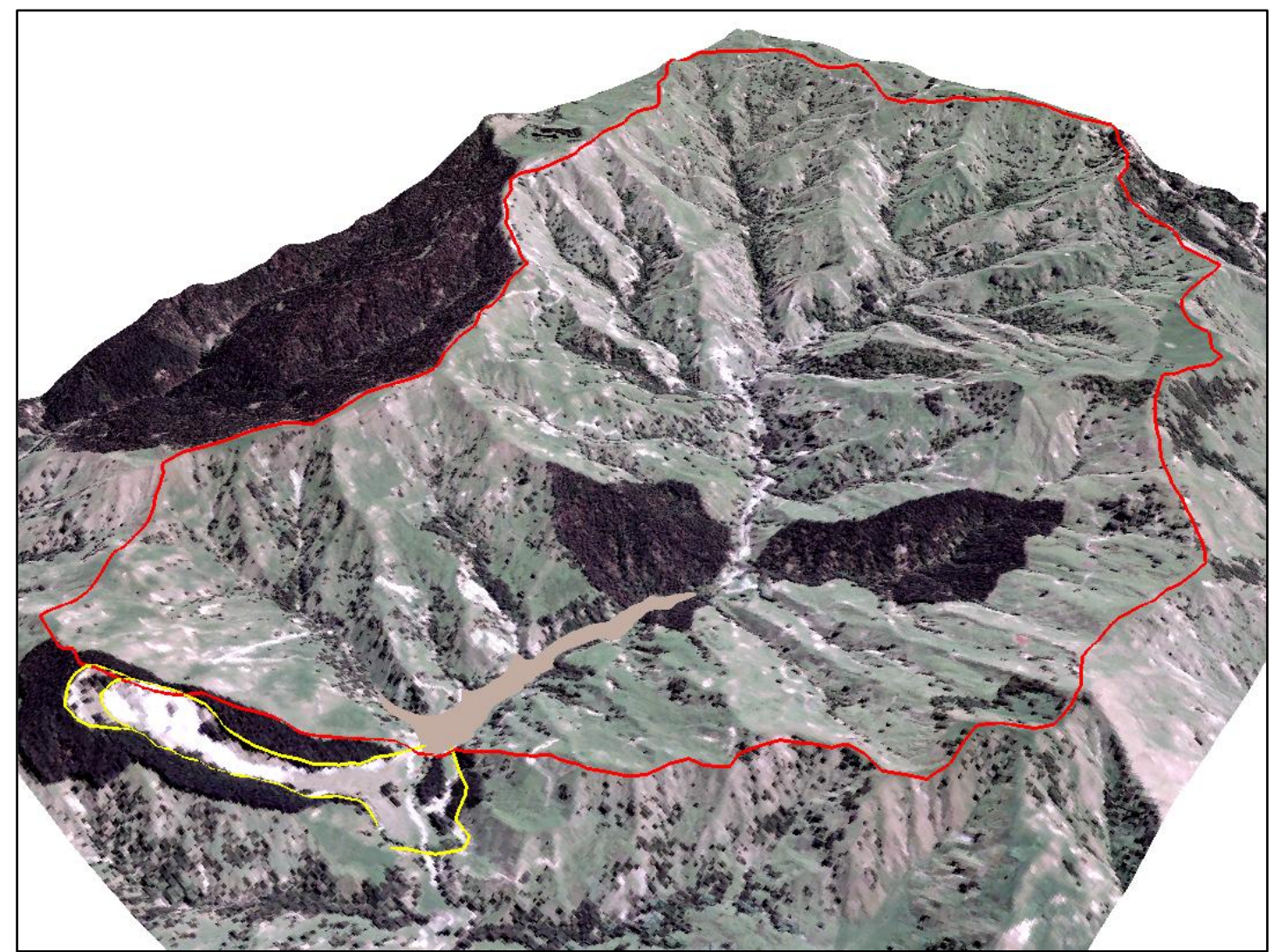

Figure 5.11. 3D model of the Mangakiore landscape. Image highlights the landslide outline in yellow and the catchment boundary in red, the sediment body is shaded brown.

\subsubsection{Core log and sedimentation}

The computer modelling of the sediment body for the Mangakiore site is shown in figure 5.12. Using the DEM and the modelled surface of the sediment body, calculations are possible for the total volume and volumes of sediment at the horizons of interest and as identified in the core analysis. A summary of the core analysis is shown in figure 5.13. At this site the coring tool bottomed out at bedrock and a full 
sequence was taken to be observed in the laboratory. Much of the core was featureless to the eye in makeup and consisted of a homogenous deposit of fine silt/clay sediments (refer appendix ' $D$ ' for core log photos). The simplified core log shown in figure 5.13 includes the analysis of radiocarbon dating, dry bulk density and the key horizons with sediment characteristic descriptions. Only four soil boundaries of interest were noted and to help with establishing a time line for the sequence, two samples were sent for radiocarbon analysis. The samples labelled TM1-6.80 (below the deepest palaeo-sol) and TM1-4.85 (the bottom of the second lowest sequence) both returned ages that were too modern to date (refer appendix ' $A$ ' for radiocarbon result). This provides weight to the argument that the sequence is a contemporary deposit. The position of the samples in the core would also mean that the reworking and introduction of younger material is not considered likely. Observations provided by the land owner and data from the Niwa CLIFO TM climate data were combined to aid interpretation of the sequence of events for this site.

The following is the interpretation of the core starting from the bottom and the older sediments and working upwards in chronological sequence. The core starts with a base of weathered bed rock and regolith at $7 \mathrm{~m}$ with the pre-infill palaeo-sol occurring at $6.65 \mathrm{~m}$ depth. This palaeo-sol is seen as an organic rich soil below a layer of organic material which is interpreted as plant debris washed off the landscape and trapped during the storm event. Projecting above this boundary, the sediments are a homogenous unit ' $C$ ' (refer figure 5.13) of silt/clay which extends up to another organic layer and stratified organic sediments at $4.85 \mathrm{~m}$ depth. The sediments of unit ' $\mathrm{C}$ ' are interpreted as storm and post storm sediments, which have accumulated during lacustrine conditions. The organic debris at $4.85 \mathrm{~m}$ indicates where post event sediment accumulation ceased and the area had become a swampy pond. The stratified organic sediment topping this boundary represent the rapid post event sediment accumulation from sediments dislodged in the landscape during the event, which found temporary storage, then were released throughout the following year's rainfall. The total volume calculated for the sediment accumulation in unit ' $\mathrm{C}$ ' is $54.18 \times 10^{3} \mathrm{~m}^{3}$ and represents deposition from a single event. 


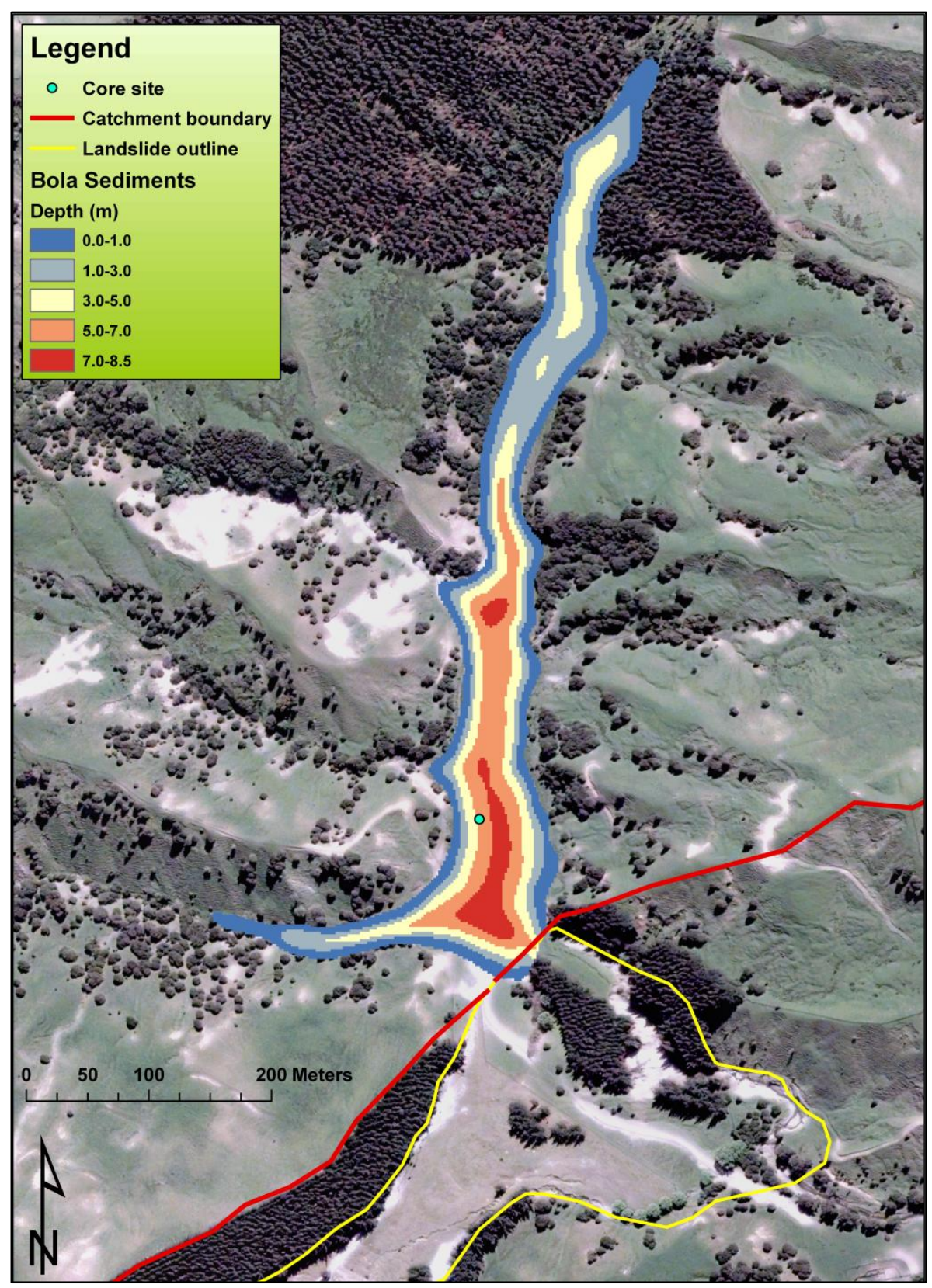

Figure 5.12. Mangakiore site showing landslide and valley infill. The modelled output for the sediment deposit shows infill depths and distribution.

Located above is the ' $\mathrm{B}$ ' sequence indicated in figure 5.13 as the infill interpreted as the Bola event sediments and represents a volume of $137.64 \times 10^{3} \mathrm{~m}^{3}$ sediments delivered to the channel during the event itself. This unit extends from the stratified layer at the top of ' $\mathrm{C}$ ' and up to $0.90 \mathrm{~m}$ below the current surface. It is the study's interpretation that the deep-seated landslide that blocked the valley occurred early in the Bola event for reasons mentioned in the following section and that unit ' $\mathrm{B}$ ' represents the full storm record for sediments delivered in the Bola event. This Bola unit is capped by sequence ' $A$ ' which is interpreted as representing the post event 
sediment accumulated in the ponded conditions prior to the dam breach. Unit ' $A$ ' is made up of sediments dislodged from the slopes during Bola that are remobilised and delivered to the channel during normal seasonal rainfall.

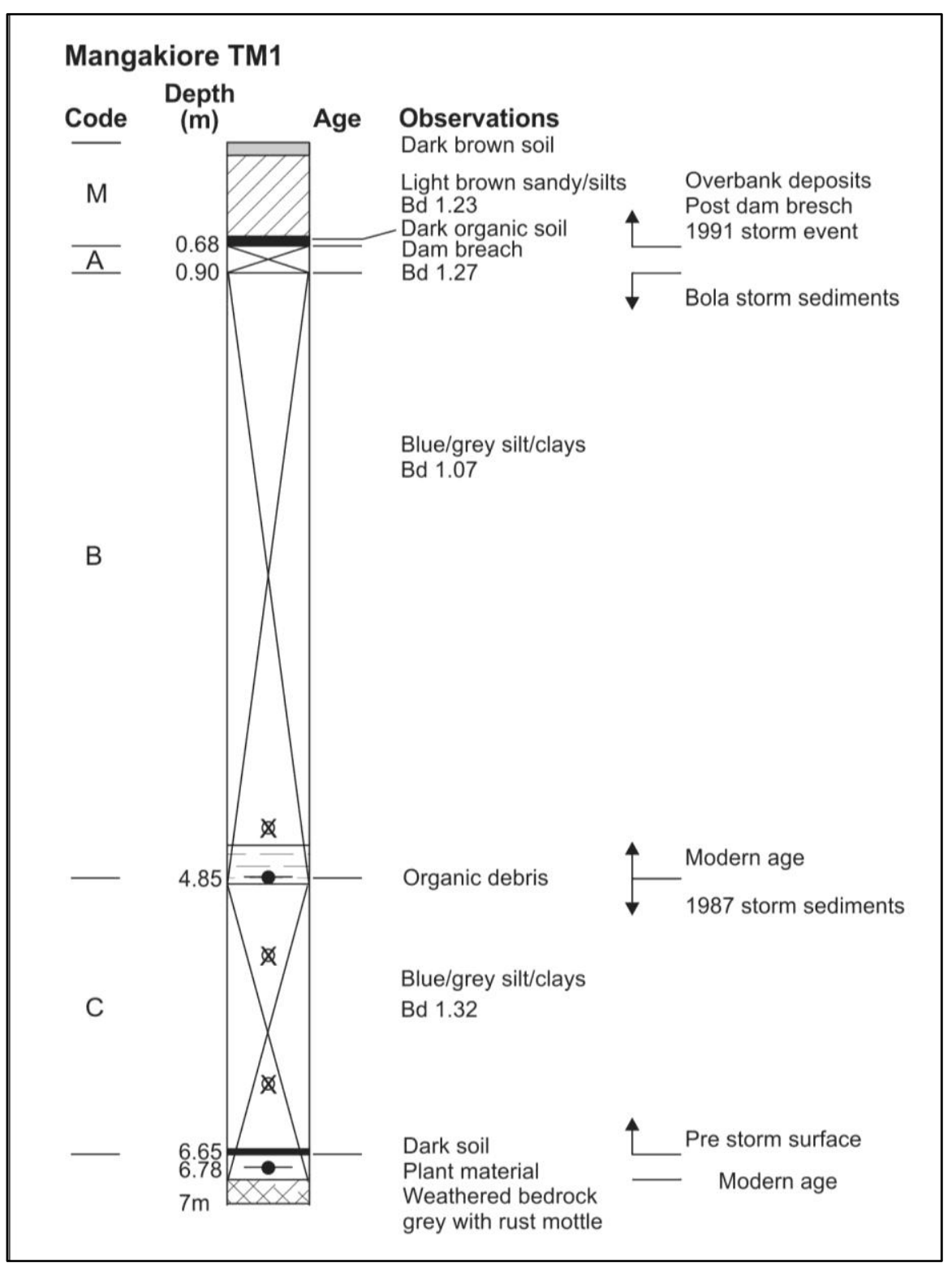

Figure 5.13. Core log for the Mangakiore field site.

The final sequence ' $M$ ' within the core represents the sediments deposited after the dam breach and is a coarser unit of sediments that have been deposited by overbanking from large rainfall events. This part of the core infill sequence contains a sediment volume of $34.20 \times 10^{3} \mathrm{~m}^{3}$ of which most is attributed to a large storm event in 1991 and with reducing inputs from storms during following years. These volumes can be analysed in terms of volumes of sediment delivered per-hectare of catchment 
and the results are shown by the green curve in figure 5.14. Due to the large number of shallow landslides that were activated by the Bola storm event, there is a corresponding high sediment delivery peak where sediment per hectare is estimated to have been $197.43 \mathrm{~m}^{3} / \mathrm{ha}$. Due to a partial blockage of the channel that occurred during the preceding 1987 event (discussed in the next section) and the activation of the deep-seated landslide early during the Bola event, it is estimated that trapping efficiency of the dam for the Bola event sediments was close to $100 \%$.

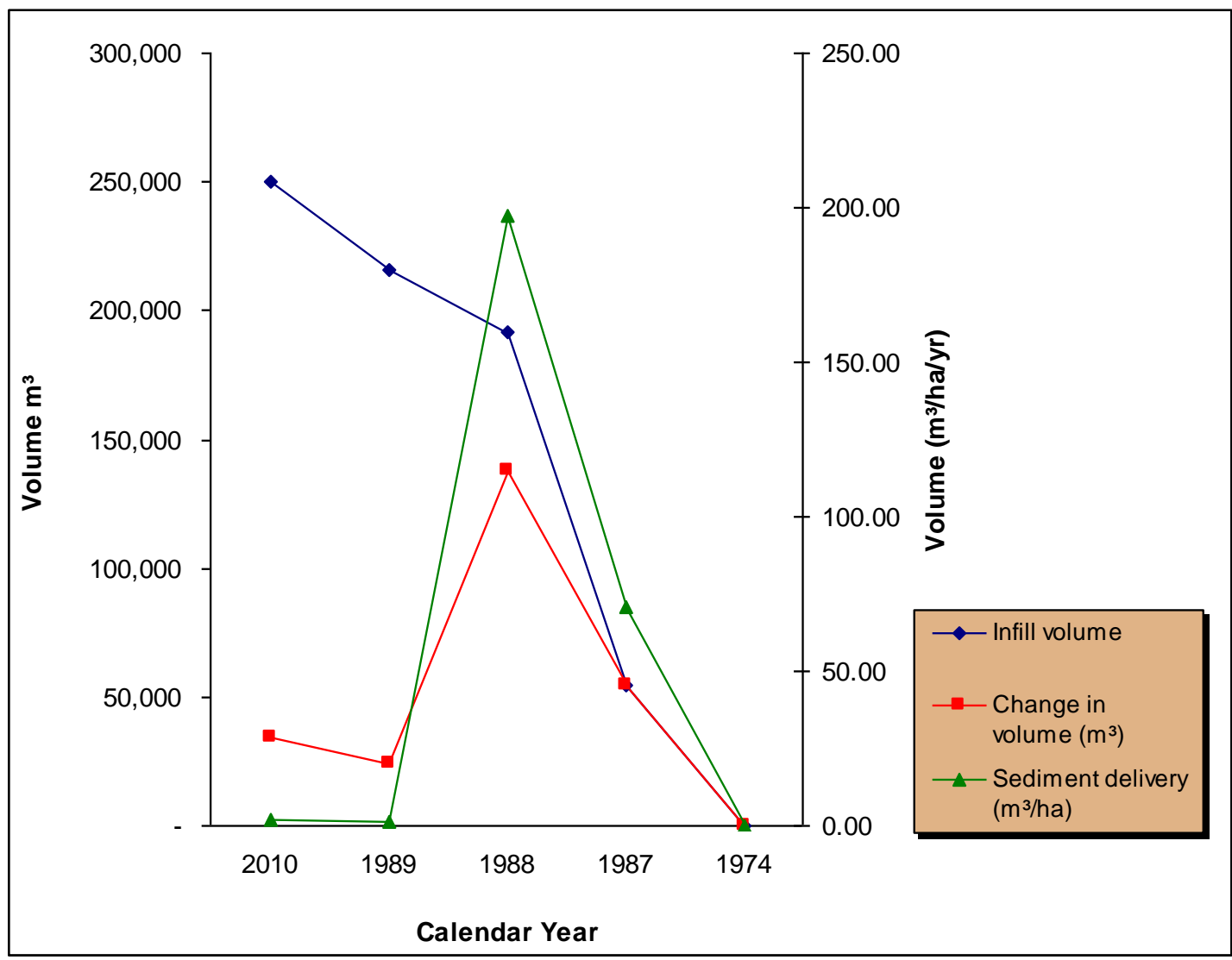

Figure 5.14. Sedimentation curves for the Mangakiore field site. The blue curve shows the volume of infill over time, while the red curve shows the change in volume between time markers. The green curve is the mean sedimentation rate for the catchment between periods calculated as $\mathrm{m}^{3} / \mathrm{ha} / \mathrm{yr}$.

\subsubsection{Analysis and observations}

The channel at the Mangakiore field site was initially blocked by a partial failure of the slope and the landslide in a storm event of high intensity in March 1987. The slope failure was the result from an extended period of high rainfall that followed a wetter than usual summer resulting in raised ground pore-water pressures. The landslide most likely occured as a two phase failure sequence similar to the Anaura 
Bay (discussed later this section). The rainfall data for the event in March of 1987 and the period prior is shown in appendix B, with the key statistics shown in table 5.11. In summary, days of moderate rainfall during the build up to the storm event kept soil moisture levels at or above field capacity. During the March 1987 storm the formation of a number of shallow surface failures occurred in the upper catchment (figure 5.15) with the large landslide that formed the channel blockage most likely occurring late in the rainfall event. The blockage of the channel formed a lake trapping the in-transit sediments and forming a swampy bog which remained throughout the following winter months and into the lead-up to the summer period prior to the Bola event. The total volume of sediment delivered from the catchment during the 1987 event and the trapping efficiency of the reservoir may not be accurately quantified due to the unknown timing for the blockage, although for the Bola event that followed a better probability exists.

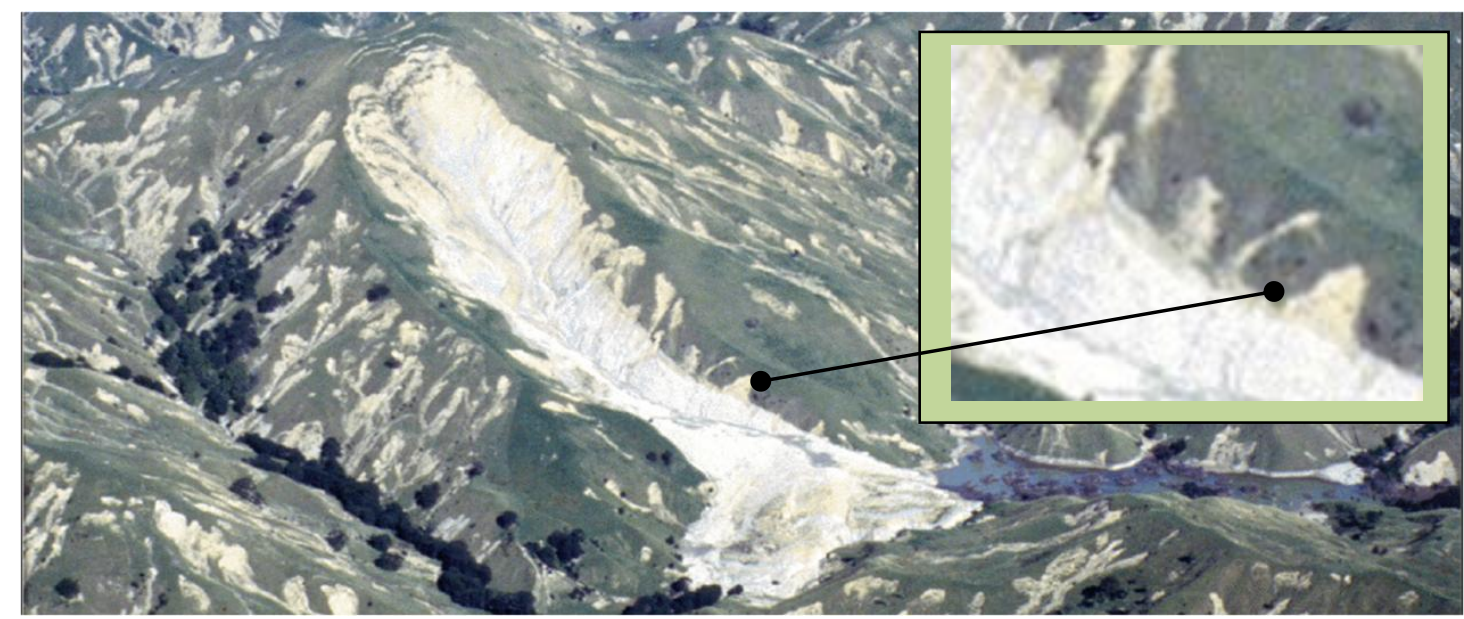

Figure 5.15. The Mangakiore landslide following Cyclone Bola. The freshness and depth of the scar is indicated by the lighter and less weathered colour. Occurrence of the landslide during the Bola event is evident as it has cut across some of the shallow landslide scars, while the debris tails of other shallow landslides have run out over the deep-seated landslide scar (refer insert). Some of these shallow landslides may also date from the 1987 storm event (photo, N. Trustrum 1988).

Soil conditions in the lead up to the Bola storm were drier than in the previous year for this period. Heavy rainfall started on the $6^{\text {th }}$ of March 1988 with the onset of Cyclone Bola, followed by three more days of intense rainfall. The storm had its peak intensity on the $7^{\text {th }}$ of March 1988 when the rain gauge closest to the Mangakiore field site recorded $304.7 \mathrm{~mm}$ for the $24 \mathrm{hr}$ period. Following the 1987 storm, the Mangakiore landslide site would likely have exhibited tension cracks similar to those of the Anaura Bay landslide seen in figure 5.16 and the lower slope was primed by the 
partial failure of that 1987 event. As the Bola storm event was over four days with its peak on the $7^{\text {th }}$ of March the major failure of the Mangakiore landslide would likely have occurred early in the Bola storm and provided a total blockage of the upper catchment (Table 5.11). The movement of the Mangakiore landslide can be described as a rapid deep-seated translational debris slide/flow, where the material mobilised in the movement has broken up due to its speed and has impacted the opposite slope causing a type 'Il' channel blockage as per the Costa and Schuster (1988) definition (refer, chapter two).

\begin{tabular}{|l|l|l|l|l|l|l|}
\hline & $\begin{array}{l}\text { February } \\
1987\end{array}$ & $\begin{array}{l}\text { March } \\
1987\end{array}$ & $\begin{array}{l}22 \text { March } \\
1987\end{array}$ & $\begin{array}{l}\text { February } \\
1988\end{array}$ & $\begin{array}{l}\text { March } \\
1988\end{array}$ & $\begin{array}{l}7 \text { March } \\
1988 \\
\text { (Bola) }\end{array}$ \\
\hline $\begin{array}{l}24 \mathrm{hr} \text { Rainfall } \\
\text { total }\end{array}$ & & $246.9 \mathrm{~mm}$ & & & $304.7 \mathrm{~mm}$ \\
\hline $\begin{array}{l}\text { Soil Moisture } \\
\text { (runoff) }\end{array}$ & $150 \mathrm{~mm}$ & $478.7 \mathrm{~mm}$ & & $103.8 \mathrm{~mm}$ & & $214.1 \mathrm{~mm}$ \\
\hline $\begin{array}{l}\text { Recorded } \\
\text { monthly } \\
\text { rainfall }\end{array}$ & & & $349.8 \mathrm{~mm}$ & $664.4 \mathrm{~mm}$ & \\
\hline
\end{tabular}

Table 5.11. Rainfall and soil moisture data from closest rain gauge to Mangakiore field site (data taken from NIWA)

The Cyclone Bola storm in 1988 caused widespread shallow surface failures $(\leq 1 \mathrm{~m})$ within the catchment and the study by Jones (2009) estimates that a delivery ratio of $25 \%$ of this sediment mobilised in the landscape was to reach the channel. The Jones study (2009) calculated that from the shallow landsliding that occurred during the Bola event, a total volume of $129 \times 10^{3} \mathrm{~m}^{3}$ of sediment was delivered to the channel and that these sediments were derived from the slopes of the catchment upstream of the Mangakiore deep-seated landslide. In this study, the estimate of the volumes of sediment trapped by the landslide-dam during the Bola event is slightly higher at $137.64 \times 10^{3} \mathrm{~m}^{3}$ and when compared to the estimate of Jones (2009), would suggest that either a greater volume of sediment was delivered to the channel or a trapping efficiency of $106 \%$ existed. This greater trapping efficiency is not probable and it is the suggestion of this study, that the additional sediment trapped by the dam was derived from old storm sediments mobilised during the prior 1987 storm event. These sediments had found temporary storage on the lower slopes or in the river banks and bed of the upper catchment and were then remobilised during the Bola storm. While there are errors inherent in both studies results, comparisons between the two results 
however gives confidence in the methodologies for the modelling and volume calculations used in this study.

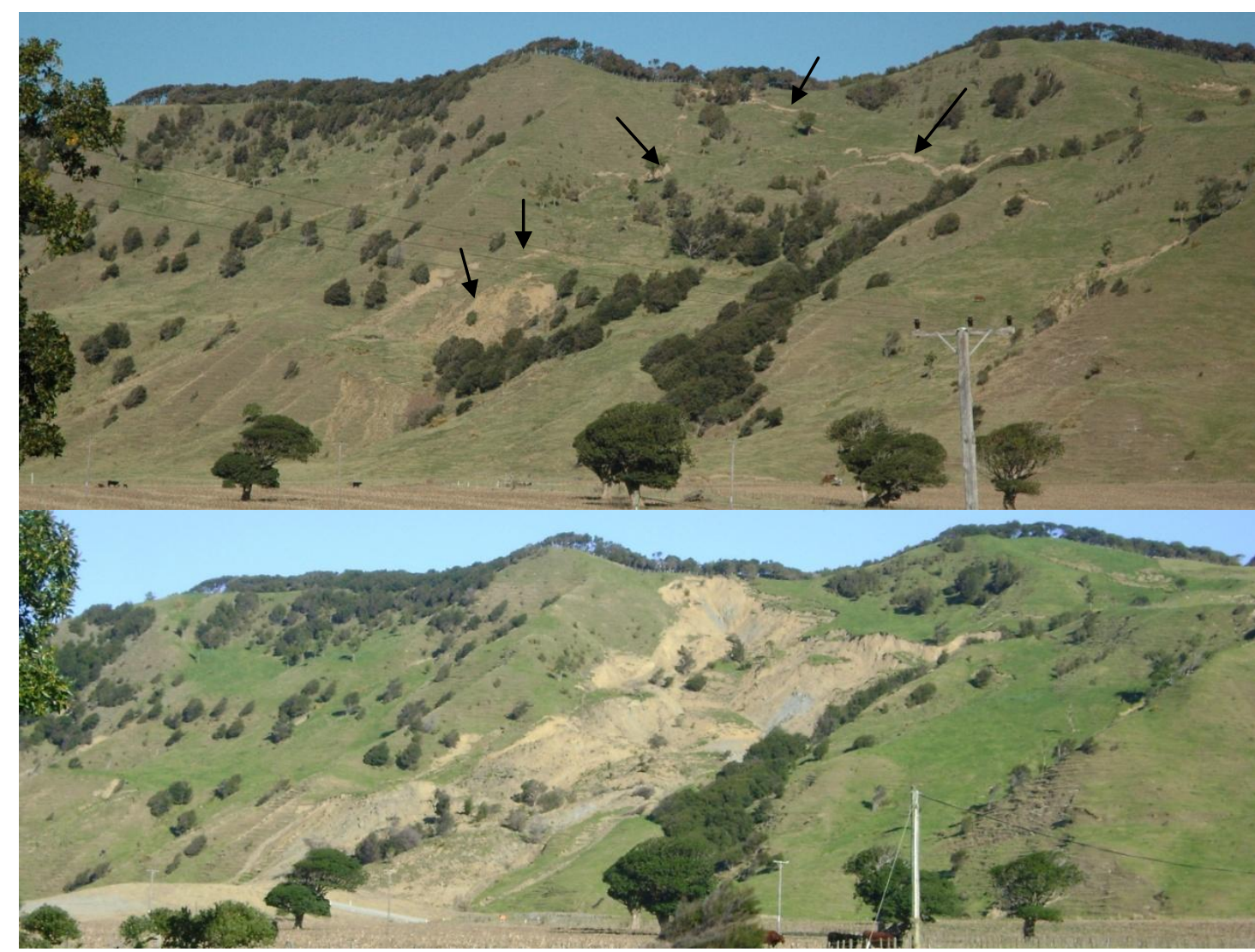

Figure 5.16. The Anaura Bay landslide. The top photo taken in 2009 with the arrows indicating the tension cracks which resulted from the earlier storm activity and which have primed the slope for failure. The bottom photo shows the landslide that occurred following the 2010 storm event, with the form of the landslide closely following the outline of the tension cracks of the earlier storm event (photos by Mike Page, 2009, 2010).

The subsequent breach of the Mangakiore dam was by the landowner using a digger during the following summer and was only speeding up a process that was already well under way. As discussed in chapter two, landslide-dams of this type, size and material are usually only able to persist for a few days to months, especially where the head catchment area is large as is the case for this site. So as a result of this early breach, there is confidence that the Bola storm event is recorded in the sediments and has been preserved. Further, the timings for the onset of the storm and the dam breach being well known put clear and precise constraints on the record. With the lake drained, the sediment body became an aerial feature and dried out, allowing a soil to form. The Bola infill took the sediment level to $0.90 \mathrm{~m}$ of the current surface. The remaining infill of the core sequence is due to the overbank deposition of sediments 
from storms in subsequent years, with the storm of the 1991 year being responsible for the bulk of this part of the sequence. Stream levels will have been still quite high relative to the sediment body surface due to the limited time available for the river's incision of the sediment body. Also, there would have been a large volume of sediment dislodged from the Bola storm still in active storage in the landscape. While it is not possible to quantify the trapping efficiency for the breached dam, the dam would have still provided a substantial barrier, even to high stream flows, and the lower slope angle of the sediment body would allow for stream power to be reduced.

\subsection{Key findings}

\begin{tabular}{|c|c|c|c|c|}
\hline $\begin{array}{l}\text { Depth } \\
\text { (m) }\end{array}$ & $\begin{array}{l}\text { Volume } \\
\left(\times 10^{3} \mathrm{~m} 3\right)\end{array}$ & $\begin{array}{l}\Delta \text { Volume } \\
\left(x_{10}^{3} \mathrm{~m} 3\right)\end{array}$ & $\begin{array}{l}\text { Sedimentation } \\
\text { rate } \\
(\mathrm{m} 3 / \mathrm{ha} / \mathrm{yr})\end{array}$ & Observation \\
\hline $\mathbf{0}$ & 249.90 & 34.21 & 2.23 & Contemporary surface \\
\hline 0.68 & 215.65 & 23.83 & 1.55 & $\begin{array}{l}\text { Dam breach surface } \\
\text { (Jan 1989) }\end{array}$ \\
\hline 0.90 & 191.82 & 137.64 & 197.43 & $\begin{array}{l}\text { Top of Bola event sediments } \\
\left(10^{\text {th }} \text { March 1988) }\right.\end{array}$ \\
\hline 4.85 & 54.17 & 54.17 & 70.64 & $\begin{array}{l}\text { Top of } 1987 \text { event infill pre Bola } \\
\left(8^{\text {th }} \text { March 1987) }\right.\end{array}$ \\
\hline 6.65 & 0 & 0 & 0 & Palaeo-valley surface (1974) \\
\hline 7.0 & & & & Weathered bedrock \\
\hline
\end{tabular}

Table 5.11 Summary of key statistics for the Mangakiore landslide-dam.

\subsection{Kopaatuaki}

The Kopaatuaki field site in the Waimata catchment is characterised by its wide valley floor and the low angle slopes of the surrounding hills as seen in the view shown in figure 5.21 and discussed in detail in the site descriptions section of chapter four. This site allows the opportunity to investigate sedimentation where two landslides in the same location have blocked the river channel. The core that was retrieved at the Kopaatuaki field site did not bottom out, so is an incomplete sequence of sedimentation. However the $7 \mathrm{~m}$ of core that was collected is a complete record of events with the exception of the initial event initiation sequence. 


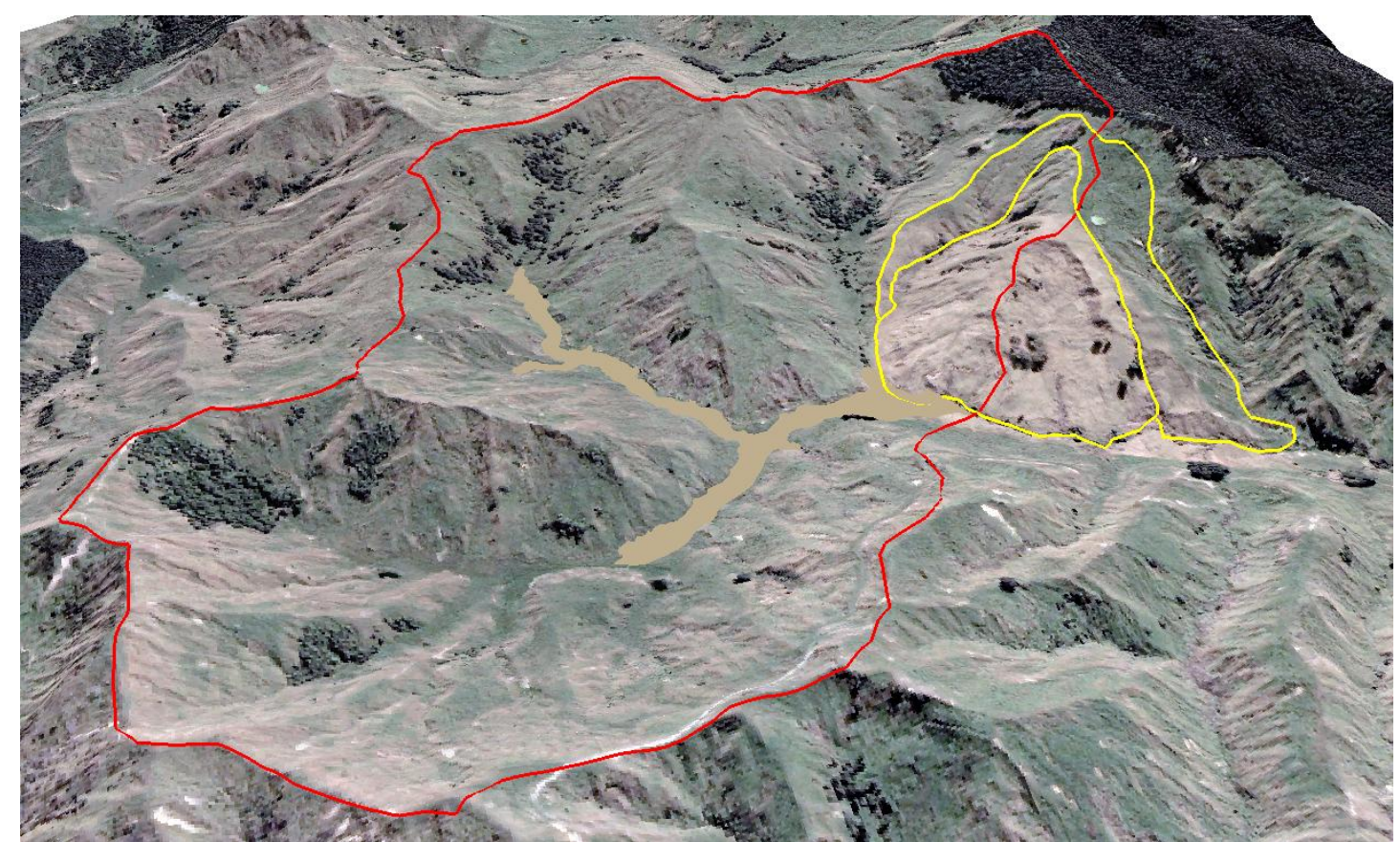

Figure 5.21. 3D model of the Kopaatuaki landscape. Image highlights the landslide outline in yellow and the catchment boundary in red, the sediment body is shaded brown.

\subsubsection{Core log and sedimentation}

Model results for infill of the palaeo-landscape and the distribution of sediments in the sediment body are shown in figure 5.22 and give an estimate for maximum infill depth at between 8 and $9 \mathrm{~m}$. At the bottom of the cored sediments at the $7 \mathrm{~m}$ mark, a thick organic layer together with the sediments immediately above, are reminiscent of the organic accumulation of the post onset phase in the Mangakiore core. This lower section of the core is interpreted as being the top of the initial infill that followed after the disturbance event which blocked the valley. This study suggests that the missing lower section of core shown as unit ' $F$ ' in figure 5.23 represents the initial rapid infill of the reservoir post valley blockage. The rate of infill stabilises once the landscape has reached a new equilibrium post event and as the slope material in the upper catchment, dislodged by the disturbance event that caused the landslide, is exhausted. The organic material mobilised during the storm is the last to settle out and forms a thick capping layer on the sediment. Unit ' $E$ ' falls between two time markers, however is interpreted as an extended period of rapid and regular sedimentation. Unit ' $\mathrm{D}$ ' is interpreted as period of slow regular sedimentation that is interrupted by four event deposit sequences. These event layers appear in the core as layers of disturbance within the sediment where texture has changed showing higher sand sized grain content and organics. 


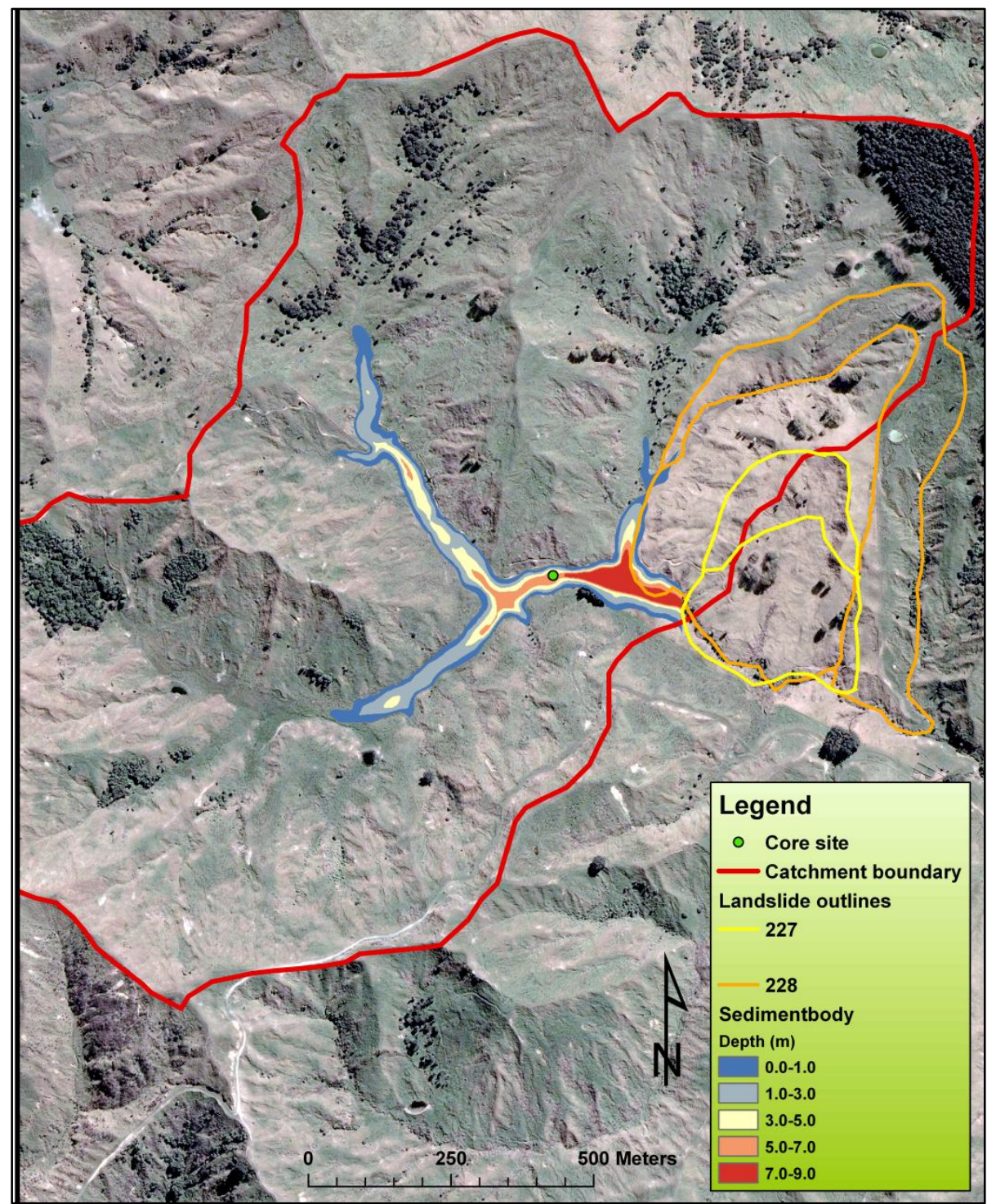

Figure 5.22. Kopaatuaki site showing landslides and valley infill. The modelled output for the sediment deposit shows infill depths and distribution.

Extending from a depth of $4.35 \mathrm{~m}$ and the top of the last sediment pulse event, to the bottom of the overbanking sediments and palaeo-sol that represents the breach of the dam is unit ' $C$ '. This is a homogenous unit of sediments only interrupted by a thick layer of tephra that shows some signs of reworking. Unit ' $\mathrm{C}$ ' is interpreted as a period of regular uninterrupted sedimentation. Unit ' $\mathrm{B}$ ' is interpreted as the dam breach unit with the lower section showing the slowing of the sedimentation rate due to overbanking deposition of sediments which blended into a dark organic palaeo-sol. The top section of the core from $1.10 \mathrm{~m}$ depth to $0.5 \mathrm{~m}$ is interpreted as a return to sedimentation under ponded conditions due to a reactivation of the landslide and a second damming of the field site. The presence of reworked tephra at the bottom of the sequence suggests some storm activity and disturbance in the landscape. The 
second breach is evident in the core at $0.3 \mathrm{~m}$ and is topped with overbanking sediments shown as unit ' $M$ ', again topped with a modern organic soil. It is possible that there has been some removal of sediment in between the time of the first breach and the second activation.

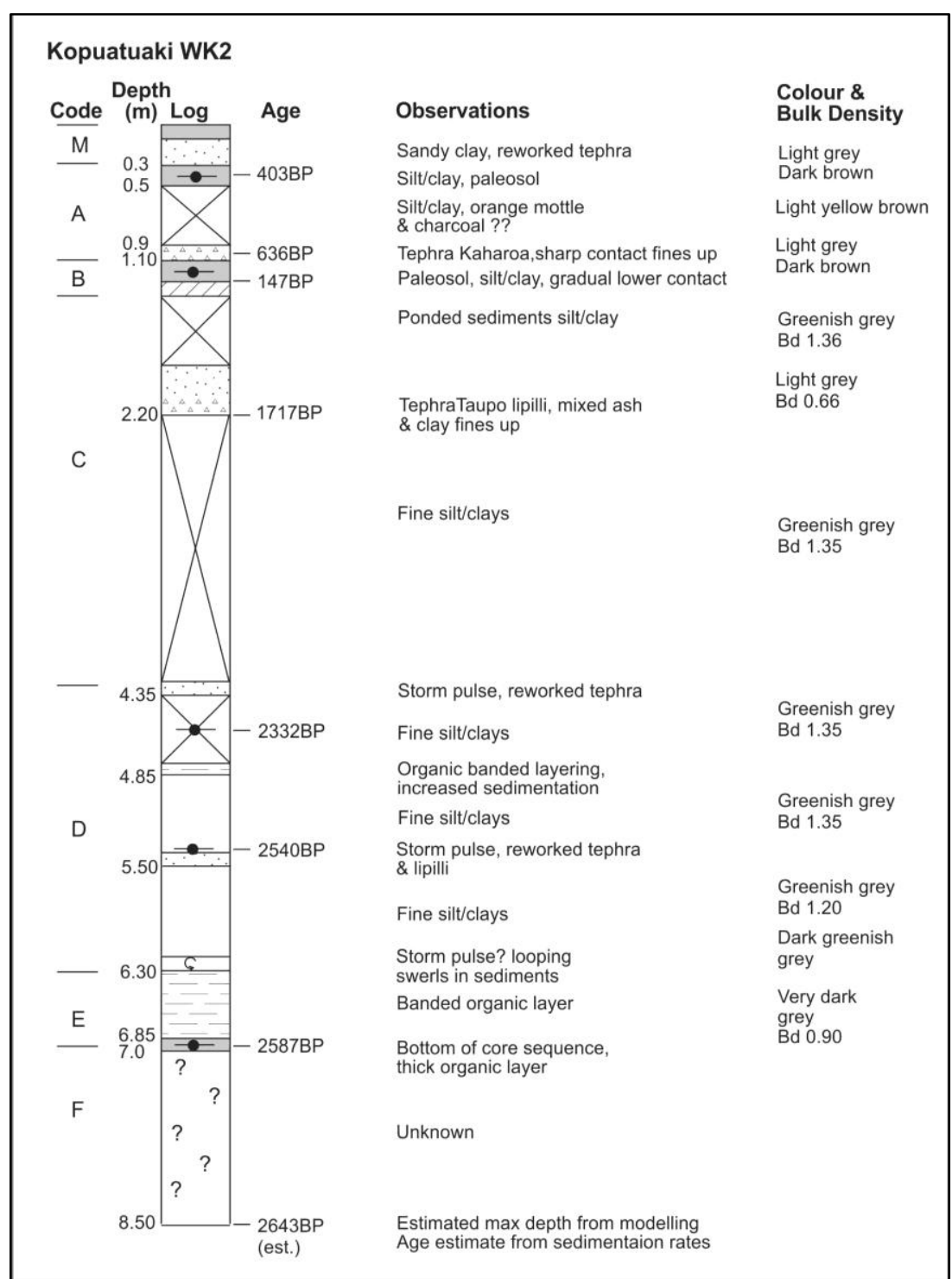

Figure 5.23. Core log for the Kopaatuaki sediment body.

\begin{tabular}{|c|c|c|c|c|c|c|}
\hline $\begin{array}{l}\text { Depth } \\
\text { (m) }\end{array}$ & Code & Material & $\begin{array}{l}\text { Fraction of } \\
\text { sample } \\
\text { used }\end{array}$ & \begin{tabular}{|l} 
Calibrated \\
$2 \sigma$ age range \\
(cal. yr BP)
\end{tabular} & $\begin{array}{l}2 \sigma \text { age } \\
\text { midpoint } \\
\text { (cal. yr } \\
\text { BP) }\end{array}$ & Reference \\
\hline 0.48 & WK2-0.48 & Bulk soil & Humic acids & 444-361 & $403 \pm 41$ & NZA 35830 \\
\hline 0.90 & Kaharoa & Tephra & & 648-624 & $636 \pm 12$ & Wilson (1993) \\
\hline 1.10 & WK2-1.10 & Bulk soil & Humic acids & 1240-1054 & $1147 \pm 93$ & NZA 34724 \\
\hline 2.20 & Taupo & Tephra & & \begin{tabular}{|l|}
$1688-1748$ \\
\end{tabular} & $1717 \pm 12$ & Wilson (1993) \\
\hline 4.60 & WK2-4.60 & Wood & Cellulose & $2358-2305$ & $2372 \pm 12$ & NZA 34557 \\
\hline 5.40 & WK2-5.40 & Wood & Cellulose & 2592-2487 & $2540 \pm 50$ & NZA 34558 \\
\hline 6.95 & WK2-6.95 & Peat & & $2718-2455$ & $2587 \pm 103$ & NZA 34554 \\
\hline
\end{tabular}

Table 5.21. Kopaatuaki core log age model. 


\subsubsection{Analysis and observations}

The total time span for channel blockage is an estimated 2488 cal. years BP and with a total volume for the sediment body of $245.25 \times 10^{3} \mathrm{~m}^{3}$ and a mean sediment delivery rate for the catchment at $0.63 \mathrm{~m}^{3} / \mathrm{ha} / \mathrm{yr}$ can be calculated. During this period of time the catchment would have been under natural forest cover. Initial infill of the valley following the first and largest of the two landslides shows that there was a rapid infill response post event. The onset of this landslide occurs outside a high storm activity period, as indicated in the Tutira record and discussed in chapter 3 and is approximately 200 years after the last period of increased storminess. With a number of active faults in the region of the failure, the initial landslide movement could likely have been initiated by an earth shaking event, with slope priming by the removal of toe support. Sediments and organic material in the lowest section of the core sequence are consistent with the phase in the Mangakiore sequence that indicated the end of the rapid deposition of sediments mobilised in the landscape following the disturbance event. While the core does not reach bedrock, modelling estimates of depth, supported by back calculation using the sedimentation rate for the initial infill put the maximum depth for the site at $8.5 \mathrm{~m}$.

The curves in figure 5.24 for the total volume (blue) and change in volume (red) suggest that a period of steady sedimentation occurs until approximately 2300 BP. After this point these curves show a sharp rise in sediment volumes. This period of increased sediment volume change occurs during a period of high storm frequency in the Tutira storm record. This trend for higher sedimentation is also echoed in the rate of sedimentation for the catchment. The green curve in figure 5.24 shows a rise in the sedimentation rate for the period between 2332 BPP and the Taupo tephra at 1717 BP. This trend is however not clear in the sediment characteristics of the core. Both volume and rate curves start to drop away post the Taupo marker, possibly caused by dam incision and rising lake level due to higher infill, reducing the trapping efficiency of the reservoir. Dam breach occurs approximately 1147 years BP for a dam life of 1454 years and a total infill volume for the first dam of $181.11 \times 10^{3} \mathrm{~m}^{3}$. This represents an average sedimentation rate of $0.74 \mathrm{~m}^{3} / \mathrm{ha} / \mathrm{yr}$, for a period that included four large disturbance events and a high storm frequency period. Rates of sedimentation for the catchment over this period indicate that background 
sedimentation rates are $0.40 \mathrm{~m}^{3} / \mathrm{ha} / \mathrm{yr}$, with periods of high storm activity doubling this to approximately $0.74 \mathrm{~m}^{3} / \mathrm{ha} / \mathrm{yr}$.

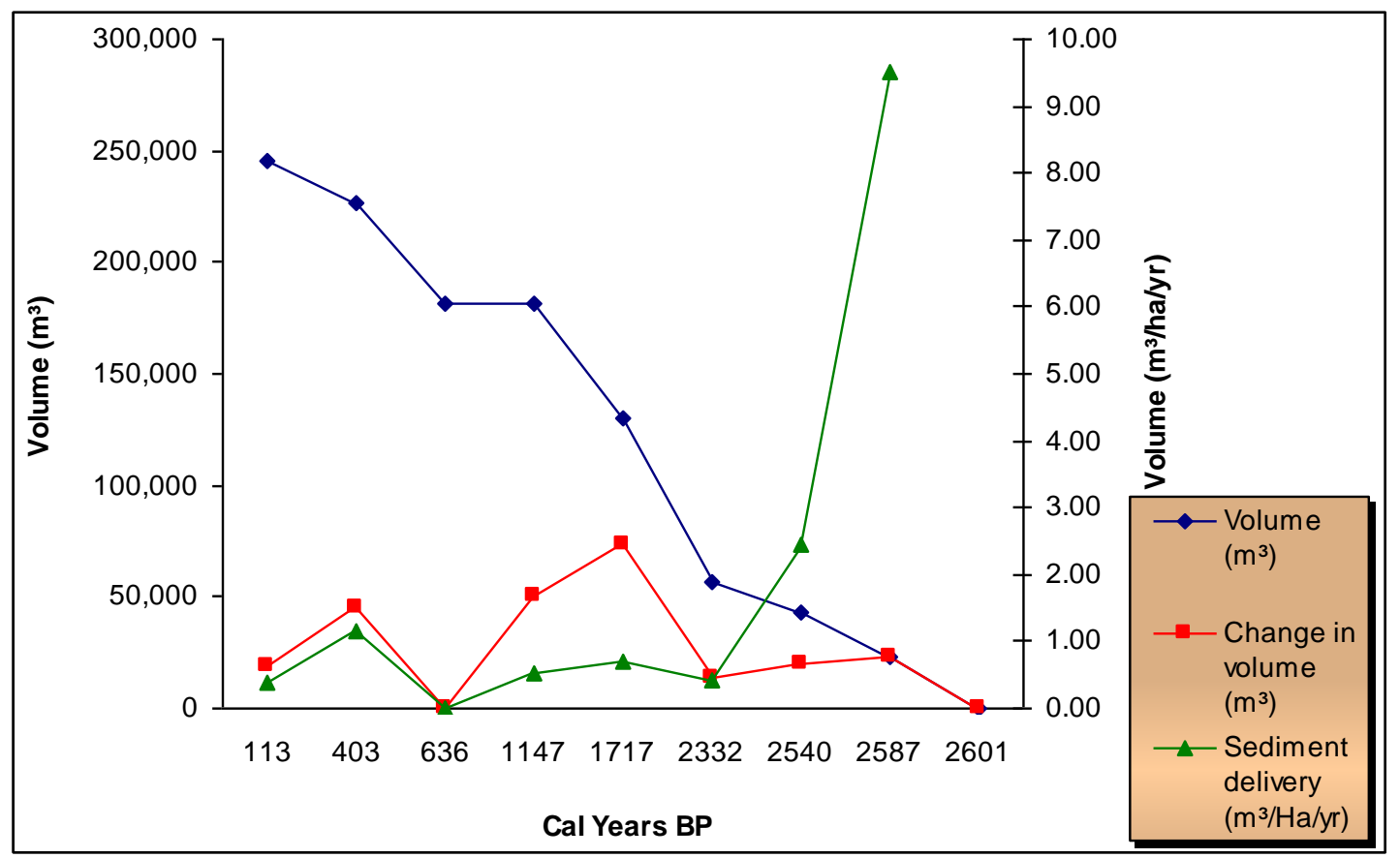

Figure 5.24. Sedimentation curves for the Kopaatuaki sediment body. The blue curve shows the volume of infill over time, while the red curve shows the change in volume between time markers. The green curve is the mean sedimentation rate for the catchment between periods calculated as $\mathrm{m}^{3} / \mathrm{ha} / \mathrm{yr}$.

The dam breach time at approximately 1100 years BP occurs at the end of a high storm frequency period in the Tutira record. It is the high frequency of dam overtopping in conjunction with the higher lake level due to infill that is responsible for the dam breach. The activation of the second landslide and blockage of the site also occurs during a period of high storm frequency at 700-500 years BP as indicated in the Tutira record. The second failure is a reactivation of the initial landslide movement, as a likely a result of increased ground water pressures and removal of toe support. This hypothesis is supported by the indication of onset time which coincides with a period of increased storm activity in the Tutira record. The second blockage lasted for an estimated 200 year period and accumulated $44.96 \times 10^{3} \mathrm{~m}^{3}$ of sediment as shown in table 5.22 . 


\subsection{Key findings}

\begin{tabular}{|c|c|c|c|c|c|c|}
\hline $\begin{array}{l}\text { Depth } \\
\text { (m) }\end{array}$ & Code & $\begin{array}{l}\text { Age } \\
\text { (BP/ } \\
\text { calendar) }\end{array}$ & $\begin{array}{l}\text { Volume } \\
\left(x_{10}^{3} \mathrm{~m} 3\right)\end{array}$ & $\begin{array}{l}\Delta \text { Volume } \\
\left(\mathbf{x}^{3} \mathbf{3}^{\mathbf{m} 3}\right)\end{array}$ & $\begin{array}{l}\text { Catchment } \\
\text { sedimentation } \\
\text { rate } \\
(\mathrm{m} 3 / \mathrm{ha} / \mathrm{yr})\end{array}$ & Observation \\
\hline $\mathbf{0}$ & & $\begin{array}{l}113 / 1838 \\
A D\end{array}$ & & & & \\
\hline 0.48 & M & $\begin{array}{l}403 / \\
1548 \mathrm{AD}\end{array}$ & 245.23 & 19.15 & 0.28 & Breach \\
\hline 0.90 & $\mathrm{~A}$ & $\begin{array}{l}636 / \\
1314 \mathrm{AD}\end{array}$ & 226.08 & 44.96 & 1.14 & $\begin{array}{l}\text { Second event and } \\
\text { period of increased } \\
\text { storm activity }\end{array}$ \\
\hline 1.10 & $\mathrm{~B}$ & $\begin{array}{l}1147 / \\
803 \mathrm{AD}\end{array}$ & 181.12 & 50.86 & 0.53 & $\begin{array}{l}\text { Breach and period of } \\
\text { increased storm } \\
\text { activity }\end{array}$ \\
\hline 2.20 & $\mathrm{C}$ & $\begin{array}{l}1717 / \\
233 \mathrm{AD}\end{array}$ & 130.27 & 73.40 & 0.71 & $\begin{array}{l}\text { Period of increased } \\
\text { storm activity }\end{array}$ \\
\hline 4.60 & $\mathrm{D}$ & $\begin{array}{l}2332 / \\
383 \mathrm{BC}\end{array}$ & 56.86 & 14.12 & 0.40 & $\begin{array}{l}4 \text { extreme sediment } \\
\text { pulses during } \\
\text { extended period of } \\
\text { low sedimentation }\end{array}$ \\
\hline 5.40 & $\mathrm{E}$ & $\begin{array}{l}2540 / \\
591 \mathrm{BC}\end{array}$ & 42.74 & 19.51 & 2.46 & Rapid sedimentation \\
\hline 7.00 & $\mathrm{~F}$ & $\begin{array}{l}2587 / \\
638 \mathrm{BC}\end{array}$ & 23.23 & 23.23 & 9.51 & Event sediments \\
\hline 8.50 & $\mathrm{P}$ & $\begin{array}{l}\text { 2601/ } \\
\text { 694BC }\end{array}$ & 0 & 0 & 0 & Palaeo-valley surface \\
\hline
\end{tabular}

Table 5.22. Summary of key statistics for the Kopaatuaki landslide-dam.

\subsection{Tangihau}

The Tangihau field site on the far western boundary of the Waipaoa catchment is a small steep catchment. This site is characterised by a large translational landslide that has failed on the bedding surface of the alternating layers of sandstone and mudstones as described in chapter four. This site is also characterised by having two landslides that have produced two separate sediment bodies. The lower sediment body is associated with the main slope failure and is the older event. The upper sediment body is associated with an independent second and much smaller failure that is likely to be associated to changes in the stream gradient and stream incision associated with the infill and breach of the lower reservoir. The image in figure 5.31 is taken from the top of the main landslide scarp looking down the landslide body with the restriction point and sediment body out of sight at the bottom of the valley. 


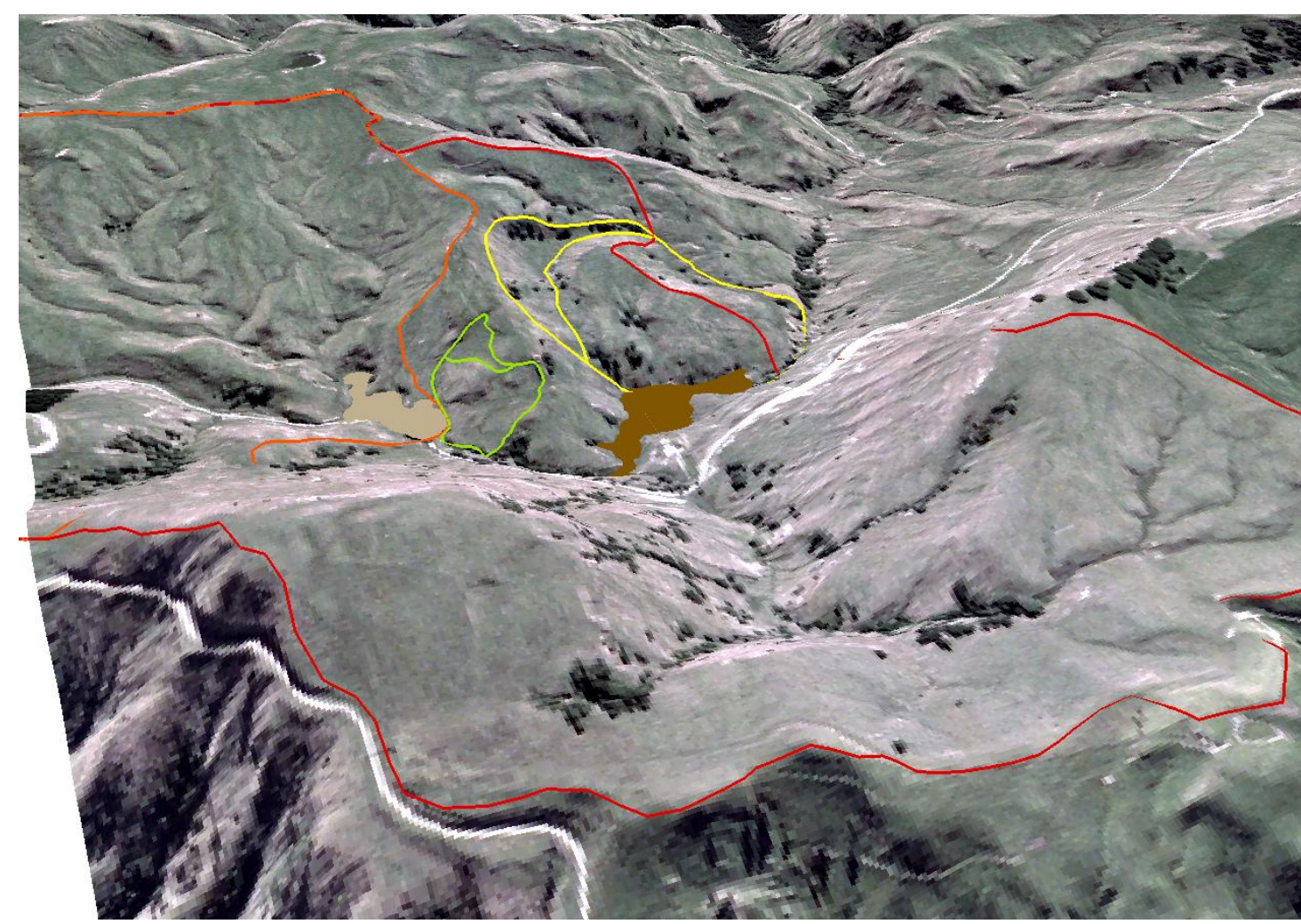

Figure 5.31. 3D model of the Tangihau landscape. Image highlights the lower landslide outlined in yellow and the upper one in green. The catchment boundary is drawn in red for the full catchment and orange for the top catchment, the sediment body is shaded brown for the lower sediment body where the core was taken and beige for the upper sediment body.

\subsection{Core log and sedimentation}

Taking the lowest section of core from the Tangihau field site, the drill struggled through the last half metre only to free up at the bottom of its length. When the core was split it was possible to see that the core had not bottomed out in bed rock, but had gone through what has been interpreted as a layer of landslide debris that sits on top of the palaeo-valley floor (refer to figure 5.33). Modelling of the infill, shown in figure 5.32 estimates that where the core was drilled, was to the side of the deepest section of the valley and that the maximum depth of the sediment body was estimated to be between 7-9 $\mathrm{m}$ depth. Upstream of the drilling point the valley widens and is not influenced by landslide debris. Where the core was taken, it is estimated that less than half a meter of the sequence is missing and this would be palaeo-valley soil development and not infill sediments. The lowest section of the core shows a unit of fine-grained sediment with reworked Waimahia tephra that is capped with a thick layer of plant material interpreted as the palaeo-forest floor leaf litter. The top section 
of the deepest section of core being made up of a blocky clast supported unit with a fine silt/clay matrix. This section of core is interpreted as the landslide debris and represents the landslide event. The lowest section of sediment infill that would have occurred immediately after the disturbance event that caused the landslide, is not represented in the core sequence. Volume estimates from the model of the palaeovalley give a total volume of $37.11 \times 10^{3} \mathrm{~m}^{3}$ of infill to the bottom of the core.

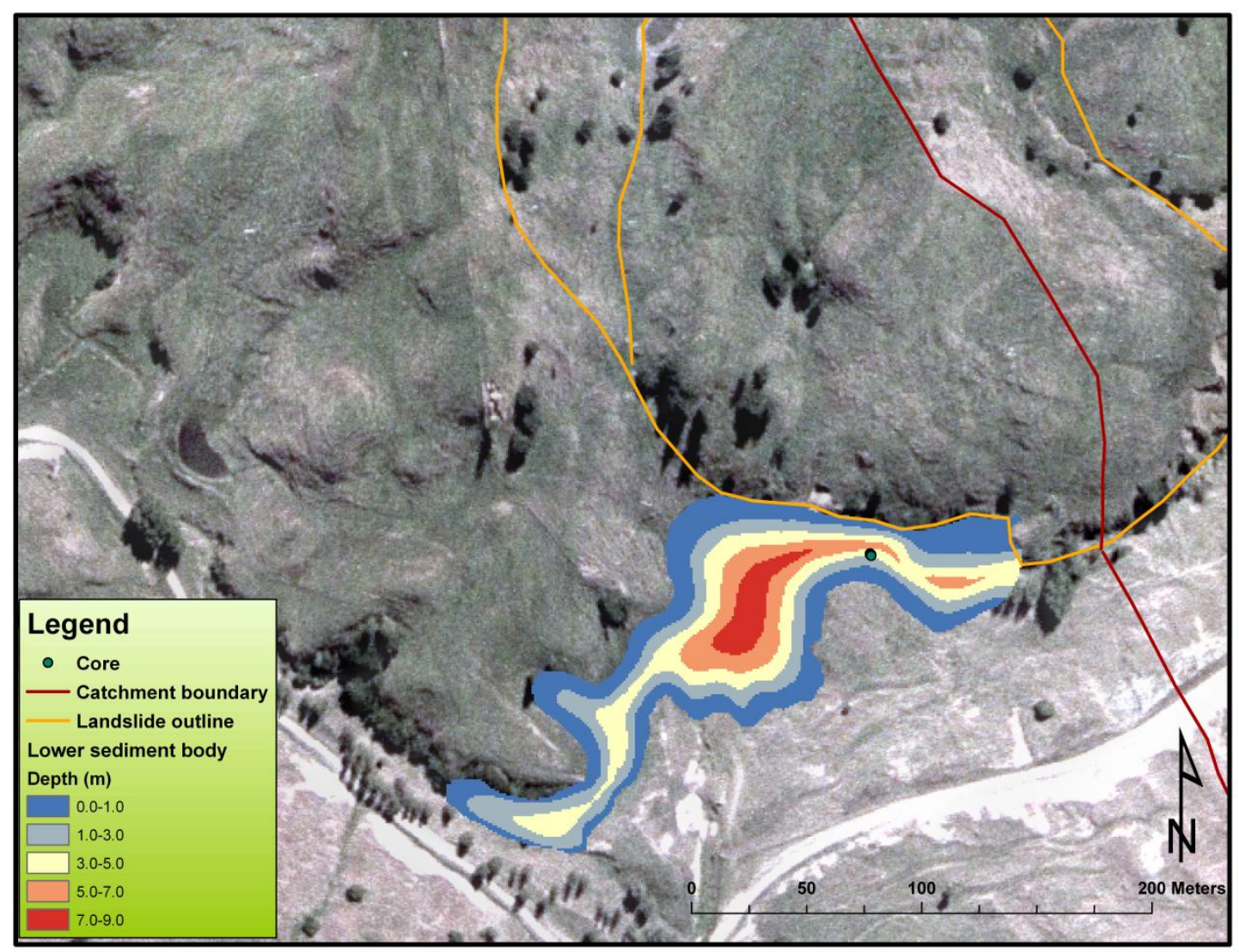

Figure 5.32. The Tangihau sedimentbody infill and distribution. Model of the infill for the site with the landslide outline and catchment boundary shown.

The estimate of sediment infill not represented in the core may be somewhat less than the volume mentioned above, as the model of the palaeo-valley closest to the landslide and to the right of the core point as seen in figure 5.32 may contain more landslide debris than is represented by the model of infill. The sediments in the core above the landslide debris show the characteristic lacustrine sediment form, as seen in other cores of this study. Unit ' $\mathrm{D}$ ' shown in figure 5.33 contains $11.02 \times 10^{3} \mathrm{~m}^{3}$ of fine silt/clay sediment with pumice and wood fragments. This layer transitions via a gradual contact to a stratified dark organic sediment layer represented as unit ' $\mathrm{C}$ ' in figure 5.33. This unit shows signs of disturbance in the top $0.6 \mathrm{~m}$ where there appear 
to be thicker light grey slit/clay layers within the dark organic rich sediment layers (refer to core photos in appendix D). The unit above makes a sharp contact at the sediment boundary and extends up to $0.85 \mathrm{~m}$ depth as unit ' $\mathrm{B}$ ' in the core log (figure 5.33). This unit is described as a homogenous silt/clay unit that is only broken by the deposition of an airfall tephra at $1.38 \mathrm{~m}$ identified by electron micro probe analysis as the Taupo event of 1717 cal. years BP (refer appendix E for micro probe results). The bottom of the Taupo tephra is a light grey sandy layer that fines upwards into a grey ash. This ash then gradually blends into the continuation of the silty/clays of the lacustrine deposition sequence.

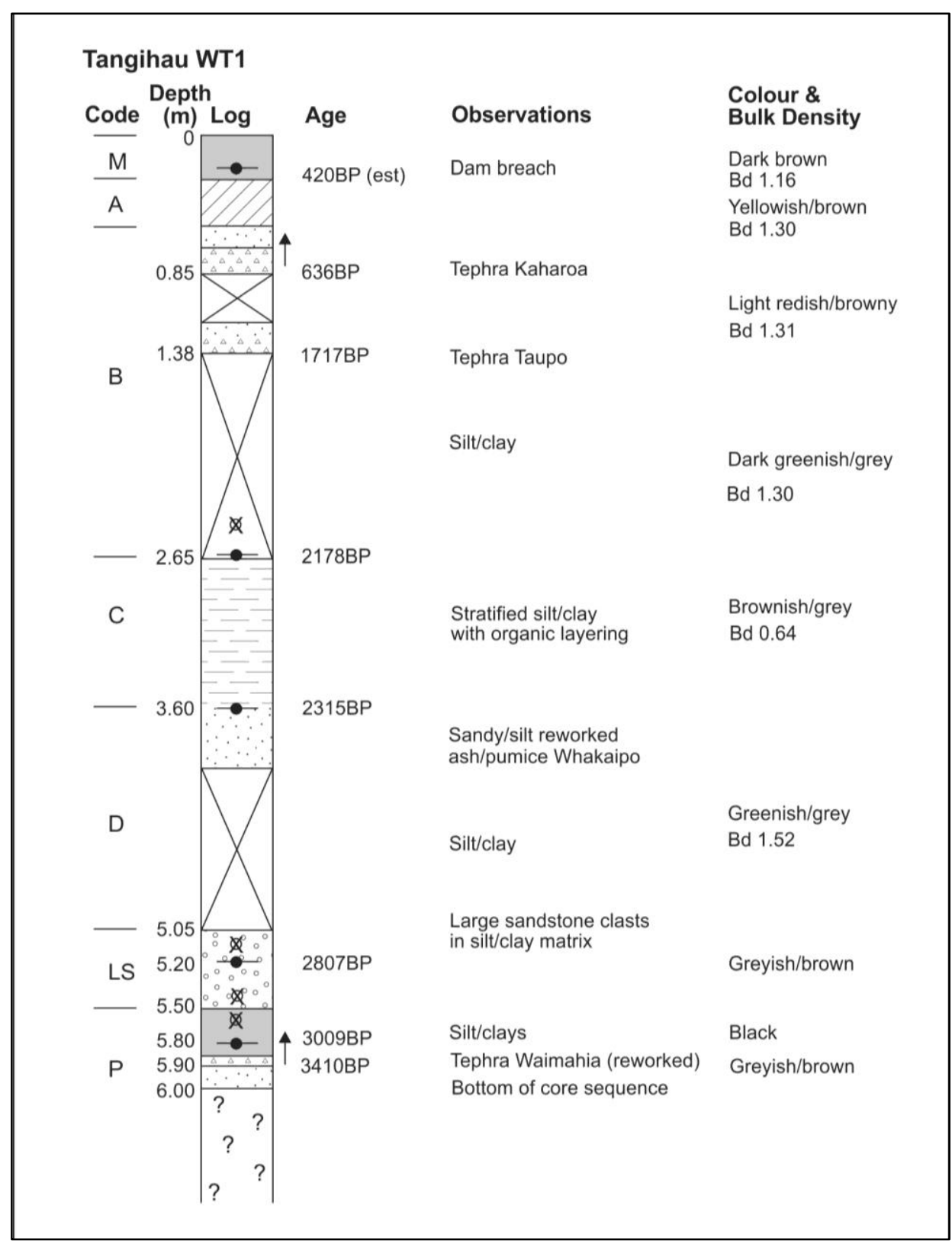

Figure 5.33. Core log for the Tangihau sediment body. 
The lowest part of the next unit (unit 'A') makes a sharp contact and starts with another airfall tephra made up of ash and pumice lapilli (4-6 mm). This tephra is identified as the Kaharoa eruption at $636 \mathrm{cal}$. years BP by stratigraphic position and through geochemical analysis and shows some reworking. Unit ' $A$ ' is characterised by a more coarse grained sediment with the top of the unit incorporating bands of reworked tephra and sands. The top section of the top core is a thick dark organic soil (unit ' $M$ ') which makes a diffuse contact to the lower unit and is made up of a coarser sandy/silt. For the sediment body of the upper landslide-dam there has been no stratigraphic column made as few notes were taken in the field. The upper sediment body was initially considered to be a modern feature and of no interest to the study. Later analysis of site data for the lower sediment body and the radiocarbon age provided by the sample taken in the field showed that this was a much older feature. The sediment profile data for the upper sediment body was not collected, with age estimates coming from a wood sample collected in the field from a depth of $0.80 \mathrm{~m}$ where the stream had cut into the sediment package. For this site, further age estimates are gained by modelling sedimentation, with ages for onset and termination being derived from known sedimentation rates from the lower site. A photo of the exposure that was examined in the field and where the wood sample was taken is provided in the appendix D.

\begin{tabular}{|l|l|l|l|l|l|l|}
\hline $\begin{array}{l}\text { Depth } \\
(\mathbf{m})\end{array}$ & Code & Material & $\begin{array}{l}\text { Fraction } \\
\text { of sample } \\
\text { used }\end{array}$ & $\begin{array}{l}\text { Calibrated } \\
\mathbf{2 \sigma} \text { age } \\
\text { range } \\
\text { (cal. yr } \\
\text { BP) }\end{array}$ & $\begin{array}{l}\mathbf{2 \sigma} \text { age } \\
\text { midpoint } \\
\text { (cal. yr } \\
\text { BP) }\end{array}$ & Reference \\
\hline $\mathbf{0 . 8 5}$ & Kaharoa & Tephra & & $648-624$ & $636 \pm 12$ & Wilson (1993) \\
\hline $\mathbf{1 . 3 8}$ & Taupo & Tephra & & $1688-1748$ & $1717 \pm 12$ & Wilson (1993) \\
\hline $\mathbf{2 . 6 5}$ & WT1-2.70 & Peat & Cellulose & $2233-2123$ & $2178 \pm 50$ & NZA 35377 \\
\hline $\mathbf{3 . 6 0}$ & WT1-3.60 & Wood & Cellulose & $2329-2301$ & $2315 \pm 14$ & NZA 34551 \\
\hline $\mathbf{5 . 2 0}$ & WT1-5.20 & Wood & Cellulose & $2860-2754$ & $2807 \pm 53$ & NZA 35372 \\
\hline $\mathbf{5 . 8 0}$ & WT1-5.80 & Wood & Cellulose & $3071-2947$ & $3009 \pm 62$ & NZA 34553 \\
\hline $\mathbf{6 . 0 0}$ & Waimahia & Tephra & & $3450-3370$ & $3410 \pm 40$ & Wilson (1993) \\
\hline
\end{tabular}

Table 5.31. Tangihau core log age model.

\subsection{Analysis and observations}

The landslide that blocked the valley creating the lower Tangihau landslide-dam lake occurred at approximately the same time as Lowe and Walker (1992) estimate Lake Waikaremoana was formed. The age estimate for Tangihau at 3400 cal. years BP 
stems from the ages gained from radiocarbon dates taken from the palaeo-valley floor and that of wood fragments incorporated in material identified as concurrent with the landslide event taken from the core and supported by the debris overlaying the Waimahia Tephra. The age of a sample of wood taken directly from the landslide itself provided a much younger age of approximately 600 years later and is considered to be a sampling error as the age is inconsistent with all other radiocarbon ages collected throughout the sediment core. In total, the landslide-dam existed for an estimated 2774 years and accumulated a total volume of $101.10 \times 10^{3} \mathrm{~m}^{3}$ of finegrained sediments. The period of time from dam formation to the first lacustrine sediment sequence in the core, unit 'LS', is 200 years. This 200 year period, post dam formation is a high storm activity period in the Tutira storm record and in the Tangiahu core is evidenced by the high rate of modelled infill as shown in figure 5.34. The top of the landslide material and the bottom of the sediment sequence in the core starts at 2807 cal. years BP (unit 'D') and is interpreted as a period of slow regular accumulation. This is seen in the reduced slope of change in volume curve (red) and the negative slope of the sediment delivery per hectare (green) in figure 5.34. The characteristics of these sediments are interpreted as being deposited during a period of low storm activity and slow regular sediment delivery to a shallow lake.

From 2300-2100 cal. years BP (unit ' $C$ ') there is a shift to high rates of accumulation as indicated in the sediment core and seen in the sediment volume curve (blue) and the sediment rate per hectare curve (Green) in figure 5.34. The core showed disturbance in the sediment layers at this time as discussed in the previous section and seen in the core log photos (refer appendix D). During this time period there is no indication of increased storm activity in the Tutira core. The high activity in the Tangihau core may indicate a period of localised storm activity. However, this period of activity from 2300-2100 also shows up in the cores of Monck Road and Kopaatuaki as disturbance events with increased sedimentation and therefore may also be related to other disturbance activity such as ground shaking from earthquakes. In comparison from the time markers at $2.65 \mathrm{~m}(2178 \mathrm{BP})$ and $1.38 \mathrm{~m}(1717 \mathrm{BP}$, Taupo Tephra) there is no indication in the core sediments of high disturbance or sedimentation rates. However, from the modelling results and the time marker ages, the sediment curves show an increase in sediment volumes delivered. This period coincides and relates to the period of highest storm activity in the Tutira record which 
can serve as an explanation. Following the Taupo eruption and up to the time marker of the Kaharoa eruption, the graphs and the core show a period of slowing sedimentation rates and volumes. This may be due to a reduction in the trapping efficiency of the dam due to increased infill and the incision of the dam lowering lake level.

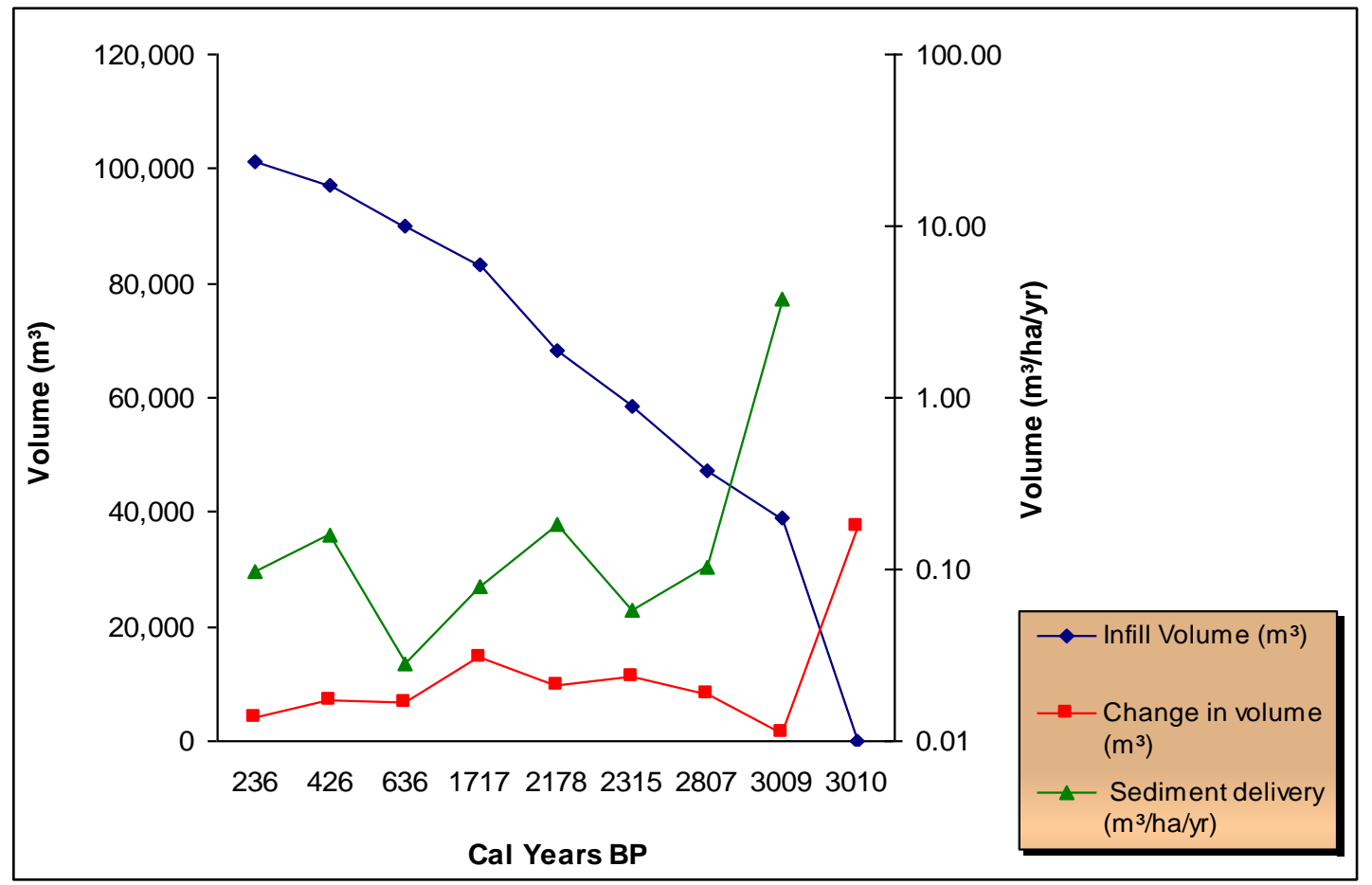

Figure 5.34. Sedimentation curves for the Tangihau sediment body. The blue curve shows the volume of infill over time, while the red curve shows the change in volume between time markers. The green curve is the mean sedimentation rate for the catchment between periods calculated as $\mathrm{m}^{3} / \mathrm{ha} / \mathrm{yr}$.

It is the suggestion of this study, that the lake was now reduced to less than one metre but still existed as a shallow pond. In the Tutira record there were two further periods of increased storm activity that occurred between the Taupo and Kaharoa time markers, yet the sediment volume curves indicate that there was a drop in activity. After the Kaharoa event the curves for sediment volume and volume change in figure 5.34 indicate a drop in activity but there is a sharp rise in the sedimentation rate per hectare. This is due to the occurrence of the second landslide-dam higher in the catchment and a reduction in the catchment area. This second dam is estimated to have occurred approximately 605 years BP reducing the catchment area for the lower dam to 218.97 ha instead of the full catchment of 398.12 ha. The formation of the second dam is also responsible for the loss of a more visible storm record in the lower lake for the time period following the Taupo eruption through to the Kaharoa event. 
From the Kaharoa event onwards the calculations for catchment sediment delivery take into account the reduced catchment area caused by the second blockage. The curves in figure 5.34 show a rise in sedimentation for unit ' $A$ ' as indicated in figure 5.33 and the time period for 636 cal. years BP (Kaharoa) and 420 cal. years BP. This increased sedimentation coincides with increased storm activity in the Tutira record. The top of unit ' $A$ ' is interpreted as the point where the total dam breach had occurred and that all sediment accumulated from this point on was event deposition and overbanking.

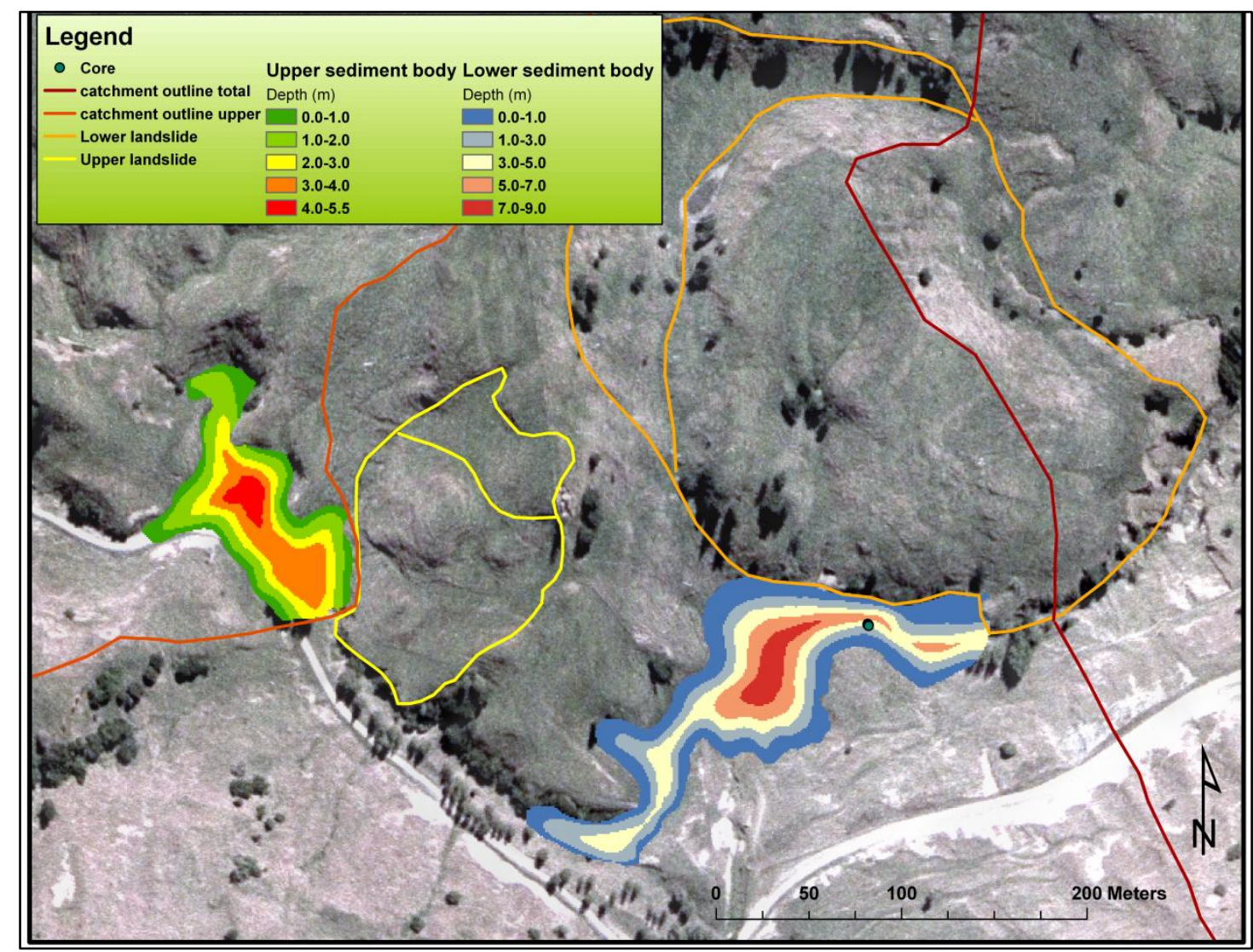

Figure 5.35. Tangihau upper and lower sediment body profiles.

It is estimated the upper dam would have lasted for approximately 485 years with the onset likely being due to storm activity as timing is coincident with the high storm activity in the Tutira record (500-700 cal. years BP). This onset age also would support the slowing down of sedimentation in the lower dam as indicated around the time of the Kaharoa tephra. In estimating the age of onset the study used the sedimentation rate for the same period of infill at the lower dam and made adjustment for change in catchment size. Termination is estimated to have occurred fully at approximately $120 \mathrm{cal}$. years BP, with the rapid infill and frequent overtopping the likely cause. This rapid infill and increased catchment response to rainfall inputs is 
coincident with European land clearances which changed catchment conditions and storm event response. This hypothesis is supported by the sharp rise in the catchment sediment delivery which is shown in figure 5.32 as a four fold increase. Tables 5.32 and 5.33 in the following section provide a summary of the modelling and core data and highlight some of the key figures and findings. Apart from the volume and age timeline data, of interest is the findings on sediment delivery for the catchment. For the Tangihau catchment covering the period of the two dams, average sedimentation for the catchment has been $0.35 \mathrm{~m}^{3} / \mathrm{ha} / \mathrm{yr}$. This rate doubles to $0.71 \mathrm{~m}^{3} / \mathrm{ha} / \mathrm{yr}$ during periods of high storm frequency.

\subsection{Key findings}

\begin{tabular}{|c|c|c|c|c|c|c|}
\hline $\begin{array}{l}\text { Depth } \\
\text { (m) }\end{array}$ & Code & $\begin{array}{l}\text { Age } \\
\text { (BP/ } \\
\text { calendar) }\end{array}$ & $\begin{array}{l}\text { Volume } \\
\left(x^{3} 0^{3} \mathrm{~m} 3\right)\end{array}$ & $\begin{array}{l}\text { AVolume } \\
\left(\mathbf{x} 10^{3} \mathrm{m3}\right)\end{array}$ & $\begin{array}{l}\text { Catchment } \\
\text { sedimentation } \\
\text { rate } \\
\left(\mathrm{m}^{3} / \mathrm{ha} / \mathrm{yr}\right)\end{array}$ & Observation \\
\hline 0 & $\mathrm{M}$ & & 101.10 & 4.07 & 0.10 & Breach \\
\hline 0.30 & $\mathrm{~A}$ & $420 /$ & 97.03 & 7.22 & 0.16 & $\begin{array}{l}\text { Reduced } \\
\text { sediment } \\
\text { accumulation due } \\
\text { to second dam }\end{array}$ \\
\hline 0.85 & $\mathrm{~B}$ & 636/1314AD & 89.82 & 6.66 & 0.03 & $\begin{array}{l}\text { Onset of second } \\
\text { dam }\end{array}$ \\
\hline 1.38 & & $1717 / 233 \mathrm{AD}$ & 83.16 & 14.75 & 0.08 & Taupo tephra \\
\hline 2.65 & $\mathrm{C}$ & $2178 / 229 B C$ & 68.41 & 9.94 & 0.18 & $\begin{array}{l}\text { Period of rapid } \\
\text { infill }\end{array}$ \\
\hline 3.60 & $\mathrm{D}$ & 2315/366BC & 58.48 & 11.20 & 0.60 & \\
\hline 5.20 & $\mathrm{LS}$ & $2807 / 858 \mathrm{BC}$ & 47.27 & 8.16 & 0.10 & $\begin{array}{l}\text { Landslide debris } \\
\text { and initial infill } \\
\text { of pond post } \\
\text { event }\end{array}$ \\
\hline 5.80 & & 3009/1060BC & 39.11 & 39.11 & 3.80 & Landslide event \\
\hline 6.00 & $\mathrm{P}$ & 3010/1061BC & & & & $\begin{array}{l}\text { Palaeo-forest } \\
\text { floor organic } \\
\text { material }\end{array}$ \\
\hline$<7.00$ & $\mathrm{P}$ & $3410 /$ & & & & $\begin{array}{l}\text { Waimahia tephra } \\
\text { at bottom of core }\end{array}$ \\
\hline
\end{tabular}

Table 5.32. Summary of key statistics for the Tangihau landslide-dam sediment body.

\begin{tabular}{|c|c|c|c|c|c|c|}
\hline $\begin{array}{l}\text { Depth } \\
\text { (m) }\end{array}$ & Code & $\begin{array}{l}\text { Age } \\
\text { (BP/ } \\
\text { calendar) }\end{array}$ & $\begin{array}{l}\text { Volume } \\
\left(x_{10}{ }^{3} \mathrm{m3}\right)\end{array}$ & $\begin{array}{l}\text { AVolume } \\
\left(\times 10^{3} \mathrm{m3}\right)\end{array}$ & $\begin{array}{l}\text { Catchment } \\
\text { sedimentation } \\
\text { rate } \\
\left(\mathrm{m}^{3} / \mathrm{ha} / \mathrm{yr}\right)\end{array}$ & Observation \\
\hline 0 & & 120 & 26.51 & 14.28 & 1.59 & Breach \\
\hline 0.80 & & 170/1779AD & 12.23 & 12.23 & 0.16 & $\begin{array}{l}\text { Radiocarbon age } \\
\text { from wood } \\
\text { sample }\end{array}$ \\
\hline 4.00 & & 605 & 0 & 0 & & Onset \\
\hline
\end{tabular}

Table 5.33. Summary of key statistics for the upper Tangihau landslide-dam. 


\subsection{Monck Road}

The Monck Road site is the largest and most coastal of the seven sites analysed for this project. The high hills in the east toward the coast and south towards the Waipaoa River and the Poverty Bay Flats provide some shielding to the cyclonic weather patterns that ravage the Waipaoa catchment. The valley floor is very wide as seen in figure 5.41 and the river channel slope is low. As discussed in chapter four, the landslide is large and shows evidence of recent movement and is considered active. The drill site was located mid way midway along the length of the sediment body and the core bottomed out in bed rock at $6 \mathrm{~m}$ providing a full sediment record. However, due to the distance that the drill site was back from the restriction point means that the initial infill sequence that followed immediately after the blockage of the channel is missing from the core record.

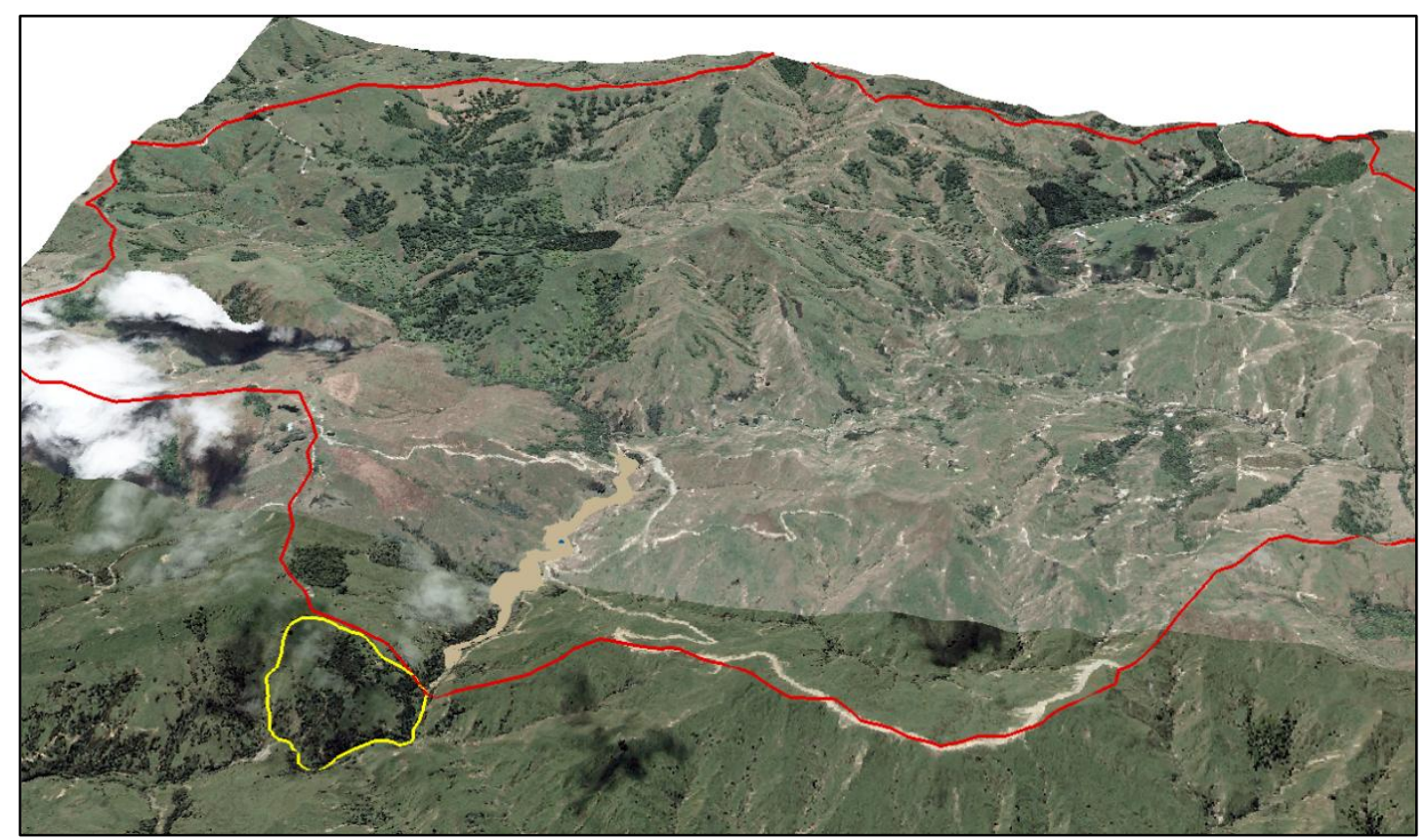

Figure 5.41. 3D model of the Monck Road landscape. Image highlights the landslide outlined in yellow and the catchment boundary is drawn in red. The sediment body is shaded brown.

\subsection{Core log and sedimentation}

Modelling of the sediment distribution is shown in figure 5.42 and for the Monck Road site the sediment body is the longest and widest of the study. Maximum depth of the sediment body is well back from the landslide as the model takes into account some infill at the toe of the landslide from landslide debris. Sections of the valley 
widen further upstream and the model tends to indicate that deposits are deeper than may be the case and may, in fact be closer only to the top of the unit depth range indicated. This over estimation where the valley widens is offset by a slight underestimation where it narrows and the two cancel each other out. These unders and overs in the modelling are within the margins of error and do not invalidate the volume estimates. The percussion corer reached bedrock at six metres depth and drew up a bedrock plug. Above this plug is a green/gray weathered bedrock unit 'P' of clast supported material in a fine silt/clay matrix base. This unit extends to a depth of 5.75 $\mathrm{m}$ and is interpreted as the palaeo-valley floor shown in figure 5.43. Sitting on top of the palaeo-valley floor is wood debris that was dated to provide the age for the base of the core and is considered to be a direct age for the landslide event. Above this and the bedrock base is unit ' $E$ ' which is a blue/grey silt/clay unit with large sharp edged clasts and incorporates woody material (refer to appendix D). This is interpreted as event debris that has been dislodged from local slopes but not landslide material and the unit is $0.40 \mathrm{~m}$ thick, shown as unit ' $\mathrm{E}$ ' in figure 5.43 . Above this unit is a brown/grey fine silt/clay lacustrine deposit comprising four distinct units as shown in figure 5.43 .

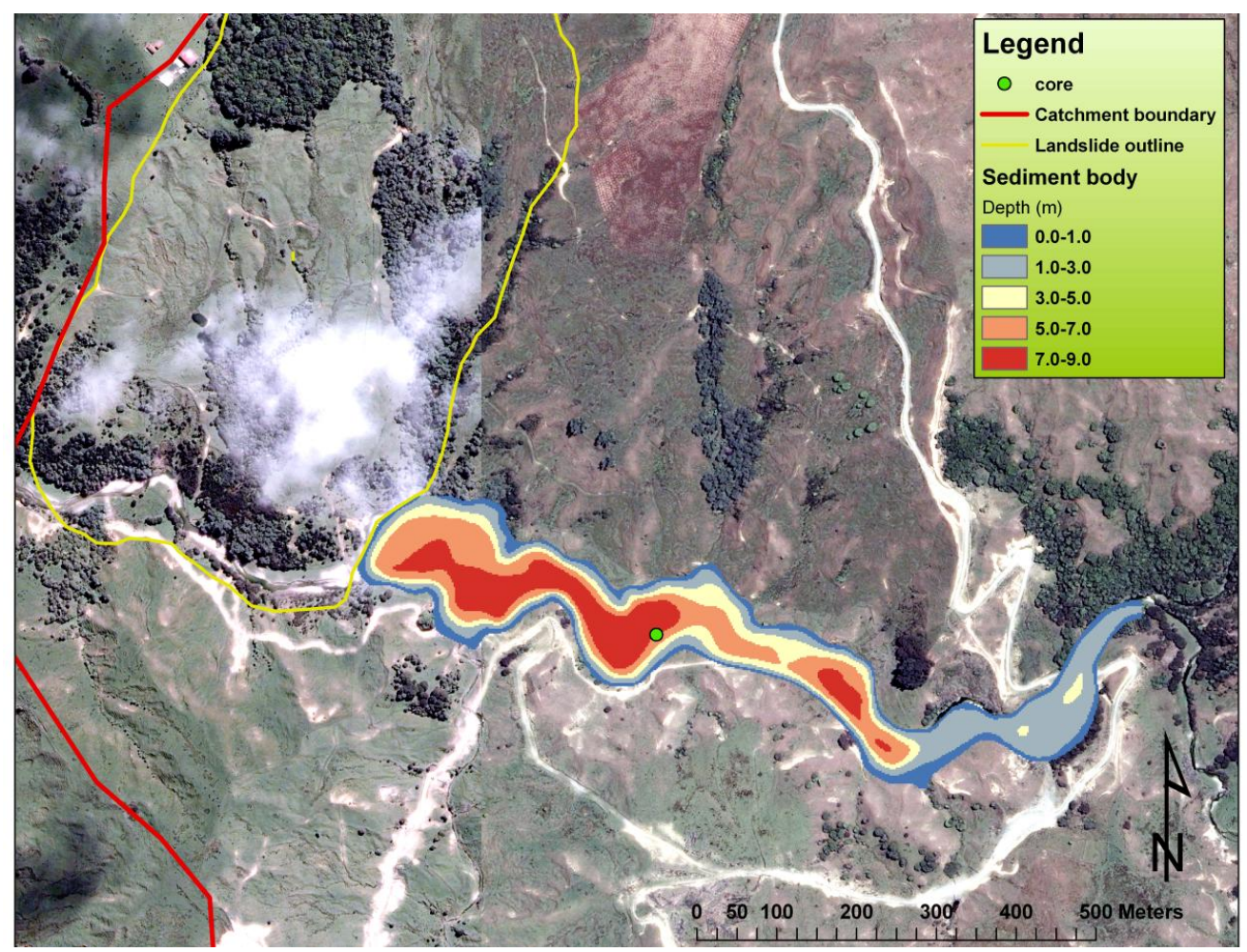

Figure 5.42. The Monck Road sediment body infill and distribution. Model of the infill for the site with the landslide outline and catchment boundary shown. 


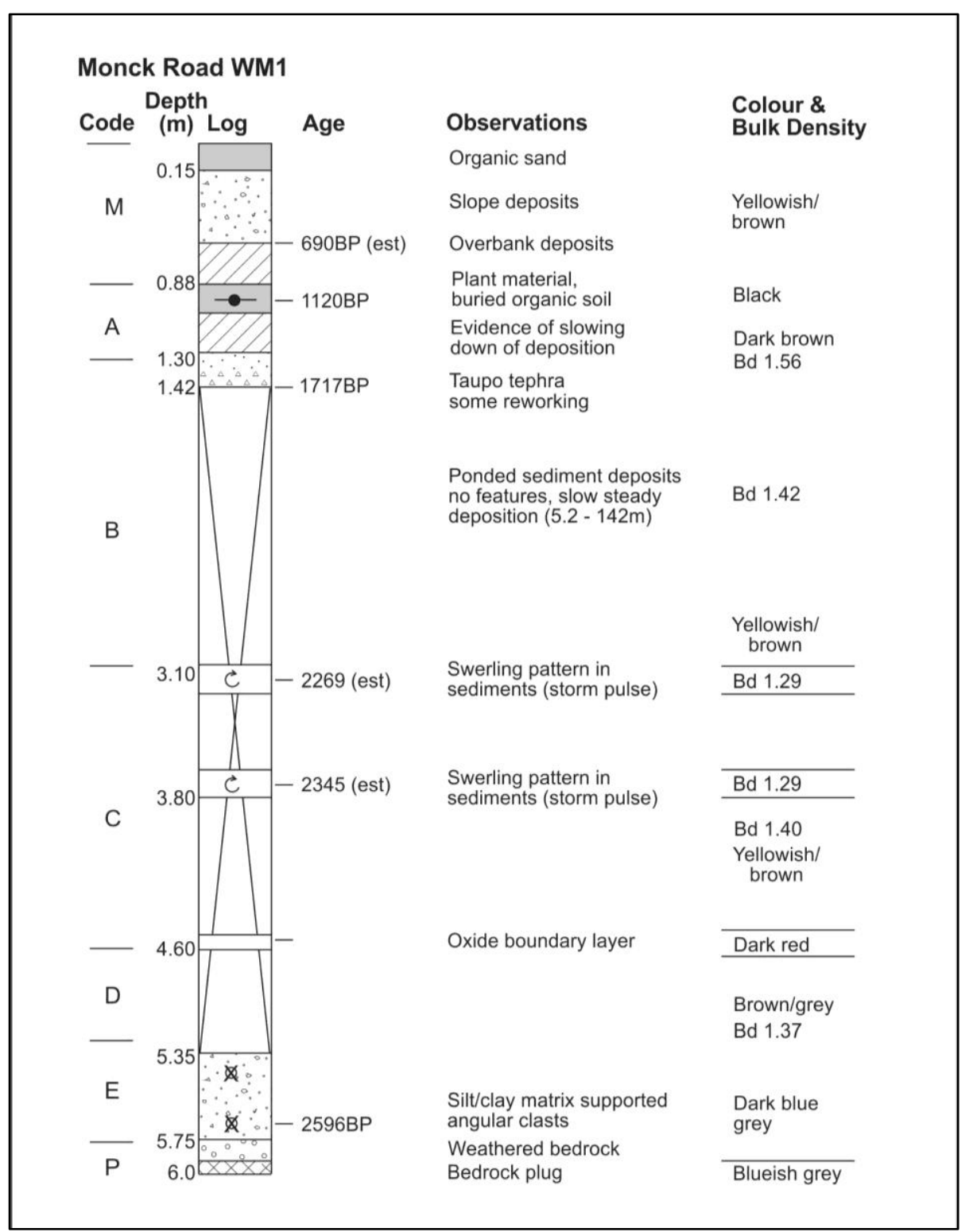

Figure 5.43. Core log for the Monck Road sediment body.

\begin{tabular}{|c|c|c|c|c|c|c|}
\hline $\begin{array}{l}\text { Depth } \\
\text { (m) }\end{array}$ & Code & Material & $\begin{array}{l}\text { Fraction of } \\
\text { sample } \\
\text { used }\end{array}$ & $\begin{array}{l}\text { Calibrated } \\
2 \sigma \text { age range } \\
\text { (cal. yr BP) }\end{array}$ & $\begin{array}{l}2 \sigma \text { age } \\
\text { midpoint } \\
\text { (cal. yr BP) }\end{array}$ & Reference \\
\hline 0.93 & $\begin{array}{l}\text { WM1- } \\
0.93\end{array}$ & Bulk soil & $\begin{array}{l}\text { Humic } \\
\text { acids }\end{array}$ & $1182-1058$ & $1120 \pm 62$ & NZA 35374 \\
\hline 1.42 & Taupo & Tephra & & $1688-1748$ & $1717 \pm 12$ & Wilson (1993) \\
\hline 5.60 & $\begin{array}{l}\text { WM1- } \\
5.60\end{array}$ & Wood & Cellulose & 2704-2488 & $2596 \pm 108$ & NZA 34550 \\
\hline
\end{tabular}

Table 5.41. Monck Road core log age model

The bottom of the lacustrine sequence, unit ' $\mathrm{D}$ ' is a fine silt/clay unit that shows the characteristics of slow steady sedimentation as seen in other cores. Unit ' $D$ ' terminates with a sharp contact surface with unit ' $\mathrm{C}$ ' at a depth of $4.60 \mathrm{~m}$. The upper boundary of the contact between ' $\mathrm{D}$ ' and ' $\mathrm{C}$ ' is emphasised by a rust coloured layer 
and can be seen in the core $\log$ photos in appendix 3. Unit ' $\mathrm{C}$ ' is made up of a fine silty clay lacustrine sediment unit and is interrupted by two $10-15 \mathrm{~cm}$ thick sandy layers at depths of $3.80 \mathrm{~m}$ and $3.10 \mathrm{~m}$ that show a distinctive swirl pattern. Above this, unit ' $\mathrm{B}$ ' consists of the same fine silty clay but shows no definition and extends up to $1.42 \mathrm{~m}$ depth where it makes a sharp contact with a thin lapilli and ash identified as Taupo tephra. This unit extends beyond the Taupo marker and terminates with a sharp contact surface at $1.30 \mathrm{~m}$ where it meets unit 'A'. The top of the lacustrine sequence is unit ' $A$ ' which is characterised by a more sandy texture and a higher bulk density than the lower units. The top of this unit is a dark organic buried soil development and its top is at $0.88 \mathrm{~m}$ depth. The top unit ' $\mathrm{M}$ ' is a mixed unit. At the lower section of this unit the sediments are similar in texture and grain size to unit 'A'". The unit is topped with a blocky large angular clast supported layer with fine silt/clay matrix and capped with the organic soil of the contemporary surface.

\subsection{Analysis and observations}

Figure 5.44 shows the results from the combination of modelling and age control data (table 5.41) for the Monck Road site. The estimated life span for the landslide-dam is 1903 years. A radiocarbon sample from organic material at the base of the core and top of unit 'P' (as indicated in figure 5.43) provides a date for the palaeo-valley floor prior to dam formation of $2596 \mathrm{cal}$ years B.P. This point is identified by the study as the top of the palaeo-valley floor prior to dam formation and indicates a minimum age for the landslide. The core is taken some distance back from the landslide and point of restriction and misses the lowest sequences of the lacustrine sedimentary infill. The bottom of the core sequence (unit 'E') is a blocky deposit of angular sandstone clasts supported in a silt/clay matrix and is interpreted as slope deposits that have covered the valley floor and were most likely coincident with the landslide event. This unit also incorporates wood and other organic material but provides a distinct boundary both above and below. Volumes calculated for valley infill to the bottom of unit ' $E$ ' are $136.51 \times 10^{3} \mathrm{~m}^{3}$ and sedimentation rates per hectare of $9.15 \mathrm{~m}^{3} / \mathrm{ha} /$ year are both consistent with the early stage infill from other sites. A maximum age for dam formation calculated by back calculating sediment volumes estimates the age at 2603 cal. years BP. 
There is a slowing down in the sedimentation rates and volumes of sediment delivered to the site following the event as seen in the slope of the curves in figure 5.44. The unit ' $\mathrm{D}$ ' is identified as lacustrine sediments that have been deposited at a slow and regular rate. Above this, unit ' $\mathrm{C}$ ' is also fine-grained lacustrine sediments, but this layer is distinguished by having two distinctive units of coarser sediments that show a distinctive swirling pattern. These two units of sediment are interpreted as disturbance events that may represent a high volume of input from either large storm events or earthquake ground shaking. Through back calculation using volumes and sedimentation rates to find ages, these events at $3.80 \mathrm{~m}$ and $3.10 \mathrm{~m}$ are estimated to have occurred at 2345 cal. years BP and 2269 cal. years BP respectively. The timing of these disturbance events is similar to events in the Kopaatuaki and Tangihau cores and is considered to be events of catchment wide significance. During this time the curves in figure 5.44 show a sharp rise in the catchment sedimentation rate to 0.21 $\mathrm{m}^{3} / \mathrm{ha} / \mathrm{yr}$ which is well above the average rate of sedimentation for the site of 0.11 $\mathrm{m}^{3} / \mathrm{ha} / \mathrm{yr}$ as calculated over the life time of the dam.

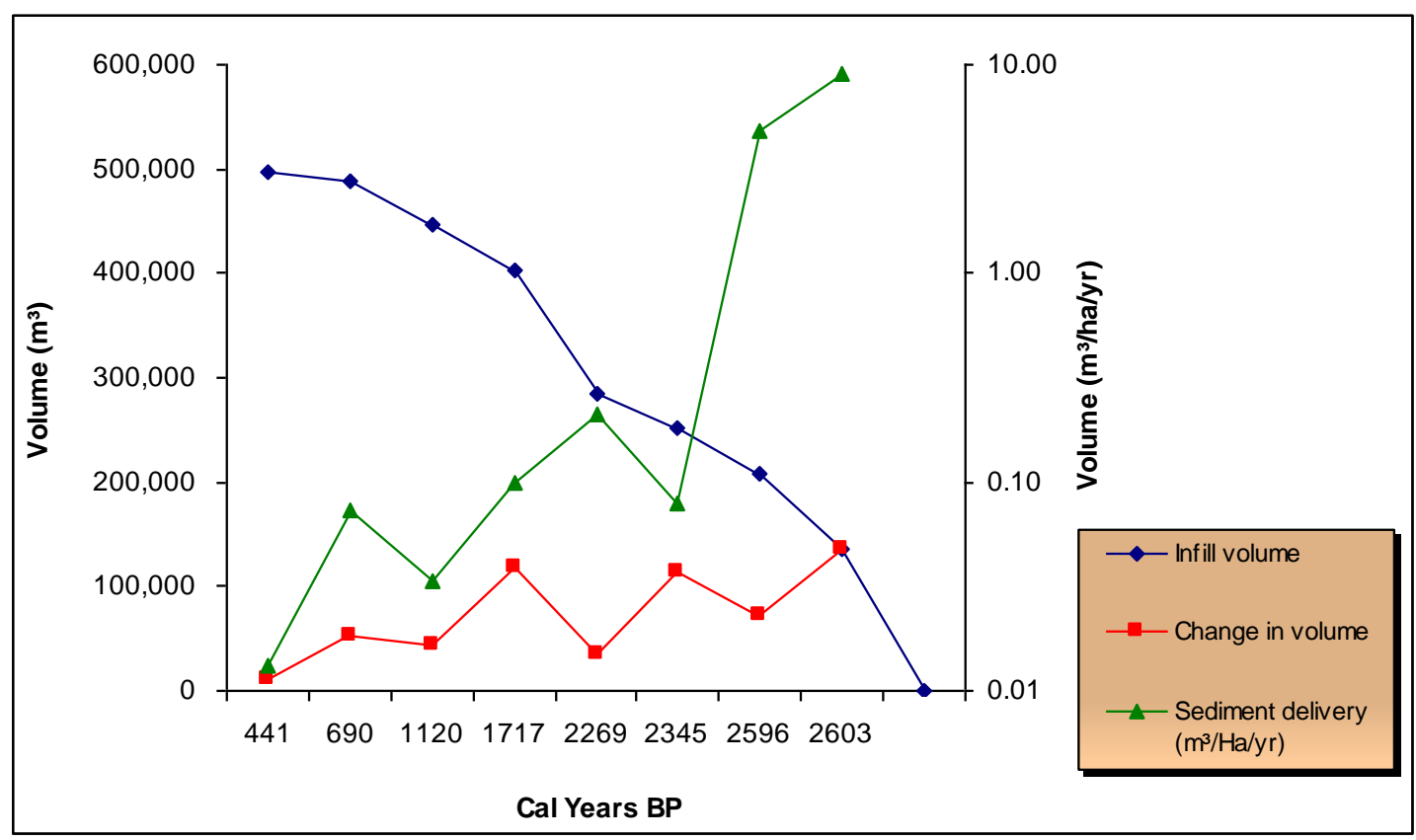

Figure 5.44. Sedimentation curves for the Monck Road sediment body. The blue curve shows the volume of infill over time, while the red curve shows the change in volume between time markers. The green curve is the mean sedimentation rate for the catchment between periods calculated as $\mathrm{m}^{3} / \mathrm{ha} / \mathrm{yr}$.

Unit ' $\mathrm{B}$ ' is a unit of fine silt/clay sediment that extends up to a depth of $1.30 \mathrm{~m}$, within which is the Taupo Tephra. Sedimentation for this unit is at a higher than background rate and covers the stormiest period in the Tutira record centred on 2000 cal. years 
BP. Reaction to the increased storm activity may be seen in the curves in figure 5.44 for total volume (blue) and volume change (red). That it is not seen in the sedimentation rate curve (green) and may be due to a reducing trapping efficiency for the reservoir. There is a sharp drop off in all curves for unit ' $A$ ' and the sediment characteristics are consistent with more event sediment deposition. On the top of the unit is a dark palaeo-organic layer which is interpreted to be where the sediment body has existed as a shallow swamp. This is interpreted as indicating that incision of the dam and sediment infills are at approximately the same level but a full dam breach has not occurred. Sedimentation above this point is by overbanking event deposition as the river channel starts to form. Unit ' $M$ ' incorporates this overbanking sedimentation and is topped by a slope deposit and contemporary soil. There is no evidence of sediment removal once the breach has occurred and this is supported by the physical condition of the sediment body in the field. The river meander shows no evidence of crossing the sediment body at the point that the core was taken. Downstream of the core location and closer to the restriction, there is field evidence of three lower terrace surfaces. Study of these may provide insights into the rates of sediment removal post dam breach and would provide greater clarification of catchment sediment dynamics but did not form part of the scope of this project.

\subsection{Key Findings}

\begin{tabular}{|c|c|c|c|c|c|c|}
\hline $\begin{array}{l}\text { Depth } \\
\text { (m) }\end{array}$ & Code & $\begin{array}{l}\text { Age } \\
\text { (BP/ } \\
\text { calendar) }\end{array}$ & $\begin{array}{l}\text { Volume } \\
\left(\mathbf{x 1 0}^{3} \mathrm{~m} 3\right)\end{array}$ & $\begin{array}{l}\Delta \text { Volume } \\
\left(\text { x10 }^{3} \mathrm{m3}\right)\end{array}$ & $\begin{array}{l}\text { Catchment } \\
\text { sedimentation } \\
\text { rate }(\mathrm{m} 3 / \mathbf{h a} / \mathbf{y r})\end{array}$ & Observation \\
\hline 0.60 & $\mathrm{M}$ & 690/1260AD & 497.41 & 0.01 & 0.01 & Breach point \\
\hline 0.80 & $\mathrm{~A}$ & 1120/830AD & 445.90 & 51.51 & 0.07 & $\begin{array}{l}\text { Overbanking } \\
\text { event sediment } \\
\text { deposition }\end{array}$ \\
\hline 1.40 & & $1717 / 233 \mathrm{AD}$ & 402.95 & 42.92 & 0.03 & Taupo tephra \\
\hline 3.20 & B & 2269 (Est) & 285.15 & 117.80 & 0.10 & $\begin{array}{l}\text { Undisturbed } \\
\text { lucsutrine } \\
\text { sedimentation }\end{array}$ \\
\hline 3.80 & $\mathrm{C}$ & 2345 (Est) & 250.91 & 41.94 & 0.21 & $\begin{array}{l}\text { Two sediment } \\
\text { disturbance } \\
\text { pulses }\end{array}$ \\
\hline 5.80 & $\mathrm{D}$ & $2596 / 654 \mathrm{BC}$ & 209.01 & 72.49 & 0.08 & $\begin{array}{l}\text { Radiocarbon } \\
\text { sample from } \\
\text { wood at base }\end{array}$ \\
\hline 6.00 & $\mathrm{E}$ & $2603 / 661 \mathrm{BC}$ & 136.51 & 136.51 & 9.15 & $\begin{array}{l}\text { Estimated onset } \\
\text { for dam. Palaeo- } \\
\text { valley floor }\end{array}$ \\
\hline 6.00 & $\mathrm{P}$ & & 0.00 & & & Bedrock plug \\
\hline
\end{tabular}

Table 5.42. Key statistics for the Monck Road landslide-dam. 


\subsection{Maungahaumi}

The most inland site with the highest elevations and greatest relief is the Maungahaumi field site. For this site no core was taken but a near full exposure enabled a good assessment of the sediment body to be gained. A number of trees were inundated by the dam lake and were preserved in the sediment body in growth position (Figure 5.51). The stratigraphy of the sediment body was constructed from a $3.5 \mathrm{~m}$ exposure next to these trees together with exposures at other locations along the sediment body and out to the river channel. The base of the tree that has been completely exposed is on the terrace that approximates the palaeo-valley floor prior to the infill.

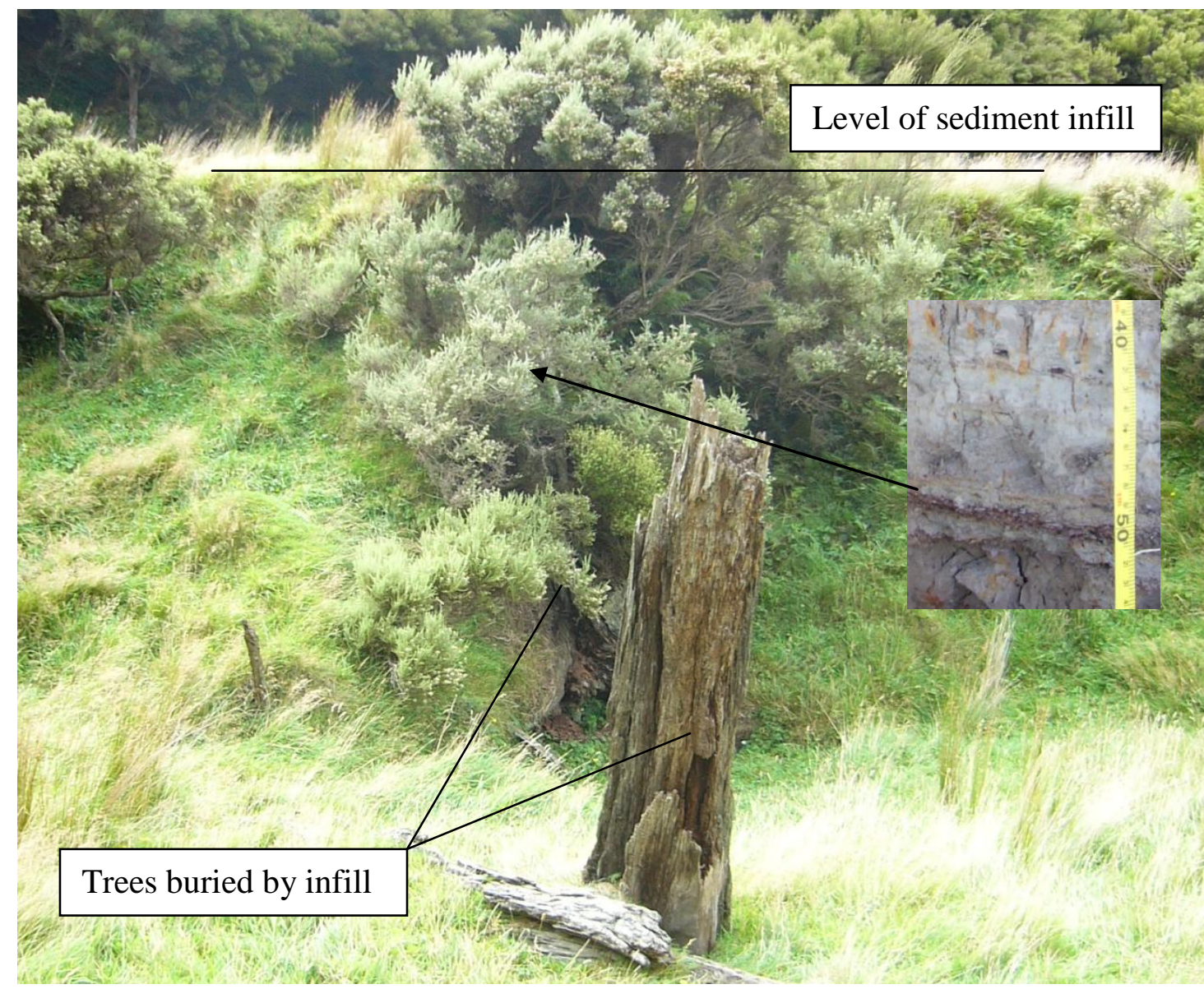

Figure 5.51. The sediment body terrace for the Maungahaumi field site. The trees are buried in the sediments that infilled behind the dam. The insert show the organic layer that was sampled for radiocarbon dating and the arrow points to the exposure location next to the buried tree. 


\subsection{Core log and sedimentation}

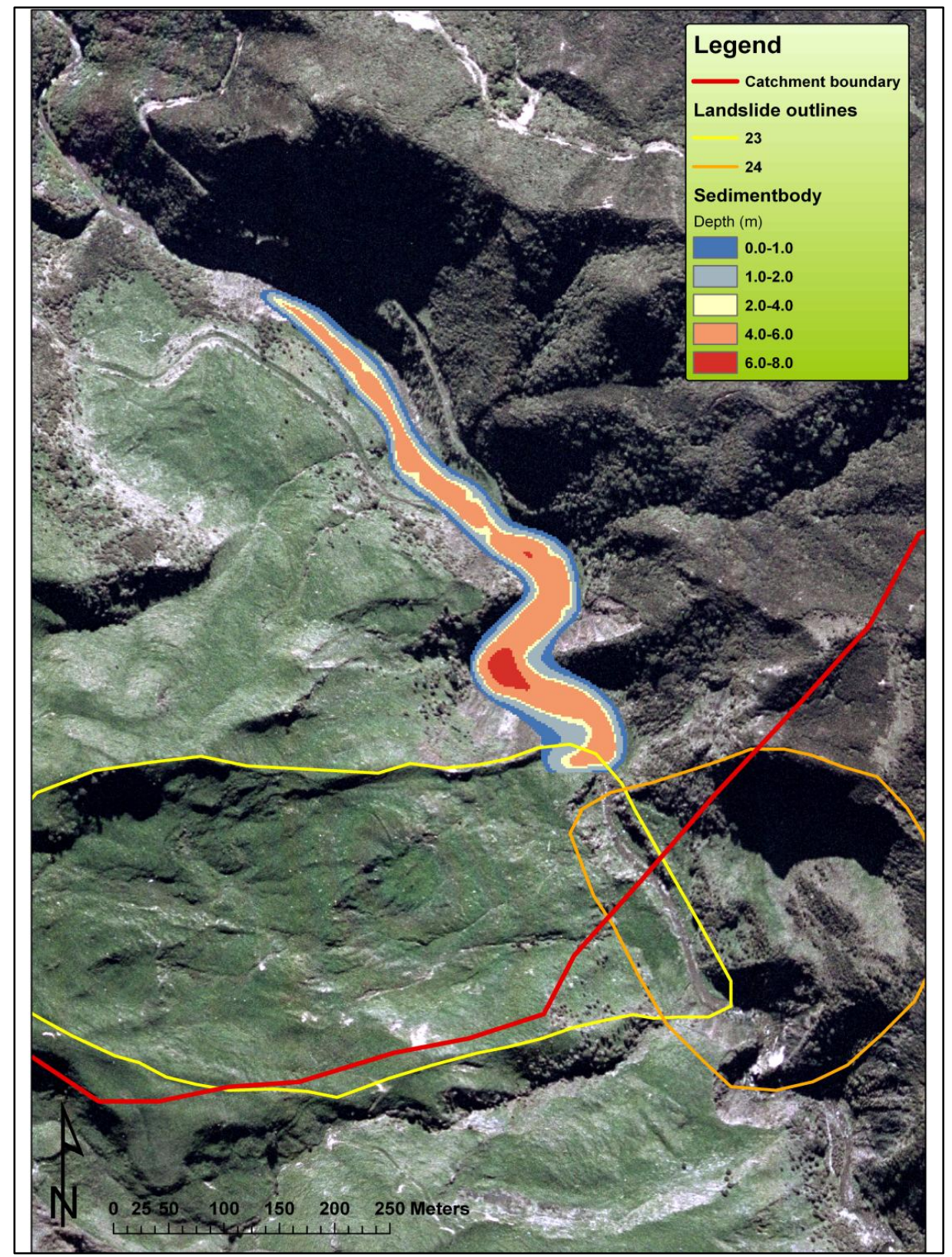

Figure 5.52. The Maungahaumi sediment body infill and distribution. Model of the infill for the site with the landslide outline and catchment boundary shown.

The depth of the sediment body as measured in the field is $5.8 \mathrm{~m}$ and the exposure measurements and details were taken from a location that was approximately mid way back from the blockage. Figure 5.52 shows the outlines of the two landslides that are responsible ('23' and '24') for the blockage as described in chapter 3 and provides details of the modelled sediment infill. The base of the profile is at bedrock where the river has cut down through the sediment body removing much of the infill in the process and exposing the palaeo-valley river terrace and the buried trees. The profile 
summary in figure 5.53 shows that the base was a gravel river terrace with the top of the terrace being at $5.80 \mathrm{~m}$ depth. Above this level is the customary lacustrine fine silt/clay sediments that appeared to be all one unit, shown as unit ' $\mathrm{C}$ ' in figure 5.53 up to a depth of $1.51 \mathrm{~m}$, where there was a continuous layer of organic debris.

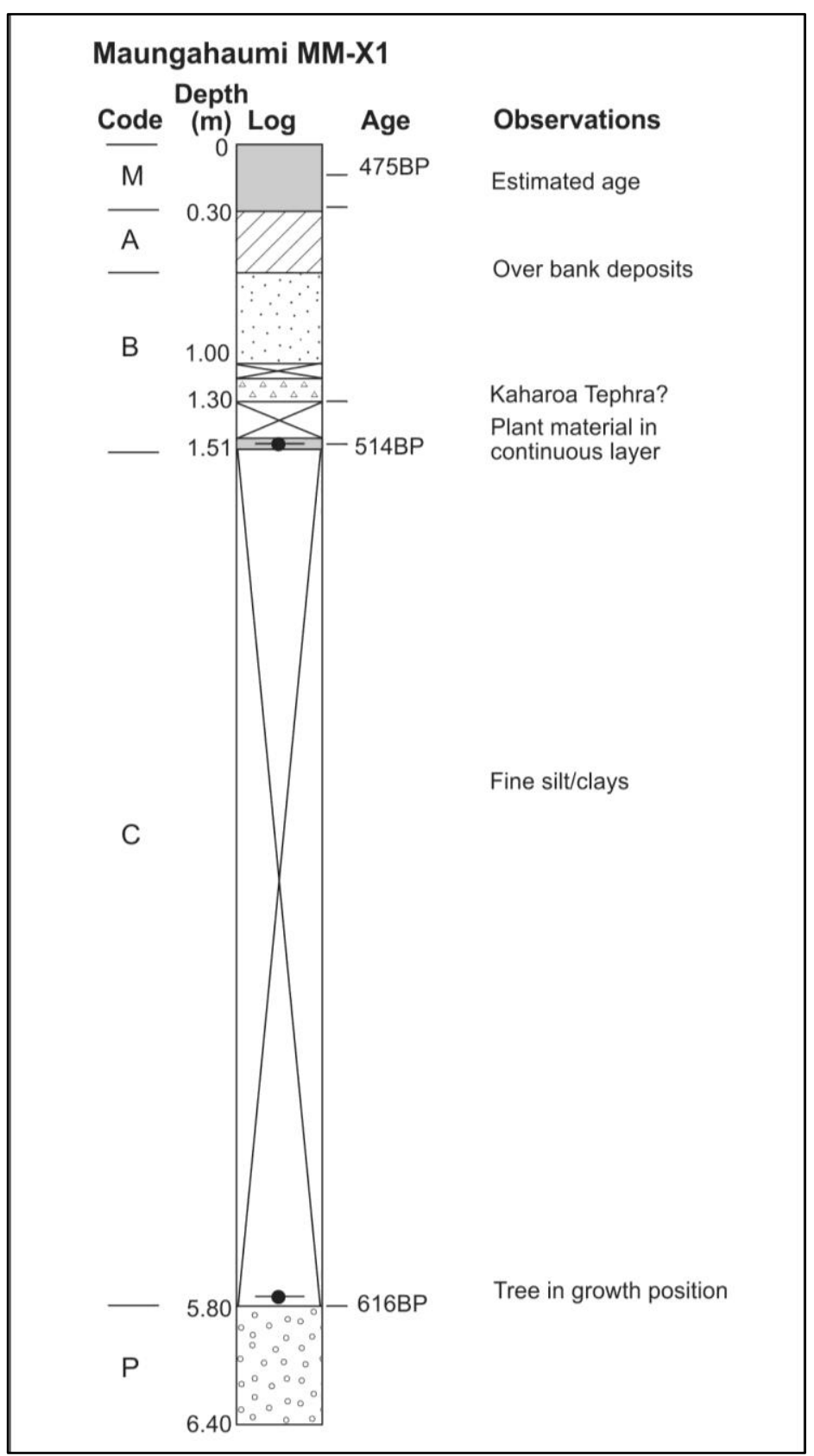

Figure 5.53. Core log for the Maungahaumi Sediment body.

\begin{tabular}{|c|c|c|c|c|c|c|}
\hline $\begin{array}{l}\text { Depth } \\
\text { (m) }\end{array}$ & Code & Material & $\begin{array}{l}\text { Fraction } \\
\text { of sample } \\
\text { used }\end{array}$ & $\begin{array}{l}\text { Calibrated } \\
2 \sigma \text { age range } \\
\text { (cal. yr BP) }\end{array}$ & $\begin{array}{l}2 \sigma \text { age } \\
\text { midpoint } \\
(\text { cal. yr BP) } \\
\end{array}$ & Reference \\
\hline 1.51 & MM1-1.51 & Peat & Cellulose & $531-497$ & $514 \pm 20$ & NZA 34546 \\
\hline 4.85 & MM1-4.85 & Wood & Cellulose & $646-586$ & $616 \pm 20$ & NZA 34552 \\
\hline
\end{tabular}

Table 5.51. Maungahuri core log age model. 
Unit ' $\mathrm{B}$ ' is also a fine silt/clay unit that contains two layers of terphra at $1.30 \mathrm{~m}$ and $1.00 \mathrm{~m}$. The first of these tephra at $1.30 \mathrm{~m}$ is a light grey ash and appears to be an air fall deposit. The second tephra at $1.00 \mathrm{~m}$, is pumice lapilli, and may be a reworked deposit from a storm event. Above this, the sediments of unit 'A' are coarser silty sand and are more characteristic of over banking deposition. This unit is capped by an established organic soil which most likely formed after the incision of the dam when conditions for plant growth were more stable and marks the end of the infill sequence.

\subsection{Analysis and observations}

Through the use of radiocarbon dating it can be established that the Maungahaumi landslide-dam occurred 616 cal. years BP and was able to persist for an estimate 139 years. During this time a total of $19.85 \times 10^{3} \mathrm{~m}^{3}$ of fine sediment was trapped by the dam to a maximum depth of $8 \mathrm{~m}$. The graph in figure 5.54 shows that initial sedimentation rates were high, and remained high for a considerable period of time, before declining. The point of change occurred at $1.51 \mathrm{~m}$ depth where there was a thick organic layer which is interpreted as the point where infill and incision were close to equal and the area existed as a swampy pond. From this point on sediment accumulation was from larger sediment delivery events due to a decline in trapping efficiencies of the reservoir. The period from the dam onset at 616 cal. years BP until the swampy stage at 514 cal. years BP cover a period of high storm activity indicated in the Tutira storm record. To this point the reservoir trapped a total of more than $16.35 \times 10^{3} \mathrm{~m}^{3}$ at an average rate per of $1.34 \mathrm{~m}^{3} / \mathrm{ha} / \mathrm{yr}$. From the end of this storm period and the swampy phase, sedimentation rates slowed down to $0.87 \mathrm{~m}^{3} / \mathrm{ha} / \mathrm{yr}$. During this time deposition of sediments was in the main only storm deposit, becoming overbanking deposits as the river was able to cut a channel in the sediment body. Development of the sediment body continued until 477 cal. years BP at which point deposition switched to erosion. Erosion of the sediment body is almost complete today and only a small remnant remains where the deposit is protected in the lee of a hard rock spur (figure 5.55) that was able to divert stream flow. 


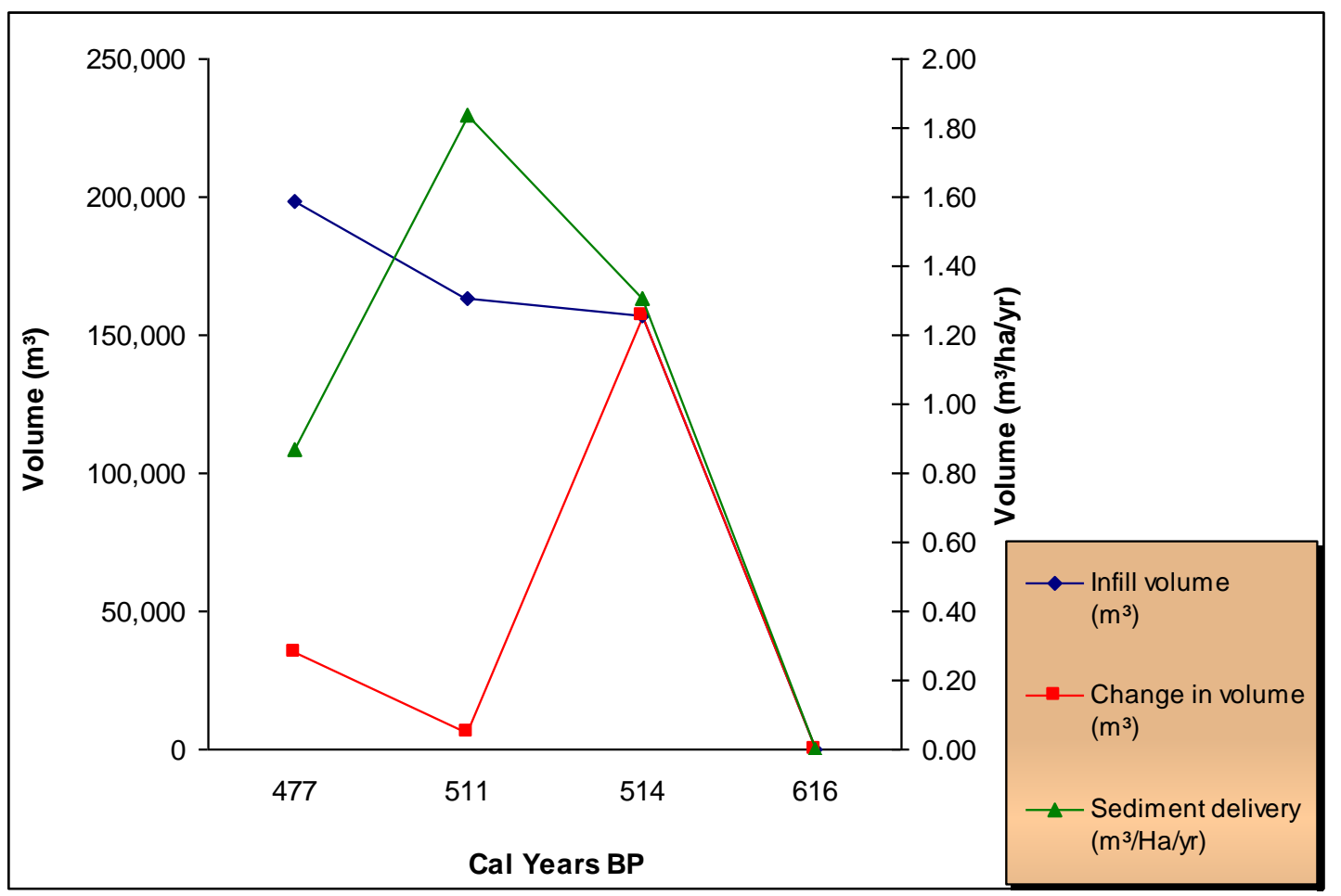

Figure 5.54. Sedimentation curves for the Maungahaumi sediment body. The blue curve shows the volume of infill over time, while the red curve shows the change in volume between time markers. The green curve is the mean sedimentation rate for the catchment between periods calculated as $\mathrm{m}^{3} / \mathrm{ha} / \mathrm{yr}$.

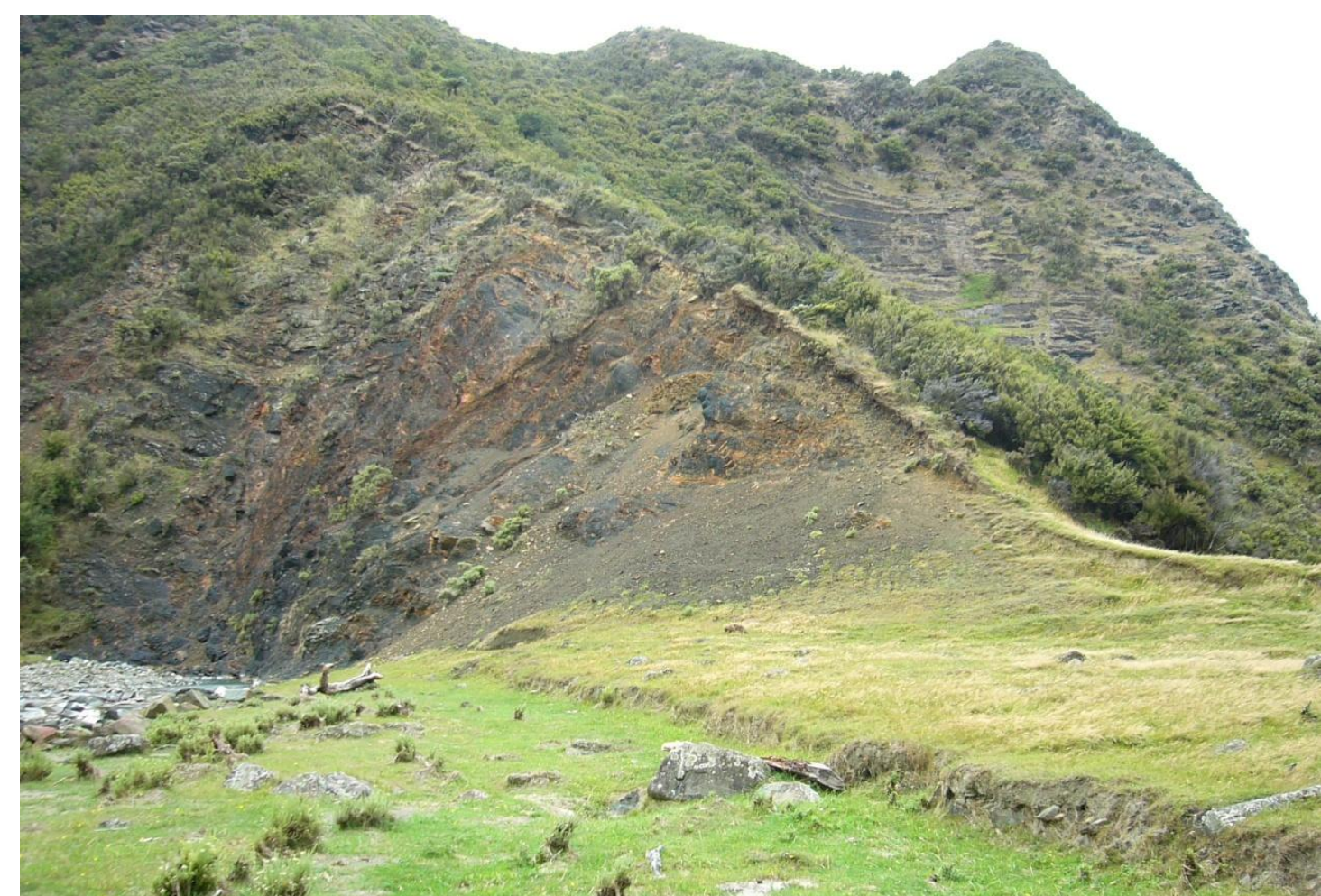

Figure 5.55. The spur of hard bedrock that was able to preserve the Maungahaumi sediment body. 


\subsection{Key findings}

\begin{tabular}{|c|c|c|c|c|c|c|}
\hline $\begin{array}{l}\text { Depth } \\
\text { (m) }\end{array}$ & Code & $\begin{array}{l}\text { Age } \\
\text { (BP/ } \\
\text { calendar) }\end{array}$ & $\begin{array}{l}\text { Volume } \\
\left(\times 10^{3} \mathrm{~m} 3\right)\end{array}$ & $\begin{array}{l}\Delta \text { Volume } \\
\left(\text { x10 }^{3} \mathrm{~m} 3\right)\end{array}$ & $\begin{array}{l}\text { Catchment } \\
\text { erosion } \\
(\mathrm{m} 3 / \mathrm{ha} / \mathrm{yr})\end{array}$ & Observation \\
\hline 0.00 & $\mathrm{~A}$ & 477 (Est) & 19.85 & 34.99 & 0.87 & Breach point \\
\hline 1.30 & B & 511 & 16.35 & 65.05 & 1.84 & $\begin{array}{l}\text { Age indicated } \\
\text { by tephra }\end{array}$ \\
\hline 1.51 & $\mathrm{C}$ & 514/1436AD & 15.70 & 15.70 & 1.30 & Organic debris \\
\hline 5.80 & $\mathrm{P}$ & $616 / 1334 \mathrm{AD}$ & 0.00 & 0 & 0.00 & $\begin{array}{l}\text { Onset for dam } \\
\text { Palaeo-valley } \\
\text { floor }\end{array}$ \\
\hline 6.00 & $\mathrm{P}$ & & & & & $\begin{array}{l}\text { River channel } \\
\text { gravel base }\end{array}$ \\
\hline
\end{tabular}

Table 5.52. Key statistics for the Maungahaumi landslide-dam.

\subsection{Arai Matawai and Otara Station}

For the sites of Arai Matawai and Otara Station had successful mapping and modelling of the sediment bodies was possible and produced useful results. The dating of the onset termination and mid points however was not successful with a number of age inconsistencies. Useful information gained from these sites are the maximum infill volumes and an estimate for minimum age for the channel blockage.

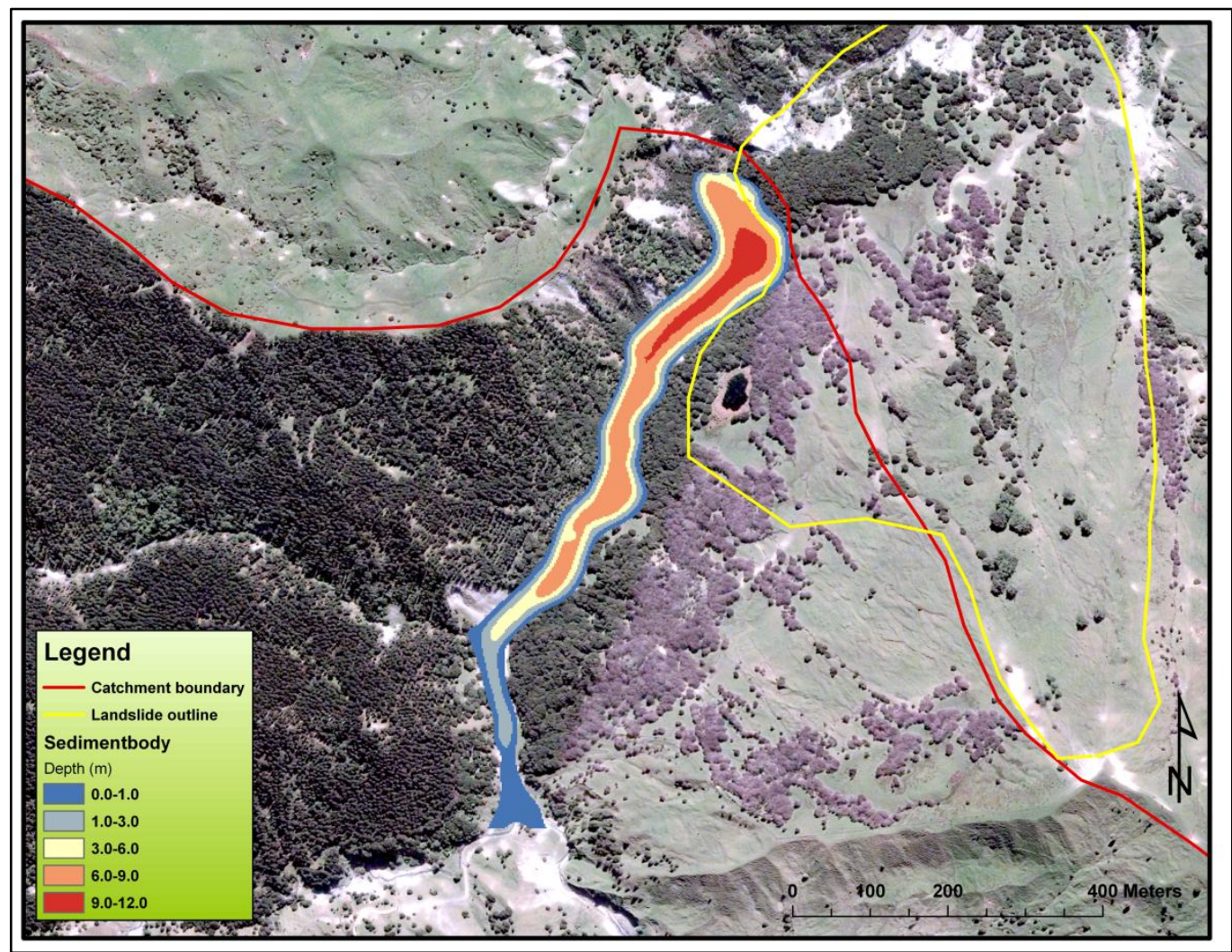

Figure 5.61. The Arai Matawai sediment body infill distribution. 
The Arai Matawai site has returned the oldest age of this study with a minimum age of 7474 cal. years BP taken from a wood sample and supported by a tephra sample from the same depth of $1.85 \mathrm{~m}$. The total depth for the sediment body at the observation point was $6.00 \mathrm{~m}$ but as this was close to the landslide and the modelling results suggest a maximum depth of infill at 9.0-12.0 m. Total volume of sediment accumulated is calculated at $38.06 \times 10^{3} \mathrm{~m}^{3}$ and an in-depth analysis of the catchment sedimentation rates and response through its life time would have provided useful research. This is especially the case when put into context with the neighbouring Mangakiore catchment, to provide a modern analogue and that the estimated age of the landslide would put it about the same time as the Tutira event.

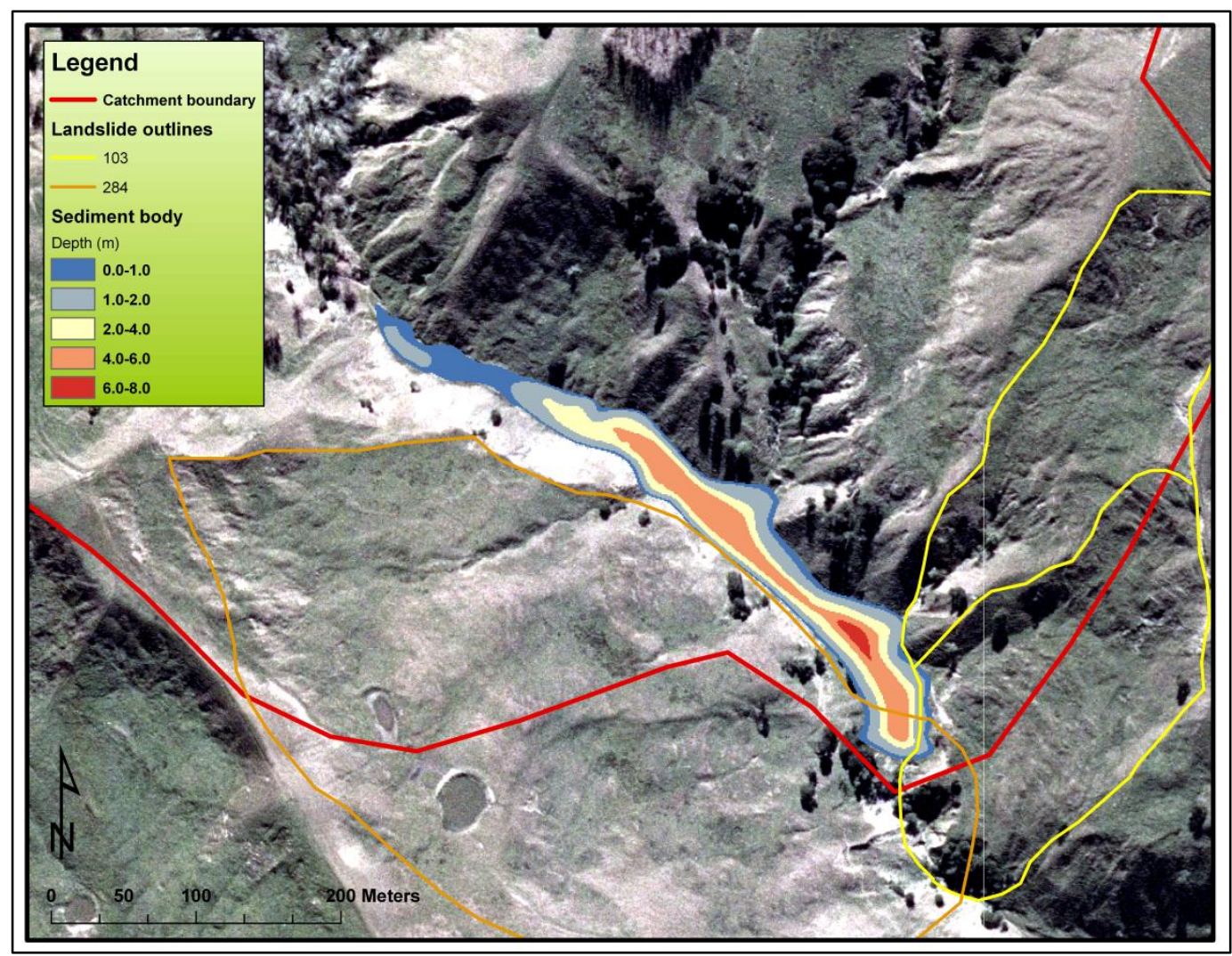

Figure 5.62. The Otara station sediment body infill distribution.

The Otara Station field site is located in a small lowland catchment at the head of the Poverty Bay Flats. The sediment body was viewed through exposures and samples collected for radiocarbon dating put the minimum age for the landslide event at 487 cal. years BP. The depth of the sediment body as measured from where the river has eroded back to the bedrock to the top of the sediment body is $5.60 \mathrm{~m}$. A total estimate for the fine sediments trapped by this blockage is $89.21 \times 10^{3} \mathrm{~m}^{3}$ and the modelled 
distribution for these sediments is shown in figure 5.62. This site showed evidence of multiple channel blockage events due to the reactivations of the two main landslides with the larger landslide \#284 shown in figure 5.62 being the first to cause disruption to the sediment transport network.

\subsection{Tephra analysis}

For all the sites and the stratigraphic columns presented in this chapter the tephra were determined by the stratigraphic position in relation to the nearest chronology provided by the radiocarbon age and named accordingly. With the exception of the Taupo tephra in the Tangihau core at $1.35 \mathrm{~m}$ which has been shown to be an airfall deposit, all others were reworked. The geochemical analysis of the tephra in this study was performed by Franziska Landes and Dr Brent Alloway and a summary of their work is provided. The reworked tephra when analysed showed a mix of tephra sources and it is the youngest of the tephra within the sample that gives its name to the stratigraphic position. While this adds some error to any age estimates used in this study, because the tephra analysed showed strong provenance and source, means that the ages could represent a maximum for their deposition within the core sequence. Table 5.71 lists the major element compositions for each of the tephras sampled and figure 5.71 plots them against known tephra taken from the Waipaoa region. The base data for the geochemical analysis can be found in appendix E. 
Table 5.71: Mean major element composition of glass shards from tephra beds within cores retrieved from the Waipaoa catchment (this study).

\begin{tabular}{|c|c|c|c|c|c|c|c|c|c|c|c|c|}
\hline Core & $\mathrm{SiO}_{2}$ & $\mathrm{TiO}_{2}$ & $\mathrm{Al}_{2} \mathrm{O}_{3}$ & $\mathrm{FeO}$ & MnO & MgO & $\mathrm{CaO}$ & $\mathrm{Na}_{2} \mathrm{O}$ & $\mathrm{K}_{2} \mathrm{O}$ & $\mathrm{Cl}$ & $\mathrm{H}_{2} \mathrm{O}$ & $n$ \\
\hline $\begin{array}{l}\text { WT1-T1 (0.86-m) } \\
\text { Pop. } 1\end{array}$ & $\begin{array}{l}78.48 \\
(0.06)\end{array}$ & $\begin{array}{c}0.11 \\
(0.02)\end{array}$ & $\begin{array}{l}12.36 \\
(0.02)\end{array}$ & $\begin{array}{c}0.88 \\
(0.06)\end{array}$ & $\begin{array}{c}0.06 \\
(0.02)\end{array}$ & $\begin{array}{c}0.09 \\
(0.03)\end{array}$ & $\begin{array}{c}0.67 \\
(0.15)\end{array}$ & $\begin{array}{c}3.78 \\
(0.05)\end{array}$ & $\begin{array}{l}3.57 \\
(0.32)\end{array}$ & $\mathrm{nd}^{\mathrm{b}}$ & $\begin{array}{c}0.54 \\
(0.66)\end{array}$ & 3 \\
\hline Pop. 2 & $\begin{array}{l}76.34 \\
(0.32)\end{array}$ & $\begin{array}{c}0.21 \\
(0.04)\end{array}$ & $\begin{array}{l}13.24 \\
(0.19)\end{array}$ & $\begin{array}{l}1.82 \\
(0.06)\end{array}$ & $\begin{array}{c}0.09 \\
(0.02)\end{array}$ & $\begin{array}{c}0.19 \\
(0.05)\end{array}$ & $\begin{array}{l}1.23 \\
(0.08)\end{array}$ & $\begin{array}{l}4.05 \\
(0.10)\end{array}$ & $\begin{array}{l}2.84 \\
(0.07)\end{array}$ & nd & $\begin{array}{c}1.69 \\
(1.39)\end{array}$ & 12 \\
\hline $\begin{array}{l}\text { WT1-T2 (1.36-m) } \\
\text { Primary fall unit }\end{array}$ & $\begin{array}{l}75.77 \\
(0.18)\end{array}$ & $\begin{array}{l}0.23 \\
(0.02)\end{array}$ & $\begin{array}{l}13.48 \\
(0.08)\end{array}$ & $\begin{array}{l}1.93 \\
(0.05)\end{array}$ & $\begin{array}{l}0.09 \\
(0.02)\end{array}$ & $\begin{array}{c}0.25 \\
(0.02)\end{array}$ & $\begin{array}{l}1.36 \\
(0.03)\end{array}$ & $\begin{array}{l}4.10 \\
(0.07)\end{array}$ & $\begin{array}{l}2.79 \\
(0.07)\end{array}$ & nd & $\begin{array}{c}4.14 \\
(1.42)\end{array}$ & 15 \\
\hline $\begin{array}{l}\text { WT1-T3 }(4.17-\mathrm{m}) \\
\quad \text { Pop. } 1\end{array}$ & $\begin{array}{l}78.31 \\
(0.22)\end{array}$ & $\begin{array}{c}0.09 \\
(0.01)\end{array}$ & $\begin{array}{l}12.45 \\
(0.12)\end{array}$ & $\begin{array}{c}0.87 \\
(0.03)\end{array}$ & $\begin{array}{c}0.08 \\
(0.02)\end{array}$ & $\begin{array}{c}0.09 \\
(0.01)\end{array}$ & $\begin{array}{c}0.62 \\
(0.05)\end{array}$ & $\begin{array}{c}3.74 \\
(0.08)\end{array}$ & $\begin{array}{l}3.75 \\
(0.07)\end{array}$ & nd & $\begin{array}{c}1.80 \\
(1.99)\end{array}$ & 3 \\
\hline Pop. 2 & $\begin{array}{l}76.17 \\
(0.29)\end{array}$ & $\begin{array}{c}0.19 \\
(0.01)\end{array}$ & $\begin{array}{l}13.27 \\
(0.12)\end{array}$ & $\begin{array}{l}1.83 \\
(0.05)\end{array}$ & $\begin{array}{c}0.10 \\
(0.03)\end{array}$ & $\begin{array}{l}0.18 \\
(0.01)\end{array}$ & $\begin{array}{c}1.23 \\
(0.03)\end{array}$ & $\begin{array}{l}4.08 \\
(0.10)\end{array}$ & $\begin{array}{l}2.94 \\
(0.07)\end{array}$ & nd & $\begin{array}{c}4.58 \\
(2.07)\end{array}$ & 12 \\
\hline $\begin{array}{l}\text { WT1-T4 (5.95-m) } \\
\quad \text { Pop. } 1\end{array}$ & $\begin{array}{l}75.84 \\
(0.38)\end{array}$ & $\begin{array}{c}0.11 \\
(0.02)\end{array}$ & $\begin{array}{l}12.61 \\
(0.09)\end{array}$ & $\begin{array}{c}0.89 \\
(0.06)\end{array}$ & $\begin{array}{c}0.05 \\
(0.02)\end{array}$ & $\begin{array}{c}0.11 \\
(0.02)\end{array}$ & $\begin{array}{c}0.67 \\
(0.10)\end{array}$ & $\begin{array}{l}3.71 \\
(0.15)\end{array}$ & $\begin{array}{l}3.51 \\
(0.24)\end{array}$ & nd & $\begin{array}{c}1.39 \\
(1.62)\end{array}$ & 8 \\
\hline Pop. 2 & $\begin{array}{l}76.58 \\
(0.16)\end{array}$ & $\begin{array}{c}0.20 \\
(0.02)\end{array}$ & $\begin{array}{l}13.27 \\
(0.08)\end{array}$ & $\begin{array}{c}1.70 \\
(0.05)\end{array}$ & $\begin{array}{c}0.08 \\
(0.01)\end{array}$ & $\begin{array}{c}0.17 \\
(0.01)\end{array}$ & $\begin{array}{l}1.15 \\
(0.05)\end{array}$ & $\begin{array}{l}3.97 \\
(0.18)\end{array}$ & $\begin{array}{l}2.87 \\
(0.14)\end{array}$ & nd & $\begin{array}{c}0.70 \\
(2.54)\end{array}$ & 8 \\
\hline $\begin{array}{l}\text { WK2-T1 (0.34-m) } \\
\text { Pop. } 1\end{array}$ & $\begin{array}{l}77.82 \\
(0.42)\end{array}$ & $\begin{array}{l}0.10 \\
(0.01)\end{array}$ & $\begin{array}{l}12.67 \\
(0.15)\end{array}$ & $\begin{array}{c}0.91 \\
(0.02)\end{array}$ & $\begin{array}{l}0.06 \\
(0.02)\end{array}$ & $\begin{array}{c}0.12 \\
(0.03)\end{array}$ & $\begin{array}{c}0.72 \\
(0.06)\end{array}$ & $\begin{array}{l}3.98 \\
(0.06)\end{array}$ & $\begin{array}{l}3.61 \\
(0.28)\end{array}$ & nd & $\begin{array}{c}3.68 \\
(1.07)\end{array}$ & 4 \\
\hline Pop. 2 & $\begin{array}{l}77.89 \\
(0.11)\end{array}$ & $\begin{array}{c}0.13 \\
(0.03)\end{array}$ & $\begin{array}{l}12.51 \\
(0.15)\end{array}$ & $\begin{array}{c}1.21 \\
(0.01)\end{array}$ & $\begin{array}{c}0.05 \\
(0.02)\end{array}$ & $\begin{array}{c}0.12 \\
(0.01)\end{array}$ & $\begin{array}{c}0.96 \\
(0.06)\end{array}$ & $\begin{array}{l}3.83 \\
(0.12)\end{array}$ & $\begin{array}{l}3.30 \\
(0.18)\end{array}$ & nd & $\begin{array}{c}6.03 \\
(2.16)\end{array}$ & 3 \\
\hline Pop. 3 & $\begin{array}{l}76.23 \\
(0.35) \\
\end{array}$ & $\begin{array}{c}0.20 \\
(0.03) \\
\end{array}$ & $\begin{array}{l}13.25 \\
(0.17) \\
\end{array}$ & $\begin{array}{c}1.82 \\
(0.07) \\
\end{array}$ & $\begin{array}{c}0.08 \\
(0.02) \\
\end{array}$ & $\begin{array}{c}0.20 \\
(0.03)\end{array}$ & $\begin{array}{l}1.21 \\
(0.05) \\
\end{array}$ & $\begin{array}{c}4.17 \\
(0.07)\end{array}$ & $\begin{array}{c}2.83 \\
(0.08) \\
\end{array}$ & nd & $\begin{array}{c}2.89 \\
(1.56)\end{array}$ & 8 \\
\hline $\begin{array}{l}\text { WK2-T2 (0.99-m) } \\
\text { Pop. } 1\end{array}$ & $\begin{array}{l}77.47 \\
(0.05)\end{array}$ & $\begin{array}{c}0.06 \\
(0.01)\end{array}$ & $\begin{array}{l}12.73 \\
(0.10)\end{array}$ & $\begin{array}{c}0.83 \\
(0.01)\end{array}$ & $\begin{array}{c}0.04 \\
(0.02)\end{array}$ & $\begin{array}{c}0.06 \\
(0.00)\end{array}$ & $\begin{array}{c}0.63 \\
(0.21)\end{array}$ & $\begin{array}{l}3.99 \\
(0.07)\end{array}$ & $\begin{array}{c}4.18 \\
(0.06)\end{array}$ & nd & $\begin{array}{c}6.07 \\
(2.08)\end{array}$ & 2 \\
\hline Pop. 2 & $\begin{array}{l}77.91 \\
(0.71)\end{array}$ & $\begin{array}{c}0.13 \\
(0.04)\end{array}$ & $\begin{array}{l}12.81 \\
(0.35)\end{array}$ & $\begin{array}{c}1.23 \\
(0.03)\end{array}$ & $\begin{array}{c}0.06 \\
(0.03)\end{array}$ & $\begin{array}{c}0.15 \\
(0.03)\end{array}$ & $\begin{array}{l}1.05 \\
(0.05)\end{array}$ & $\begin{array}{l}3.79 \\
(0.30)\end{array}$ & $\begin{array}{l}2.87 \\
(0.09)\end{array}$ & nd & $\begin{array}{c}6.13 \\
(2.46)\end{array}$ & 4 \\
\hline Pop. 3 & $\begin{array}{l}76.22 \\
(0.18)\end{array}$ & $\begin{array}{l}0.19 \\
(0.01)\end{array}$ & $\begin{array}{l}13.20 \\
(0.05)\end{array}$ & $\begin{array}{c}1.78 \\
(0.07)\end{array}$ & $\begin{array}{l}0.08 \\
(0.03)\end{array}$ & $\begin{array}{c}0.19 \\
(0.01)\end{array}$ & $\begin{array}{l}1.22 \\
(0.03)\end{array}$ & $\begin{array}{c}4.25 \\
(0.11)\end{array}$ & $\begin{array}{l}2.86 \\
(0.06)\end{array}$ & nd & $\begin{array}{l}2.96 \\
(0.90)\end{array}$ & 8 \\
\hline $\begin{array}{l}\text { WK2-T3 (1.90-m) } \\
\quad \text { Pop. } 1\end{array}$ & $\begin{array}{l}77.98 \\
(0.33)\end{array}$ & $\begin{array}{c}0.10 \\
(0.02)\end{array}$ & $\begin{array}{l}12.55 \\
(0.08)\end{array}$ & $\begin{array}{c}1.16 \\
(0.04)\end{array}$ & $\begin{array}{c}0.06 \\
(0.02)\end{array}$ & $\begin{array}{c}0.12 \\
(0.02)\end{array}$ & $\begin{array}{l}1.01 \\
(0.06)\end{array}$ & $\begin{array}{c}3.80 \\
(0.24)\end{array}$ & $\begin{array}{c}3.21 \\
(0.14)\end{array}$ & nd & $\begin{array}{c}4.55 \\
(2.84)\end{array}$ & 6 \\
\hline Pop. 2 & $\begin{array}{l}75.57 \\
(0.21) \\
\end{array}$ & $\begin{array}{c}0.23 \\
(0.03) \\
\end{array}$ & $\begin{array}{l}13.50 \\
(0.10) \\
\end{array}$ & $\begin{array}{c}1.87 \\
(0.08)\end{array}$ & $\begin{array}{c}0.10 \\
(0.01) \\
\end{array}$ & $\begin{array}{l}0.25 \\
(0.04) \\
\end{array}$ & $\begin{array}{c}1.37 \\
(0.07) \\
\end{array}$ & $\begin{array}{l}4.30 \\
(0.08) \\
\end{array}$ & $\begin{array}{l}2.81 \\
(0.12) \\
\end{array}$ & nd & $\begin{array}{r}4.28 \\
(1.69) \\
\end{array}$ & 8 \\
\hline $\begin{array}{l}\text { WK2-T4 (4.65-m) } \\
\text { Pop. } 1\end{array}$ & $\begin{array}{l}76.67 \\
(0.53)\end{array}$ & $\begin{array}{c}0.11 \\
(0.04)\end{array}$ & $\begin{array}{l}12.77 \\
(0.36)\end{array}$ & $\begin{array}{l}1.11 \\
(0.19)\end{array}$ & $\begin{array}{c}0.04 \\
(0.02)\end{array}$ & $\begin{array}{c}0.15 \\
(0.05)\end{array}$ & $\begin{array}{c}0.96 \\
(0.18)\end{array}$ & $\begin{array}{c}3.91 \\
(0.41)\end{array}$ & $\begin{array}{l}3.28 \\
(0.43)\end{array}$ & nd & $\begin{array}{c}6.67 \\
(2.75)\end{array}$ & 7 \\
\hline Pop. 2 & $\begin{array}{l}75.99 \\
(0.27)\end{array}$ & $\begin{array}{c}0.18 \\
(0.02)\end{array}$ & $\begin{array}{l}13.23 \\
(0.12)\end{array}$ & $\begin{array}{c}1.81 \\
(0.05)\end{array}$ & $\begin{array}{c}0.09 \\
(0.02)\end{array}$ & $\begin{array}{c}0.18 \\
(0.01)\end{array}$ & $\begin{array}{l}1.27 \\
(0.04)\end{array}$ & $\begin{array}{c}4.32 \\
(0.11)\end{array}$ & $\begin{array}{l}2.93 \\
(0.08)\end{array}$ & nd & $\begin{array}{c}4.39 \\
(1.11)\end{array}$ & 10 \\
\hline $\begin{array}{l}\text { TT1-T1 }(1.40-\mathrm{m}) \\
\text { Pop. } 1\end{array}$ & $\begin{array}{l}78.41 \\
(0.43)\end{array}$ & $\begin{array}{c}0.11 \\
(0.03)\end{array}$ & $\begin{array}{l}12.57 \\
(0.12)\end{array}$ & $\begin{array}{c}0.91 \\
(0.04)\end{array}$ & $\begin{array}{l}0.06 \\
(0.01)\end{array}$ & $\begin{array}{c}0.13 \\
(0.03)\end{array}$ & $\begin{array}{c}0.70 \\
(0.09)\end{array}$ & $\begin{array}{c}3.73 \\
(0.46)\end{array}$ & $\begin{array}{l}3.38 \\
(0.36)\end{array}$ & nd & $\begin{array}{c}7.03 \\
(1.96)\end{array}$ & 4 \\
\hline Pop. 2 & $\begin{array}{l}75.78 \\
(0.39)\end{array}$ & $\begin{array}{c}0.22 \\
(0.04)\end{array}$ & $\begin{array}{l}13.39 \\
(0.19)\end{array}$ & $\begin{array}{c}1.93 \\
(0.11)\end{array}$ & $\begin{array}{c}0.09 \\
(0.02)\end{array}$ & $\begin{array}{c}0.23 \\
(0.04)\end{array}$ & $\begin{array}{l}1.25 \\
(0.10)\end{array}$ & $\begin{array}{l}4.26 \\
(0.08)\end{array}$ & $\begin{array}{l}2.84 \\
(0.09)\end{array}$ & nd & $\begin{array}{c}4.70 \\
(1.31)\end{array}$ & 10 \\
\hline $\begin{array}{l}\text { TT1-T2 (4.10-m) } \\
\quad \text { Pop. } 1\end{array}$ & $\begin{array}{l}77.91 \\
(0.48)\end{array}$ & $\begin{array}{c}0.12 \\
(0.03)\end{array}$ & $\begin{array}{l}12.60 \\
(0.29)\end{array}$ & $\begin{array}{c}0.98 \\
(0.13)\end{array}$ & $\begin{array}{c}0.06 \\
(0.03)\end{array}$ & $\begin{array}{c}0.13 \\
(0.04)\end{array}$ & $\begin{array}{c}0.78 \\
(0.17)\end{array}$ & $\begin{array}{l}4.00 \\
(0.15)\end{array}$ & $\begin{array}{c}3.42 \\
(0.33)\end{array}$ & nd & $\begin{array}{c}3.31 \\
(2.79)\end{array}$ & 8 \\
\hline Pop. 2 & $\begin{array}{l}75.84 \\
(0.38)\end{array}$ & $\begin{array}{c}0.21 \\
(0.03)\end{array}$ & $\begin{array}{l}13.29 \\
(0.16)\end{array}$ & $\begin{array}{l}1.88 \\
(0.07)\end{array}$ & $\begin{array}{c}0.09 \\
(0.02)\end{array}$ & $\begin{array}{c}0.22 \\
(0.04)\end{array}$ & $\begin{array}{l}1.31 \\
(0.10)\end{array}$ & $\begin{array}{l}4.26 \\
(0.12)\end{array}$ & $\begin{array}{l}2.90 \\
(0.10)\end{array}$ & nd & $\begin{array}{c}4.54 \\
(1.77)\end{array}$ & 10 \\
\hline $\begin{array}{l}\text { MM1-T1 (1.38-m) } \\
\text { Pop. } 1\end{array}$ & $\begin{array}{l}77.98 \\
(0.46)\end{array}$ & $\begin{array}{c}0.11 \\
(0.03)\end{array}$ & $\begin{array}{l}12.56 \\
(0.21)\end{array}$ & $\begin{array}{c}1.01 \\
(0.16)\end{array}$ & $\begin{array}{c}0.07 \\
(0.02)\end{array}$ & $\begin{array}{c}0.12 \\
(0.04)\end{array}$ & $\begin{array}{c}0.75 \\
(0.17)\end{array}$ & $\begin{array}{c}3.75 \\
(0.29)\end{array}$ & $\begin{array}{c}3.65 \\
(0.39)\end{array}$ & nd & $\begin{array}{c}3.25 \\
(2.75)\end{array}$ & 11 \\
\hline Pop. 2 & $\begin{array}{l}76.31 \\
(0.42)\end{array}$ & $\begin{array}{c}0.19 \\
(0.02)\end{array}$ & $\begin{array}{l}13.14 \\
(0.13)\end{array}$ & $\begin{array}{c}1.83 \\
(0.10)\end{array}$ & $\begin{array}{c}0.09 \\
(0.03)\end{array}$ & $\begin{array}{c}0.17 \\
(0.01)\end{array}$ & $\begin{array}{l}1.22 \\
(0.04)\end{array}$ & $\begin{array}{c}4.13 \\
(0.14)\end{array}$ & $\begin{array}{l}2.92 \\
(0.11)\end{array}$ & nd & $\begin{array}{c}4.85 \\
(1.54)\end{array}$ & 5 \\
\hline $\begin{array}{l}\text { WM1-T1 (1.25-m) } \\
\text { Pop. } 1\end{array}$ & $\begin{array}{l}77.69 \\
(0.21)\end{array}$ & $\begin{array}{c}0.10 \\
(0.01)\end{array}$ & $\begin{array}{l}12.54 \\
(0.06)\end{array}$ & $\begin{array}{c}1.13 \\
(0.20)\end{array}$ & $\begin{array}{c}0.04 \\
(0.05)\end{array}$ & $\begin{array}{c}0.11 \\
(0.03)\end{array}$ & $\begin{array}{c}0.83 \\
(0.09)\end{array}$ & $\begin{array}{c}3.79 \\
(0.42)\end{array}$ & $\begin{array}{c}3.75 \\
(0.29)\end{array}$ & nd & $\begin{array}{c}6.58 \\
(2.65)\end{array}$ & 3 \\
\hline Pop. 2 & $\begin{array}{l}75.90 \\
(0.26)\end{array}$ & $\begin{array}{c}0.23 \\
(0.03)\end{array}$ & $\begin{array}{l}13.34 \\
(0.10)\end{array}$ & $\begin{array}{c}1.89 \\
(0.09)\end{array}$ & $\begin{array}{c}0.10 \\
(0.02)\end{array}$ & $\begin{array}{c}0.22 \\
(0.03)\end{array}$ & $\begin{array}{c}1.32 \\
(0.06)\end{array}$ & $\begin{array}{c}4.19 \\
(0.08)\end{array}$ & $\begin{array}{l}2.81 \\
(0.05)\end{array}$ & nd & $\begin{array}{c}3.55 \\
(1.53)\end{array}$ & 11 \\
\hline
\end{tabular}

${ }^{a}$ All major element determinations were made on a JEOL Superprobe (JXA-8230) housed at Victoria University of Wellington, using the ZAF correction method. Analyses were performed using an accelerating voltage of $15 \mathrm{kV}$ under a static electron beam operating at $8 \mathrm{nA}$. The electron beam was defocused to $20 \mu \mathrm{m}$. All elements calculated on a water-free basis, with $\mathrm{H}_{2} \mathrm{O}$ by difference from $100 \%$. Total $\mathrm{Fe}$ expressed as $\mathrm{FeO}_{\mathrm{t}}$. Mean and \pm 1 standard deviation (in parentheses), based on $n$ analyses. All samples normalised against glass standard VG-568. Analysts: B. V. Alloway \& Franziska Landes; ${ }^{\mathrm{b}}$ Not determined or not available. 

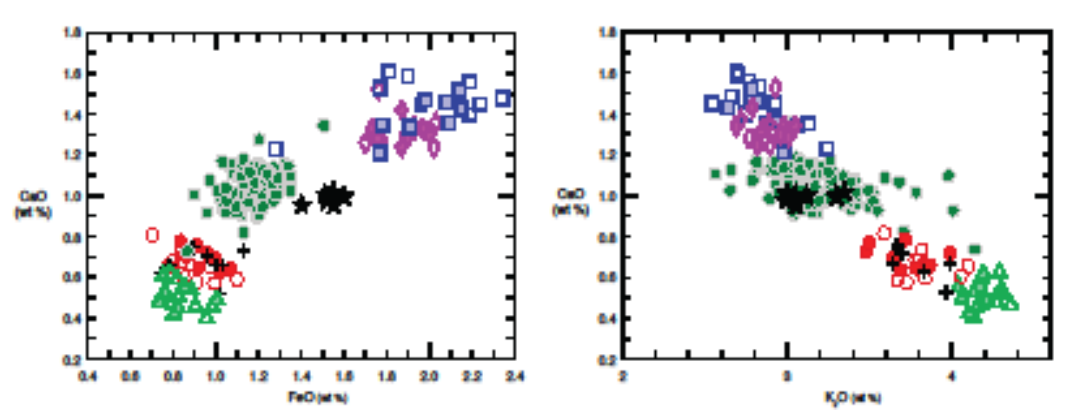

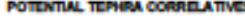

Katwes Tachis

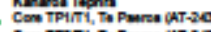

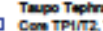

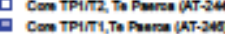

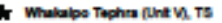

Walretata Troph

Con TPST2, To Pavra $(N=20 \%$

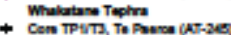

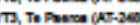

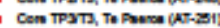

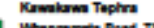
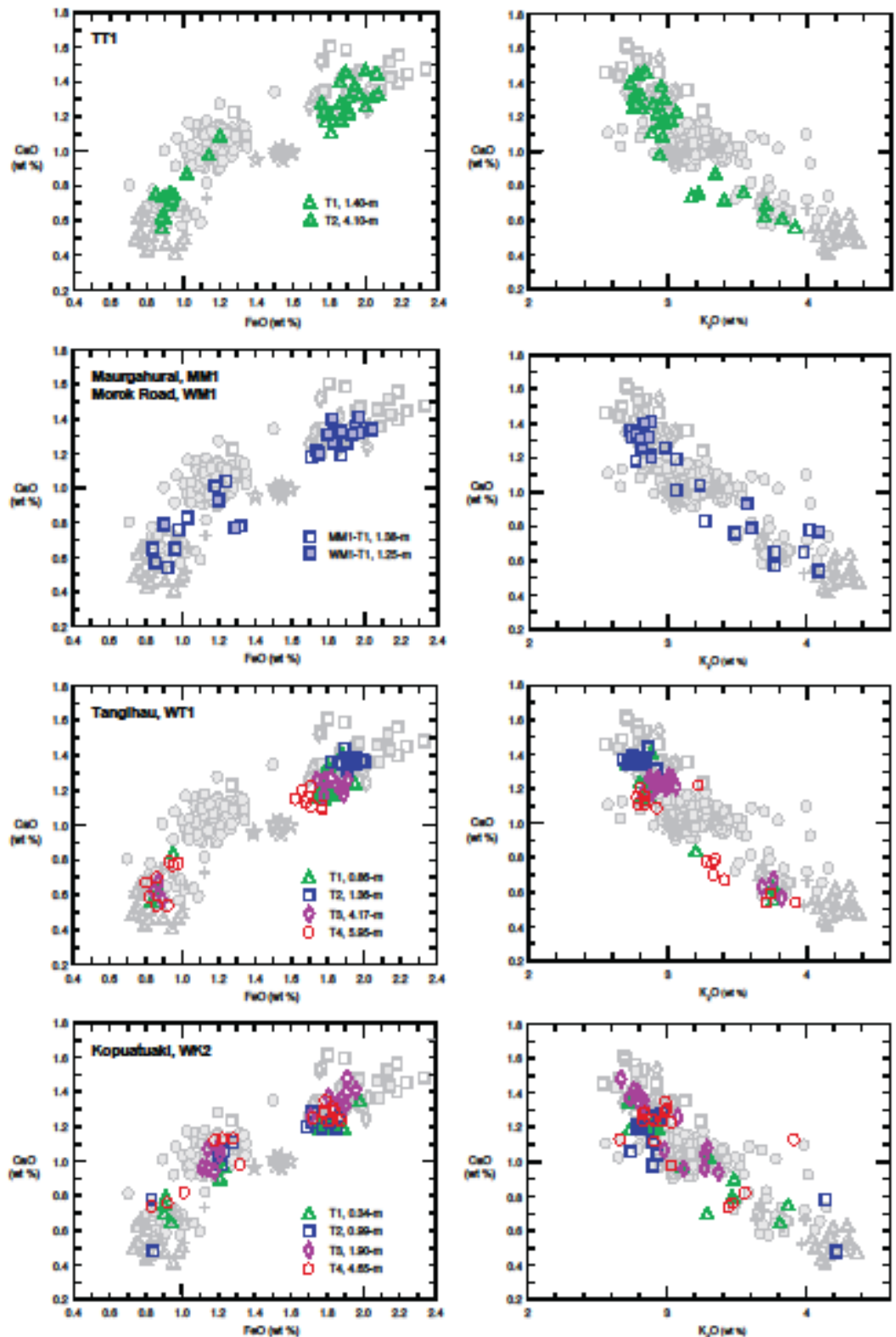

Figure 5.71. Tephra comparative plots. Shows the plots for tephra analysed at each site and compared to known standards. 


\subsection{Chapter summary}

The five main field sites of Mangakiore, Kopaatuaki, Tangihau, Monck Rd and Maungahaumi provide estimates for the ages of the landslide-dams and their termination date, total volumes of sediment captured by these features and also provide insights into the catchment dynamics throughout their existence. For the sites of Arai Matawai and Otara station only estimates for total volumes and minimum age of the blockage could be obtained. Onset ages for all seven landslide dams range from the present to more than 7000 cal. years BP with dams able to persist for several thousand years. . During this time they were efficient sediment traps, accumulating large volumes of fine-grained sediments. While the trapping efficiencies for these features cannot be readily determined by this study, initially they are likely to have been close to $100 \%$, with reducing efficiencies throughout their life span. The range of settings and catchment configurations has been useful for providing an understanding for the dynamics of the greater Waipaoa catchment. Modelled sediment accumulation volumes that were obtained from the Mangakiore site have compared favourably with the sediment delivery estimates for Cyclone Bola by Jones 2009. From this we can have confidence that the sediment volume estimates obtained by the modelling methodologies employed are reliable.

This study acknowledges that due to the many interpretations that have been made on where the age mid-points are, there could be considerable variations in rates of sedimentation and ages of landslide onset for the sites. For each of the sites presented in this study, there has been a preferred line of discussion that has been taken and it is understood that other interpretations could be taken from the data collected. This is especially the case in the use of the radiocarbon ages in the chronologies where there are considerable levels in the overlaps for the age ranges at each level of infill. Further, interpretations on the rate of decay in the trapping efficiencies of the dams may also in some cases affect the estimated ages for termination in some of the sites. This study has taken what it considers to be the best fit in terms of the studies understanding of the way these sites behave and has taken guidance from other complimentary studies and discussions outlined in the backgrounding chapters of this document. The interpretation of the findings and how they relate to the literature on sediment dynamics for the region will be discussed in the following chapter. 


\section{Chapter 6:}

\section{The measure of control; \\ landslide-dams and the Waipaoa region's sedimentary regime}




\subsection{Introduction}

This chapter is a synthesis of the preceding discussions on landslide-dams, catchment erosion and sediment transport. Chapter one of this report outlined the study's aims and objectives and posed the questions: 1/ What is the impact of landslide-dams on sediment transport in the Waipaoa catchment?; 2/ What does the sediment record of lakes formed from landslide-dams tell us about subsequent changes in catchment sediment dynamics? The following chapter uses the findings outlined in chapter five to address these questions and puts them into context with the key studies that have been introduced throughout the earlier discussions.

\subsection{Lifecycle of a landslide-dam lake}

From the analysis of the sediments and core logs for each of this study's sites, a few general observations can be made on the infill sequences for the landslide-dam lakes of the Waipaoa (figure 6.11). As discussed in earlier chapters, the blockage of the stream channel is dependent on the nature of the slope/channel coupling and on valley configuration, and these criteria generally limit landslide-dams to lower order channels, often in catchment headwaters. The landslide which creates the channel blockage may be triggered by ground shaking, a high magnitude but low frequency cyclonic rainstorm event, or a combination of elevated pore pressure due to extended wet periods and a lower magnitude earthquake. Irrespective of how the landslide is triggered, a large magnitude disturbance event is required for these features to form. Such large magnitude events not only initiate the deep-seated landslide that creates the landslide-dam feature, but may also trigger shallow surface failures on an extensive scale throughout the local catchment. These shallow surface failures mobilise large volumes of sediment as seen in the sediment delivery volume and analysis for the Mangakiore field site and in complementary studies such as those by Hicks et al. 2000, Kasai et al. 2005 and Marden et al. 2008a (discussed in chapter Three). Once the landslide-dam is formed, the initial infill rate for the reservoir is very rapid in the period that immediately follows. This rapid infill can be seen in the curves of all the infill charts in chapter five and is also evident in the structure of the sediment itself. Once the sediments dislodged by the disturbance event are exhausted in the landscape, sedimentation of the reservoir may settle into a regular rate for the 
individual catchment, punctuated by episodic disturbance events. The trapping efficiency of the reservoir is at its highest shortly after the initial event where it may be close to $100 \%$ and nearly all fine sediments generated from both storm events and background erosion are captured.

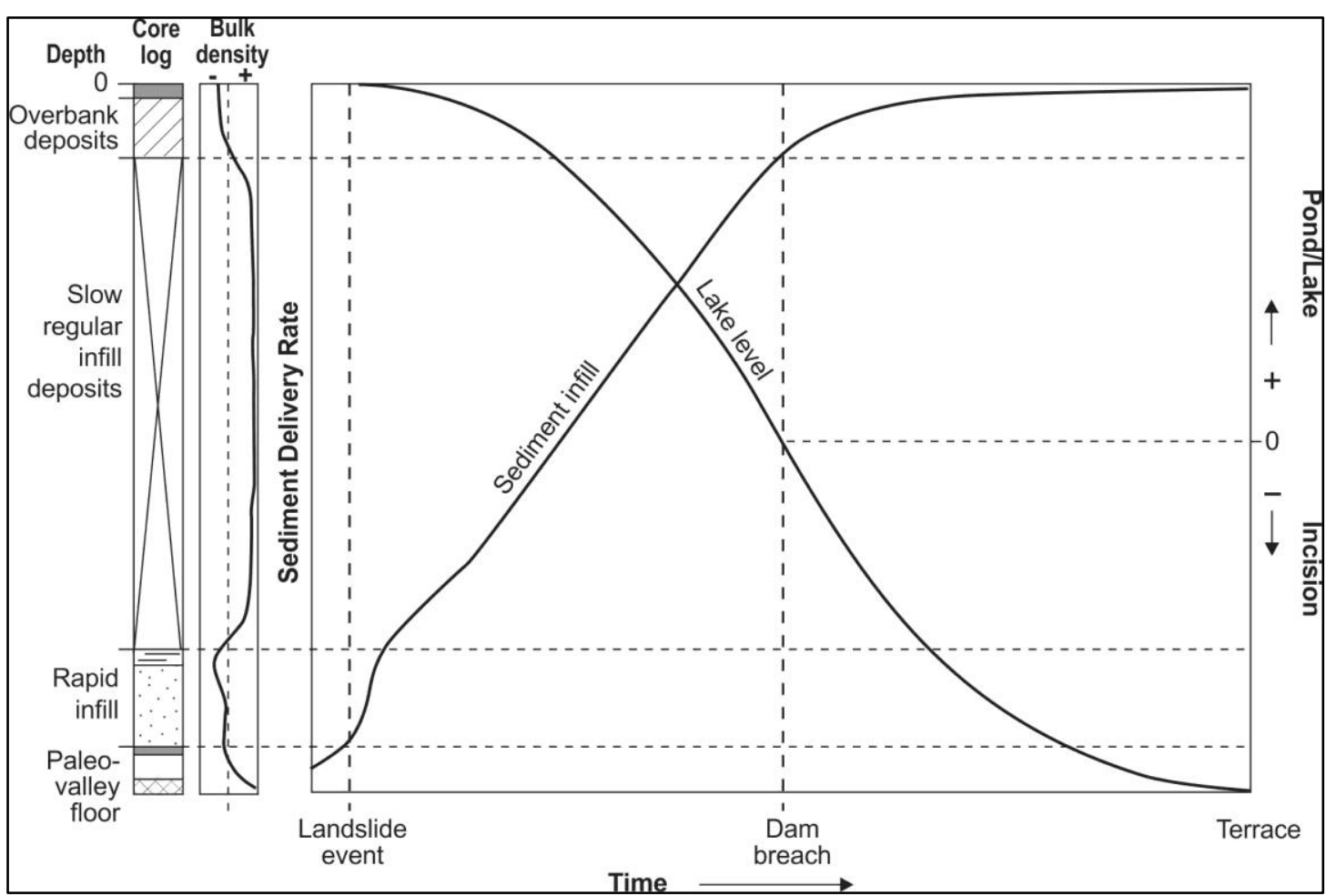

Figure 6.11. Landslide-dam lifecycle. An idealised model of the lifecycle of a landslide-dam lake. The sediment column on the left uses the symbols shown in figure 5.0 and shows the sediment history from the formation of the dam to the modern times as described in this section.

As described in chapter two, the drainage of landslide-dams typically occurs by seepage through the structure of the dam and the pond level is maintained below the dam crest. It is only for larger rainfall events that the reservoir will fill to the top with subsequent flow over the dam structure. The trapping efficiency of the dam for the regular rainfall events of up to a bank-full discharge will remain high, while the frequency for overtopping of the dam is still low. It is the catchment area to pond area ratio that is critical in the frequency of dam overtopping and a major control on dam longevity (discussed in chapter Two). During the second and slower stage of infill, a homogenous unit of fine-grained sediments typically represents both disturbance events and background erosion rates. When the catchment experiences extended periods of high rainfall and/or increased frequency of environmental disturbance, the reservoir sedimentation rates are much higher. The sediments laid down during these 
periods are less tightly packed, with lower bulk density and often a higher organic content due to higher volumes of topsoils and plant material washed off upper catchment slopes. This observation in the change of sediment structure is supported by the work at Tutira by Page et al. (2010) and Eden and Page (1998).

Through the dating of these periods of high activity in the Waipaoa cores, comparisons to the Tutira storm record and the known fault movement return periods are possible. When the landslide-dam lake's catchment experiences an isolated but large disturbance event, the event may be recorded in the cores taken from the sediment body as a band of coarser grained sediments. These single disturbance events are interpreted as being either ground shaking events or very large individual storm events. As the reservoir fills with sediments and the dam is incised by overtopping events, reservoir water depths drop, the ponds become shallower and overtopping occurs more frequently with smaller magnitude events. Therefore, the trapping efficiency for storm events is reduced over time and as a result suspended sediments are exported due to the establishment of more direct channel connections. The effect of a reducing trapping efficiency is not as great however for rainfall events of less than bankfull discharge and for these events trapping efficiency will still remain relatively high. For such events the trapping of sediments will continue to be high until there is a permanent channel formed in the deposited sediments and the incision of the dam is below that of the level of the infilled sediments. At this point the development of the sediment body transitions from one of a ponded environment to that of an alluvial terrace.

Once the channel has formed, the sediment body is only impacted by events which are large enough to cause overbanking deposits. Regular rainfall events below bankfull carry sediments in the channel and are deposited downstream of the reservoir. Texture of the sediment deposits becomes comparatively coarser, as a higher percentage of the fine clays are exported. When channelisation of the sediment body is deep enough that overbanking deposit events become rare, organic soil and vegetation develop. Sedimentation of the sediment body from this point on is from soil development processes and from slope wash of surrounding local slopes. Thus we see sediment accumulation reduce with time (refer chapter Two) and the rate of the decline is dependent on the many factors that control the catchment's sediment dynamic, 
together with the ratio of catchment area to reservoir (Verstraeten and Poesen, 2000). This study does not attempt to quantify the trapping efficiencies or what the curve is for the decline in efficiency with time, but looks at the average rates of deposition for the time slices taken within the sediment infill and makes the assumption that the rate of sedimentation experiences only minimal change within each section of the infill curve.

\subsection{Quantifying sediment volumes and timing for landslide- dams}

The arrival of warmer and wetter conditions that followed the termination of last glacial maximum (LGM), heralded a transition in the catchment's sedimentary regime. A fundamental change occurred from an environment of oversupply and deposition that had dominated throughout the colder glacial conditions, to one of undersupply and incision, where the erosion and transport of slope sediments exceeded the availability of terrestrial storage. As discussed in earlier chapters, much of the post glacial incision occurred during the last $12 \mathrm{ka}$ and is seen throughout the catchments as over-steepened slopes, abandoned river terraces and accelerated knickpoint retreat (Berryman et al. 2000 and Crosby and Whipple, 2006). Volumes of sediment transported by the Waipaoa River for this period of incision have been estimated at $24.6 \mathrm{~km}^{3}$, with the Marden et al. 2008b study suggesting that the slope mass-movement processes were responsible for up to $75 \%$ of this figure. Chapter four has shown that these sediments have been delivered to the coastal alluvial plain and the offshore sediment store of the continental shelf. Measurement of sediment volumes impounded behind large landslides provides rates of sediment delivery to the fluvial network, which can be used to estimate/indicate delivery volumes for the whole Waipaoa catchment.

The ages of landslide-dams in this study range from contemporary back through to the early-mid Holocene and their lifespans range from a few years to a few thousand years (table 6.21). With exception of the contemporary Mangakiore field site, all other sites represent a time period where the region experienced essentially complete forest cover. Despite the spread in age of onset and lifespan for the landslide-dams, there seems to be a clustering of ages for these features at around approximately $600 \mathrm{cal}$. 
years BP and 2600 cal. years BP. The landslide-dams that occur around 2600 cal. year BP are both in the same coastal sub-catchment of the Waimata. The two that occur around 600 cal. year BP are in different catchments and lithologies, but with similarly steep slopes and stream channels in the inland regions of the Waipaoa. As the landslides that are responsible for these landslide-dams can be triggered by either ground shaking from seismic events or elevated porewater pressures from extreme rainfall events (or a combination of the two), clustering of landslides in time may indicate that a significant event occurred at that time. The spread of the features across the catchment leads to the conclusion that the event was of significance at a catchment or local scale. Although with the small number of events in this study it is not possible to provide a conclusive answer to the scale of influence, one can speculate in terms of reference to events raised in other literature.

\begin{tabular}{|l|c|c|c|}
\hline Site name & $\begin{array}{l}\text { Age / Lifespan } \\
\text { (cal. years BP) }\end{array}$ & Sediment Volume & $\begin{array}{l}\text { Average sediment } \\
\text { delivery rate } \\
\text { (m } \mathbf{m} / \mathbf{h a} / \mathbf{y r})\end{array}$ \\
\hline Mangakiore & $1988 / 1$ year & $274.91 \times 10^{3} \mathrm{~m}^{3}$ & 1.90 \\
\hline Arai Matawai & $>7474 / ?$ & $443.09 \times 10^{3} \mathrm{~m}^{3}$ & \\
\hline Kopaatuaki & $2540 / 2400$ & $245.23 \times 10^{3} \mathrm{~m}^{3}$ & 0.74 \\
\hline Monck Road & $2600 / 1900$ & $497.41 \times 10^{3} \mathrm{~m}^{3}$ & 0.12 \\
\hline Otara Station & $>487 / ?$ & $89.21 \times 10^{3} \mathrm{~m}^{3}$ & 0.09 \\
\hline Tangihau & $3010 / 2774$ & $101.10 \times 10^{3} \mathrm{~m}^{3}$ & 1.21 \\
\hline Maungahaumi & $616 / 139$ & $19.85 \times 10^{3} \mathrm{~m}^{3}$ & . \\
\hline
\end{tabular}

Table 6.21. Sediment volumes, catchment sediment delivery rates and ages for the landslide-dams studied in the Waipaoa catchment.

For the Maungahaumi and Otara Station field sites, where the occurrence of the landslide is at around 600 cal. years BP, the sites are dominated by steep catchment slopes and stream channels, located in headwater catchments. These two sites are likely to be dominated by high incision rates and susceptible to strong fluctuations in climatic inputs. The storm record from Lake Tutira indicates a period of storminess around 500-600 cal. years BP and this study suggests that these two sites were influenced by the high storm frequency of this period. The increased channel incision and high rates of knickpoint retreat result from high flow events and prime the slopes for failure as discussed in chapter two (Marden et al. 2008b; Crosby and Whipple, 2006). These increased incision rates are due to the increased stream power that results from the amplified rainfall inputs of the high storm frequency periods. It is also likely that the conditions mentioned above were also responsible for the 
formation of the second slope failures that occurred at both the Mangakiore and Tangihau sites which formed landslide-dams around the same time as the Maungahaumi and Otara Station landslide-dams. The occurrence of these the four large landslides of similar timing may indicate an individual event of catchment wide significance, or the accumulative impact of increased catchment wide intense storm activity.

The two sites that cluster at the 2600 cal. years BP time period are in catchments that have a number of known active shallow faults and due to their coastal location, may be also susceptible to smaller movements on the offshore subduction faults. In the Tutira storm record the timing of these two landslides also correlates with a period of increased storm activity. While it is not one of the ten major storm periods the there is increased storm activity over a 70 year period that centres on 2485 cal. years BP (Page et al. 2010) and with the associated age control errors from both studies could mean that there is sufficient overlap. Earthquakes could also be considered as responsible for the onset of both the Tangihau and the Arai Matawai sites, where onset ages of 3010 and $>7474$ cal. years BP place them as coincident with movements within the large dextral fault belt of the Raukumara Ranges and the formation of lakes Waikaremoana and Tutira, respectively. However the formation of the Tangihau landslide-dam at $3010 \mathrm{cal}$. years BP also centres on one of the ten periods of major storm activity in the Tutira storm record, while the Arai Matawai landslide-dam is considered to be of similar age to the Tutira dam itself so no storm record information is available.

Turning to the consideration of the lifespan of landslide-dams, this research shows a connection to the location of the catchment. As discussed in chapter two, the longevity of the dams are a function of the competency and volume of the dam material, the pond area in relation to the catchment area and the rate of inflow or stream power which is a function of catchment area and slope (Adams, 1981; Costa and Schuster, 1988; Korup, 2004). Table 6.22 below shows at each site the values for the factors that have been shown to control dam longevity. For the sites in this study it would appear that channel slope and drainage density may be a stronger control on dam life than area. Sites located in the two steepest catchments both have the shortest life spans, though both have vastly different catchment areas. Whereas for the longer 
lived dams the catchments all have lower channel gradients. While this finding is not one of the aims of this project, it could be tested by a study of further sites.

\begin{tabular}{|l|l|l|l|l|l|l|l|}
\hline & Maungahaumi & $\begin{array}{l}\text { Otara } \\
\text { St }\end{array}$ & Tangihau & $\begin{array}{l}\text { Arai } \\
\text { Matawi }\end{array}$ & Mangakiore & Kopaatuki & $\begin{array}{l}\text { Monk } \\
\text { Rd }\end{array}$ \\
\hline $\begin{array}{l}\text { Dam lifespan } \\
\text { (years) }\end{array}$ & 139 & $?$ & 2774 & $?$ & 1 & 2400 & 1900 \\
\hline $\begin{array}{l}\text { Catchment } \\
\text { area (ha) }\end{array}$ & 1180 & 168 & 398 & 764 & 697 & 168 & 2130 \\
\hline $\begin{array}{l}\text { Landslide area } \\
\text { (ha) }\end{array}$ & 16.97 & 19.38 & 15.10 & 49.61 & 15.48 & 10.10 & 20.30 \\
\hline $\begin{array}{l}\text { Channel } \\
\text { gradient }\end{array}$ & 0.10 & 0.15 & 0.11 & 0.09 & 0.07 & 0.08 & 0.03 \\
\hline $\begin{array}{l}\text { Drainage } \\
\text { density } \\
\text { (km/km2) }\end{array}$ & 6.15 & 10.58 & 3.49 & 6.00 & 6.37 & 7.76 & 2.99 \\
\hline $\begin{array}{l}\text { Catchment/po } \\
\text { nd } \\
\text { Ratio }\end{array}$ & 0.002 & 0.009 & 0.003 & 0.007 & 0.006 & 0.035 & 0.005 \\
\hline $\begin{array}{l}\text { Site } \\
\text { orientation }\end{array}$ & SE & S-SE & NE & E-NE & S & E-SE & NW \\
\hline
\end{tabular}

Table 6.22. Controls on dam longevity.

The factors that influence the stream power calculations are also however interesting in terms of catchment sediment dynamics and the infill of the landslide-dam lakes. This is seen in the rating curves of figure 6.31, where the steeper northern catchment of Mangatu has a higher per hectare sediment delivery rate than the less steep catchments of Te Arai, Wharekopae and Waimata, and is supported by studies such as Hicks et al. 2000 and discussed in chapter three. The volumes of sediment trapped by the dams and calculated by the modelling shows a range of $100-500 \times 10^{3} \mathrm{~m}^{3}$ of fine grain sediments. These volumes relate to what the reservoir can hold and are influenced by the shape and size of the valley, with the time for accumulation relating to the catchment characteristics influencing stream power. The individual site volumes listed in table 6.21 are small when compared to the volumes of the displaced material that formed the channel blockage and the volumes of sediment exported by the catchment as discussed in chapter three. The results of the volume modelling data combined with the chronologies for sediment infill have been used to estimate sediment delivery in terms of volume per catchment area on an annualised basis.

\subsection{Comparing catchment erosion rates}

The sub-catchments in which the landslide dams are located have a range of catchment characteristics and erosion/sedimentation rates. For five of the field sites 
the dating of key horizons (defined by sedimentary changes within the cores) has allowed sediment volumes to be converted into catchment sediment delivery rates to the transport network and are expressed in $\mathrm{m}^{3} / \mathrm{ha} / \mathrm{yr}$, with considerable variation shown within and between the catchments of this study (figure 6.31).

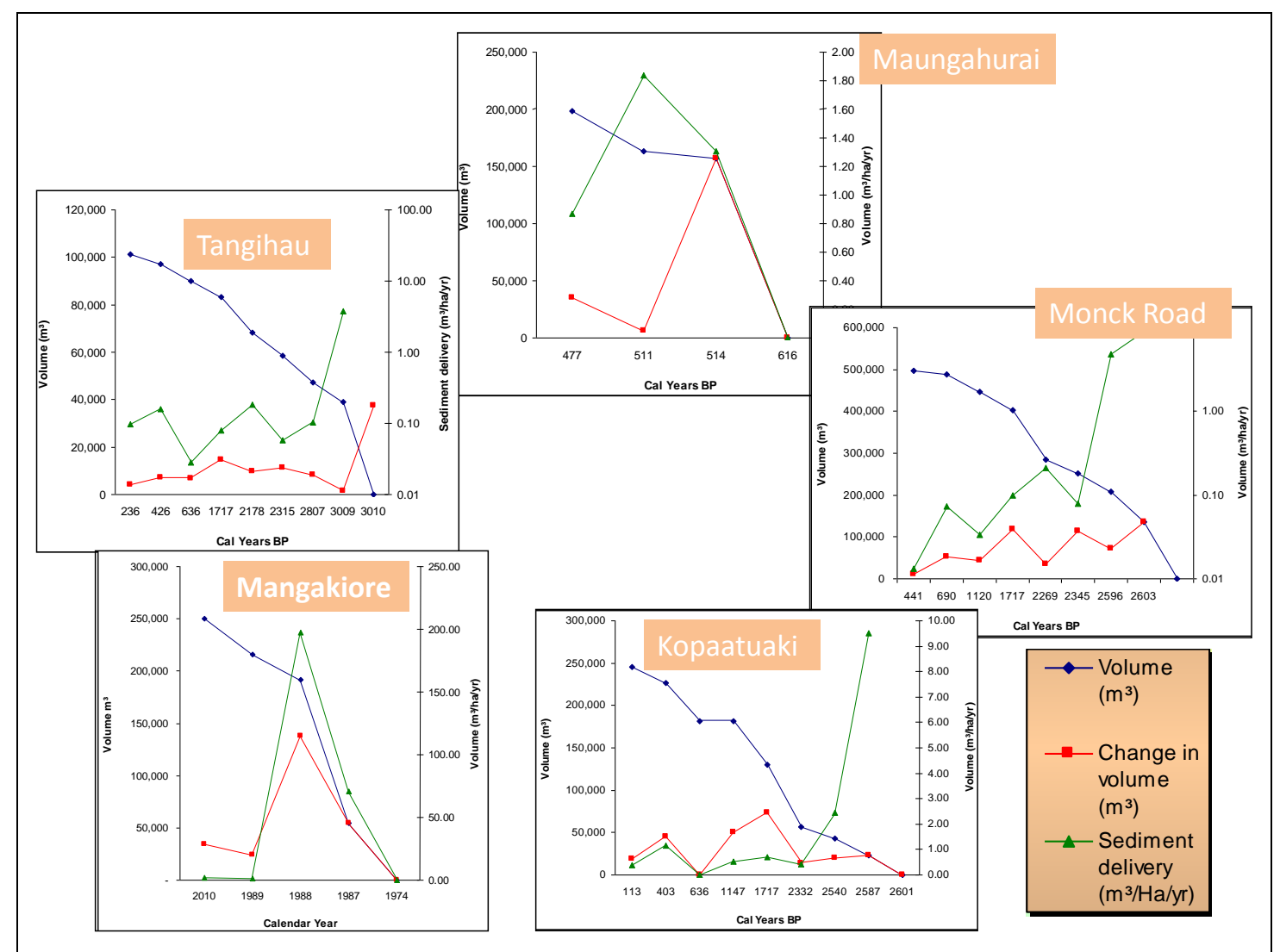

Figure 6.31. Sedimentation rates curves for five of the study sites.

For this study, the average calculated sediment delivery rate throughout the catchment under forest cover and for all sub-catchments is $0.49 \mathrm{~m}^{3} / \mathrm{ha} / \mathrm{yr}$. For a catchment under non-forested conditions, the Mangakiore catchment has been used as a modern analogue and has been calculated at $1.90 \mathrm{~m}^{3} / \mathrm{ha} / \mathrm{yr}$. This shows a fourfold increase in mean sediment delivery rate between these two land cover types. This suggests that sediment delivery for the catchment under the cooler, non-forested conditions that prevailed early in the post glacial period was greater than during the conditions that would prevail under the forest canopy that existed from approximately $12 \mathrm{ka}$ and is in agreement with studies on incision rates such as Litchfield and Berryman (2006). This calculated fourfold increase between landcover types however is low when compared to that of other studies such as Kasai et al. (2005) and Marden et al. (2008b) where a 
tenfold change in erosion rates between forested and non-forested catchments under modern conditions has been recorded. Climatic records such as the Tutira record suggest that the climatic conditions of the Holocene while variable, have not been greatly different from that of today. The comparisons of erosion rates between landcover types for this study should therefore still be comparable to those of studies in today's conditions. There is however a considerable variation between the individual sites of this study, with the study site in the Mangatu catchment showing delivery rates considerably higher than sites of the Te Arai, Wharekopae and Waimata catchments. When Mangatu results are removed and comparisons of the catchment delivery rates between forest cover and non-forest cover are made with sites of similar lithology to that of the Mangakiore site, the rates compare more closely to the tenfold estimates used in other studies in the Waipaoa $\left(0.24 \mathrm{~m}^{3} / \mathrm{ha} / \mathrm{yr}\right.$ and $1.90 \mathrm{~m}^{3} / \mathrm{ha} / \mathrm{yr}$ rate respectively). The catchments of Tangihau, Monck Road and Kopaatuaki are all in similar lithologies to that of Mangikiore and the sedimentation rates for these sites are similar as seen in the graphs in figure 6.31.

In the older, more erodible lithologies of the Waipaoa catchment, as represented by the Maungahurai field site, where there is a higher per-hectare sediment delivery rate with an average of $1.21 \mathrm{~m}^{3} / \mathrm{ha} / \mathrm{yr}$. The Maungahurai site is further inland and at higher elevation experiencing a higher average rainfall. The Maungahuai catchment is also in a region that experiences uplift and incision rates of up to four times that of the lower field sites in this study as shown in the studies by Hicks et al. (2000), Berryman et al. (2000) and Litchfield and Berryman, 2006 and discussed in chapter three. The difference in the sediment delivery rates between the higher and lower elevation regions of the Waipaoa is approximately 4 times and this study suggests that this is expressed in the sediment delivery rates for the regions, suggesting that sediment delivery rates are comparable to the uplift and incision rate of these catchments. There could be an influence of individual catchment characteristics on sediment delivery between the catchments in the younger Tolaga Group. Here, long term average infill rates and catchment erosion rates for the larger Monck Road and Tangihau catchments are similar at $0.13 \mathrm{~m}^{3} / \mathrm{ha} / \mathrm{yr}$, while the much smaller Kopaatuaki catchment has a greater rate of $0.59 \mathrm{~m}^{3} / \mathrm{ha} / \mathrm{yr}$. The main differences between these sites, apart from catchment area, are the hydraulic conditions of the catchment with the drainage density for the higher yielding Kopaatuaki catchment, which is 
approximately three times that of the other sites. This suggests that slope channel connectivity is an important control on sediment delivery, as discussed in the section on sediment delivery concepts in chapter two.

At the individual sites there is also considerable variability in the estimated catchment sediment delivery rates through time, indicating that there have been changes in the environmental conditions affecting erosion. Table 6.31 summarises the annualised mean high and low rate for each of the catchments. Once again variability is seen within and between the catchments of the study. Periods with low sedimentation rates represent the background erosion for the catchments, while the periods with high sedimentation indicate catchment disturbances from events such as intense storms or earthquakes. For the older sites that represent the forested conditions for the catchment, the disturbance periods deliver approximately twice the volume as for those of the calm periods. For the Mangakiore site delivery rates under grass cover are an order of magnitude larger for both the background rate and event disturbance rate than the forested catchments of this study. These differences between these rates for landcover type are consistent with what we would expect and are comparable to the findings in the Tutira records found in Page et al. (2010) and Orpin et al., (2010).

\begin{tabular}{|l|l|l|l|}
\hline Site Name & $\begin{array}{l}\text { High sedimentation } \\
\text { rate } \\
\left(\mathrm{m}^{3} / \mathrm{ha} / \mathrm{yr}\right)\end{array}$ & $\begin{array}{l}\text { Low sedimentation } \\
\text { rate } \\
\left(\mathrm{m}^{3} / \mathrm{ha} / \mathrm{yr}\right)\end{array}$ & Duration (years) \\
\hline Maungahaumi & 1.87 & 0.87 & 139 \\
\hline Tangihau & 0.18 & 0.07 & 389 \\
\hline Kopaatuaki & 0.79 & 0.44 & 168 \\
\hline Monck Road & 0.21 & 0.09 & 2130 \\
\hline Mangakiore & 150.49 & 1.90 & 697 \\
\hline
\end{tabular}

Table 6.31. Ranges in sedimentation rates.

\subsection{The role of storms and earthquakes}

Of the study sites for this project, four have overlapping time lines, with the Tangihau, Monck Road and Kopaatuaki sites experiencing approximately 2000 years of shared history. The sites of Arai Matawai and Otara Station also may have overlapped but the lack of age control at the termination of sedimentation of the sites excludes them. The linking of the four cores with known overlap was established through the stratigraphies and chronologies provided by the radiocarbon ages and the 
tephra layers discussed in chapter four. The geographic spread of the sub-catchments means they likely experienced differing environmental conditions and underwent differing response rates to shared events. Where a period of increased sediment influx is evident at only one site, it may be that the site experienced a disturbance event that was only locally felt. However, there are periods of both high and low sedimentation at the Kopaatuaki (WK2), Monck Road (WM1) and Tangihau (WT1) sites that can be correlated (Fig. 6.41).

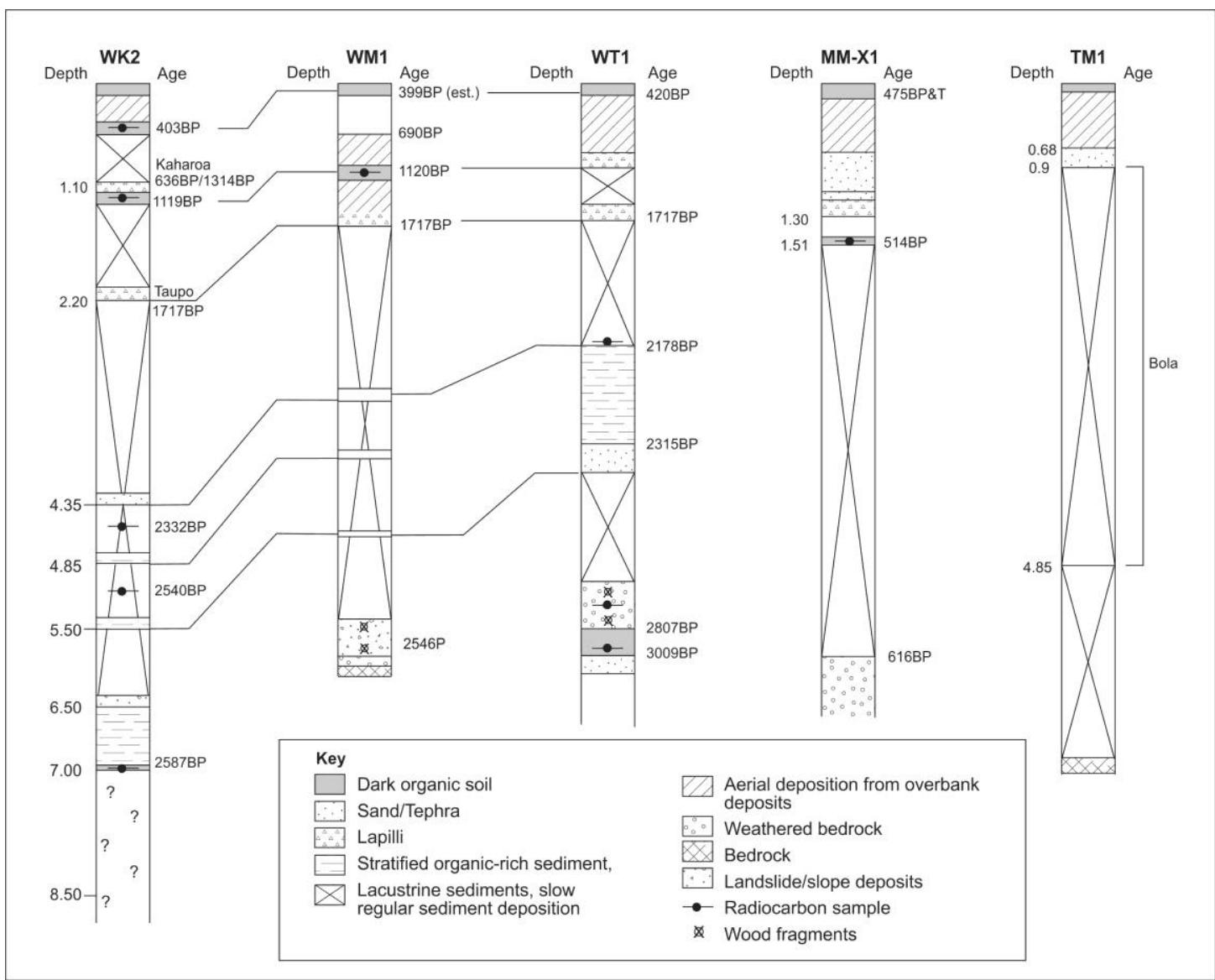

Figure 6.41. Core log comparisons for the main sites.

The sediment columns for the sites of WK2, WM1 and WT1 shown in figure 6.41 all exhibited layers of sediments representing erosion from within the catchment caused by disturbance events. From the age and volume calculations for these sites it is evident that there are similarities in the timing, the volumes delivered and the relative core depths of these events for each of the sites. The timing of these events is estimated at approximately 2500-2200 cal. years BP. The disturbance events occurred during periods when the cores had settled into regular sedimentation patterns following the dam formation and the phase of rapid infill that usually follows. The disturbance events are most strongly evident in the coastal sites of WK2 and WM1 
where there are three clear individual layers of sediment where the texture and bulk density is different to the sediments above and below. The changes in texture and bulk density represent event delivery were rapid accumulation leads to less well packed coarser grain sediments that have a lower bulk density value. These event layers are less well defined for the more inland site of WT1 but sedimentation was similarly rapid during this time period.

In the sedimentary sequence at the further inland WT1 site, these three disturbance events are evident as a sequence of sediments of high organic content. As these cores all indicate disturbances of similar timing and across a wide region, it seems that each individual event was large enough to have a regionwide impact. Using the evidence from modern earthquakes compiled by Litchfield et al. (2009b) and discussed in the chapter three section on the geological and tectonic setting of the region, these events could be caused by faults such as the Repongaere fault of the central forearc region. Individual faults in this group are thought to have movement return intervals of 5500 years but for ground shaking events of MM7 plus from the combined faults return time is estimated to be 26 years (Litchfield et al., 2009b). The timing of these disturbance events does not line up with any of the known storm periods in the Tutira record, however the return time of approximately 1 in 100 years is consistent with return intervals of the Bola size cyclonic events. The diminished catchment response further inland would also suggest that while these events were large in themselves, they were more coastal in their impact and focused on the Gisborne region.

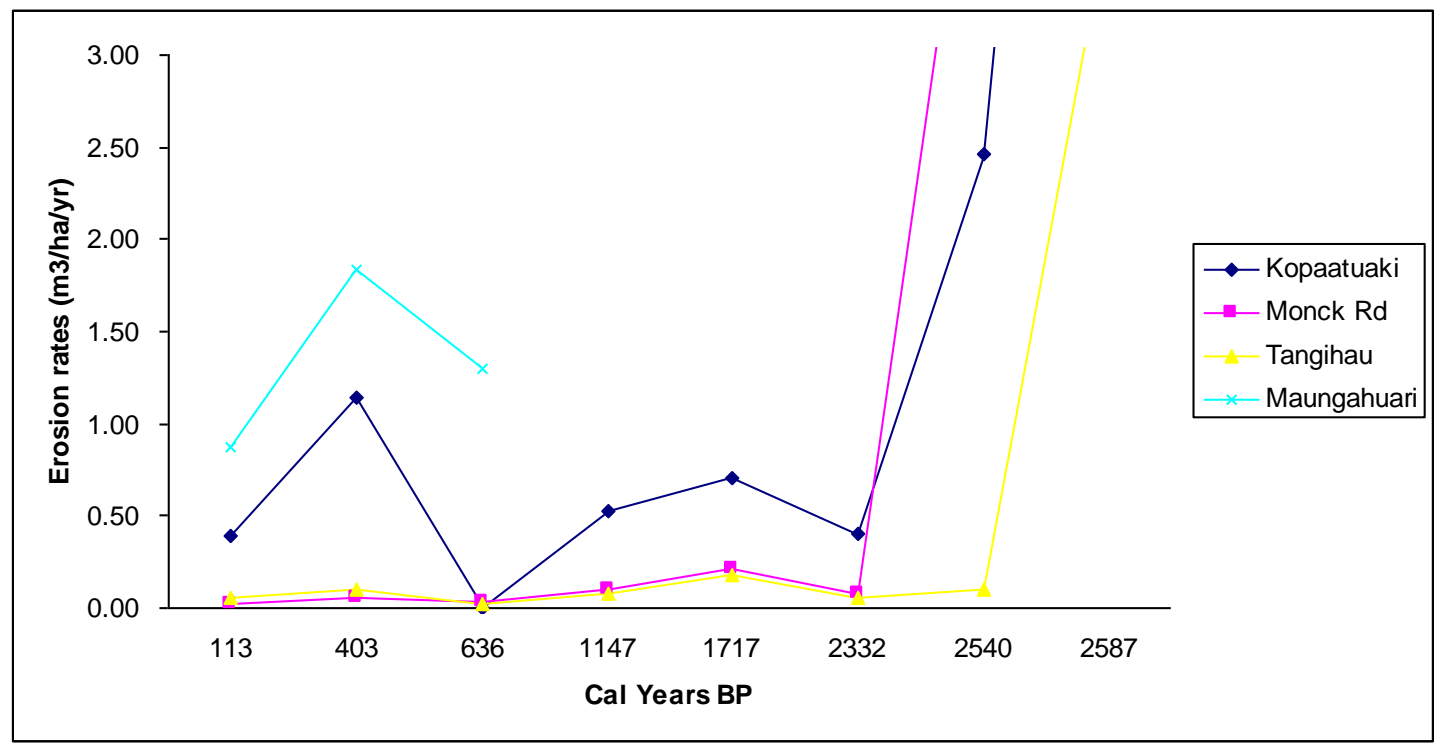

Figure 6.42. Comparisons for sediment delivery rates for Waipaoa core sites. 
Figure 6.42 shows that the Tangihau, Monck Road and Kopaatuaki field sites all record a period of increased sedimentation which peaks at 1717 cal. years BP. This correlates with a period of increased storm activity centring on 2000 cal. years BP in the Lake Tutira record. Page et al. (2010) described this period as being one of the most intense in terms of both storm magnitude and frequency. The curves in figure 6.42 show that this period of intense storm activity is also evident in the Waipaoa cores with the impact of the storm activity being felt region wide. High rates of infill also continue in the Waipaoa cores of Kopaatuaki, Monk Road and Tangihau during the next Tutira storm phase of 1250-1100 cal. years BP, although this period is not as intense as that of the $2100-1850$ cal. years BP period of storm activity. Due to a lack of dating points in the cores it is not possible to narrow down further these high frequency periods and those of the intervening low activity periods. For those periods however, catchment erosion rates are above the average and background rates for infill. The most recent of the storm activity periods and the second highest in terms of activity and intensity from the Tutira record, occurs from 700-500 cal. years BP and is seen in the Waipaoa cores as shown in figure 6.42. This period of storm intensity was also of region wide impact and is recorded in the Kopaatuaki, Monck Road, Tangihau and the Maungahuri cores.

\subsection{The spatial and temporal influence on sediment delivery}

Modelling results of sediment volumes presented in chapter five and displayed in table 6.21 have provided an estimated minimum volume for fine sediments that have been impounded for each of the landslide-dams surveyed as part of this study. The values for these individual sites can be viewed as a cumulative volume (table 6.51) and as a represented sample set expanded to include the 33 sites that have been identified in the large landslides database as having impounded sediments. This study calculates that the total volume for the 33 landslide-dams is $8 \times 10^{-9} \mathrm{~km}^{3}$. This volume, when looked at in terms of the $24.5 \mathrm{~km}^{3}$ of sediment eroded in the Waipaoa since the LGM, is inconsequentially small. If these volumes calculated were extended to the 831 landslides that were identified as having interacted with the stream channel, but having no evidence of impounded sediment, the total volume could be as much as $0.39 \mathrm{~km}^{3}$. This would assume that these additional landslides have an average age of the landslides in the study, have blocked the stream channel for a period of time and 
that evidence of these impounded sediments is masked in the landscape or has been removed. Here the volumes of sediment trapped at these additional sites may be much larger and if this were the case, the sediment volumes would need to be further refined by including the erosion rates of these features post incision and allowing for the volume of removed sediments.

\begin{tabular}{|c|c|}
\hline Sites & Sediment volume \\
\hline Total for all sites & $1.85 \times 10^{6} \mathrm{~m}^{3}$ \\
\hline $\begin{array}{c}\text { For the 33 sites of the } \\
\text { LLDB }\end{array}$ & $8.71 \times 10^{6} \mathrm{~m}^{3}$ \\
\hline
\end{tabular}

Table 6.51. Sediment volume and projections. Includes all of large landslides showing evidence of channel blockage in the large landslide database (LLDB).

As discussed in chapter two, large deep-seated landslides can stay visible in the landscape for many thousands of years and where they have interacted with the valley floor they change the profile and slope of the river channel. For each of the landslide-dams in this study there has been removal of sediments from the impounded sediment body. This removal of sediments varied from minor to almost complete removal of the sediment body. This would suggest that landslide scars may stay visible long after the sediment body has been removed and that channel blockages from landslide-dams may be more common than the landslide database suggests. Also, where large deep-seated landslides have displaced stream channels and raised river beds but not interacted with the opposite valley slope to create a full channel blockage, these features may still impound volumes of sediment upstream of the slope failure. It is the suggestion of this study that the impoundment of sediments from deep-seated landslides in the Waipaoa may be a significant influence on the pulsing of sediments throughout the catchment. From the small sample set of deep-seated landslides in this study it would be speculation to comment further on the spatial and temporal patterns of these features.

The age distribution of landslide-dams in this study can be evaluated in relation to the theory of Crosby and Whipple, (2006) in regards to knickpoint retreat in response to the base level change acting as a primer to slope stability. The data presented here suggest there is a trend to younger landslides higher in the catchment and older well preserved landslides in the coastal reaches, which 
would support their theory. Also, the Tangihau field site, where two landslides occurred in the same stretch of channel, is consistent with this theory as the younger landslide occurred upstream. There were several examples at other sites of landslides that had occurred both upstream and downstream of the studied site. In these cases there is no empirical evidence to support the theory of knickpoint migration but the circumstantial evidence would support it. There are many large deep-seated landslides in the Waipaoa catchment and the landscape is predisposed to failures from many other controls such as bedding structure and slope angle and this study therefore suggests that the response to knickpoint retreat is inconclusive. Further study of landslide distribution and age in one catchment (e.g. Kopaatuaki catchment) would be warranted to assess the spatial distribution of these large landslides in relation to knickpoint retreat.

\subsection{Chapter summary}

- Landslide-dams experience a decay in the trapping efficiency and the retention of sediments eroded in the catchment with time. The rate in this reduction in trapping efficiency is dependent on stream power and is initially more marked for sediments eroded during storm events where stream discharges are high. Once dam breach occurs and stream channel connectivity is re-established, then the sediment accumulation of the sediment body stems only from overbanking deposition. This means that sediments from storm discharges are more evident in the lower sections of the cores as pulses of high sediment input which interrupt the pattern of regular sedimentation as well as after a dam breach, evident as layered overbank deposits.

- Formation of landslide-dams in this study can be linked to both known intense storm periods from the Tutira storm record and movements of the major offshore faults that have formed lakes Tutira and Waikaremoana. Large storms and ground shaking events can both have region-wide effect. Core sequences with overlapping timelines show that there have been disturbance events that have been experienced catchment wide. The disturbance events are considered 
to be most likely due to cyclonic storms and indicate a recurrence period of 100 years, similar to what the catchment experiences today.

- Sediment delivery rates are variable within and between the catchments of this study. The delivery rates calculated in this study show a 1.7 times increase in headwater versus lowland catchments. This is comparable to the variation in uplift rates across the Waipaoa catchment. The study has also shown that a doubling of catchment sediment delivery rates occurs during periods of increased storm activity for all lithologies. Comparisons of the erosion rates for forested and non-forested catchments confirm an order of magnitude increase in both the storm rate and the background rates of erosion. 
Chapter 7

\section{Conclusions and reflections on landslide-dam lakes in palaeo- environmental research}




\subsection{Conclusions of sedimentary significance}

It has been the thesis of this study that research into the sedimentation of small landslide-dam lakes can provide useful insights into the catchment dynamics and further the understanding of palaeo-climatic and seismic studies of a region. Through the investigation of seven of these landslide-dams and their reservoir sediments in the Waipaoa catchment, this study set out to achieve three objectives.

Objective 1: To provide minimum ages for the onset and termination of landslidedams selected for this study.

The study has shown that the seven landslide-dams are of mid to late Holocene age, with a cluster of ages at approximately 600 and 2600 cal. years BP. The youngest landslide-dam was at the modern Mangakiore landslide, which occurred during a cyclonic storm event which delivered a devastating volume of rainfall and had a catchment wide impact. The oldest site was that of the Arai Matawai landslide-dam in the Te Arai sub-catchment, the same sub-catchment as Mangakiore. The study found that in general the older and longer lived landslide-dams were in the coastal Te Arai and Waimata catchments. The younger and shorter lived landslide-dams tended to be in the steeper inland catchments of Mangatu and a small sub-catchment at the head of the Poverty Bay Flats. These landslide-dams were able to persist in the landscape for timescales ranging from a few years to a few thousand years and the longevity of the landslide-dam was dictated by catchment characteristics affecting stream power and the ratio of catchment area to landslide-dam reservoir area.

Objective 2: To quantify the volumes of sediment trapped behind the landslide-dams.

For the seven field sites a cumulative total of approximately 1.8 million cubic metres of sediment was retained by landslide-dams. When this was extrapolated to the other known landslide dams, the volume estimated was close to 10 million cubic metres. The sediment volumes retained by landslidedams represent only a temporary disruption to sediment delivery in the 
Waipaoa catchment, with the onset and termination of the dam causing a pulsing of sediment delivery. The cumulative volumes of sediment are also relatively small on a catchment wide scale and while there are large numbers of landslides throughout the greater Waipaoa catchment, there are not many where sediments impounded by channel blockage have persisted to the present day. Following dam breach and the re-establishment of sediment pathways, sediments trapped by landslide dams are remobilised and exported from the catchment. The rate of removal has not been established by this study, but as with all sites, there are varying degrees of sediment removal. Further research into the removal rates would enhance the understanding of sediment pulsing within the catchment.

Objective 3: Establish rates of sediment delivery for the sub-catchments and the changes to the catchment's sediment delivery regime over time.

With the exception of the modern field site of Mangakiore, all other field sites are of mid to late Holocene age and represent conditions when the Waipaoa catchment was covered in dense natural forest. The pastoral grass cover of today's catchment, provides an analogue for sediment delivery rates under the native grass cover of the cooler post glacial catchment, and these rates are an order of magnitude greater than under the dense native forest cover that was common for much of the last $\sim 12 \mathrm{ka}$. The study has shown that there has been considerable variability in sediment delivery for sub-catchments of the Waipaoa and that this is a reflection on the environmental conditions that affected catchment erosion rates. Catchment erosion is highly influenced by cyclonic storm activity and these large scale weather events can be both of regional and local influence within the Waipaoa catchment. The study has also demonstrated that erosion rates are influenced by uplift and stream incision rates and that the headwaters of the Waipaoa catchment are experiencing 1.7 times the erosion rates to that of the lowland and coastal catchments. Throughout the Holocene, as demonstrated in the Tutira studies by Page et al. (2010) and Orpin et al. (2010), there have been periods where cyclonic activity has been both more frequent and more intense. The study has demonstrated that during these periods of increased storm activity the erosion 
response in the Waipaoa was catchment wide and that there was a fourfold increase in catchment sediment delivery during period of storm activity. The study was also able to demonstrate that the Waipaoa catchment under the forested conditions responded to individual rain storm events with only a twofold increase in sediment delivery independent of catchment lithology.

This study has attempted to show that landscape change in the Waipaoa has strong links to the climatic changes that result in the increased cyclonic storm activity that affects the region and that impacts of these climatic effects are region wide. The study has shown these climatic changes may be responsible for the triggering of many of the large deep-seated landslides in the Waipaoa catchment, where these features may lower ridgelines, change valley configuration and impact sediment transport networks. In terms of the total impact to sediment delivery and the trapping of sediment by landslide-dams for the Greater Waipaoa the volumes of sediments impounded by these features are very small when compared to the large volumes of sediments eroded in the catchment over the last 18ka. The volumes of sediment that these features retain and the timeframe that they are able to persist as a landslide-dam and a barrier to sediment transport, represents only a temporary impediment to the sediment delivery to the ocean. The formation and failure of landslide-dams and the eventual erosion of the sediment body constitute a pulsing of sediments in the sedimentary cascade over time scales of hundreds to thousands of years. This study of the infill sediments and the dating of the formation and breach of landslide-dams, along with the in-depth study of horizons in several of the sites, has been useful in the understanding of catchment erosion dynamics. Here, the study has been able to provide a first understanding of the sediment delivery within the sub-catchments of the Waipaoa under Holocene forested conditions at a range of locations and for a range of catchment characteristics.

\subsection{Conjecture, musings and future research}

The key contribution of this project has been as a pilot study into the use of impounded sediments of landslide-dam lakes to provide a proxy for environmental change in the East Cape's Waipaoa catchment. Sediments accumulated in these features provide a palaeo-record of catchment erosion and 
catchment disturbance ranging from several years to several thousand years. When used in conjunction with other studies such as those of regional palaeoclimatic and seismic patterns, these landslide-dam sedimentary records have shown where impacts from disturbance events have been restricted to an individual catchment, and where they have been of region wide significance. This study has found that the main limiting factor for the use of sedimentary records from landslide-dams is related to the disturbance and redistribution of sediments. This is due to the relatively shallow depths of the landslide-dam lakes and means that the sediments provide only a relatively coarse record of catchment dynamics. This study would have been enhanced and the resolution of catchment erosion rates refined through a greater understanding of the trapping efficiencies of the reservoirs and the evolution of this efficiency with time. An enhanced understanding of the infill and trapping patterns as well as the breaching and erosion of these features would benefit understanding of the pulsing of sediments within the sedimentary cascade of the Waipaoa catchment and for other catchments where landslide-dams are prominent features.

The sedimentary record in the core sequences taken from the reservoirs of the landslide-dams of the Waipaoa are considered to be a record of catchment storm history. This study has shown that the linking of multiple sites with overlapping timelines has enabled a catchment wide picture of sediment erosion and transport to emerge. While the study has been successful in its endeavours, there are aspects within the project that provide opportunities for improvement for future projects. The use of the national scale data made the process of producing accurate 3D landscape models slow and laborious and if LiDAR were available for these sites it would have been quicker. This was also the case with the choice of modelling program where the cartography based Arc GIS was quite cumbersome to use and a more geology and engineering based program such as Maptec Vulcan 3D may prove to be easier to use. While these options were not available, they would not have resulted in a more accurate outcome, simply a faster one. Lastly, the project would have been enhanced by revisiting and a recoring of the Arai Matawi site, which as the oldest site would have extended the timeframe of the project. 
As shown in this study, these landslide-dam features are intermittent and temporary disruptors to sediment transport existing on a range of time scales. The landslides are visible in the landscape for many thousands of years, although the in-channel sediments trapped by these features may not be. The use of a stream channel- slope index would find unexpected changes in slope of the stream's channel which may indicate trapped sediments by landslides. The index, when used in conjunction with the location of the known large landslides from the large landslide database, would make it possible to increase the known number of sites where sediments have been impounded. Through a concentrated study on one river channel and the dating of landslides, it would be possible to understand landslide distribution in relation to the migration of knickpoints as primers for these deep-seated slope failures. There is an assumption of decreasing age of landslides with distance upstream and through dating landslide features it would be possible to get an understanding of timing of deep-seated landslides within the Waipaoa.

Landslide-dams that result from deep-seated landslides are common features of the Waipaoa and have a major impact on the sedimentary regime not only as a source of sediments to sediment pathways but also as a regulator. While the volumes of sediment for the individual sites of this study are quite small, the sheer number of these features and the number that show a degree of interaction with the river channel is very high. These features also provide a source of natural hazard to human development of the region. Hazards of landslide-dams to human environments may be through the landslide material itself, the flooding of the land upstream of the restriction, or the downstream stream threat of flooding from dam breach. The further study of sediments that are impounded in landslide-dam lakes will help our understanding of these features and their distribution. 


\section{References}


Adams, J., 1981. Earthquake-dammed lakes in New Zealand. Geology, 9: pp 215219.

Alloway, B.V., Larsen, G., Lowe, D.J., Shane, P.A.R. and Westgate, J.A., 2006. Tephracronology. In: Elias, S.A. (editor-in-chief), Encyclopaedia of Quaternary Science. Elsevier, London, pp 2869-2898.

Allsop, F., 1973. The story of Mangatu: the forest which healed the land. New Zealand Forest Service Information Series 62, Government Printer, Wellington New Zealand.

Barnes, P.M., Nicol, A. and Harrison, T., 2002. Late Cenozoic evolution and earthquake potential of an active listric thrust complex above the Hikurangi subduction zone, New Zealand. Geological Society of America Bulletin 114, pp 1379-1405.

Berryman, K.R., Marden, M., Eden, D.N., Mazengarb, C., Ota, Y. \& Moriya, I., 2000. Tectonic and paleoclimatic significance of Quaternary river terraces of the Waipaoa River, east coast, New Zealand. New Zealand Journal of Geology and Geophysics 43, pp. 229-245.

Berryman, K., Marden. M., Palmer, A., Wilson, K., Mazengarb, C. \& Litchfield, N., (2010). The post-glacial downcutting history in the Waihuka tributary of Waipaoa River, Gisborne district, New Zealand, and implications for tectonics and landscape evolution. Marine Geology 270, pp 5-71.

Bishop, P., 2007. Long-term landscape evolution: linking tectonics and surface processes. Earth Surface Processes and Landforms 32, pp. 329-365.

Boggs, S. Jr., 2006. Principles of Sedimentology and Stratigraphy (fourth edition). New Jersey, USA: Pearson Prentice Hall.

Brackley, H.L., Blair, N.E., Trustrum, N.A., Carter, L., Leithold, E.L., Canuel, E.A., Johnston, J.H. and Tate, K.R., 2010. Dispersal and transformation of organic carbon across an episodic, high sediment discharge continental margin, Waipaoa Sedimentary System, New Zealand. Marine Geology 270, 202-212.

Brierley, G.J., 2010. Landscape memory: the imprint of the past on contemporary landscape forms and processes. Area 42, pp. 76-85.

Bromhead, E.N., Coppola, L., Rendell, H.M., 1996. Field reconnaissance of valley blocking landslide remnants: the Cordevole and Piave catchments. Journal of the Geological Society of China 39, 373-389.

Brown, A.G., Carey, C., Erkins, G., Fuchs, M., Hoffmenn, T., Macarie, J., Moldenhauer, K. and Walling, D., 2009. From sedimentary records to sediment budgets: Multiple approaches to catchment sediment flux. Geomorpholgy 109, pp $25-47$. 
Brune, G.M., 1953. Trap efficiency of reservoirs. Transactions, American Geophysical Union 34, pp 407-418.

Brunsden, D., 1985. The revolution in geomorphology: a prospect for the future. In: King, R. (Ed), Geographical features. The Geographical Association, Sheffield, England, pp 30-55.

Brutsaert, W., 2005. Hydrology: An Introduction. Cambridge University Press, Cambridge UK.

Carter, L., Orpin, R.R., Kuehl, S.A., 2010. From mountain source to ocean sink the passage of sediment across an active margin, Waipaoa Sedimentary System, New Zealand. Marine Geology, 270, pp. 1-10.

Castelltort, S. and Van Den Driessche, J., 2003. How plausible are high-frequency sediment supply-driven cycles in the stratigraphic record? Sedimentary Geology 157, pp. 3-13.

Chorley, R.J. and Kennedy, B.A., 1971. Physical geography, a systems approach. London, Prentice-Hall International.

Cochran, U., Berryman, K., Zachariasen, J., Mildenhall, D., Hayward, B., Southall, K., Hollis, C., Barker, P., Wallace, L., Alloway, B., Wilson, K., 2006. Paleoecological insights into subduction zone earthquake occurrence, eastern North Island, New Zealand. Geological Society of America Bulletin 118, pp 10511074.

Cossart. E and Fort. M., 2008. Consequences of landslide dams on alpine river valleys: Examples and typology from the French Southern Alps. Norsk Geografisk Tidsskrift-Norwegian Journal of Geography, 62, pp 75-88.

Costa, J.E. and Schuster, R.L., 1988. The formation and failure of natural dams. Geological Society of America Bulletin 100, pp.. 1054-1068.

CRFS, 2011. GIS image. Retrieved from http://www.cfses.org/salmonid/html/spatial/spatial.htm, 31/01/2001.

Crosby, B.T. and Whipple, K.X., 2006. Knickpoint initiation and distribution within fluvial networks: 236 waterfalls in the Waipaoa River, North Island, New Zealand. Geomorphology 82, pp 16-38.

Crozier, M.J., 1986. Landslides: causes, consequences and environment. Croom Helm, London.

Crozier, M.J., 2010. Landslide geomorphology: An argument for recognition, with examples from New Zealand. Geomorphology 120, pp 3-15.

Crozier, M.J., Deimel, M.S. and Simon, J.S., 1995. Investigation of earthquake triggering for deep-seated landslides, Taranaki, New Zealand. Quaternary International 25, pp 65-73. 
Crozier M.J. and Pillans B.J., 1991. Geomorphic events and landform response in south-eastern Taranaki, New Zealand. Catena, 18, pp 471-487.

Crozier, M.J. and Preston, N.J., 1998. Modelling changes in terrain resitance as a component of landform evolution in unstable hill country. In. Process Modelling and Landform Evolution. Lecture Notes in Earth Sciences 78 (Ed. By S. Hergarten \& H.J. Neygebaure), pp 267-284, Springer, Berlin.

Cruden, D.M. and Varnes, D.J., 1996. Landslide types and processes. In A.K. Turner and R.L. Schuster (Eds.), Landslides: Investigation and mitigation, Transportation research board special report 247, (pp 36-76). National Academy Press, Washington, D.C., USA.

Davis, W.M., 1903. The mountain ranges of the great basin. Bulletin Museum of Comparative Zoology XLII, 129-177.

Dearing, J.A. and Foster, I.D.L., 1986. Lake sediments and paleohydrological stdies. In B.E. Bergland (Ed.), Handbook of Holocene Paleoecology and Paleohydrology. Chichester, England: John Wiley and Sons Ltd.

Dendy, F.E., 1974. Sediment trap efficiency of small reservoirs. Transactions of the American Society of Agricultural Engineers 17, 898-908.

DeRose, R.C., 1996. Relationship between slope morphology, regolith depth, and the incidence of shallow landslides in eastern Taranaki hill country. Zeitschrift fur Geomorphologie Supplementband 8, pp 131-144.

Dortch, J.M., Owen, L.A., Haneburg, W.C., Caffee, M.C. and Kamp, U., 2009. Nature and timing of large landslides in the Himalaya and Transhimalaya of northern Indea. Quaternary Science Reviews 28, pp 1037-1054.

Eden, D.N. and Page, M.J., 1998. Palaeoclimatic implications of a storm erosion record from late Holocene lake sediments, North Island, New Zealand. Palaeogeography, Palaeoclimatology, Palaeoecology 139, pp 37-58.

Eden, D.N., Palmer, A.S. Cronin, S.J., Marden, M. and Berryman, K.R., 2001. Dating the cumulation of river aggredation at the end of the last glaciation using distal tephra compositions, eastern North Island, New Zealand. Geomorphology 38 , pp. 133-151.

Esri ${ }^{\circledR}, 2008$. What is Arc-GIS 9.3? ESRI, 380 New York Street, Redlands, CA.

Fernandes, N. F., and Dietrich, W. E., (1997). Hillslope Evolution by Diffusive Processes: The Timescale for Equilibrium Adjustments, Water Recourses Research 33, pp. 1307-1318.

Foster, G., Carter, L., 1997. Mud sedimentation on the continental shelf at an accretionary margin-Poverty Bay, New Zealand. New Zealand Journal of Geology and Geophysics. 40, pp 157-173. 
Fryirs K. A., Brierley G. J., Preston N. J., Kasai M., 2007. Buffers, barriers and blankets: The (dis)connectivity of catchment scale sediment cascades. Catena 70 , pp. 49-67.

Fuller, I.C. and Marden, M., 2008. Connectivity in steep-land environments: Gully-fan coupling in the Tarndale system, Waipaoa catchment, New Zealand. Sediment Dynamics in Changing Environments (Proceedings of a symposium held in Christchurch, New Zealand, December 2008). IAHS Publ. 325, 2008, 275-282.

Fuller, I.C. and Marden, M., 2010. Rapid channel response to variability in sediment supply: Cutting and filling of the Tarndale Fan, Waipaoa catchment, New Zealand. Marine Geology 270, pp 45-54.

Gage, M. and Black, R.D., 1979. Slope-stability and geological investigations at Mangatu State Forest. Technical Paper 66. O.D.C. 114, 116-014.1. Forest Research Institute, New Zealand Forest Service, Wellington.

Glew, J.R., Smol, J.P. and Last, W.M., 2001. Sediment core collection and extrusion. In Tracking Environmental Change Using Lake Sediments: Basin Analysis, Coring and Chronological Techniques (W.M. Last and J.P. Smol eds.) vol1 pp 73-105. Kluwer, Dordrecht.

Godwin, H., 1962. Half-life of radiocarbon. Nature 195:984.

Gomez, B., Carter, L., Orpin, A.R., Cobb, K.M., Paage, M.J., Trustrum, N.A. and Palmer, A.S., In Press. ENSO/SAM interactions during the middle and late Holocene. The Holocene.

Gomez, B., Eden, D.N., Hicks, D.M., Trustrum, N.A., Peacock, D.H. and Wimshurst, J., 1999. Contribution of floodplain sequestration to the sediment budget of the Waipaoa River, New Zealand. In: Floodplains: Interdisciplinary approaches )ed. By S.B. Marriott and J Alexander). Geological Society of London Special Publication 163, pp. 69-88.

Gomez, B., Carter, L., Trustrum, N.A., 2007. A 2400 yr record of natural events and anthropogenic impacts in intercorrelated terrestrial and marine sediment cores: Waipaoa sedimentary system, New Zealand. Geological Society of America Bulletin 119, 1415-1432.

Google images, 2011. GIS image, retrieved from Google images, 31/01/11. http://ifgivor.uni-muenster.de/vorlesungen/Geoinformatik/kap/kap4/k04_6.htm

Grossman, R.B. and T.G. Reinsch. 2002. Bulk density and linear extensibility. p. 201-228. In J.H. Dane and G.C. Topp (eds.) Methods of soil analysis, Part 4. Physical methods. Soil Sci. Am. Book Series No. 5. ASA and SSSA, Madison, WI.

Guthrie, R.H. and Evans, S.G., 2007. Work, persistence, and formative events: The geomorphic impact of landslides. Geomorphology 88, pp 266-275. 
Hajdas I, Lowe DJ, Newnham RM, Bonani G. 2006. Timing of the late-glacial climate reversal in the Southern Hemisphere using highresolution radiocarbon chronology for Kaipo bog, New Zealand. Quaternary Research 65: 340-345.

Hancox, G.T., Perin, N.D. and Dellow, G.D., 1997. Earthquake-induced landsliding in New Zealand and implications for MM intensity and seismic hazard assessment. Institute of Geological and Nuclear Science Client Report 43601B.

Hancox, G.T., Perin, N.D. and Dellow, G.D., 2002. Recent studies of historic earthquake-induced landsliding, ground damage, and MM intensity in New Zealand. Bulletin of the New Zealand Society for Earthquake Engineering 35, 5995.

Heinemann, H.G., 1981. A new sediment trap efficiency curve for small reservoirs. Water Resources Bulletin 17(5), pp 825-830.

Hewitt, K., 1998. Catastrophic landslides and their effects on the upper Indus streams, Karakorum Himalaya, northern Pakistan. Geomorphology 26, 47-80.

Hewitt, K., 2006. Disturbance regime landscapes: Mountain drainage systems interrupted by large rockslides. Progress in Physical Geography 30, 365-393.

Heywood, I., Cornelius, S. and Carver, S., 2002. An introduction to Geographical Information Systems ( $2^{\text {nd }}$ Ed.). Pearson Education Limited, Harlow, England.

Hicks, D.M., Gomez, B. and Trustrum, N.A., 2000. Erosion thresholds and suspended sediment yields. Waipaoa River Basin, New Zealand. Water Resource Research 36, pp 1129-1142.

Hicks, D.M., Gomez, B. and Trustrum, N.A., 2004. Event suspended sediment characteristics and the generation of hyperpycnal plumes at river mouths: East Coast continental margin, North Island. New Zealand. Journal of Geology 112, pp. 471-485.

Higham, T.F.G. and Hogg, A.G., 1997. Evidence for late Polynesian colonisation of New Zealand: University of Waikato radiocarbon measurements. Radiocarbon 39, pp 149-192.

Hoffmann T., Erkins G., Gerlich R., Klorstermann J., Lang A., 2009. Trends and controls on Holocene floodplain sedimentation in the Rhine catchment. Catena 77, pp 96-106.

Hooke J., 2003. Coarse sediment connectivity in river channel systems: a conceptual framework and methodology. Geomorphology 56, pp 79-94.

Jamison, V.C, Weaver, H.H. and Reed, I.F., 1950. A hammer-driven soil core sampler. Soil Science 69, pp 487-496.

Jones, K.E., 2009. Contemporary sediment delivery ratios for small catchments subject to shallow rainfall triggered earthflows in the Waipaoa catchment, North 
Island, New Zealand (Unpublished MSc thesis). Victoria University, Wellington, New Zealand.

Jones, K.L., 1988. Horticulture and settlement chronology of the Waipaoa River catchment, East Coast, North Island, New Zealand. New Zealand Journal of Archaeology 10, pp 19-51.

Julien, P.Y., 1995. Erosion and Sedimentation. New York, USA. Cambridge University Press.

Kasai, M., Brierley, G.J., Page, M.J., Marutani, T. and Trustrum, N.A., 2005. Impacts of land use change on patterns of sediment flux in Weraamaia catchment, New Zealand. Catena 64, pp 27-60.

Kasai, M., 2006. Channel processes following land use change in a degraded steep headwater stream in North Island, New Zealand.

Keefer, D.K., 1984. Landslides caused by earthquakes. Geological Society of America Bulletin 52, pp 406-421.

Kettner, A.J. and Syvitski, J.P.M, 2009. Fluvial responses to environmental perturbations in the Northern Mediteranean sinse the Last Glacial Maximum. Quaternary Science Reviews 28, pp. 2386-2397.

Koi, T., Hotta, N., Ishigki, I., Matuzaki, N., Uchiyama, Y. and Suzuki, M., 2008. Prolonged impact earthquake-induced landslides on sediment yield in a mountain watershed: The Tanzawa region Japan. Geomorphology 101, pp 692-702.

Korup, O., 2002. Recent research on landslide dams - a literature review with special attention to New Zealand. Progress in Physical Geography 26, pp 206235.

Korup, O., 2004. Geomorphic characteristics of New Zealand landslide dams. Engineering Geology 73, pp. 13-35.

Korup, O., 2005. Geomorphic imprint of mass movements on alpine river systems, Southwest New Zealand. Earth Surface Processes and Landforms 30, pp 783-800.

Korup, O., 2006. Effects of large deep-seated landslides on hillslope morphology, western Southern Alps, New Zealand. Journal of Geophysical Research, 111, F01018. doi:10.1029/2004JF000242

Korup, O., Clague, J.J., Hermanns, R.L., Hewitt, K., Storm, A.L. and Weidinger, J.T., 2007. Giant landslides, topography and erosion. Earth and Planetary Science Letters 261, pp 578-589.

Litchfield, N. \& Berryman, K., 2005. Correlation of fluvial terraces within the Hikurangi Margin, New Zealand: implications for climate and base level controls. Geomorphology 68, 291-313. 
Litchfield, N. \& Berryman, K., 2006. Relations between post glacial fluvial incision rates and uplift rates in the eastern North Island, New Zealand. Journal of Geophysical Research 111, 15 pp.

Litchfield, N., Berryman, K., Brackley, H., Carter, L., Marden, M., Page, M., \& Trustrum, N. (2008) The Waipaoa Sedimentary System: research review and future directions. IAHS Publ. 325.

Litchfield, N., Bilberback, E., McNinch, J., Marden, M. and Wolinsky, M., 2009 (April). Waipaoa sedimentary field system trip: Integration and synthesis of MARGINS sediment source-to-sink research workshop. GNS science, miscellaneous series 22 .

Litchfield, N.J., Smith, W.D. and Berryman, K.R., 2009b Return times for high levels of ground shaking (MM7) in the Waipaoa and Waihuka River catchments. GNS Science Report 2009/03, February 2009.

Litchfield, N.J., Wilson, K., Berryman, K.R. and Wallace, L., 2010. Coastal uplift mechanisms at Pakarae River mouth: Constraints from a combined Holocene fluvial and marine terrace dataset. Marine Geology 270, pp 72-83.

Lowe, D.J., Shane, P.A.R., Alloway, B.V. and Newnham, R.M., 2008. Fingerprints and age models for widespread New Zealand tephra marker beds erupted since 30,000 years ago: a framework for NZ-INTIMATE. Quaternary Science Reviews 27, pp 2008.

Lowe, D.J. and Walker, J.D., 1992. Lakes. In Landforms New Zealand, (2 ${ }^{\text {nd }}$ edn), Soons JM, Selby MJ, (eds). Longmann Paul: Auckland New Zealand.

Lutz, J.F., 1947. Apparatus for collecting undisturbed soil samples. Soil Science 64, pp 399-401.

Marden, M., Betts, H, Arnold, G., and Hambling, R. 2008a. Gully erosion and sediment load: Waipaoa, Waiapu and Uawa rivers, eastern North Island, New Zealand. Sediment dynamics in changing environments, (Proceedings of a symposium held in Christchurch, New Zealand, December 2008) IAHS Publ. 325, 2008.

Marden, M., Mazengarb, C., Palmer, A., Berryman, K. and Rowan, D., 2008b. Last glacial aggradation and postglacial sediment production from the noonglacial Waipaoa and Waimata catchments, Hikurangi margin, North Island New Zealand. Geomorphology 99, pp. 404-419.

Marsaglia, K.M., DeVaughn, A.M., James, D.E. and Marden, M., 2010. Provenance of fluvial terrace sediments within the Waipaoa sedimentary system and their importance to New Zealand source-to-sink studies. Marine Geology 270, pp 84-93.

Mazengarb C, Speden IG. 2000. Geology of the Raukumara Area. Institute of Geological and Nuclear Sciences: Wellington, New Zealand. 
McCormac, F.G., Hogg, A.G., Blackwell, P.G., Buck, C.E., Higham, T.F.G and Reimer, P.J., 2004. SHCAL04 SOUTHERN HEMISPHERE CALIBRATION, 011.0 CAL KYR BP. RADIOCARBON, Vol 46, Nr 3, 2004, p 1087-1092

McKay, J.A., 1982. Historic Poverty Bay-East Coast. Centennial Council, Gisborne, New Zealand.

McGlone, M.S., Howarth, R. and Pullar, W.A., 1984. Late Pleistocene stratigraphy, vegetation and climate of the Bay of Plenty and Gisborne regions, New Zealand. New Zealand Journal of Geology and Geophysics 27, pp 327-350.

McGlone, M.S., 1989. The Polynesian settlement of New Zealand in relation to environmental and biotic changes. New Zealand Journal of Ecology 12, pp. 115129.

McGlone, M.S. and Wilmshurst, J.M., 1999. Dating initial Maori environmental impact in New Zealand. Quaternary International 59, pp. 5-16.

McGlone, M.S., 2002. A Holocene and latest Pleistocene pollen record from Lake Poukawa, Hawke's Bay, New Zealand. Global and Planetary Change 33, $283-299$.

Miller, D.J., Luce, C. and Benda, L., 2003. Time, Space and epostolicity of physical disterbances to streams. Forest Ecology and Management 178, pp 121140.

Milliman, J.D. and Syvitski, J.P.M., 1992. Geomorphic/tectonic control of sediment discharge to the ocean: the importance of small mountainous rivers, The Journal of Geology 100, pp. 525-544.

Montgomery, D.R. and Brandon, M.T., 2002. Topographic controls on erosion rates in tectonically active mountain ranges. Earth and Planetary Science Letters 201, pp 481-489.

Newnham, R.M., Lowe, D.J. and Mathews, B.W., 1998. A late Holocene and prehistoric record of environmental change from Lake Waikaemoana, New Zealand. The Holocene 8, pp 443-454.

Orpin, A.R., 2004. Holocene sediment deposition on the Poverty-slope margin by the muddy Waipaoa River, East Coast New Zealand. Marine Geology 209, pp. 6990 .

Orpin, A.R., Carter, L., Page, M.J., Cochran, U.A., Trustrum, N.A., Gomez, B., Palmer, A.S., Mildenhall, D.C., Rogers, K.M., Brackley, H.L. and Northcote, L., 2010. Holocene sedimentary record from Lake Tutira; A template for upland watershed erosion proximal to the Waipaoa Sedimentary System, northeastern New Zealand. Marine Geology 270, pp 11-29. 
Otto, J., Schrott, L., Jaboyedoff, M. and Dikau, R. 2009. Quantifying sediment storage in a high alpine valley (Turtmanntal, Switzerland). Earth Surface Processes and Landforms 34, pp 1726-1742.

Page, M.J., Lukovic, B., 2011. An inventory of deep-seated landslides in the Waipaoa and Waimata catchments. GNS Science Report 2011/08 74p.

Page, M., Marden, M., Kasai, M., Gomez, B., Peacock, D., Betts, H., Parkner, T., Marutani, T. and Trustrum, N., 2007. 13; Changes in basin sediment supp.ly and transfer in a rapidly transformed New Zealand landscape. Developments in Earth Surface Processes 11, pp. 335-337.

Page, M.J., Reid, L.M. and Lynn, I.H., 1999. Sediment production from cyclone Bola landslides, Waipaoa catchment. Journal of Hydrology 38, pp. 289-308.

Page, M.J. and Trustrum, N.A., 1997. A late Holocene lake sediment record of the erosion response to land use change in a steep-land catchment, New Zealand. Zeitschrift fur Geomorpologie Supplementband 41, pp 369-392.

Page, M.J., Trustrum, N.A and Dymond, J.R., 1994. Sediment budget to assess the geomorphic effect of a cyclonic storm, New Zealand. Geomorphology 9, pp 169188.

Page, M.J., Trustrum, N.A., Orpin, A.R., Carter, L., Gomez, B., Cochran, U.A., Mildenhall, D.C., Rogers, K.M., Brackley, H.L., Palmer, A.S., Northcote, L., 2010. Storm frequency and magnitude in response to Holocene climate variability, Lake Tutira, North-Eastern New Zealand. Marine Geology 270, pp. 30-44.

Parkner, T., Page, M., Marden, M. and Marutani, T., 2007. Gully systems under undisturbed indigenous forest, East Coast Region, New Zealand. Geomorphology, 84 pp 241-253.

Parsons, A.J., Brazier, R.E., Wainwright, J. and Powell, D.M., 2006. Scale relationships in hillslope runoff and erosion. Earth Surface Processes and Landforms 31, pp 1384-1393.

Pearce, A.J. and Watson, A.J., 1986. Effects of earthquake induced landslides on sediment budgets and transport over a 50 year period. Geology 14, pp 52-55.

Peacock DH Ltd \& John Philpott and Associates Ltd., 2009. Waipaoa River flood control scheme: Proposals for an upgrade of the Waipaoa River flood control scheme.

Pere, V. H., 2003. Formation and consequences of the Totangi Landslide Dam in the Ngatapa Valley, Gisborne, New Zealand. MSc Thesis, University of Canterbury, Christchurch, New Zealand.

Perrin, N.D. and Hancox, G.T., 1991. Landslide-dammed lakes in New Zealand Preliminary studies on distribution, causes and effects. Landslides. Balkema, Rotterdam. 
Pettinga, J.R., 1987a. Ponui landslide: a deep seated wedge failure in Tertiary weak-rock flysch, Southern Hawkes Bay, New Zealand. New Zealand Journal of Geology and Geophysics 30, pp 415-430.

Pettinga, J.R., 1987b. Waipoapoa landslide: a deep seated complex block slide in Tertiary weak-rock flysch, Southern Hawkes Bay, New Zealand. New Zealand Journal of Geology and Geophysics 30, pp 401-414.

Philips, J.D. and Gomez, B, 2007. Controls on sediment export from the Waipaoa River basin, New Zealand. Basin Research 19, pp 241-252.

Phillips J.D. and Slattery M.C., 2006. Sediment storage, sea level, and sediment delivery to the ocean by coastal plain rivers. Progress in Physical Geography, 30 (4), pp 513-530.

Preston, N.J., 2008. Off-slope sediment delivery from landsliding during a storm, muriwai hills, North Island, New Zealand. (2008) IAHS-AISH Publication, (325), pp 237-241. ISBN: 978-190150284-8.

Preston, N.J. and Crozier M. J., 1999. Resistance to shallow landslide failure through root-derived cohesion in east coast hill country soils, North Island, New Zealand. Earth Surface Processes and Landforms, 24, pp 665-675.

Prior, C.A., 2010. Lecture handout; Quaternary Techniques Short Course. GNS, Wellington, New Zealand.

Reid, L.M. and Page, M.J., 2002. Magnatude and frequency of landsliding in a large New Zealand catchment. Geomorphology 49, pp 71-88.

Reid, S.A.L., Beetham, R.D. and Riley, P.B. (Editors), 1991. Lake Waikaremoana barrier - a large landslide dam in New Zealand. Landslides. Balkema, Rotterdam.

Roehl, J.W., 1962. Sediment source areas, delivery ratios and influencing morphological factors. International Association of Scientific Hydrology 59, pp 202-213.

Selby, M.J., 1982. Hillslope materials and processes. Oxford University Press, Oxford.

Schmidt, K.M. and Montgomery, D.R., 1995. Limits to relief. Science, 27, pp 617-620.

Schrott, L., Hufschmidt, G., Hankammer, M., Hoffman, T. and Dikau, R., 2003. Spatial distribution of sediment storage types and quantification of valley fill deposits in an alpine basin, Reintal, Bavarian Alps, Germany. Geomorphology 55, pp 45-63.

Schumm, S.A., 1977. Geomorphic thresholds: the concept and its applications. Transactions of the Institute of British Geographers, New Series 4, pp. 485-515. 
Schuster, R.L., 1993. Landslide dams - a worldwide phenomenon. Proceedings Annual Symposium of The Japanese Landslide Society, Kansai Branch, 27 April. Osaka, pp. 1-23.

Schuster, R.L., 1995. Landslide dams - a worldwide phenomenon. Journal of the Japanese Landslide Society 3 1, 38-49 (in Japanese).

Shotbolt, L.A., Thomas, A.D. and Hutchinson, S.M., 2005. The use of reservoirs as environmental archives of catchment inputs and atmospheric pollution. Progress in Physical Geography 29, pp 337-361.

Smith, R.K., 1977. The morphology and hydrology of the Waipaoa basin. Unpublished report, Ministry of Works and Development, Napier, 130p.

Sømme, T.O., Helland-Hensen, W., Martinsen, O.J., Thormond, J.B., 2009. Relationships between morphological and sedimentological parameters in sourceto-sink systems: a basis for predicting semi-quantitative characteristics in subsurface systems. Basin Research 21, pp 361-387.

Trimble, 2011. Trimble GPS tutorial. Retrieved from http://www.trimble.com/gps/dgps-why.shtml

USGU, 2010. Image of normal and shear stresses on slopes. Retrieved from http://www.google.co.nz/imgres?imgurl=http://www.uwsp.edu/geo/faculty/lemke/ geomorphology/images/10d_slope_unconsolidated. on 23rd of September 2010.

Varnes, D.J., 1958. Landslide types and processes. In E.B. Eckel (Ed.) Landslides and engineering practice. Highway research board special report 29, NAS-NRC publication 544, pp 20-47.

Varnes, D.J., 1978. Slope movement and types and processes. In R.L. Schuster and R.J. Krizeck (Eds.). Landslides: analysis and control. Transportation research board special report 176, National Academy of Sciences, Washington, D.C., pp 11-33.

Verstraeten, G. and Poesen, J., 2000. Estimating trap efficiency of small reservoirs and ponds: methods and implications for the assessment of sediment yield. Progress in Physical Geography 24, pp 219-251.

Verstraeten, G. and Poesen, J., 2002. Using sediment deposits in small ponds to quantify sediment yield from small catchments: possibilities and limitations. Earth Surface Processes and Landforms 27, pp1425-1439.

Wallace, M., Beaven, J., McCaffrey, R., Darby, D., 2004. Subduction zone coupling and tectonic block rotations in the North Island, New Zealand. Journal of Geophysical Research 109: do:10. 1029/2004JB006241.

Walling D. E., 1983. The sediment delivery problem. Journal of hydrology 65, pp. 209-237. 
Walling, D.E. and Fang, D., 2003. Recent trends in the suspended sediment loads of the world's rivers. Global and Planetary Change 39, pp. 111-126.

Whipple, K.X., 2001. Fluvial landscape response time: How plausible is steadystate denudation? American Journal of Science. 301, pp. 313-325.

Wieczorek, G.F., 1996. Landslide triggering mechanisms. In A.K. Turner and R.L. Schuster (Eds.), Landslides: Investigation and mitigation, Transportation research board special report 247, (pp 76-87). National Academy Press, Washington, D.C., USA.

Wilson, C. J. N., 1993. Stratigraphy, chronology, styles and dynamics of late Quaternary eruptions from Taupo volcano, New Zealand. Philosophical Transactions: Physical Sciences and Engineering Vol 343, pp 205-306.

Wolinsky, M.A; Swenson, J.B.; Litchfield, N.; McNinch J.E. 2010. Late Holocene shoreline dynamics and sediment partitioning in the Waipaoa sedimentary system, New Zealand. Marine Geology, 270 pp 94-107.

Wolman, M.G., Miller, J.P., 1960. Magnitude and frequency of forces in geomorphic processes. Journal of Geology 68, pp 54-74. 
Appendix A 


\section{A 1.1 Mangakiore}

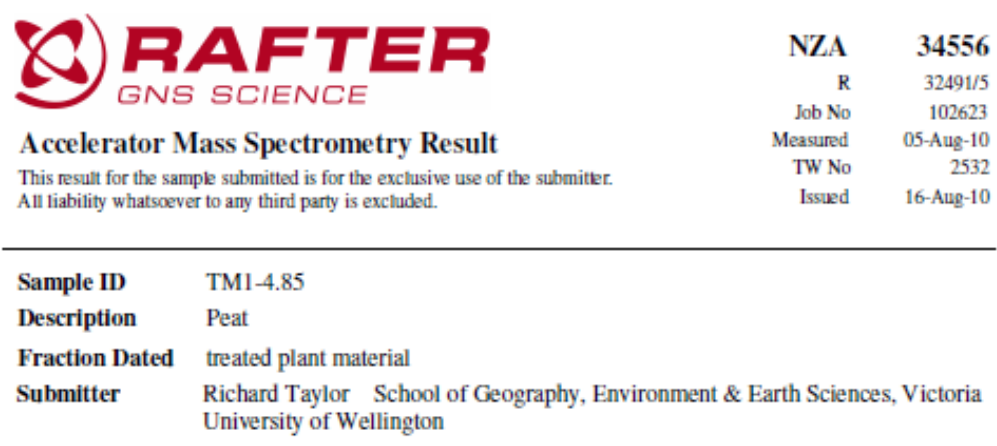

\begin{tabular}{|c|c|c|c|}
\hline * Radiocarbon Age & $-839 \pm 15 \mathrm{BP}$ & $\delta^{13} \mathrm{C}=$ & $-28.3 \%$ \\
\hline$* *$ Per cent modern $=110.2 \pm 0.23$ & $94.5 \pm 2.3 \%$ & $\Delta^{14} \mathrm{C}=$ & $102 \pm 2.3 \%$ \\
\hline \multicolumn{4}{|c|}{ Comment: Sample is modern, i.e., late 20th century } \\
\hline \multicolumn{4}{|c|}{ - Reported age is the conventional radiocarbon age before present (BP) } \\
\hline \multicolumn{4}{|c|}{$\begin{array}{l}\text { ** Per cent modern means absolute per cent modern relative to the NBS axalic acid standard (HOxD) } \\
\text { conected for decay since } 1950 \text {. }\end{array}$} \\
\hline
\end{tabular}

Sample Treatment Details

Plant material in clay matrix, wet, bound in clay. Microscopic exam revealed leaf and plant bits Used ultrasonic bath to separate. Cleaned clays off with distilled water and sieve. Hand picked out plant and leaf material. Dried in vacuum oven. Treated with acid / alkali /acid process. Dried in vacuum oven.

\section{C) RAFTER}

Accelerator Mass Spectrometry Result

This result for the sample submitted is for the exclusive use of the submitter. All liability whatsoever to any third party is excluded.

$\begin{array}{rr}\text { NZA } & \mathbf{3 4 5 5 5} \\ \mathrm{R} & 32491 / 6 \mathrm{a} \\ \text { Job No } & 102624 \\ \text { Measured } & 05-\mathrm{Aug}-10 \\ \text { TW No } & 2532 \\ \text { Issued } & 16 \text {-Aug-10 }\end{array}$

$\begin{array}{ll}\text { Sample ID } & \text { TM1-6.80 } \\ \text { Description } & \text { Plant materia }\end{array}$

Fraction Dated treated plant material

Submitter Richard Taylor School of Geography, Environment \& Earth Sciences, Victoria University of Wellington

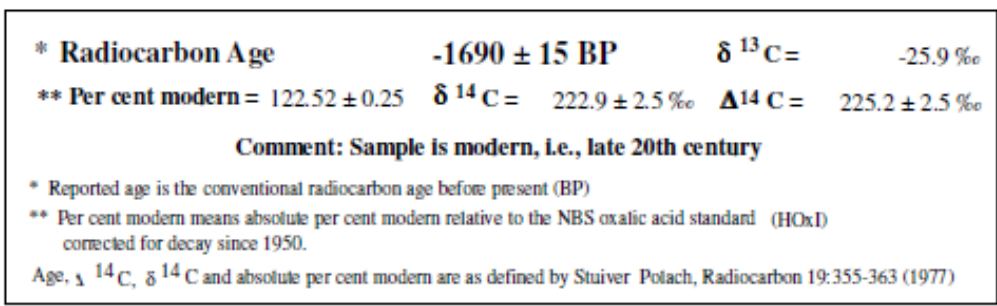

Sample Treatment Details

Twigs/plant roots in clay matrix. Microscopic exam revealed fibrous plant material in clay. Used ultrasonic bath to separate. Rinsed as much clay off as possible. Filtered and dried in vacuum oven. Hand picked out plant material. Cut up with scissors and ground in mortar and pestle. Dried in vacuum oven. Treated with acid / alkali /acid process. Dried in vacuum oven. 


\section{A 1.2 Kopaatuaki}

\section{C) RAFTER}

NZA $\quad 35838$

Accelerator Mass Spectrometry Result

Job No $\quad 105252$

Measured 02-Apr-11

This result for the sample submitted is for the exclusive use of the submitter. All liability whatsoever to any third party is excluded.

\section{Sample ID WK2-0.48}

Description Bulk soil

Fraction Dated Sieved sample, charcoal removed

Submitter Richard Taylor School of Geography, Environment \& Earth Sciences, Victoria University of Wellington

\begin{tabular}{|c|c|c|c|c|}
\hline \multirow{2}{*}{$\begin{array}{l}\text { * Radiocarbon Age } \\
\text { ** Per cent modern }=83.64 \pm 0.23\end{array}$} & \multicolumn{2}{|c|}{$1376 \pm 20 \mathrm{BP}$} & \multirow{2}{*}{$\begin{array}{l}8^{13} \mathrm{C}= \\
\Delta^{14} \mathrm{C}=\end{array}$} & \multirow{2}{*}{$\begin{array}{r}-26.9 \% \\
-163.6 \pm 2.3 \%\end{array}$} \\
\hline & $8^{14} \mathrm{C}=$ & $-167 \pm 2.3 \%$ & & \\
\hline \multicolumn{5}{|c|}{ * Reported age is the conventional radiocarbon age before present (BP) } \\
\hline \multicolumn{5}{|c|}{$\begin{array}{l}\text { ** Per cent modern means absolute per cent modern relative to the NBS oxalic acid standard (HOxI) } \\
\text { contected for decay since } 1950 \text {. }\end{array}$} \\
\hline
\end{tabular}

Sample Treatment Details

Richard Taylor prepared own sample in lab. To test whether previous "old" date was a result of reworked material biasing age, similar sediment as R32599/1 was treated with A/A/A as bulk sediment, and as sediment with charcoal removed. Humic acids collected from alkali step for dating

\section{RAFTER RADIOCARBON LABORATORY}

INSTITUTE OF GEOLOGICAL AND NUCLEAR SCIENCES LTD. PO Box 31312, Lower Hutt, New Zealand

RADIOCARBON CALIBRATION REPORT

NZA 35838 CONVENTIONAL RADIOCARBON AGE $1376 \pm 20$ years BP

Southern He misphere Atmospheric data from MoCormac et al (2004):

FG McCormac, AG Hoge, PG Blackwell, CE Buck, TFG Higham, and PJ Reimer (2004)

CALIBRATED AGE in erms of confidence intervals (Smoothing paraneter: 0, Offset 0)

\begin{tabular}{rl}
\hline $68 \%$ confidence inlerval is $660 \mathrm{AD}$ to $691 \mathrm{AD}$ & $1290 \mathrm{BP}$ to $1259 \mathrm{BP}$ (55.3\% of area) \\
plus $751 \mathrm{AD}$ to $762 \mathrm{AD}$ & $1199 \mathrm{BP}$ to $1188 \mathrm{BP}$ (11.9\% of area)
\end{tabular}

95\% confidence interval is $654 \mathrm{AD}$ to $719 \mathrm{AD} \quad 1296 \mathrm{BP}$ to $1231 \mathrm{BP}$ (74.7\% of area)

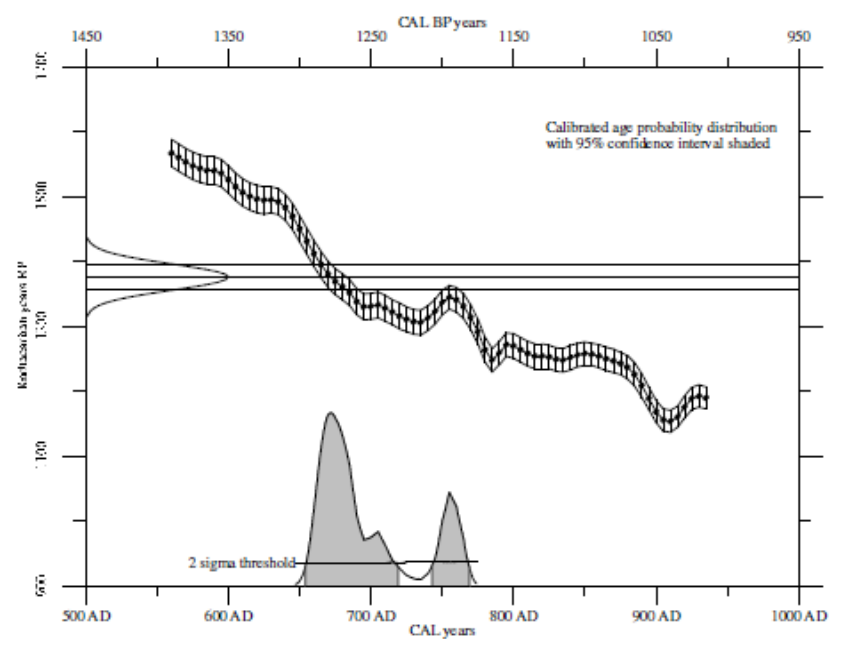


Accelerator Mass Spectrometry Result

\section{Sample ID WK2-0.48}

Description Bulk soil

Fraction Dated humic acids

Submitter Richard Taylor School of Geography, Environment \& Earth Sciences, Victoria University of Wellington

\begin{tabular}{|c|c|c|c|c|}
\hline * Radiocarbon Age & \multicolumn{2}{|c|}{$332 \pm 20 \mathrm{BP}$} & \multirow{2}{*}{$\begin{array}{l}8^{13} \mathrm{C}= \\
\Delta^{14} \mathrm{C}=\end{array}$} & \multirow{2}{*}{$\begin{array}{r}-26.2 \% \\
-47.5 \pm 2.4 \%\end{array}$} \\
\hline ** Per cent modern $=95.25 \pm 0.24$ & $8^{14} \mathrm{C}=$ & $-49.9 \pm 2.4 \%$ & & \\
\hline \multicolumn{5}{|c|}{ * Reported age is the conventional radiocarbon age before present (BP) } \\
\hline \multicolumn{5}{|c|}{$\begin{array}{l}\text { ** Per cent modem means absolute per cent modern relative to the NBS axalic acid standard (HOxI) } \\
\text { conected for decay since } 1950 \text {. }\end{array}$} \\
\hline \multicolumn{5}{|c|}{ Age, $1{ }^{14} \mathrm{C}, \delta^{14} \mathrm{C}$ and absolute per cent modern are as defined by Stuiver Polach, Radiocarbon 19:355-363 (1977) } \\
\hline
\end{tabular}

Sample Treatment Details

Richard Taylor prepared own sample in lab. To test whether previous "old" date was a result of reworked material biasing age, similar sediment as R32599/1 was treated with A/A/A as bulk sediment, and as sediment with charcoal removed. Humic acids collected from alkali step for dating.

\section{RAFTER RADIOCARBON LABORATORY}

\section{INSTITUTE OF GEOLOGICAL AND NUCLEAR SCIENCES LTD, \\ PO Box 31312, Lower Hutt, New Zealand}

Phone (+64 4) 570 4671, Fax (+64 4) 5704657

RADIOCARBON CALIBRATION REPORT

NZA 35830 CONVENTIONAL RADIOCARBON AGE $332 \pm 20$ years BP

Southern Hemisphere Atmospheric data from McCormac et al (2004)

FG McCormac, AG Hoge, PG Blackwell, CE Buck, TFG Higham, and PJ Reimer (2004) Radiocarbon 46, 1087-1092

CALIBRATED AGE in erms of confidence intervals (Smoothing parameter: 0 , Offset: 0 )

\begin{tabular}{|rl|}
\hline $68 \%$ confidence interval is 1512 AD to $1549 \mathrm{AD}$ & $438 \mathrm{BP}$ to $401 \mathrm{BP}$ (39.2\% of area) \\
plus 1561 AD to $1571 \mathrm{AD}$ & $389 \mathrm{BP}$ to $379 \mathrm{BP}$ (8.0\% of area) \\
plus 1622 AD to 1641 AD & $328 \mathrm{BP}$ to $309 \mathrm{BP}$ (21.3\% of area) \\
$95 \%$ confidence interval is $1506 \mathrm{AD}$ to $1589 \mathrm{AD}$ & $444 \mathrm{BP}$ to $361 \mathrm{BP}$ (68.9\% of area) \\
plus $1617 \mathrm{AD}$ to $1646 \mathrm{AD}$ & $333 \mathrm{BP}$ to $304 \mathrm{BP}$ (26.2\% of area) \\
\hline
\end{tabular}

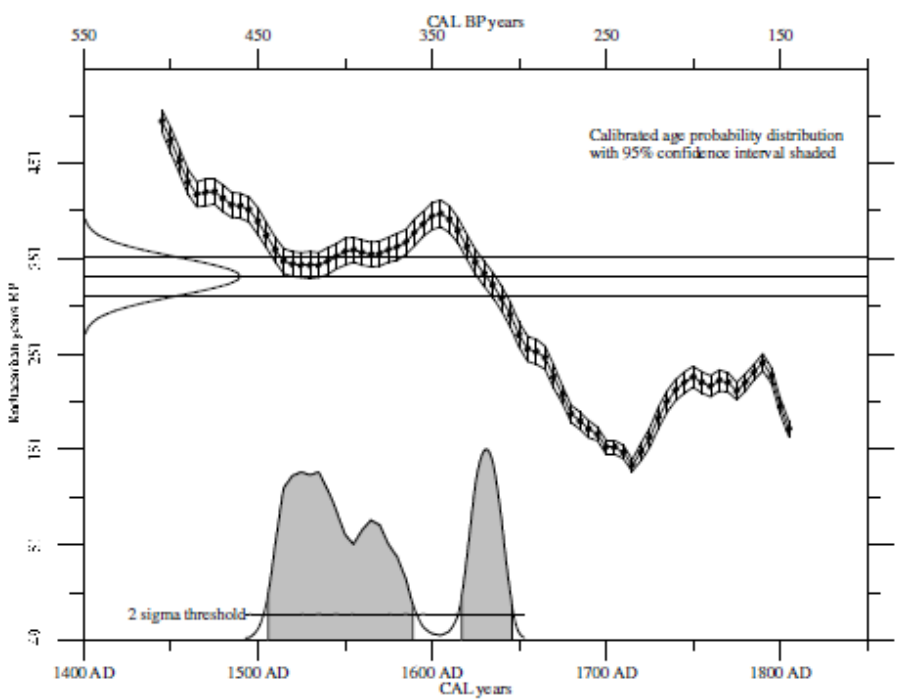


Sample ID WK2-0.48

Description Bulk soil

Fraction Dated bulk soil, containing charcoal

Submitter Richard Taylor School of Geography, Environment \& Earth Sciences, Victoria University of Wellington

\begin{tabular}{|c|c|c|c|c|}
\hline \multicolumn{2}{|l|}{ * Radiocarbon Age } & $1418 \pm 20 \mathrm{BP}$ & \multirow{2}{*}{$\begin{array}{l}8^{13} \mathrm{C}= \\
\Delta^{14} \mathrm{C}=\end{array}$} & \multirow{2}{*}{$\begin{array}{r}-27.2 \% \\
-168 \pm 2.3 \%\end{array}$} \\
\hline ** Per cent modern = & $83.2 \pm 0.23$ & $\mathbf{\delta}^{14} \mathrm{C}=-171.8 \pm 2.3 \%$ & & \\
\hline \multicolumn{5}{|c|}{ * Reported age is the conventional radiocarbon age before present (BP) } \\
\hline \multicolumn{5}{|c|}{$\begin{array}{l}\text { ** Per cent modern means absolute per cent modern relative to the NBS axalic acid standard (HOxI) } \\
\text { conected for decay since } 1950 \text {. }\end{array}$} \\
\hline \multicolumn{5}{|c|}{ Age, $1{ }^{14} \mathrm{C}, 8^{14} \mathrm{C}$ and absolute per cent modern are as defined by Stuiver Polach, Ratiocarbon 19:355-363 (1977) } \\
\hline
\end{tabular}

Sample Treatment Details

Richard Taylor prepared own sample in lab. To test whether previous "old" date was a result of reworked material biasing age, similar sediment as R32599/1 was treated with A/A/A as bulk sediment, and as sediment with charcoal removed. Humic acids collected from alkali step for dating.

\section{RAFTER RADIOCARBON LABORATORY}

R32674

INSTITUTE OF GEOLOGICAL AND NUCLFAR SCIENCES LTD.

PO Box 31312, Lower Hutt, New Zealand

Phone (+64 4) 5704671 , Fax (+64 4) 5704657

RADIOCARBON CALIBRATION REPORT

NZA 35839 CONVENTIONAL RADIOCARBON AGE $1418 \pm 20$ years BP

Southern Hemisphere Atmospheric data from McCormac et al (2004)

FG McCormac, AG Hoge, PG Blackwell, CE Buck, TFG Higham, and PJ Reimer (2004) Radiocarbon 46, 1087-1092

CALIBRATED AGE in erms of confidence intervals (Smoothing parameter: 0, Offset: 0 )

$68 \%$ confidence interval is $650 \mathrm{AD}$ to $670 \mathrm{AD} \quad 1300 \mathrm{BP}$ to $1280 \mathrm{BP}$ ( $69.5 \%$ of area)

95\% confidence interval is $634 \mathrm{AD}$ to $689 \mathrm{AD} \quad 1316 \mathrm{BP}$ to $1261 \mathrm{BP}$ (94.6\% of area)

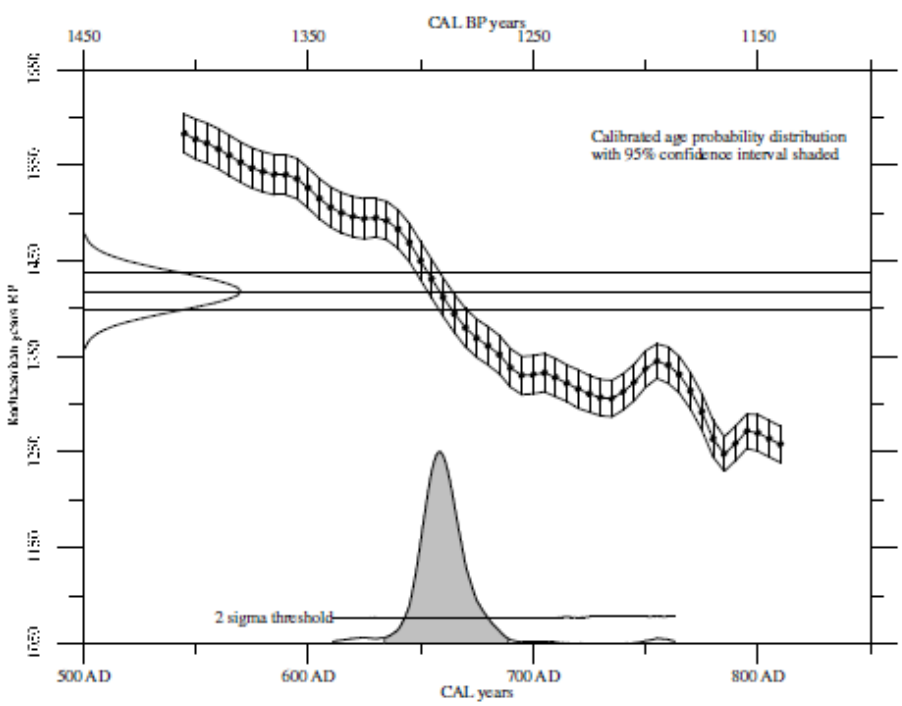




\begin{tabular}{ll}
\hline Sample ID & WK2-1.10 \\
Description & Sediment \\
Fraction Dated & treated organic soil \\
Submitter & Richard Taylor School of Geography, Environment \& Earth Sciences, Victoria \\
& University of Wellington
\end{tabular}

\begin{tabular}{|c|c|c|c|}
\hline * Radiocarbon Age & $1256 \pm 30 \mathrm{BP}$ & \multirow{2}{*}{$\begin{array}{l}8^{13} \mathrm{C}= \\
\Delta 14 \mathrm{C}=\end{array}$} & \multirow{2}{*}{$\begin{array}{r}-27 \% \\
-151 \pm 3.3 \%\end{array}$} \\
\hline was Per cent modern $=$ & $\boldsymbol{\delta}^{14} \mathrm{C}=-154.4 \pm 3.3 \%$ & & \\
\hline \multicolumn{4}{|c|}{ * Reported age is the conventional radiocarbon age before present (BP) } \\
\hline \multicolumn{4}{|c|}{$\begin{array}{l}\text { ** Per cent modern means absolute per cent modem relative to the NBS oxalic acid standard (HOxI) } \\
\text { corrected for decay since } 1950 \text {. }\end{array}$} \\
\hline \multicolumn{4}{|c|}{ Age, ${ }^{14} \mathrm{C}, \delta^{14} \mathrm{C}$ and absolute per cent modern are as defined by Stuiver Polach, Radiocarbon 19:355-363 (1977) } \\
\hline
\end{tabular}

Sample Treatment Details

Organic soil. Microscopic exam revealed soil with small amount of plant material. Picked out and removed roots. Dried soil. Ground in mortar and pestle. Dried in vacuum oven. Treated with acid / alkali /acid process. Dried in vacuum oven.

\section{RAFTER RADIOCARBON LABORATORY}

INSTITUTE OF GEOLOGICAL AND NUCLEAR SCIENCES LTD.

PO Box 31312, Lower Hutt, New Zealand

Phone (+64 4) 5704671 , Fax $(+64$ 4) 5704657

RADIOCARBON CALIBRATION REPORT

NZA 34724 CONVENTIONAL RADIOCARBON AGE $1256 \pm 30$ years BP

Southern Hemisphere Atmospheric data from McCormac et al (2004);

FG McCormac, AG Hoge, PG Blackwell, CE Buck, TFG Higham, and PJ Reimer (2004)

Radiocarbon 46, 1087-1092

CALIBRATED AGE in terms of confidence intervals (Smoothing parameter: 0, Offset: 0)

$68 \%$ confidence inlerval is $780 \mathrm{AD}$ to $877 \mathrm{AD} \quad 1170 \mathrm{BP}$ to $1073 \mathrm{BP}$ ( $67.6 \%$ of area)

95\% confidence interval is $710 \mathrm{AD}$ to $747 \mathrm{AD} \quad 1240 \mathrm{BP}$ to $1203 \mathrm{BP}$ (7.3\% of area) plus $766 \mathrm{AD}$ to $896 \mathrm{AD} \quad 1184 \mathrm{BP}$ to $1054 \mathrm{BP}$ ( $85.9 \%$ of area)
plus $924 \mathrm{AD}$ to $939 \mathrm{AD} \quad 1026 \mathrm{BP}$ to $1011 \mathrm{BP}$ (1.9\% of area)

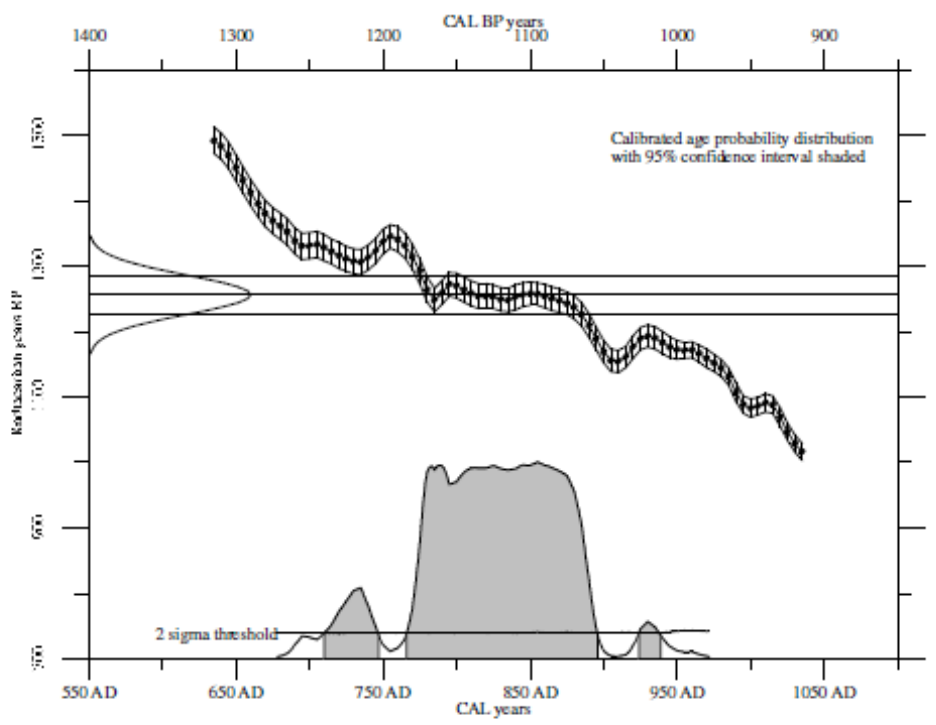




\section{Sample ID WK2-4.6}

Description Charcoal/wood

Fraction Dated degraded wood

Submitter Richard Taylor School of Geography, Environment \& Earth Sciences, Victoria University of Wellington

\begin{tabular}{|c|c|c|c|}
\hline * Radiocarbon Age & $2372 \pm 20 \mathrm{BP}$ & $\delta^{13} \mathrm{C}=$ & $-27.7 \%$ \\
\hline ** Per cent modern $=73.89 \pm 0.18$ & $\delta^{14} \mathrm{C}=-265.1 \pm 1.8 \%$ & $\Delta^{14} \mathrm{C}=$ & $-261.1 \pm 1.8 \%$ \\
\hline \multicolumn{4}{|c|}{ - Reported age is the conventional radiocarbon age before present (BP) } \\
\hline \multicolumn{4}{|c|}{$\begin{array}{l}\text { ** Per cent modern means absolute per cent modern relative to the NBS axalic acid standard (HOxD) } \\
\text { conrected for decay since } 1950 \text {. }\end{array}$} \\
\hline \multicolumn{4}{|c|}{ Age, ${ }_{1}^{14} \mathrm{C}, \delta^{14} \mathrm{C}$ and absolute per cent modern are as defined by Stuiver Polach, Radiocarbon 19:355-363 (1977) } \\
\hline
\end{tabular}

Sample Treatment Details

Woody fragments. Microscopic exam revealed degraded fragments of wood, dirty with sand and clays, wet. Picked degraded looking wood out of sand etc. and dried. Ground in mortar and pestle. Dried in vacuum oven. Treated with acid / alkali /acid process. Dried in vacuum oven.

\section{RAFTER RADIOCARBON LABORATORY}

INSTITUTE OF GEOLOGICAL AND NUCLEAR SCIENCES LTD,

PO Box 31312, Lower Hutt, New Zealand

Phone (+64 4) 570 4671, Fax (+64 4) 5704657

RADIOCARBON CALIBRATION REPORT

NZA 34557 CONVENTIONAL RADIOCARBON AGE $2372 \pm 20$ years BP

Southern Hemisphere Atmospheric data from McCormac et al (2004);

FG McCormas, AG Hogs, PG Blackwell, CE Buck, TFG Higham, and PJ Reimer (2004) Radiocarbon 46, 1087-1092

CALBRRATED AGE in terms of confidence intervals (Smoothing parameter: 0, Offset: 0)

\begin{tabular}{|r|r|}
\hline $68 \%$ confidence interval is $401 \mathrm{BC}$ to $381 \mathrm{BC}$ & $2350 \mathrm{BP}$ to $2330 \mathrm{BP}$ (67.1\% of area) \\
$95 \%$ confidence inlerval is $409 \mathrm{BC}$ to $356 \mathrm{BC}$ & $2358 \mathrm{BP}$ to $2305 \mathrm{BP}$ (88.8\% of area) \\
plus $280 \mathrm{BC}$ to $256 \mathrm{BC}$ & $2229 \mathrm{BP}$ to $2205 \mathrm{BP}$ (5.0\% of area) \\
plus $243 \mathrm{BC}$ to $234 \mathrm{BC}$ & $2192 \mathrm{BP}$ to $2183 \mathrm{BP}$ (1.1\% of area) \\
\hline
\end{tabular}

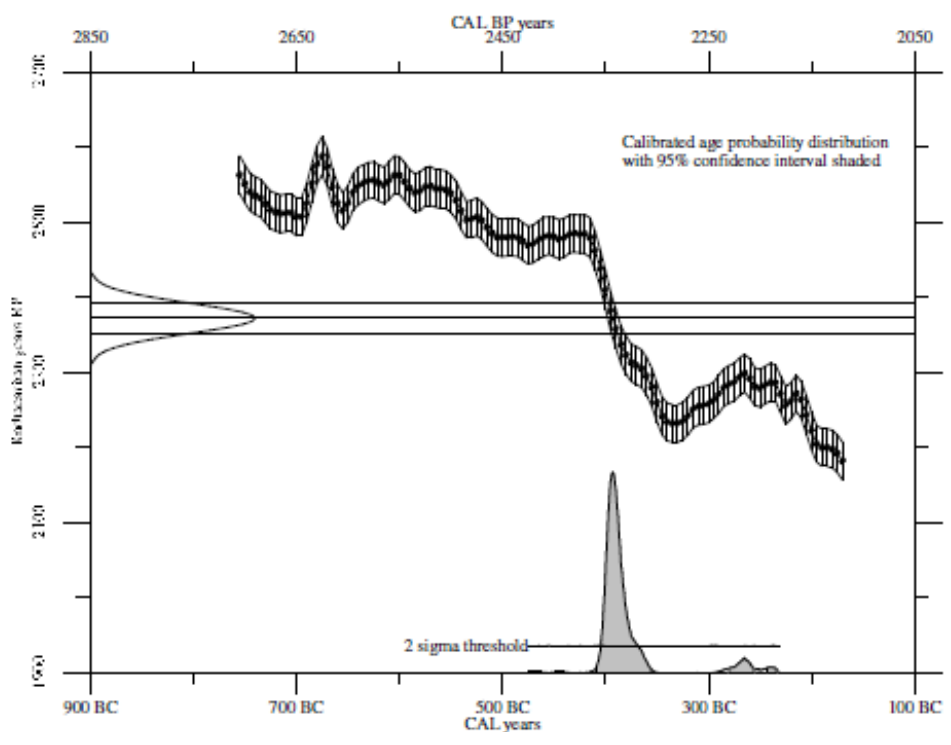




$\begin{array}{ll}\text { Sample ID } & \text { WK2-5.4 } \\ \text { Description } & \text { Charcoal/wood } \\ \text { Fraction Dated } & \text { degraded wood } \\ \text { Submitter } & \begin{array}{l}\text { Richard Taylor School of Geography, Environment \& Earth Sciences, Victoria } \\ \text { University of Wellington }\end{array}\end{array}$

\begin{tabular}{|c|c|c|c|c|}
\hline \multicolumn{2}{|l|}{ * Radiocarbon Age } & $2570 \pm 20 \mathrm{BP}$ & \multirow{2}{*}{$\begin{array}{l}\delta^{13} \mathrm{C}= \\
\Delta^{14} \mathrm{C}=\end{array}$} & \multirow{2}{*}{$\begin{array}{r}-27.9 \% \\
-279 \pm 1.8 \%\end{array}$} \\
\hline ** Per cent modern = & $72.1 \pm 0.18$ & $\delta^{14} \mathrm{C}=-283.3 \pm 1.8 \%$ & & \\
\hline \multicolumn{5}{|c|}{ - Reported age is the conventional radiocarbon age before present (BP) } \\
\hline \multicolumn{5}{|c|}{$\begin{array}{l}\text { *4 Per cent modern means absolute per cent modern relative to the NBS axalic acid standard (HOxI) } \\
\text { contected for decay since } 1950 \text {. }\end{array}$} \\
\hline \multicolumn{5}{|c|}{ Age, ${ }^{14} \mathrm{C}, \delta^{14} \mathrm{C}$ and absolute per cent modern are as defined by Stuiver Polach, Radiocarbon 19:355-363 (1977) } \\
\hline
\end{tabular}

Sample Treatment Details

Wood/charcoal fragments in soil. Microscopic exam revealed somewhat degraded fragments of wood, dirty with sand, wet. Picked degraded looking wood out of sand etc, scraped away soil with tweezers. Ground in mortar and pestle. Dried in vacuum oven. Treated with acid / alkali /acid process. Dried in vacuum oven.

\section{RAFTER RADIOCARBON LABORATORY}

INSTITUTE OF GEOLOGICAL AND NUCLEAR SCIENCES LTD.

PO Box 31312, Lower Hutt, New Zealand

Phone (+64 4) 5704671 , Fax $(+64$ 4) 5704657

RADIOCARBON CALIBRATION REPORT

NZA 34558 CONVENTIONAL RADIOCARBON AGE $2570 \pm 20$ years BP

Southern Hemisphere Atmospheric data from McCormac et al (2004); FG McCormac, AG Hogg, PG Blackwell, CE Buck, TFG Higham, and PJ Reimer (2004)
Radiocarhon 46, 1087-1092

CALIBRATED AGE in terms of confidence intervals (Smoothing parameter: 0, Offset: 0)

\begin{tabular}{|r|r|}
\hline $68 \%$ confidence inlerval is $769 \mathrm{BC}$ to $745 \mathrm{BC}$ & $2718 \mathrm{BP}$ to $2694 \mathrm{BP}$ (13.1\% of area) \\
plus $686 \mathrm{BC}$ to $663 \mathrm{BC}$ & $2635 \mathrm{BP}$ to $2612 \mathrm{BP}$ (13.0\% of area) \\
plus $643 \mathrm{BC}$ to $587 \mathrm{BC}$ & $2592 \mathrm{BP}$ to $2536 \mathrm{BP}(30.3 \%$ of area) \\
plus $579 \mathrm{BC}$ to $553 \mathrm{BC}$ & $2528 \mathrm{BP}$ to $2502 \mathrm{BP}$ (11.8\% of area) \\
&
\end{tabular}

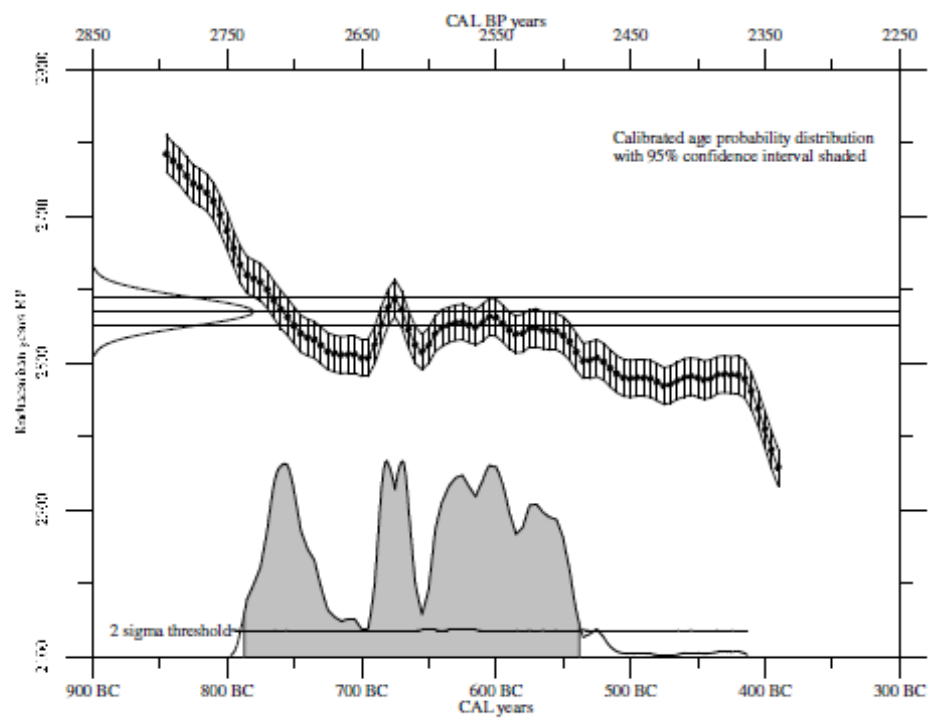


This result for the sample submitted is for the exclusive use of the submitter

\begin{tabular}{ll}
\hline Sample ID & WT1-River \\
Description & Wood \\
Fraction Dated & wood \\
Submitter & $\begin{array}{l}\text { Richard Taylor School of Geography, Environment \& Earth Sciences, Victoria } \\
\text { University of Wellington }\end{array}$
\end{tabular}

\begin{tabular}{|c|c|c|c|}
\hline \multirow{2}{*}{$\begin{array}{l}* \text { Radiocarbon Age } \\
* * \text { Per cent modern }=74.57 \pm 0.18\end{array}$} & $2298 \pm 20 \mathrm{BP}$ & \multirow{2}{*}{$\begin{array}{l}\delta^{13} \mathrm{C}= \\
\Delta^{14} \mathrm{C}=\end{array}$} & \multirow{2}{*}{$\begin{array}{r}-27.5 \% \\
-254.3 \pm 1.8 \%\end{array}$} \\
\hline & $\delta^{14} \mathrm{C}=-258.1 \pm 1.8 \%$ & & \\
\hline \multicolumn{4}{|c|}{ - Reported age is the conventional radiocarbon age before present (BP) } \\
\hline \multicolumn{4}{|c|}{$\begin{array}{l}\text { ** Per cent modern means absolute per cent modern relative to the NBS axalic acid standard (HOxD) } \\
\text { corrected for decay since } 1950 \text {. }\end{array}$} \\
\hline
\end{tabular}

Sample Treatment Details

Wood wet and somewhat degraded. Microscopic exam: Waterlogged and degraded appearance. Broke off outermost growth area bark trimmed off. Outer layers removed with scalpel. Treated with Cellulose extraction process of acid wash, $\mathrm{NaOH}$ pulping, hydrogen peroxide oxidation and acid wash steps. Dried in vacuum oven.

\section{RAFTER RADIOCARBON LABORATORY}

\section{INSTITUTE OF GEOLOGICAL AND NUCLEAR SCIENCES LTD.} PO Box 31312, Lower Hutt, New Zealand Phone (+64 4) 5704671 , Fax (+64 4) 5704657

RADIOCARBON CALIBRATION REPORT

NZA 34554 CONVENTIONAL RADIOCARBON AGE $2540 \pm 20$ years BP

Southern Hemisphere Atmospheric data from McCormac et al (2004);

FG McCormac, AG Hogg, PG Blackwell, CE Buck, TFG Higham, and PJ Reimer (2004) Radiocarbon 46, 1087-1092

CALIBRATED AGE in terms of confidence intervals (Smoothing parameter: 0 , Offset: 0 )

\begin{tabular}{|rl|}
\hline $68 \%$ confidence interval is $754 \mathrm{BC}$ to $725 \mathrm{BC}$ & $2703 \mathrm{BP}$ to $2674 \mathrm{BP}$ (12.0\% of area) \\
plus $692 \mathrm{BC}$ to $682 \mathrm{BC}$ & $2641 \mathrm{BP}$ to $2631 \mathrm{BP}$ (4.0\% of area) \\
plus $668 \mathrm{BC}$ to $540 \mathrm{BC}$ & $2617 \mathrm{BP}$ to $2489 \mathrm{BP}$ (52.3\% of area) \\
& \\
$95 \%$ confidence interval is $769 \mathrm{BC}$ to $506 \mathrm{BC}$ & $2718 \mathrm{BP}$ to $2455 \mathrm{BP}$ (92.1\% of area) \\
plus $458 \mathrm{BC}$ to $451 \mathrm{BC}$ & $2407 \mathrm{BP}$ to $2400 \mathrm{BP}$ (0.6\% of area) \\
plus $438 \mathrm{BC}$ to $416 \mathrm{BC}$ & $2387 \mathrm{BP}$ to $2365 \mathrm{BP}$ (2.1\% of area)
\end{tabular}

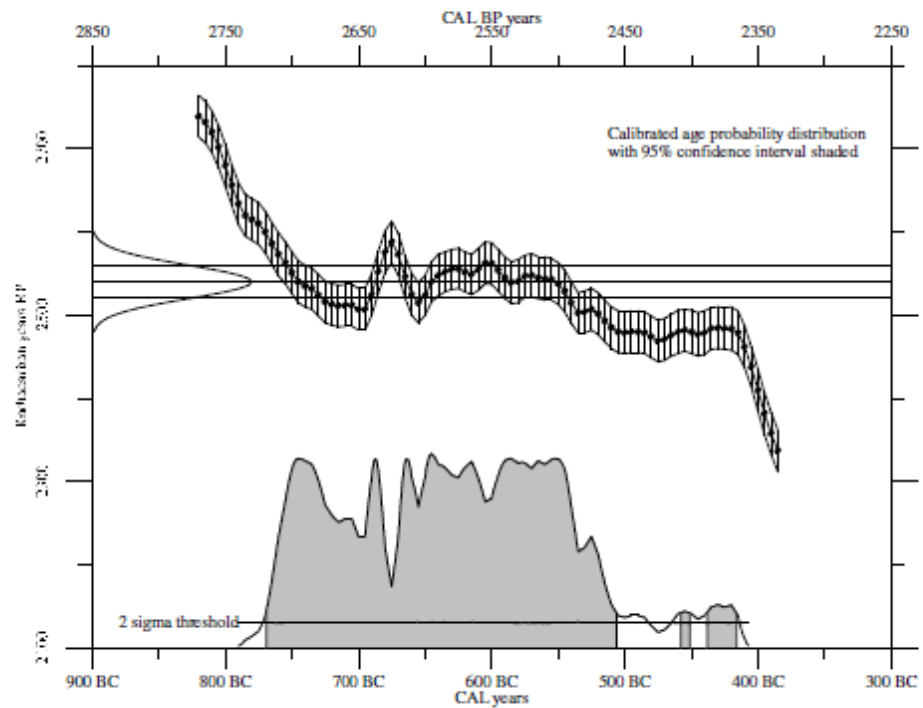


Submitter Richard Taylor School of Geography, Environment \& Earth Sciences, Victoria University of Wellington

\begin{tabular}{|c|c|c|c|}
\hline * Radiocarbon Age & $2194 \pm 25 \mathrm{BP}$ & \multirow{2}{*}{$\begin{array}{l}\delta^{13} \mathrm{C}= \\
\Delta 14 \mathrm{C}=\end{array}$} & \multirow{2}{*}{$\begin{array}{r}-29.7 \% \\
-244.6 \pm 2.4 \%\end{array}$} \\
\hline Nover cent modern $=75.54 \pm 0.24$ & $\boldsymbol{\delta}{ }^{14} \mathrm{C}=-251.8 \pm 2.4 \%$ & & \\
\hline \multirow{2}{*}{\multicolumn{4}{|c|}{$\begin{array}{l}\text { * Reported age is the conventional radiocarbon age before present (BP) } \\
* \text { * Per cent modem means absolute per cent modern relative to the NBS oxalic acid standard } \\
\text { corrected for decay since } 1950 \text {. }\end{array}$}} \\
\hline & & & \\
\hline \multicolumn{4}{|c|}{ Age, $\triangle{ }^{14} \mathrm{C}, \delta{ }^{14} \mathrm{C}$ and absolute per cent modem are as defined by Stuiver Polach, Radiocarbon 19:355-363 (1977) } \\
\hline
\end{tabular}

Sample Treatment Details

Sample consisted of dry sandy soil. Surface cleaning consisted of picking out modern roots, then grinding. Treated with acid / alkali /acid process and dried in vacuum oven.

\section{RAFTER RADIOCARBON LABORATORY}

INSTITUTE OF GEOLOGICAL AND NUCLEAR SCIENCES LTD.

PO Box 31312, Lower Hutt, New Zealand

Phone (+64 4) 5704671 , Fax (+64 4) 5704657

RADIOCARBON CALIBRATION REPORT

NZA 35376 CONVENTIONAL RADIOCARBON AGE $2194 \pm 25$ years BP

Southem Hemisphere Atmospheric data from McCornac et al (2004);

源 Radiocarbon 46, $1087-1092$

CALIBRATED AGE in terms of confidence intervals (Smoothing parameter: 0, Offset: 0)

\begin{tabular}{|rl|}
\hline $68 \%$ confidence interval is $341 \mathrm{BC}$ to $323 \mathrm{BC}$ & $2290 \mathrm{BP}$ to $2272 \mathrm{BP}(8.7 \%$ of area $)$ \\
plus $203 \mathrm{BC}$ to $110 \mathrm{BC}$ & $2152 \mathrm{BP}$ to $2059 \mathrm{BP}(59.7 \%$ of area) \\
& \\
$95 \%$ confidence interval is $351 \mathrm{BC}$ to $294 \mathrm{BC}$ & $2300 \mathrm{BP}$ to $2243 \mathrm{BP}(18.2 \%$ of area $)$ \\
plus $227 \mathrm{BC}$ to $53 \mathrm{BC}$ & $2176 \mathrm{BP}$ to $2002 \mathrm{BP}(76.7 \%$ of area)
\end{tabular}

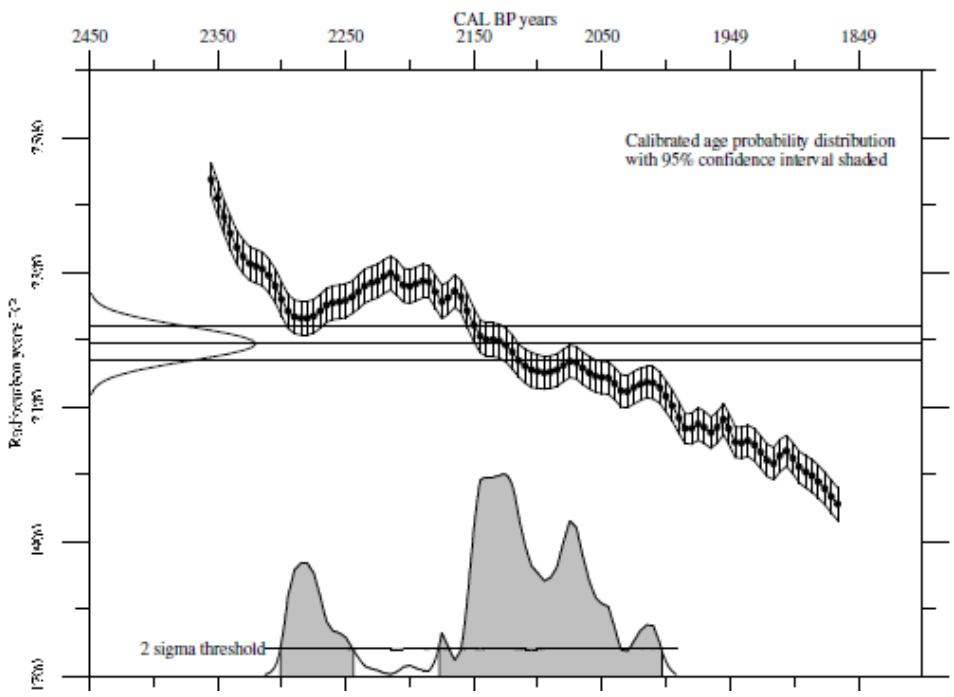




\section{A 1.3 Tanghau}

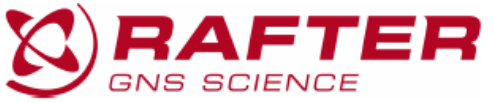

Accelerator Mass Spectrometry Result

$32599 / 5$

19-Jan-11

This result for the sample submitted is for the exclusive use of the submitter

All liability whatsoever to any third party is excluded.

Issued 25-Jan-11

$\begin{array}{ll}\text { Sample ID } & \text { WT1-0.30 } \\ \text { Description } & \text { Bulk soil } \\ \text { Fraction Dated } & \text { bulk soil } \\ \text { Submitter } & \begin{array}{l}\text { Richard Taylor School of Geography, Environment \& Earth Sciences, Victoria } \\ \text { University of Wellington }\end{array}\end{array}$

\begin{tabular}{|c|c|c|c|}
\hline \multirow{2}{*}{$\begin{array}{l}\text { Radiocarbon Age } \\
\text { * Per cent modern }=77.45 \pm 0.24\end{array}$} & $1993 \pm 25 \mathrm{BP}$ & \multirow{2}{*}{$\begin{array}{l}\delta^{13} \mathrm{C}= \\
\Delta^{14} \mathrm{C}=\end{array}$} & \multirow{2}{*}{$\begin{array}{r}-30.7 \% \text { o } \\
-225.5 \pm 2.4 \%\end{array}$} \\
\hline & $\boldsymbol{\delta}^{14} \mathrm{C}=-234.5 \pm 2.4 \%$ & & \\
\hline \multirow{2}{*}{\multicolumn{4}{|c|}{$\begin{array}{l}\text { * Reported age is the conventional radiocarbon age before present (BP) } \\
\text { ** Per cent modem means absolute per cent modern relative to the NBS oxalic acid standard (HOxI) } \\
\text { corrected for decay since } 1950 \text {. }\end{array}$}} \\
\hline & & & \\
\hline \multicolumn{4}{|c|}{ Age, $\triangle 1{ }^{14} \mathrm{C}, \delta^{14} \mathrm{C}$ and absolute per cent modem are as defined by Stuiver Polach, Radiocarbon 19:355-3e } \\
\hline
\end{tabular}

Sample Treatment Details

Sample consisted of dark brown damp soil. Microscopic examination revealed sandy soil with lots of white roots, lots of pumice, silicas and glass; not much deitrital material. Sample selection

consisted of selecting a representative sample without root hairs. Treated with acid / alkali /acid process and dried in vacuum oven.

\section{RAFTER RADIOCARBON LABORATORY}

\section{INSTITUTE OF GEOLOGICAL AND NUCLEAR SCIENCES LTD. \\ PO Box 31312, Lower Hutt, New Zealand}

Phone (+64 4) 5704671 , Fax (+64 4) 5704657

RADIOCARBON CALIBRATION REPORT

NZA 35375 CONVENTIONAL RADIOCARBON AGE $1993 \pm 25$ years BP

Southern Hemisphere Atmospheric data from MoCormacet al (2004)

PJ Reimer $(2004)$ Radiocarbon 46, 1087-1092

CALIBRATED AGE in terms of confidence intervals (Smoothing parameter: 0, Offset: 0 )

\begin{tabular}{|cl|}
\hline $68 \%$ confidence interval is $26 \mathrm{AD}$ to $43 \mathrm{AD}$ & $1924 \mathrm{BP}$ to $1907 \mathrm{BP}$ (14.8\% of area) \\
plus $47 \mathrm{AD}$ to $87 \mathrm{AD}$ & $1903 \mathrm{BP}$ to $1863 \mathrm{BP}(43.0 \%$ of area $)$ \\
plus $107 \mathrm{AD}$ to $121 \mathrm{AD}$ & $1843 \mathrm{BP}$ to $1829 \mathrm{BP}$ ( $9.9 \%$ of areas) \\
95\% confidence interval is $17 \mathrm{BC}$ to $131 \mathrm{AD}$ & $1966 \mathrm{BP}$ to $1819 \mathrm{BP}$ ( $95.1 \%$ of area) \\
\hline
\end{tabular}

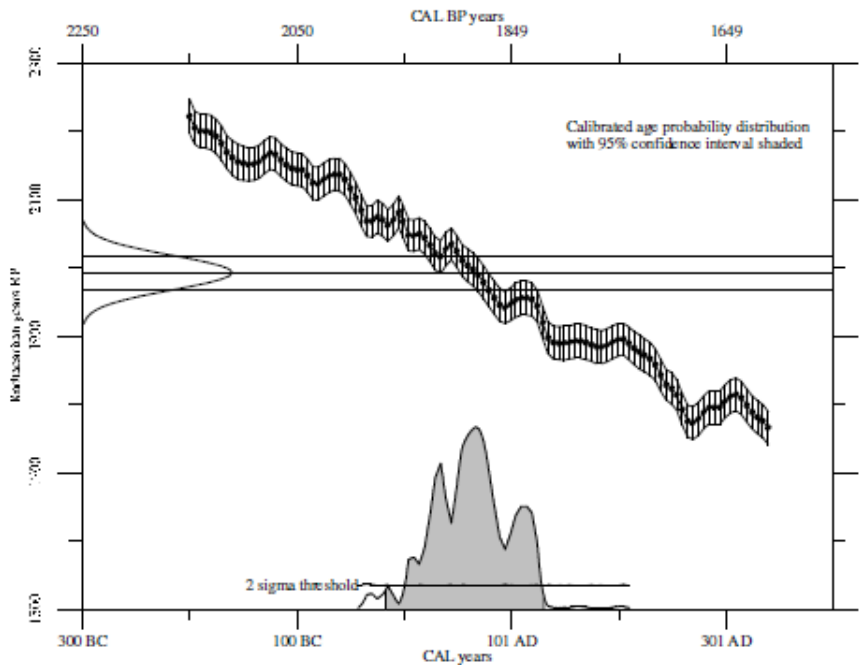




\begin{tabular}{ll}
\hline Sample ID & WT1-2.70 \\
Description & Peat \\
Fraction Dated & cellulose \\
Submitter & Richard Taylor School of Geography, Environment \& Earth Sciences, Victoria \\
& University of Wellington
\end{tabular}

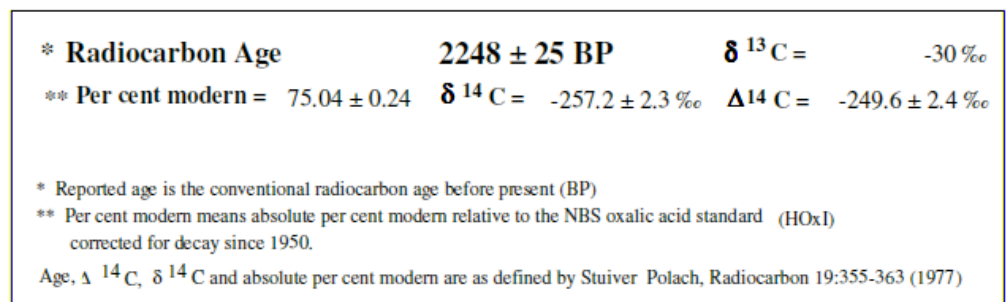

Sample Treatment Details

Sample consisted of damp organic material in sediment. Microscopic examination revealed very degraded wood fragments and detritus in sediment. Sample selection consisted of selecting wood fragments and scraping off dirt. Treated with cellulose extraction process of acid wash, followed with alkali pulping, oxidation in hydrogen peroxide and final acid wash and dried in vacuum oven

\section{RAFTER RADIOCARBON LABORATORY R32599/6}

INSTITUTE OF GEOLOGICAL AND NUCLEAR SCIENCES LTD.

PO Box 31312, Lower Hutt, New Zealand

Phone (+64 4) 570 4671, Fax (+64 4) 5704657

RADIOCARBON CALIBRATION REPORT

NZA 35377 CONVENTIONAL RADIOCARBON AGE $2248 \pm 25$ years BP

Southern Hemisphere Atmospheric data from McCormac et al (2004)

FG McCormac, AG Hoge, PG Blackwell, CE Buck, TFG Higham, and PJ Reimer (2004) Radiocarbon 46, 1087-1092

CALIBRATED AGE in terms of confidence intervals (Smoothing parameter: 0, Offset: 0)

\begin{tabular}{|r|r|}
\hline $68 \%$ confidence interval is $355 \mathrm{BC}$ to $284 \mathrm{BC}$ & $2304 \mathrm{BP}$ to $2233 \mathrm{BP}$ (44.8\% of area) \\
plus $253 \mathrm{BC}$ to $248 \mathrm{BC}$ & $2202 \mathrm{BP}$ to $2197 \mathrm{BP}$ (23\% of area) \\
plus $233 \mathrm{BC}$ to $198 \mathrm{BC}$ & $2182 \mathrm{BP}$ to $2147 \mathrm{BP}$ (21.3\% of area) \\
$95 \%$ confidence interval is $365 \mathrm{BC}$ to $174 \mathrm{BC}$ & $2314 \mathrm{BP}$ to $2123 \mathrm{BP}$ (94.9\% of atea) \\
\hline
\end{tabular}

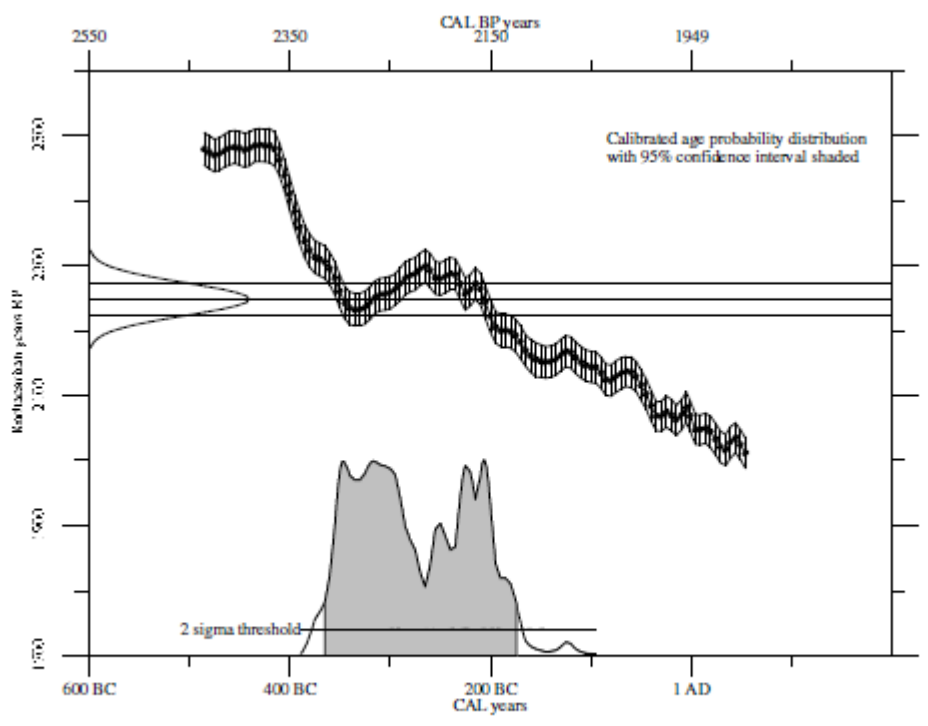




$\begin{array}{ll}\text { Sample ID } & \text { WT1-3.6/1 } \\ \text { Description } & \text { Peat/Wood } \\ \text { Fraction Dated } & \text { peat } \\ \text { Submitter } & \text { Richard Taylor School of Geography, Environment \& Earth Sciences, Victoria } \\ & \text { University of Wellington }\end{array}$

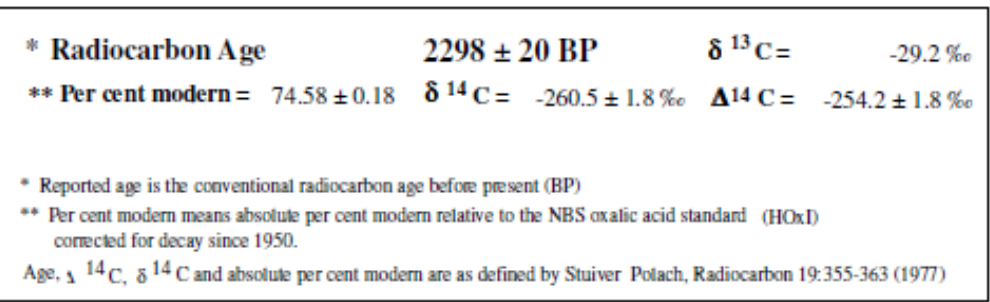

Sample Treatment Details

Fibrous plant material and soil wet condition. Microscopic exam: Leaf and pungs like fibrous material bound in clays. Fibrous material selected from sample dried portion and scraped off dirt. Ground with pestle and mortar. The sample was treated with acid / alkali /acid process. Dried in vacuum oven. Noted that possible contamination of this sample in vacuum oven.

\section{RAFTER RADIOCARBON LABORATORY}

INSTITUTE OF GEOLOGICAL AND NUCLEAR SCIENCES LTD.

PO Box 31312, Lower Hutt, New Zealand

Phone (+64 4) 5704671 , Fax (+64 4) 5704657

RADIOCARBON CALIBRATION REPORT

NZA 34551 CONVENTIONAL RADIOCARBON AGE $2298 \pm 20$ years BP

Southern Hemisphere Atmospheric data from McCormac et al (2004);

FG McCormac, AG Hogg, PG Blackwell, CE Buck, TFG Higham, and PJ Reimer (2004)

Radiocarbon 46, 1087-1092

CALIBRATED AGE in terms of confidence intervals (Smoothing parameter: 0, Offset: 0)

\begin{tabular}{|r|r|}
\hline $68 \%$ confidence interval is $380 \mathrm{BC}$ to $352 \mathrm{BC}$ & $2329 \mathrm{BP}$ to $2301 \mathrm{BP}$ (21.4\% of area) \\
plus $290 \mathrm{BC}$ to $229 \mathrm{BC}$ & $2239 \mathrm{BP}$ to $2178 \mathrm{BP}$ (46.3\% of area) \\
plus $215 \mathrm{BC}$ to $214 \mathrm{BC}$ & $2164 \mathrm{BP}$ to $2163 \mathrm{BP}(0.6 \%$ of area) \\
$95 \%$ confidence interval is $388 \mathrm{BC}$ to $345 \mathrm{BC}$ & $2337 \mathrm{BP}$ to $2294 \mathrm{BP}$ (27.3\% of area) \\
plus $318 \mathrm{BC}$ to $205 \mathrm{BC}$ & $2267 \mathrm{BP}$ to $2154 \mathrm{BP}(67.7 \%$ of area) \\
\hline
\end{tabular}

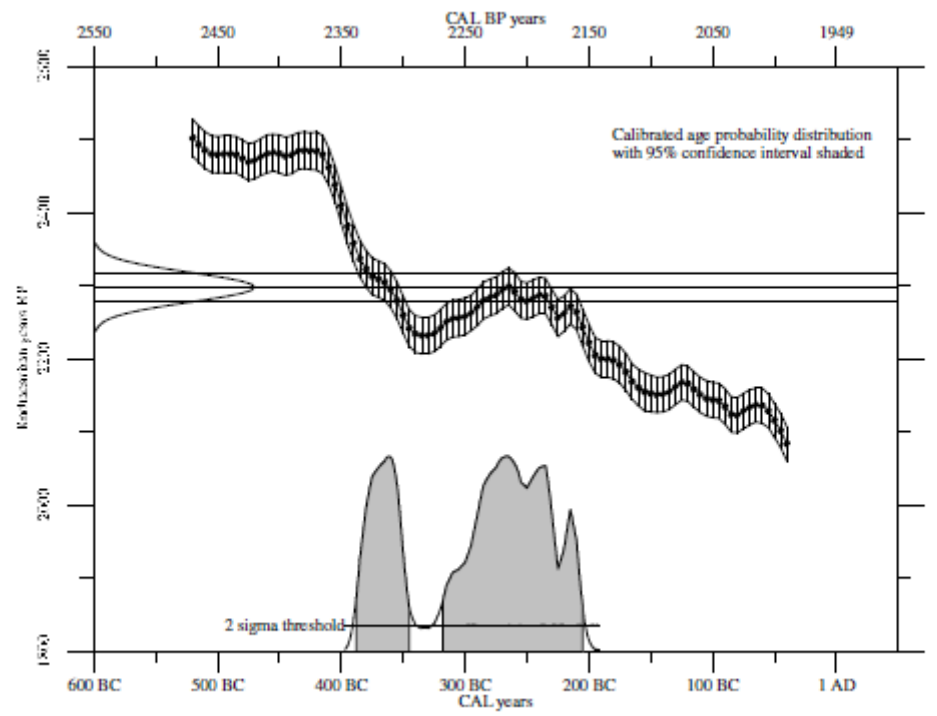


Accelerator Mass Spectrometry Result

\begin{tabular}{ll}
\hline Sample ID & WT1-5.20 \\
Description & Wood fragments \\
Fraction Dated & cellulose \\
Submitter & $\begin{array}{l}\text { Richard Taylor School of Geography, Environment \& Earth Sciences, Victoria } \\
\text { University of Wellington }\end{array}$
\end{tabular}

\begin{tabular}{|c|c|c|c|}
\hline \multirow{2}{*}{$\begin{array}{l}* \text { Radiocarbon Age } \\
* \text { Per cent modern }=70.36 \pm 0.23\end{array}$} & $2765 \pm 25 \mathrm{BP}$ & \multirow{2}{*}{$\begin{array}{l}\delta^{13} \mathrm{C}= \\
\Delta^{14} \mathrm{C}=\end{array}$} & \multirow{2}{*}{$\begin{array}{r}-28 \% \\
-296.4 \pm 2.3 \%\end{array}$} \\
\hline & $\delta^{14} \mathrm{C}=-300.8 \pm 2.3 \%$ & & \\
\hline \multirow{2}{*}{\multicolumn{4}{|c|}{$\begin{array}{l}\text { * Reported age is the conventional radiocarbon age before present (BP) } \\
\text { ** Per cent modern means absolute per cent modern relative to the NBS oxalic acid standard (HOxI) } \\
\text { corrected for decay since } 1950 .\end{array}$}} \\
\hline & & & \\
\hline \multicolumn{4}{|c|}{ Age, $\triangle{ }^{14} \mathrm{C}, \delta^{14} \mathrm{C}$ and absolute per cent modem are as defined by Stuiver Polach, Radiocarbon 19:355-363 (1977) } \\
\hline
\end{tabular}

Sample Treatment Details

Sample consisted of three small fragments of wood, degraded and damp. Sample selection consisted of selecting one of the wood fragments. Surface cleaning consists of scraping outer surfaces and cut away outer edges to expose clean wood. A square of clean wood was removed for chemical treatment. Treated with cellulose extraction process of acid wash, followed with alkali pulping, oxidation in hydrogen peroxide and final acid wash and dried in vacuum oven.

\section{RAFTER RADIOCARBON LABORATORY}

\section{INSTITUTE OF GEOLOGICAL AND NUCLEAR SCIENCES LTD. \\ PO Box 31312, Lower Hutt, New Zealand \\ Phone (+64 4) 5704671 , Fax (+64 4) 5704657 \\ RADIOCARBON CALIBRATION REPORT}

NZA 35372 CONVENTIONAL RADIOCARBON AGE $2765 \pm 25$ years BP

Southern He misphere Atmospheric data from MoCornace et al (2004):

FG McCormac, AG Hoge, PG Blackwell, CE Buck, TFG Higham, and PJ Reimer (2004) Radiocarbon 46, 1087-1092

CALIBRATED AGE in terms of confidenoe intervals (Smoothing parameter: 0, Offset: 0)

\begin{tabular}{|r|r|}
\hline $68 \%$ confidence interval is $894 \mathrm{BC}$ to $865 \mathrm{BC}$ & $2843 \mathrm{BP}$ to $2814 \mathrm{BP}$ (29.4\% of area) \\
plus $854 \mathrm{BC}$ to $819 \mathrm{BC}$ & $2803 \mathrm{BP}$ to $2768 \mathrm{BP}$ (37.5\% of area) \\
$95 \%$ confidence interval is $911 \mathrm{BC}$ to $805 \mathrm{BC}$ & $2860 \mathrm{BP}$ to $2754 \mathrm{BP}$ (94.9\% of area) \\
\hline
\end{tabular}

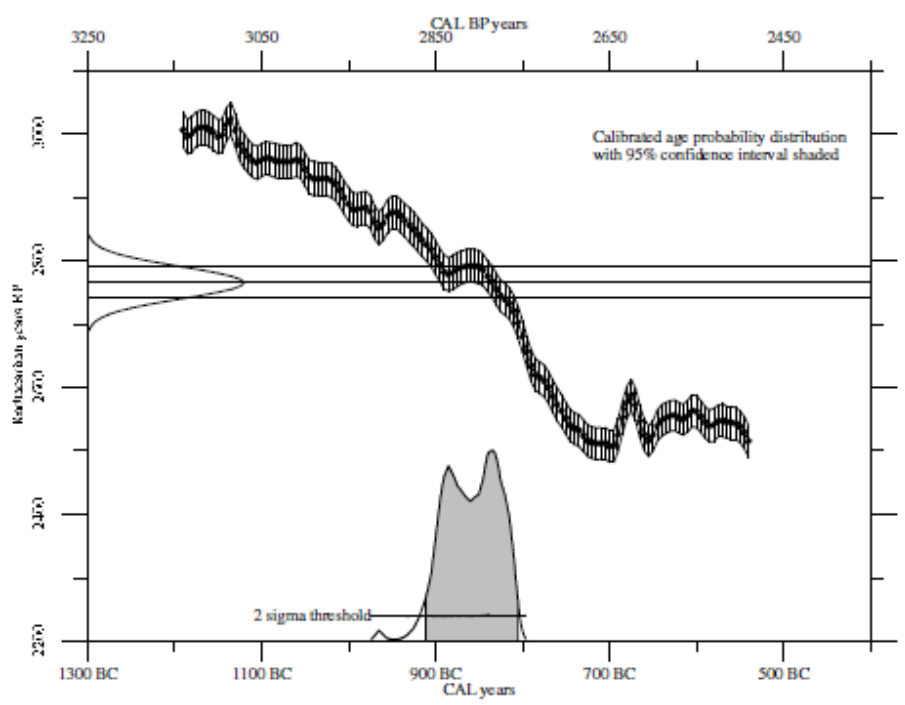




\section{C) RAFTER}

Accelerator Mass Spectrometry Result

This result for the sample submitted is for the exclusive use of the submitter

\section{Sample ID WT1-5.8}

Description Peat

Fraction Dated peat

Submitter Richard Taylor School of Geography, Environment \& Earth Sciences, Victoria University of Wellington

\begin{tabular}{|c|c|c|c|}
\hline \multirow{2}{*}{$\begin{array}{l}\text { * Radiocarbon Age } \\
* * \text { Per cent modern }=68.74 \pm 0.17\end{array}$} & $2953 \pm 20 \mathrm{BP}$ & \multirow{2}{*}{$\begin{array}{l}\delta^{13} \mathrm{C}= \\
\Delta^{14} \mathrm{C}=\end{array}$} & \multirow{2}{*}{$\begin{array}{r}-27.6 \% \text { c } \\
-312.6 \pm 1.7 \%\end{array}$} \\
\hline & $\delta^{14} \mathrm{C}=-316.3 \pm 1.7 \%$ & & \\
\hline \multicolumn{4}{|c|}{ - Reported age is the conventional radiocarbon age before present (BP) } \\
\hline \multicolumn{4}{|c|}{$\begin{array}{l}\text { ** Per cent modern means absolute per cent modern relative to the NBS axalic acid standard (HOxD) } \\
\text { conected for decay since } 1950 \text {. }\end{array}$} \\
\hline \multicolumn{4}{|c|}{ Age, ${ }^{14} \mathrm{C}, \delta^{14} \mathrm{C}$ and absolute per cent modern are as defined by Stuiver Potach, Radiocarbon 19:355-363 (1977) } \\
\hline
\end{tabular}

Sample Treatment Details

Damp sample of dark soil with visible plant frgaments. Microscopic exam: Small dark twig-like fragments in amongst sandy soil, not much other plant material, a synthetic fibre picked out.

Twigs picked out and cleaned in ultrasonic bath and dried in vac oven. The sample was treated with acid / alkali/acid process. Dried in vacuum oven.

\section{RAFTER RADIOCARBON LABORATORY}

INSTITUTE OF GEOLOGICAL AND NUCLEAR SCIENCES LTD.

PO Box 31312, Lower Hutt, New Zealand

Phone $(+644) 5704671$, Fax $(+644) 5704657$

RADIOCARBON CALIBRATION REPORT

NZA 34553 CONVENTIONAL RADIOCARBON AGE $2953 \pm 20$ years BP

Southern Hemisphere Atmospheric data from McCormac et al (2004);

FG McCormac, AG Hogg, PG Blackwell, CE Buck, TFG Higham, and PJ Reimer (2004)
Radiocarbon 46, 1087-1092

CALIBRATED AGE in terms of confidence intervals (Smoothing parameter: 0, Offset: 0)

$68 \%$ confidence inlerval is $1122 \mathrm{BC}$ to $1023 \mathrm{BC} 3071 \mathrm{BP}$ to $2972 \mathrm{BP}$ ( $68.1 \%$ of anea)

95\% confidence interval is $1207 \mathrm{BC}$ to $998 \mathrm{BC} 3156 \mathrm{BP}$ to $2947 \mathrm{BP}$ ( $94.9 \%$ of area)

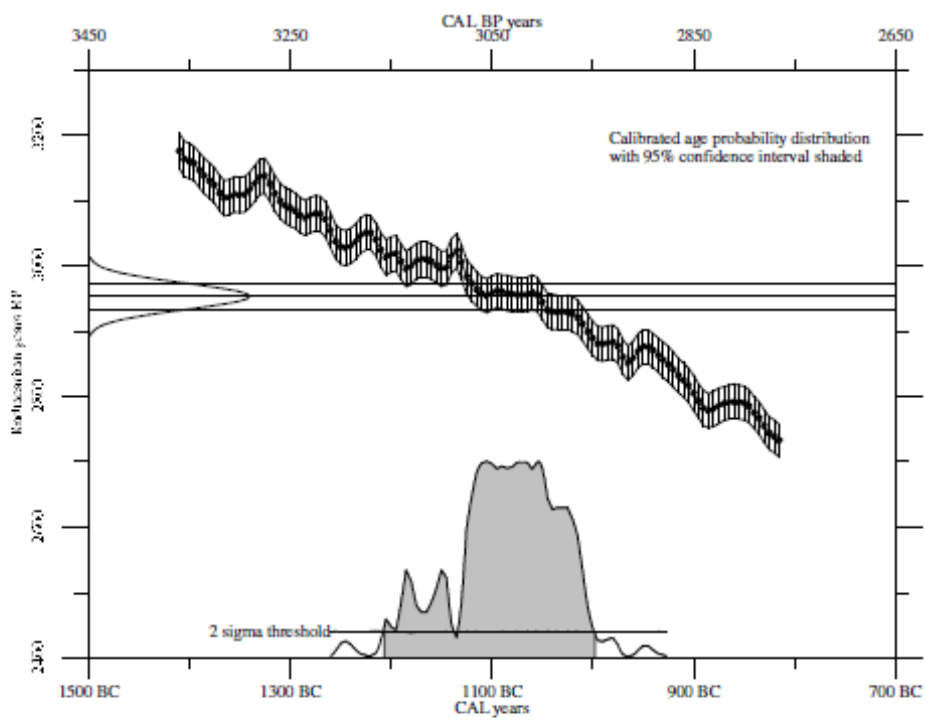




\section{C) RAFTER}

Accelerator Mass Spectrometry Result

This result for the sample submitted is for the exclusive use of the submitter.

All liability whatsoever to any thind party is encludal

\begin{tabular}{ll}
\hline Sample ID & WT1-River \\
Description & Wood \\
Fraction Dated & wood \\
Submitter & $\begin{array}{l}\text { Richard Taylor School of Geography, Environment \& Earth Sciences, Victoria } \\
\text { University of Wellington }\end{array}$
\end{tabular}

\begin{tabular}{|c|c|c|c|}
\hline * Radiocarbon Age & $2298 \pm 20 \mathrm{BP}$ & \multirow{2}{*}{$\begin{array}{l}\delta^{13} \mathrm{C}= \\
\Delta^{14} \mathrm{C}=\end{array}$} & \multirow{2}{*}{$\begin{array}{r}-27.5 \% \\
-254.3 \pm 1.8 \%\end{array}$} \\
\hline ** Per cent modern $=74.57 \pm 0.18$ & $\delta^{14} \mathrm{C}=-258.1 \pm 1.8 \%$ & & \\
\hline \multicolumn{4}{|c|}{ - Reported age is the conventional radiocarbon age before present (BP) } \\
\hline \multicolumn{4}{|c|}{$\begin{array}{l}\text { ** Per cent modern means absolute per cent modern relative to the NBS axalic acid standard (HOxD) } \\
\text { conrected for decay since } 1950 \text {. }\end{array}$} \\
\hline
\end{tabular}

Sample Treatment Details

Wood wet and somewhat degraded. Microscopic exam: Waterlogged and degraded appearance. Broke off outermost growth area bark trimmed off. Outer layers removed with scalpel. Treated with Cellulose extraction process of acid wash, $\mathrm{NaOH}$ pulping, hydrogen peroxide oxidation and acid wash steps. Dried in vacuum oven.

\section{RAFTER RADIOCARBON LABORATORY}

INSTITUTE OF GEOLOGICAL AND NUCL EAR SCIENCES LTD.

PO Box 31312, Lower Hutt, New Zealand

Phone (+64 4) 5704671 , Fax $(+64$ 4) 5704657

RADIOCARBON CALIBRATION REPORT

NZA 34549 CONVENTIONAL RADIOCARBON AGE $2298 \pm 20$ years BP

Southern Hemisphene Atmospheric data from McCormac et al (2004);

FG McCormac, AG Hogs, PG Blackwell, CE Buck, TFG Higham, and PJ Reimer (2004)

Radiocarbon 46, 1087-1092

CALIBRATED AGE in terms of confidence intervals (Smoothing parameter: 0, Offset: 0)

\begin{tabular}{|c|c|}
\hline $\begin{array}{r}68 \% \text { confidence interval is } 380 \mathrm{BC} \text { to } 352 \mathrm{BC} \\
\text { plus } 290 \mathrm{BC} \text { to } 229 \mathrm{BC} \\
\text { plus } 215 \mathrm{BC} \text { to } 214 \mathrm{BC}\end{array}$ & $\begin{array}{l}2329 \mathrm{BP} \text { to } 2301 \mathrm{BP}(21.4 \% \text { of area }) \\
2239 \mathrm{BP} \text { to } 2178 \mathrm{BP} \text { ( } 46.3 \% \text { of area }) \\
2164 \mathrm{BP} \text { to } 2163 \mathrm{BP}(0.6 \% \text { of area })\end{array}$ \\
\hline $\begin{array}{l}95 \% \text { confidence interval is } 388 \mathrm{BC} \text { to } 345 \mathrm{BC} \\
\text { plus } 318 \mathrm{BC} \text { to } 205 \mathrm{BC}\end{array}$ & $\begin{array}{l}2337 \mathrm{BP} \text { to } 2294 \mathrm{BP} \text { ( } 27.3 \% \text { of area) } \\
2267 \mathrm{BP} \text { to } 2154 \mathrm{BP}(6.7 \% \text { of area })\end{array}$ \\
\hline
\end{tabular}

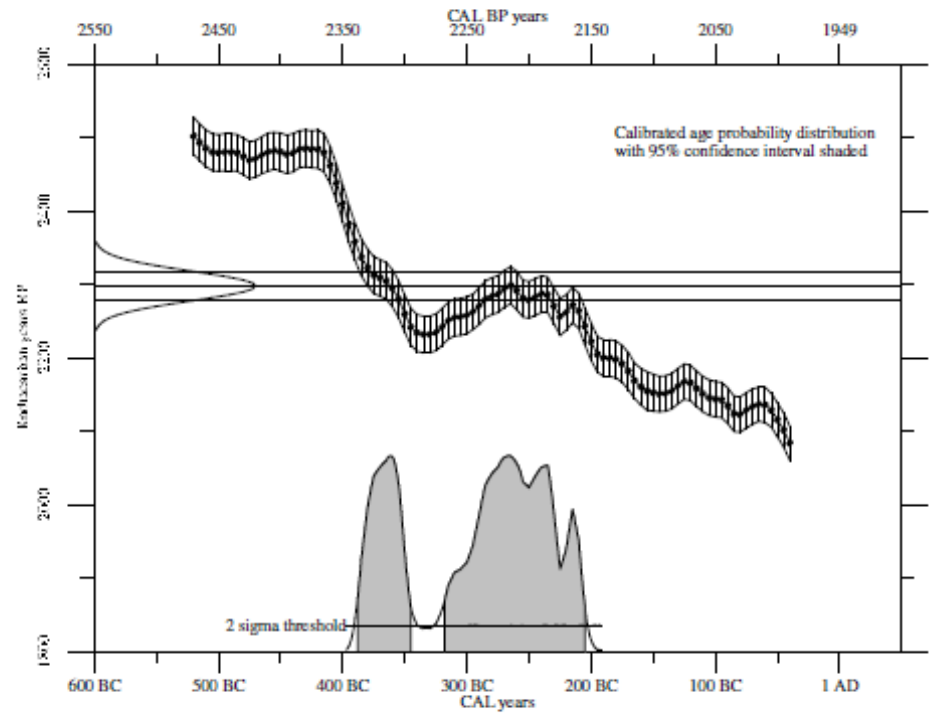




\section{A 1.4 Monck Road}

\section{C) RAFTER}

Accelerator Mass Spectrometry Result

This result for the sample submitted is for the exclusive use of the submitter.

TW No 2571 All liability whatsoever to any third party is excluded.

\begin{tabular}{ll}
\hline Sample ID & WM1-093 \\
Description & Bulk soil \\
Fraction Dated & bulk soil \\
Submitter & $\begin{array}{l}\text { Richard Taylor School of Geography, Environment \& Earth Sciences, Victoria } \\
\text { University of Wellington }\end{array}$
\end{tabular}

\begin{tabular}{|c|c|c|c|c|}
\hline Radiocarbon Age & \multicolumn{2}{|c|}{$1261 \pm 25 \mathrm{BP}$} & \multirow{2}{*}{$\begin{array}{l}\delta^{13} \mathrm{C}= \\
\Delta^{14} \mathrm{C}=\end{array}$} & \multirow{2}{*}{$\begin{array}{r}-26.4 \% \\
-151.6 \pm 2.5 \%\end{array}$} \\
\hline wn: Per cent modern $=84.84 \pm 0.25$ & $\delta^{14} \mathrm{C}=$ & $-154 \pm 2.5 \%$ & & \\
\hline \multicolumn{5}{|c|}{ * Reported age is the conventional radiocarbon age before present (BP) } \\
\hline \multicolumn{5}{|c|}{$\begin{array}{l}\text { ** Per cent moderm means absolute per cent modern relative to the NBS oxalic acid standard (HOxI) } \\
\text { corrected for decay since } 1950 \text {. }\end{array}$} \\
\hline \multicolumn{5}{|c|}{ Age, ${ }^{14} \mathrm{C}, \delta^{14} \mathrm{C}$ and absolute per cent modem are as defined by Stuiver Polach, Radiocarbon 19:355-363 (1977) } \\
\hline
\end{tabular}

Sample Treatment Details

Sample consisted of fine-grained compacted soil. Sample selection consisted of sifting through soil grains to select darker, more organic, soil without modern roots, etc. Treated with acid / alkali /acid process and dried in vacuum oven.

\section{RAFTER RADIOCARBON LABORATORY}

\section{INSTITUTE OF GEOLOGICAL AND NUCLEAR SCIENCES LTD.} PO Box 31312, Lower Hutt, New Zealand Phone (+64 4) 5704671 , Fax (+64 4) 5704657

RADIOCARBON CALIBRATION REPORT

NZA 35374 CONVENTIONAL RADIOCARBON AGE $\quad 1261 \pm 25$ years BP

\section{FG McCormac, AG Hoge, PG Blackwell, CE Buck, TFG Higham, and PJ Reimer (2004} Radiocarbon 46, 1087-1092

CALIBRATED AGE in terms of confidence intervals (Smoothing parameter: 0, Offset: 0)

68\% confidence interval is $779 \mathrm{AD}$ to $868 \mathrm{AD} \quad 1171 \mathrm{BP}$ to $1082 \mathrm{BP}$ ( $67.9 \%$ of area

95\% confidence interval is $716 \mathrm{AD}$ to $745 \mathrm{AD} \quad 1234 \mathrm{BP}$ to $1205 \mathrm{BP}$ (6.4\% of area) plus $768 \mathrm{AD}$ to $892 \mathrm{AD} \quad 1182 \mathrm{BP}$ to $1058 \mathrm{BP}$ (88.5\% of are

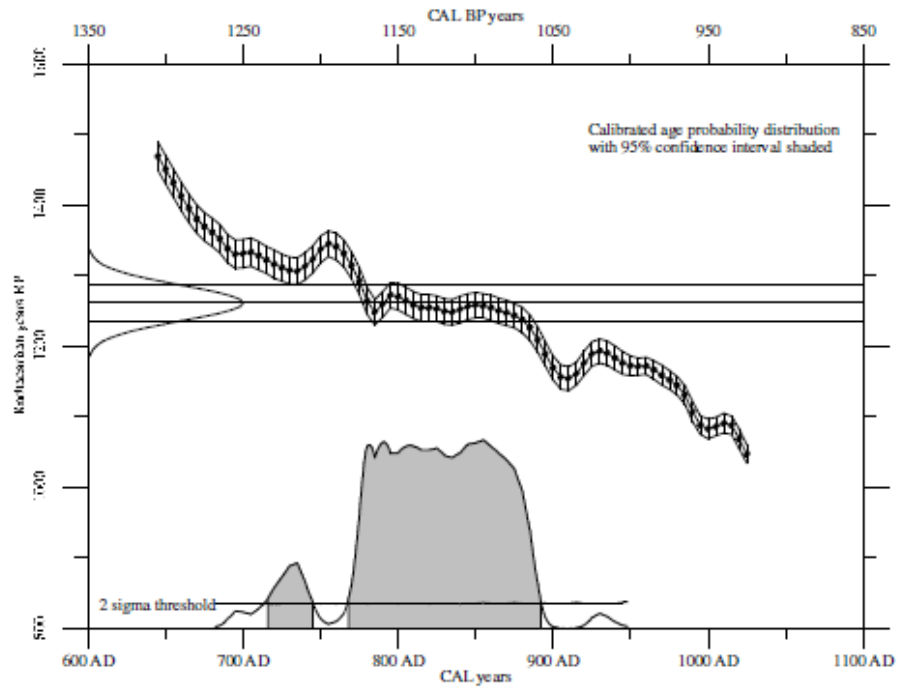




\begin{tabular}{ll}
\hline Sample ID & WM1-5.6/1 \\
Description & Wood \\
Fraction Dated & wood \\
Submitter & $\begin{array}{l}\text { Richard Taylor School of Geography, Environment \& Earth Sciences, Victoria } \\
\text { University of Wellington }\end{array}$
\end{tabular}

\begin{tabular}{|c|c|c|c|}
\hline \multirow{2}{*}{$\begin{array}{l}\text { * Radiocarbon Age } \\
* * \text { Per cent modern }=72.38 \pm 0.21\end{array}$} & $2539 \pm 25 \mathrm{BP}$ & \multirow{2}{*}{$\begin{array}{l}\delta^{13} \mathrm{C}= \\
\Delta^{14} \mathrm{C}=\end{array}$} & \multirow{2}{*}{$\begin{array}{r}-26.6 \% \\
-276.2 \pm 2.1 \%\end{array}$} \\
\hline & $\delta^{14} \mathrm{C}=-278.6 \pm 2.1 \%$ & & \\
\hline \multicolumn{4}{|c|}{ - Reported age is the conventional radiocarbon age before present (BP) } \\
\hline \multicolumn{4}{|c|}{$\begin{array}{l}\text { ** Per cent modern means absolute per cent modern relative to the NBS axalic acid standard (HOxD) } \\
\text { conrected for decay since } 1950 \text {. }\end{array}$} \\
\hline \multicolumn{4}{|c|}{ Age, ${ }^{14} \mathrm{C}, \delta^{14} \mathrm{C}$ and absolute per cent modern are as defined by Stuiver Polach, Radiocarbon 19:355-363 (1977) } \\
\hline
\end{tabular}

Sample Treatment Details

Wood wet and somewhat degraded. Microscopic exam: Waterlogged and dirty wood, outermost growth area broken off and cut into small rectangle with selected outer 2 growth rings. Treated with Cellulose extraction process of acid wash, $\mathrm{NaOH}$ pulping, hydrogen peroxide oxidation and acid wash steps. Dried in vacuum oven.

\section{RAFTER RADIOCARBON LABORATORY}

\section{INSTITUTE OF GEOLOGICAL AND NUCLEAR SCIENCES LTD.}

PO Box 31312, Lower Hutt, New Zealand

Phone (+64 4) 5704671 , Fax (+64 4) 5704657

RADIOCARBON CALIBRATION REPORT

NZA 34550 CONVENTIONAL RADIOCARBON AGE $2539 \pm 25$ years BP

Southern Hemisphere Atmospheric data from McCormac et al (2004);

Southern Hemisphere Atmospheric data from McCormac et al (2004);
FG McCormac, AG Hogs, PG Blackwell, CE Buck, TFG Higham, and PJ Reimer (2004)

Radiocarbon 46, 1087-1092

CALIBRATED AGE in terms of confidence intervals (Smoothing parameter: 0, Offset: 0)

$68 \%$ confidence inlerval is $755 \mathrm{BC}$ to $719 \mathrm{BC} \quad 2704 \mathrm{BP}$ to $2668 \mathrm{BP}$ (13.7\% of area) plus $693 \mathrm{BC}$ to $682 \mathrm{BC}$
plus $668 \mathrm{BC}$ to $539 \mathrm{BC}$
$2617 \mathrm{BP}$ to $2488 \mathrm{BP}$ ( $50.3 \%$ of area)

95\% confidence interval is $769 \mathrm{BC}$ to $414 \mathrm{BC} \quad 2718 \mathrm{BP}$ to $2363 \mathrm{BP}$ (95.1\% of area)

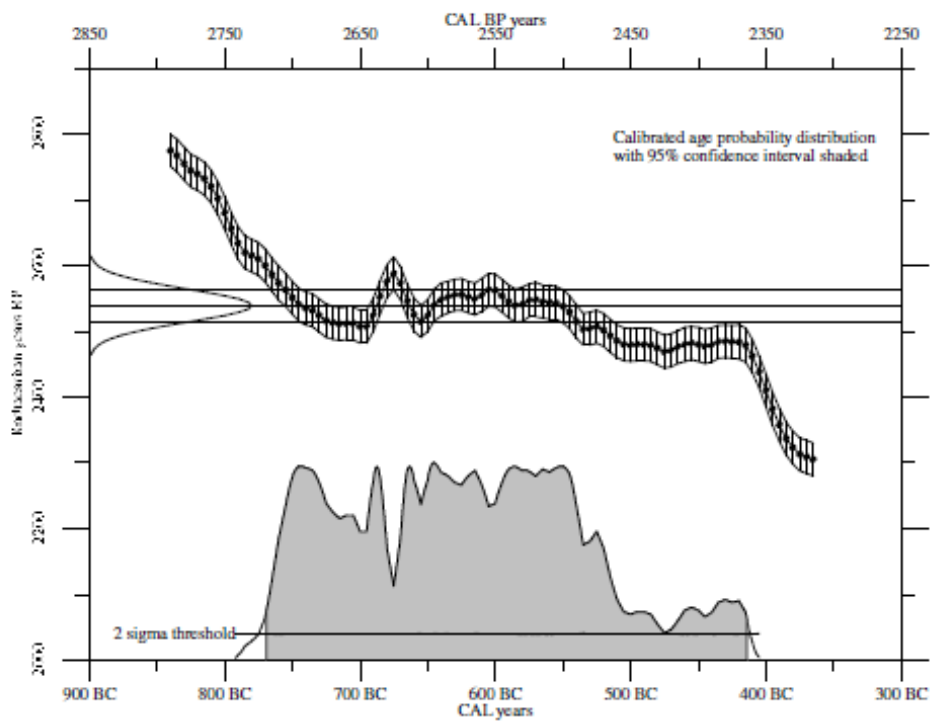




\section{A 1.5 Maungahuri}

\section{C) RAFTER}

Accelerator Mass Spectrometry Result

This result for the sample submitted is for the exclusive use of the submitter. All liability whatsoever to any third party is excluded.

$\begin{array}{rr}\text { NZA } & \mathbf{3 4 5 5 2} \\ \text { R } & 32491 / 1 \\ \text { Job No } & 102619 \\ \text { Measured } & 05-\text { Aug-10 } \\ \text { TW No } & 2532 \\ \text { Issued } & 16-\text { Aug-10 }\end{array}$

\begin{tabular}{ll}
\hline Sample ID & MM1-1.51 \\
Description & Peat \\
Fraction Dated & plant material \\
Submitter & Richard Taylor School of Geography, Environment \& Earth Sciences, Victoria \\
& University of Wellington
\end{tabular}

\begin{tabular}{|c|c|c|c|c|}
\hline * Radiocarbon Age & \multicolumn{2}{|c|}{$511 \pm 20 \mathrm{BP}$} & \multirow{2}{*}{$\begin{array}{l}\delta^{13} \mathrm{C}= \\
\Delta^{14} \mathrm{C}=\end{array}$} & \multirow{2}{*}{$\begin{array}{r}-29.1 \% \\
-68.4 \pm 2.1 \%\end{array}$} \\
\hline ** Per cent modern $=93.16 \pm 0.21$ & $\delta^{14} \mathrm{C}=$ & $-76.2 \pm 2.1 \%$ & & \\
\hline \multicolumn{5}{|c|}{ - Reported age is the conventional radiocarbon age before present (BP) } \\
\hline \multicolumn{5}{|c|}{$\begin{array}{l}\text { ** Per cent modern means absolute per cent modern relative to the NBS axalic acid standand (HOxI) } \\
\text { conrected for decay since 1950. }\end{array}$} \\
\hline \multicolumn{5}{|c|}{ Age, $1{ }^{14} \mathrm{C}, 8^{14} \mathrm{C}$ and absolute per cent modern are as defined by Stuiver Polach, Radiocarbon 19:355-363 (1977) } \\
\hline
\end{tabular}

Sample Treatment Details

Dry sandy soil with large amounts of macro plant rootlets and grassheads. Microscopic exam: Lots of rootlets, and a variety of plant material; leaves and small woody plant fragments, Root hairs picked out. The leaf like fragments and thin bark cambian were selected for dating.and crunched up in beaker. The sample was treated with acid / alkali /acid process. Dried in vacuum oven.

$$
\text { RAFTER RADIOCARBON LABORATORY }
$$

\section{INSTITUTE OF GEOLOGICAL AND NUCLEAR SCIENCES LTD. \\ PO Box 31312, Lower Hutt, New Zealand \\ Phone (+64 4) 5704671 , Fax $(+644) 5704657$}

RADIOCARBON CALIBRATION REPORT

NZA 34552 CONVENTIONAL RADIOCARBON AGE $511 \pm 20$ years BP

Southern Hemisphere Atmospheric data from McCormac et al (2004);

FG McCormac, AG Hogg, PG Blackwell, CE Buck, TFG Higham, and PJ Reimer (2004)
Radiocarbon 46, 1087-1092

CALIBRATED AGE in terms of confidence intervals (Smoothing parameter. 0, Offset: 0)

\begin{tabular}{|ll|}
\hline $68 \%$ confidence inlerval is $1430 \mathrm{AD}$ to $1448 \mathrm{AD}$ & $520 \mathrm{BP}$ to $502 \mathrm{BP}$ (70.5\% of area) \\
$95 \%$ confidence interval is $1419 \mathrm{AD}$ to $1453 \mathrm{AD}$ & $531 \mathrm{BP}$ to $497 \mathrm{BP}$ (95.2\% of area) \\
\hline
\end{tabular}

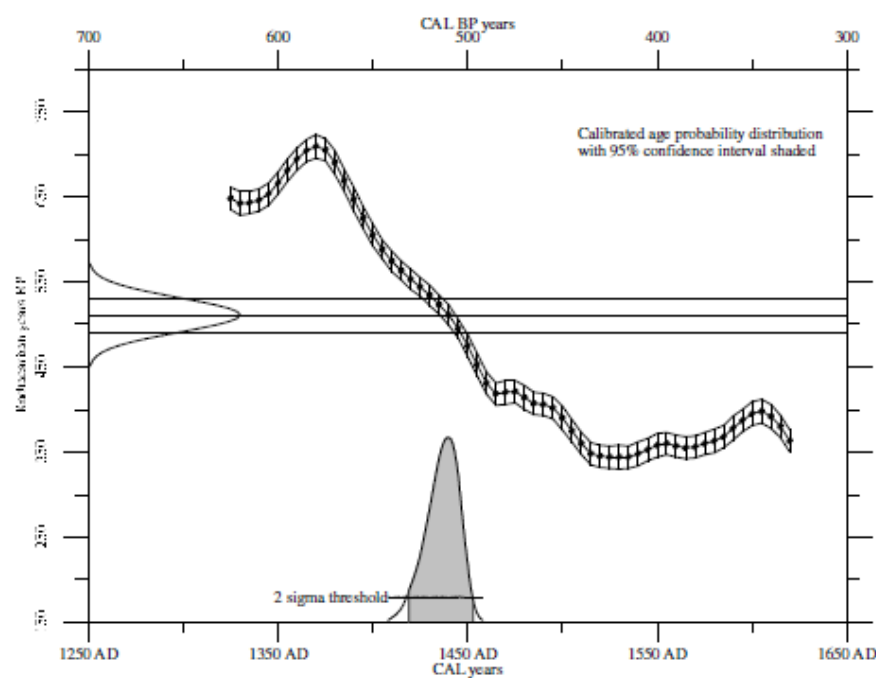




\section{Sample ID MMl-4.85}

Description Wood

Fraction Dated wood

Submitter Richard Taylor School of Geography, Environment \& Earth Sciences, Victoria University of Wellington

\begin{tabular}{|c|c|c|c|c|}
\hline * Radiocarbon Age & \multicolumn{2}{|c|}{$656 \pm 20 \mathrm{BP}$} & \multirow{2}{*}{$\begin{array}{l}\delta^{13} \mathrm{C}= \\
\Delta^{14} \mathrm{C}=\end{array}$} & \multirow{2}{*}{$\begin{array}{r}-24.7 \% \\
-85.1 \pm 2.1 \%\end{array}$} \\
\hline$* *$ Per cent modern $=91.49 \pm 0.21$ & $\delta^{14} \mathrm{C}=$ & $-84.6 \pm 2.1 \%$ & & \\
\hline \multicolumn{5}{|c|}{ - Reported age is the conventional radiocarbon age before present (BP) } \\
\hline \multicolumn{5}{|c|}{$\begin{array}{l}\text { ** Per cent modern means absolute per cent modern relative to the NBS axalic acid standard (HOxD) } \\
\text { conrected for decay since } 1950 \text {. }\end{array}$} \\
\hline \multicolumn{5}{|c|}{ Age, ${ }^{14} \mathrm{C}, \delta^{14} \mathrm{C}$ and absolute per cent modern are as defined by Stuiver Polach, Radiocarbon 19:355-363 (1977) } \\
\hline
\end{tabular}

Sample Treatment Details

Large hunk of wood about $12 \mathrm{~cm} \times 7 \mathrm{~cm}$. Dry, somewhat weathered. Broke off a piece of what appaears to be from outermost growth area. Microscopic exam: wood has weathered and dirty appearance. Used scalpel to cut off smaller hunk of wood inside material is "fresh" and clean looking. Used scalpel to scrape away all weathered surfaces. Treated with Cellulose extraction process of acid wash, $\mathrm{NaOH}$ pulping, hydrogen peroxide oxidation and acid wash steps. Dried in vacuum oven.

\section{RAFTER RADIOCARBON LABORATORY}

INSTITUTE OF GEOLOGICAL AND NUCLEAR SCIENCES LTD.

PO Box 31312, Lower Hutt, New Zealand

Phone $(+64$ 4) 5704671 , Fax $(+64$ 4) 5704657

RADIOCARBON CALIBRATION REPORT

NZA 34546 CONVENTIONAL RADIOCARBON AGE $656 \pm 20$ years BP

Southern Hemisphere Atmospheric data from McCormac et al (2004):

FG McCormac, AG Hogs, PG Blackwell, CE Buck, TFG Higham, and PJ Reimer (2004)

Radiocarbon 46, 1087-1092

CALIBRATED AGE in terms of confidence intervals (Smoothing parameter: 0, Offset: 0

\begin{tabular}{|c|c|}
\hline $\begin{array}{r}68 \% \text { confidence interval is } 1319 \mathrm{AD} \text { to } 1353 \mathrm{AD} \\
\text { plus } 1384 \mathrm{AD} \text { to } 1392 \mathrm{AD}\end{array}$ & $\begin{array}{l}631 \mathrm{BP} \text { to } 597 \mathrm{BP} \text { (54.3\% of area) } \\
566 \mathrm{BP} \text { to } 558 \mathrm{BP}(12.6 \% \text { of area) }\end{array}$ \\
\hline $\begin{array}{l}95 \% \text { confidence interval is } 1304 \mathrm{AD} \text { to } 1364 \mathrm{AD} \\
\text { plus } 1377 \mathrm{AD} \text { to } 1399 \mathrm{AD}\end{array}$ & $\begin{array}{l}646 \mathrm{BP} \text { to } 586 \mathrm{BP}(71.9 \% \text { of area }) \\
573 \mathrm{BP} \text { to } 551 \mathrm{BP}(23.1 \% \text { of area })\end{array}$ \\
\hline
\end{tabular}

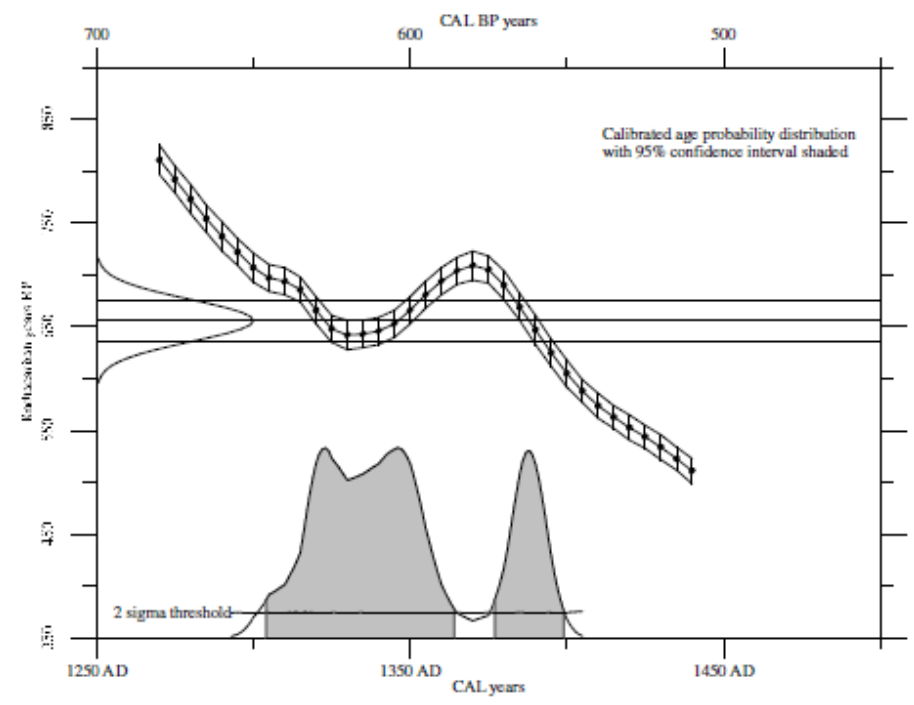




\section{A 1.6 Otara Station}

\section{C) RAFTER}

Accelerator Mass Spectrometry Result

$32599 / 2$

Job No $\quad 104150$

Measured 17-Dec-10

This result for the sample submitted is for the exclusive ue of the submitter.

TW No 2568 All liability whatsoever to any third party is excluded.

Sample ID SO1-3.30

Description Wood

Fraction Dated cellulose

Submitter Richard Taylor School of Geography, Environment \& Earth Sciences, Victoria University of Wellington

\begin{tabular}{|c|c|c|c|c|}
\hline \multirow{2}{*}{$\begin{array}{l}\text { * Radiocarbon Age } \\
\text { * Per cent modern }=93.68 \pm 0.27\end{array}$} & \multicolumn{2}{|c|}{$467 \pm 25 \mathrm{BP}$} & \multirow{2}{*}{$\begin{array}{l}8^{13} \mathrm{C}= \\
\Delta^{14} \mathrm{C}=\end{array}$} & \multirow{2}{*}{$\begin{array}{r}-27.8 \% \\
-63.2 \pm 2.7 \% \text { o }\end{array}$} \\
\hline & $\delta^{14} \mathrm{C}=$ & $-68.7 \pm 2.7 \%$ & & \\
\hline \multicolumn{5}{|c|}{ * Reported age is the conventional radiocarbon age before present (BP) } \\
\hline \multicolumn{5}{|c|}{$\begin{array}{l}\text { ** Per cent modern means absolute per cent modern relative to the NBS oxalic acid standard (HOxI) } \\
\text { corrected for decay since } 1950 \text {. }\end{array}$} \\
\hline \multicolumn{5}{|c|}{ Age, ${ }^{14} \mathrm{C}, \delta^{14} \mathrm{C}$ and absolute per cent modern are as defined by Stuiver Polach, Ratiocarbon 19:355-363 (1977) } \\
\hline
\end{tabular}

Sample Treatment Details

Sample consists of somewhat degraded wood. Cut out a piece to work with. Microscopic examination revealed damp and sandy degraded wood. Surface cleaning consists of scraping off sand and removing a small square of cle an wood from close to bark layer. Treated with cellulose extraction process of acid wash, followed with alkali pulping, oxidation in hydrogen peroxide and final acid wash. Large weight loss in sample noted during processing. Chemical treatment was repeated on fresh material as such a small amount of cellulose was recovered the first time. Dried in vacuum oven.

\section{RAFTER RADIOCARBON LABORATORY}

INSTITUTE OF GEOLOGICAL AND NUCLEAR SCIENCES LTD. PO Box 31312, Lower Hutt, New Zealand Phone (+64 4) 5704671 , Fax (+64 4) 5704657

RADIOCARBON CALIBRATION REPORT

NZA 35328 CONVENTIONAL RADIOCARBON AGE $467 \pm 25$ years BP

Southern Hemisphere Atmospheric data from McCormace et al (2004):

. Radiocarbon 46, 1087-1092

CALIBRATED AGE in terms of confidence intervals (Smoothing parameter: 0, Offset 0 )

\begin{tabular}{|rl|}
\hline $68 \%$ confidence interval is $1440 \mathrm{AD}$ to $1464 \mathrm{AD}$ & $510 \mathrm{BP}$ to $486 \mathrm{BP}$ (65.8\% of area) \\
plus $1474 \mathrm{AD}$ to $1476 \mathrm{AD}$ & $476 \mathrm{BP}$ to $474 \mathrm{BP}$ (22\% of area) \\
$95 \%$ confidence interval is $1430 \mathrm{AD}$ to $1497 \mathrm{AD}$ & $520 \mathrm{BP}$ to $453 \mathrm{BP}$ (94.7\% of area) \\
\hline
\end{tabular}

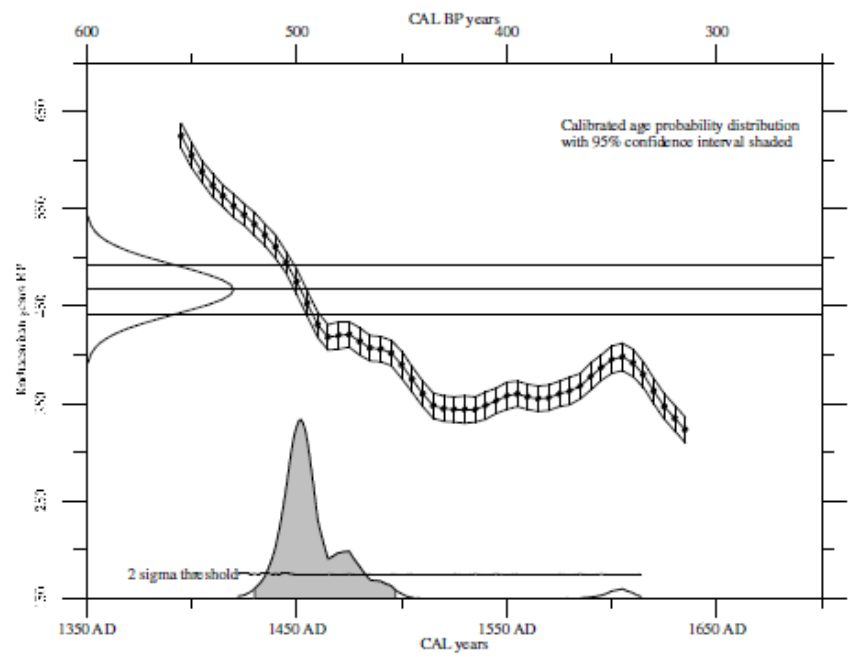


Sample ID SO1-4.70

Description Wood fragments

Fraction Dated cellulose

Submitter Richard Taylor School of Geography, Environment \& Earth Sciences, Victoria University of Wellington

\begin{tabular}{|c|c|c|c|c|}
\hline * Radiocarbon Age & \multicolumn{2}{|c|}{$167 \pm 25 \mathrm{BP}$} & \multirow{2}{*}{$\begin{array}{l}\delta^{13} \mathrm{C}= \\
\Delta^{14} \mathrm{C}=\end{array}$} & \multirow{2}{*}{$\begin{array}{r}-28.8 \% \\
-27.8 \pm 2.9 \%\end{array}$} \\
\hline ** Per cent modern $=97.22 \pm 0.29$ & $\delta^{14} \mathrm{C}=$ & $-35.4 \pm 2.9 \%$ & & \\
\hline \multicolumn{5}{|c|}{ * Reported age is the conventional radiocarbon age before present (BP) } \\
\hline \multicolumn{5}{|c|}{$\begin{array}{l}\text { ** Per cent modern means absolute per cent modern relative to the NBS oxalic acid standard (HOxI) } \\
\text { conrected for decay since } 1950 \text {. }\end{array}$} \\
\hline \multicolumn{5}{|c|}{ Age, ${ }^{14} \mathrm{C}, \delta^{14} \mathrm{C}$ and absolute per cent modern are as defined by Stuiver Polach, Radiocarbon 19:355-363 (1977) } \\
\hline
\end{tabular}

Sample Treatment Details

Sample consisted of several small pieces of degraded wood. Selected one for examination.

Microscopic examination revealed dry dirty wood fragment. Not able to detect what part of tree or how close to growth surface. Surface cleaning consisted of scraping off dirt and cutting a small square of clean wood to grind up. Treated with cellulose extraction process of acid wash, followed with alkali pulping, oxidation in hydrogen peroxide and final acid wash. Large weight loss noted. Dried in vacuum oven.

\section{RAFTER RADIOCARBON LABORATORY}

\section{INSTITUTE OF GEOLOGICAL AND NUCLEAR SCIENCES LTD.} PO Box 31312, Lower Hutt, New Zealand Phone (+64 4) 5704671 , Fax (+64 4) 5704657

RADIOCARBON CALIBRATION REPORT

NZA 35371 CONVENTIONAL RADIOCARBON AGE $\quad 167 \pm 25$ years BP

Southern Hemisphere Atmospheric data from McCormac et al (2004) FG McCormac, AG Hopg, PG Blackwell, CE Buck, TFG Higham, and PJ Reimer (2004)
Radiocarbon 46, 1087-1092

CALIBRATED AGE in erms of confidence intervals (Smoothing parameter. 0, Offset: 0)

\begin{tabular}{|rl|}
\hline $68 \%$ confidence interval is $1681 \mathrm{AD}$ to $1711 \mathrm{AD}$ & $269 \mathrm{BP}$ to $239 \mathrm{BP}$ (16.8\% of area) \\
plus 1720 $\mathrm{AD}$ to $1732 \mathrm{AD}$ & $230 \mathrm{BP}$ to $218 \mathrm{BP}$ (6.6\% of area) \\
plus $1802 \mathrm{AD}$ to $1812 \mathrm{AD}$ & $148 \mathrm{BP}$ to $138 \mathrm{BP}(5.6 \%$ of area) \\
plus $1837 \mathrm{AD}$ to $1882 \mathrm{AD}$ & $113 \mathrm{BP}$ to $68 \mathrm{BP}(23.8 \%$ of area) \\
plus $1924 \mathrm{AD}$ to $1950 \mathrm{AD}$ & $26 \mathrm{BP}$ to $0 \mathrm{BP}$ (15.1\% of area) \\
& $276 \mathrm{BP}$ to $209 \mathrm{BP}(31.1 \%$ of area) \\
$95 \%$ confidence interval is $1674 \mathrm{AD}$ to $1741 \mathrm{AD}$ & $152 \mathrm{BP}$ to $0 \mathrm{BP}$ (63.8\% of area) \\
plus 1798 AD to $1950 \mathrm{AD}$ &
\end{tabular}

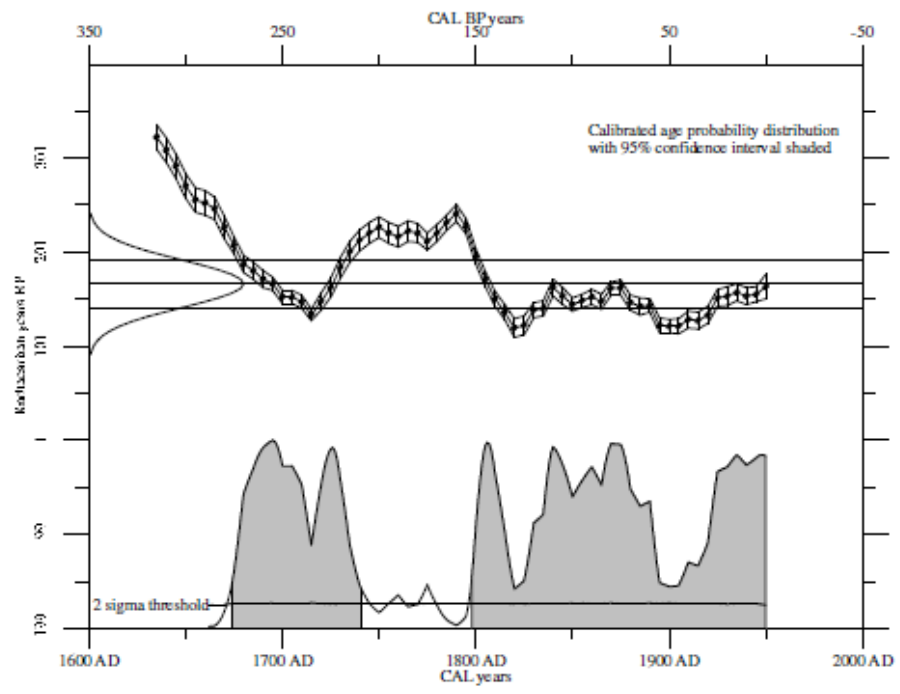




\section{A 1.7 Arai Matawai}

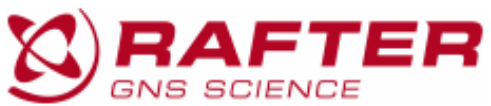

Accelerator Mass Spectrometry Result

This result for the sample submitted is for the exclusive use of the submitter

16-Aug-10

$\begin{array}{ll}\text { Sample ID } & \text { TT1-1.85 } \\ \text { Description } & \text { Wood } \\ \text { Fraction Dated } & \text { wood } \\ \text { Submitter } & \text { Richard Taylor School of Geography, Environment \& Earth Sciences, Victoria } \\ & \text { University of Wellington }\end{array}$

\begin{tabular}{|c|c|c|c|}
\hline * Radiocarbon Age & $6650 \pm 25 \mathrm{BP}$ & \multirow{2}{*}{$\begin{array}{l}\delta^{13} \mathrm{C}= \\
\Delta^{14} \mathrm{C}=\end{array}$} & \multirow{2}{*}{$\begin{array}{r}-24.2 \% \\
-566.2 \pm 1.4 \%\end{array}$} \\
\hline ** Per cent modern $=43.38 \pm 0.14$ & $\delta^{14} \mathrm{C}=-565.5 \pm 1.4 \%$ & & \\
\hline \multicolumn{4}{|c|}{ - Reported age is the conventional radiocarbon age before present (BP) } \\
\hline \multicolumn{4}{|c|}{$\begin{array}{l}\text { ** Per cent modern means absolute per cent modern relative to the NBS axalic acid standard (HOxD) } \\
\text { corrected for decay since } 1950 \text {. }\end{array}$} \\
\hline \multicolumn{4}{|c|}{ Age, ${ }_{1}^{14} \mathrm{C}, \delta^{14} \mathrm{C}$ and absolute per cent modern are as defined by Stuiver Polach, Radiocarbon 19:355-363 (1977) } \\
\hline
\end{tabular}

Sample Treatment Details

$7 \mathrm{~cm} \times 3 \mathrm{~cm}$ piece of wood, dry and weathered. Broke off $1 \mathrm{~g}$ piece from larger section. Microscopic exam: wood has weathered and dirty appearance, moulds present. Used scalpel to scrape away all weathered surfaces and expose clean inner wood.. Treated with Cellulose extraction process of

acid wash, $\mathrm{NaOH}$ pulping, hydrogen peroxide oxidation and acid wash steps. Dried in vacuum oven.

\section{RAFTER RADIOCARBON LABORATORY}

\section{INSTITUTE OF GEOLOGICAL AND NUCLEAR SCIENCES LTD.
PO Box 31312, Lower Hutt, New Zealand}

Phone (+64 4) 5704671 , Fax (+64 4) 5704657

RADIOCARBON CALIBRATION REPORT

NZA 34547 CONVENTIONAL RADIOCARBON AGE $6650 \pm 25$ years BP

Southern He misphere Atmospheric data from McCormac et al (2004)

twell, CE Buck, TTG Radiocarbon 46, 1087-1092

CALIBRATED AGE in terms of confidence intervals (Smoothing parameter: 0, Offset: 0 )

68\% confidence interval is $5604 \mathrm{BC}$ to $5594 \mathrm{BC} 7553 \mathrm{BP}$ to $7543 \mathrm{BP}(8.4 \%$ of area)
plus $5558 \mathrm{BC}$ to $5507 \mathrm{BC} 7507 \mathrm{BP}$ to $7456 \mathrm{BP}$ (50.3\% of area)
plus $5500 \mathrm{BC}$ to $5489 \mathrm{BC} 7449 \mathrm{BP}$ to $7438 \mathrm{BP}(9.0 \%$ of areas)
$95 \%$ confidence interval is $5614 \mathrm{BC}$ to $5582 \mathrm{BC} 7563 \mathrm{BP}$ to $7531 \mathrm{BP}(19.7 \%$ of area $)$
plus $5569 \mathrm{BC}$ to $5480 \mathrm{BC} 7518 \mathrm{BP}$ to $7429 \mathrm{BP}(75.2 \%$ of area)

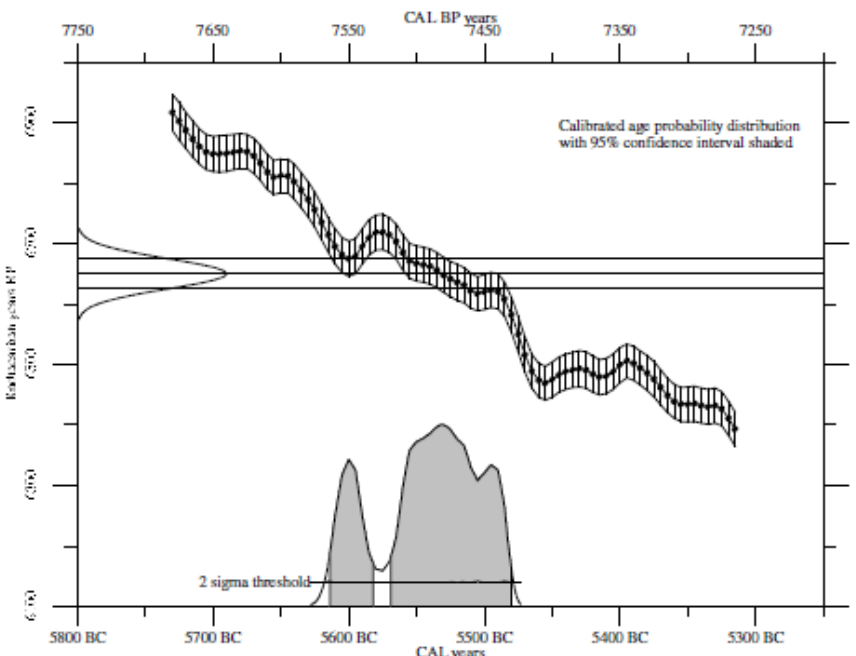


Sample ID TT1-5.20

Description Wood

Fraction Dated wood

Submitter Richard Taylor School of Geography, Environment \& Earth Sciences, Victoria University of Wellington

\begin{tabular}{|c|c|c|c|c|}
\hline * Radiocarbon Age & \multicolumn{2}{|c|}{$134 \pm 20 \mathrm{BP}$} & \multirow{2}{*}{$\begin{array}{l}\delta^{13} \mathrm{C}= \\
\Delta^{14} \mathrm{C}=\end{array}$} & \multirow{2}{*}{$\begin{array}{r}-26.5 \% \\
-23.7 \pm 2.2 \%\end{array}$} \\
\hline ** Per cent modern $=97.63 \pm 0.22$ & $\delta^{14} \mathrm{C}=$ & $-26.7 \pm 2.2 \%_{0}$ & & \\
\hline \multicolumn{5}{|c|}{ - Reported age is the conventional radiocarbon age before present (BP) } \\
\hline \multicolumn{5}{|c|}{$\begin{array}{l}\text { ** Per cent modern means absolute per cent modern relative to the NBS axalic acid standard (HOxD) } \\
\text { corrected for decay since } 1950 \text {. }\end{array}$} \\
\hline \multicolumn{5}{|c|}{ Age, ${ }_{1}^{14} \mathrm{C},{ }^{14} \mathrm{C}$ and absolute per cent modern are as defined by Stuiver Polach, Radiocarbon 19:355-363 (1977) } \\
\hline
\end{tabular}

Sample Treatment Details

Large piece of water logged wood: $10 \mathrm{~cm} \times 4 \mathrm{~cm}$. Broke small piece off from larger section.

Microscopic exam: wood very wet and dirty decayed looking. Used scalpel to scrape away all weathered surfaces and expose clean inner wood. Treated with Cellulose extraction process of acid wash, $\mathrm{NaOH}$ pulping, hydrogen peroxide oxidation and acid wash steps. Dried in vacuum oven.

\section{RAFTER RADIOCARBON LABORATORY}

INSTITUTE OF GEOLOGICAL AND NUCLEAR SCIENCES LTD.

$$
\begin{aligned}
& \text { PO Box 31312, Lower Hutt, New Zealand } \\
& \text { Phone (+64 4) 570 4671, Fax (+64 4) } 5704657
\end{aligned}
$$

RADIOCARBON CALIBRATION REPORT

NZA 34548 CONVENTIONAL RADIOCARBON AGE $134 \pm 20$ years BP

Southern Hemisphere Atmospheric data from McCornac et al (2004):

F McCormac, AG Hogg, PG Blackwell, CE Buck, TFG Higham, and PJ Reimer (2004)

Radiocarbon 46, 1087-1092

\begin{tabular}{|c|c|}
\hline $\begin{array}{r}68 \% \text { confidence interval is } 1707 \mathrm{AD} \text { to } 1722 \mathrm{AD} \\
\text { plus } 1810 \mathrm{AD} \text { to } 1838 \mathrm{AD} \\
\text { plus } 1847 \mathrm{AD} \text { to } 1859 \mathrm{AD} \\
\text { plus } 1862 \mathrm{AD} \text { to } 1867 \mathrm{AD} \\
\text { plus } 1879 \mathrm{AD} \text { to } 1925 \mathrm{AD}\end{array}$ & $\begin{array}{l}243 \mathrm{BP} \text { to } 228 \mathrm{BP}(9.7 \% \text { of area }) \\
140 \mathrm{BP} \text { to } 112 \mathrm{BP}(18.4 \% \text { of area) } \\
103 \mathrm{BP} \text { to } 91 \mathrm{BP}(7.0 \% \text { of area }) \\
88 \mathrm{BP} \text { to } 83 \mathrm{BP}(2.8 \% \text { of area }) \\
71 \mathrm{BP} \text { to } 25 \mathrm{BP}(30.4 \% \text { of area })\end{array}$ \\
\hline $\begin{array}{l}95 \% \text { confidence interval is } 1697 \mathrm{AD} \text { to } 1726 \mathrm{AD} \\
\text { plus } 1808 \mathrm{AD} \text { to } 1950 \mathrm{AD}\end{array}$ & $\begin{array}{l}253 \mathrm{BP} \text { to } 224 \mathrm{BP}(15.8 \% \text { of area }) \\
142 \mathrm{BP} \text { to } 0 \mathrm{BP}(79.0 \% \text { of area }\end{array}$ \\
\hline
\end{tabular}

CALIBRATED AGE in terms of confidence intervals (Smoothing parameter: 0, Offset: 0)

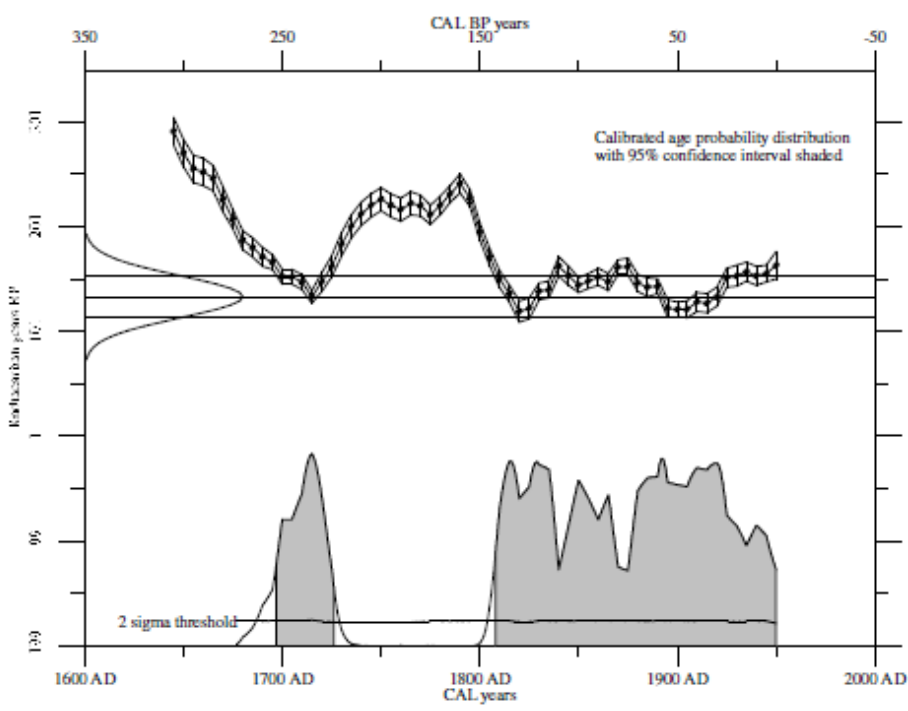


Appendix B 


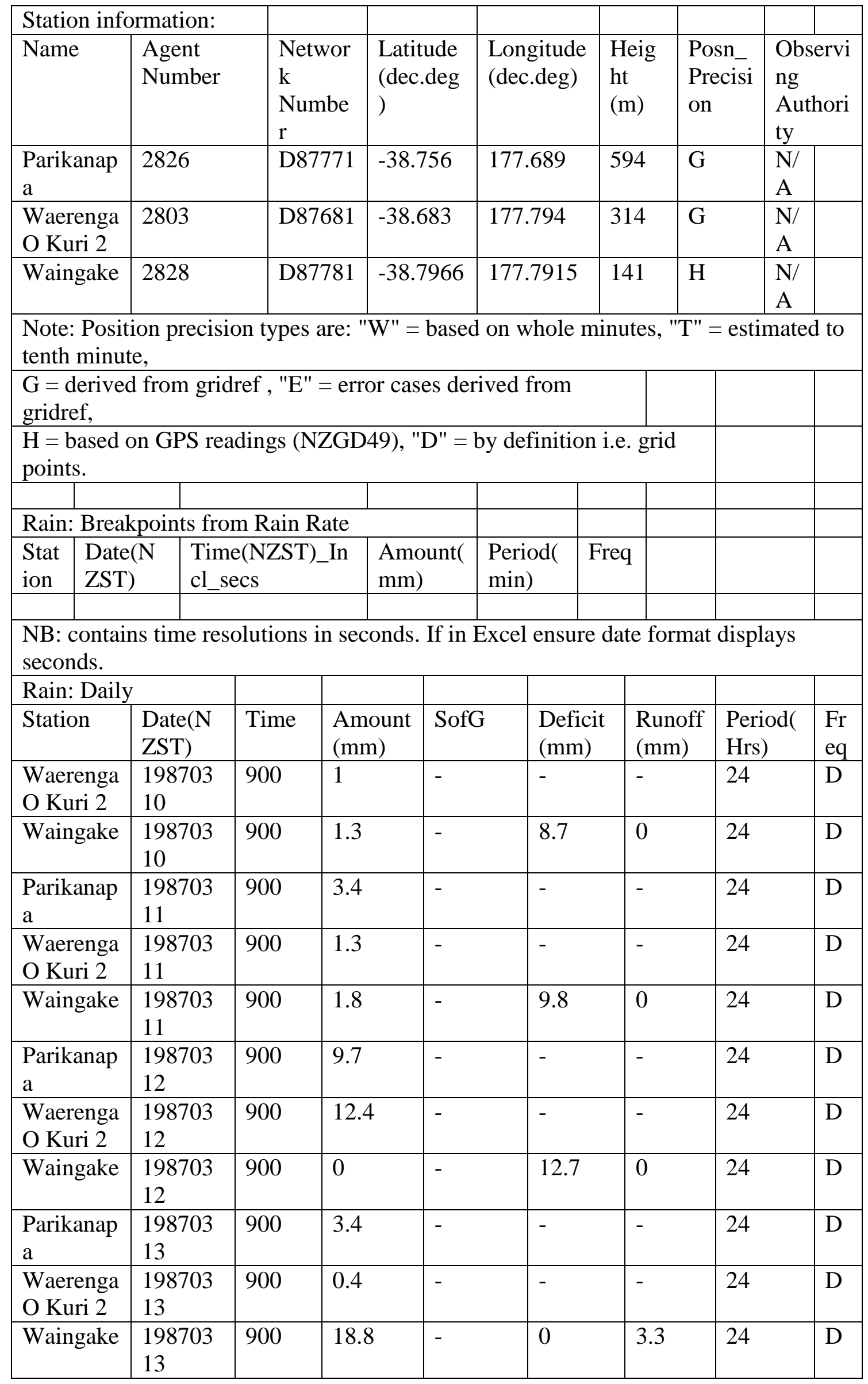




\begin{tabular}{|c|c|c|c|c|c|c|c|c|}
\hline $\begin{array}{l}\text { Parikanap } \\
\text { a }\end{array}$ & $\begin{array}{l}198703 \\
14\end{array}$ & 900 & 0 & - & - & - & 24 & $\mathrm{D}$ \\
\hline $\begin{array}{l}\text { Waerenga } \\
\text { O Kuri } 2\end{array}$ & $\begin{array}{l}198703 \\
14\end{array}$ & 900 & 0 & - & - & - & 24 & $\mathrm{D}$ \\
\hline Waingake & $\begin{array}{l}198703 \\
14\end{array}$ & 900 & 0 & - & 2.9 & 0 & 24 & $\mathrm{D}$ \\
\hline $\begin{array}{l}\text { Waerenga } \\
\text { O Kuri } 2\end{array}$ & $\begin{array}{l}198703 \\
15\end{array}$ & 900 & 0.5 & - & - & - & 24 & $\mathrm{D}$ \\
\hline Waingake & $\begin{array}{l}198703 \\
15\end{array}$ & 900 & 0.6 & - & 5.2 & 0 & 24 & $\mathrm{D}$ \\
\hline $\begin{array}{l}\text { Parikanap } \\
\text { a }\end{array}$ & $\begin{array}{l}198703 \\
16\end{array}$ & 900 & 5.5 & - & - & - & 48 & $\mathrm{D}$ \\
\hline $\begin{array}{l}\text { Waerenga } \\
\text { O Kuri } 2\end{array}$ & $\begin{array}{l}198703 \\
16\end{array}$ & 900 & 4.2 & - & - & - & 24 & $\mathrm{D}$ \\
\hline Waingake & $\begin{array}{l}198703 \\
16\end{array}$ & 900 & 6.4 & - & 1.6 & 0 & 24 & $\mathrm{D}$ \\
\hline $\begin{array}{l}\text { Parikanap } \\
\text { a }\end{array}$ & $\begin{array}{l}198703 \\
17\end{array}$ & 900 & 10.3 & - & - & - & 24 & $\mathrm{D}$ \\
\hline $\begin{array}{l}\text { Waerenga } \\
\text { O Kuri } 2\end{array}$ & $\begin{array}{l}198703 \\
17\end{array}$ & 900 & 5.3 & - & - & - & 24 & $\mathrm{D}$ \\
\hline Waingake & $\begin{array}{l}198703 \\
17\end{array}$ & 900 & 12 & - & 0 & 7.5 & 24 & D \\
\hline $\begin{array}{l}\text { Waerenga } \\
\text { O Kuri } 2\end{array}$ & $\begin{array}{l}198703 \\
18\end{array}$ & 900 & 5 & - & - & - & 24 & $\mathrm{D}$ \\
\hline Waingake & $\begin{array}{l}198703 \\
18\end{array}$ & 900 & 11.8 & - & 0 & 8.9 & 24 & $\mathrm{D}$ \\
\hline $\begin{array}{l}\text { Waerenga } \\
\text { O Kuri } 2\end{array}$ & $\begin{array}{l}198703 \\
19\end{array}$ & 900 & 12.4 & - & - & - & 24 & $\mathrm{D}$ \\
\hline Waingake & $\begin{array}{l}198703 \\
19\end{array}$ & 900 & 12.3 & - & 0 & 9.4 & 24 & $\mathrm{D}$ \\
\hline $\begin{array}{l}\text { Waerenga } \\
\text { O Kuri } 2\end{array}$ & $\begin{array}{l}198703 \\
20\end{array}$ & 900 & 1.2 & - & - & - & 24 & $\mathrm{D}$ \\
\hline Waingake & $\begin{array}{l}198703 \\
20\end{array}$ & 900 & 5.7 & - & 0 & 2.8 & 24 & $\mathrm{D}$ \\
\hline $\begin{array}{l}\text { Waerenga } \\
\text { O Kuri } 2\end{array}$ & $\begin{array}{l}198703 \\
21\end{array}$ & 900 & 5.4 & - & - & - & 24 & $\mathrm{D}$ \\
\hline Waingake & $\begin{array}{l}198703 \\
21\end{array}$ & 900 & 40 & - & 0 & 37.1 & 24 & $\mathrm{D}$ \\
\hline $\begin{array}{l}\text { Waerenga } \\
\text { O Kuri } 2\end{array}$ & $\begin{array}{l}198703 \\
22\end{array}$ & 900 & 126.2 & - & - & - & 24 & $\mathrm{D}$ \\
\hline Waingake & $\begin{array}{l}198703 \\
22\end{array}$ & 900 & 106.7 & - & 0 & 103.8 & 24 & D \\
\hline $\begin{array}{l}\text { Parikanap } \\
\text { a }\end{array}$ & $\begin{array}{l}198703 \\
23\end{array}$ & 900 & 246.9 & - & - & - & 144 & $\mathrm{D}$ \\
\hline $\begin{array}{l}\text { Waerenga } \\
\text { O Kuri } 2\end{array}$ & $\begin{array}{l}198703 \\
23\end{array}$ & 900 & 0 & - & - & - & 24 & $\mathrm{D}$ \\
\hline Waingake & $\begin{array}{l}198703 \\
23\end{array}$ & 900 & 0 & - & 2.9 & 0 & 24 & $\mathrm{D}$ \\
\hline Waingake & 198803 & 800 & 0 & - & - & - & 24 & $\mathrm{D}$ \\
\hline
\end{tabular}




\begin{tabular}{|c|c|c|c|c|c|c|c|c|}
\hline & 05 & & & & & & & \\
\hline $\begin{array}{l}\text { Parikanap } \\
\text { a }\end{array}$ & $\begin{array}{l}198803 \\
06\end{array}$ & 900 & 0 & - & - & - & 24 & $\mathrm{D}$ \\
\hline $\begin{array}{l}\text { Waerenga } \\
\text { O Kuri } 2\end{array}$ & $\begin{array}{l}198803 \\
06\end{array}$ & 900 & 1.5 & - & - & - & 24 & $\mathrm{D}$ \\
\hline Waingake & $\begin{array}{l}198803 \\
06\end{array}$ & 900 & 35 & - & - & - & 24 & $\mathrm{D}$ \\
\hline $\begin{array}{l}\text { Waerenga } \\
\text { O Kuri } 2\end{array}$ & $\begin{array}{l}198803 \\
07\end{array}$ & 900 & 116 & - & - & - & 24 & $\mathrm{D}$ \\
\hline Waingake & $\begin{array}{l}198803 \\
07\end{array}$ & 900 & 98.8 & - & - & - & 24 & $\mathrm{D}$ \\
\hline Parikanap & $\begin{array}{l}198803 \\
08\end{array}$ & 900 & 312 & - & F & 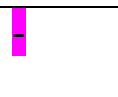 & 48 & D \\
\hline $\begin{array}{l}\text { Waerenga } \\
\text { O Kuri } 2\end{array}$ & $\begin{array}{l}198803 \\
08\end{array}$ & 900 & 304.7 & 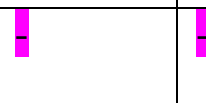 & 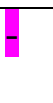 & 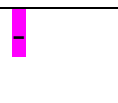 & 24 & D \\
\hline Waingake & $\begin{array}{l}198803 \\
08\end{array}$ & 900 & 255 & 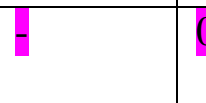 & 0 & 0 & 24 & D \\
\hline $\begin{array}{l}\text { Parikanap } \\
\text { a }\end{array}$ & $\begin{array}{l}198803 \\
09\end{array}$ & 900 & 304 & - & - & - & 24 & $\mathrm{D}$ \\
\hline $\begin{array}{l}\text { Waerenga } \\
\text { O Kuri } 2\end{array}$ & $\begin{array}{l}198803 \\
09\end{array}$ & 900 & 143 & - & - & - & 24 & $\mathrm{D}$ \\
\hline Waingake & $\begin{array}{l}198803 \\
09\end{array}$ & 900 & 217.1 & - & 0 & 214.1 & 24 & $\mathrm{D}$ \\
\hline $\begin{array}{l}\text { Parikanap } \\
\text { a }\end{array}$ & $\begin{array}{l}198803 \\
10\end{array}$ & 900 & 25.1 & - & - & - & 24 & $\mathrm{D}$ \\
\hline $\begin{array}{l}\text { Waerenga } \\
\text { O Kuri } 2\end{array}$ & $\begin{array}{l}198803 \\
10\end{array}$ & 900 & 6.8 & - & - & - & 24 & $\mathrm{D}$ \\
\hline $\begin{array}{l}\text { Parikanap } \\
\text { a }\end{array}$ & $\begin{array}{l}198803 \\
11\end{array}$ & 900 & 0 & - & - & - & 24 & $\mathrm{D}$ \\
\hline \multicolumn{9}{|c|}{ UserName is $=r$ - $\mathrm{j}$-taylor } \\
\hline \multicolumn{9}{|c|}{ Total number of rows output $=1536$} \\
\hline \multicolumn{6}{|c|}{$\begin{array}{l}\text { Number of rows remaining in subscription }= \\
1996462\end{array}$} & & & \\
\hline \multirow{2}{*}{\multicolumn{6}{|c|}{$\begin{array}{l}\text { Copyright NIWA } 2010 \text { Subject to NIWA's Terms and } \\
\text { Conditions } \\
\text { See: http://cliflo.niwa.co.nz/pls/niwp/doc/terms.html }\end{array}$}} & & & \\
\hline & & & & & & & & \\
\hline \multicolumn{6}{|c|}{ Comments to: cliflo@niwa.co.nz } & & & \\
\hline
\end{tabular}


Appendix C 


\section{Mangakiore}

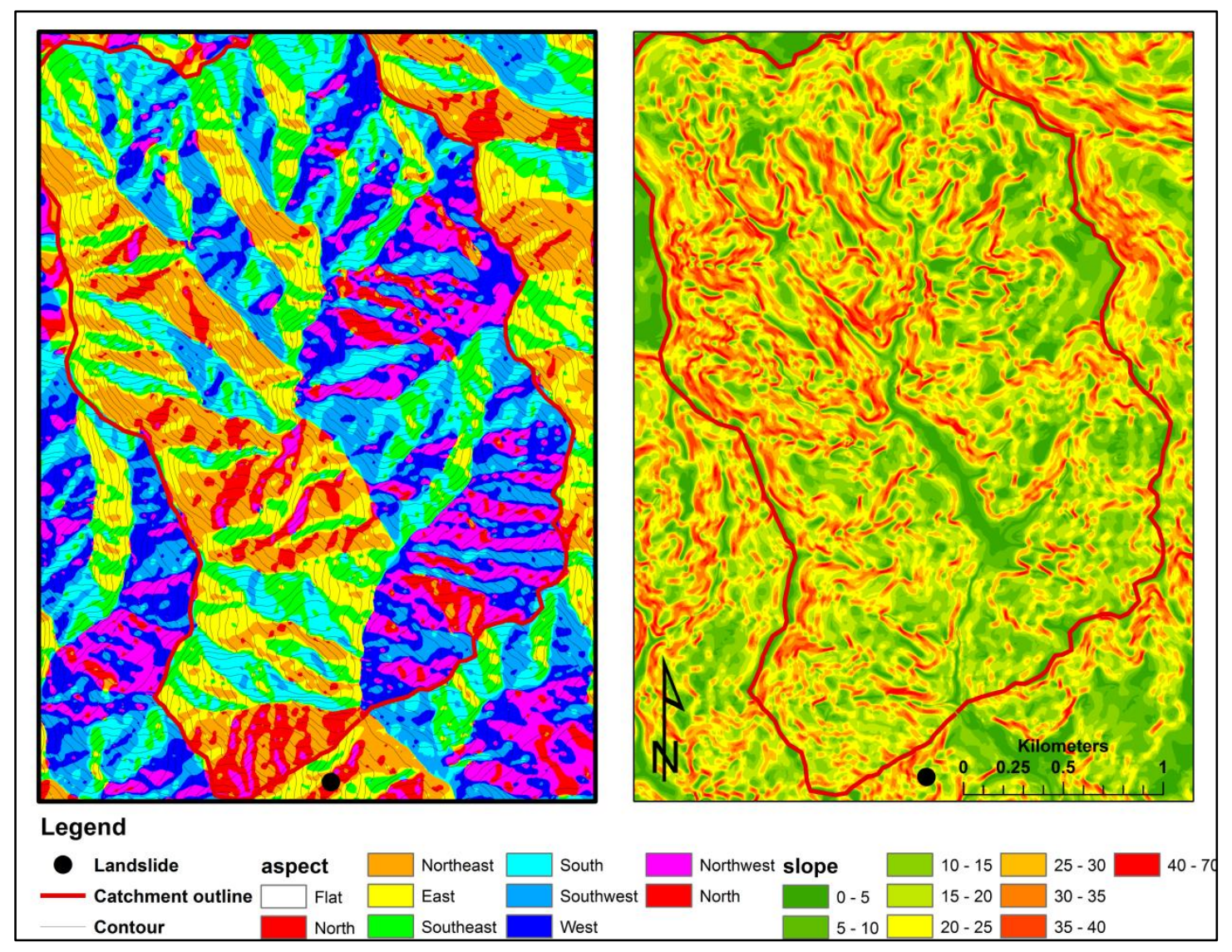




\section{Monck Road}

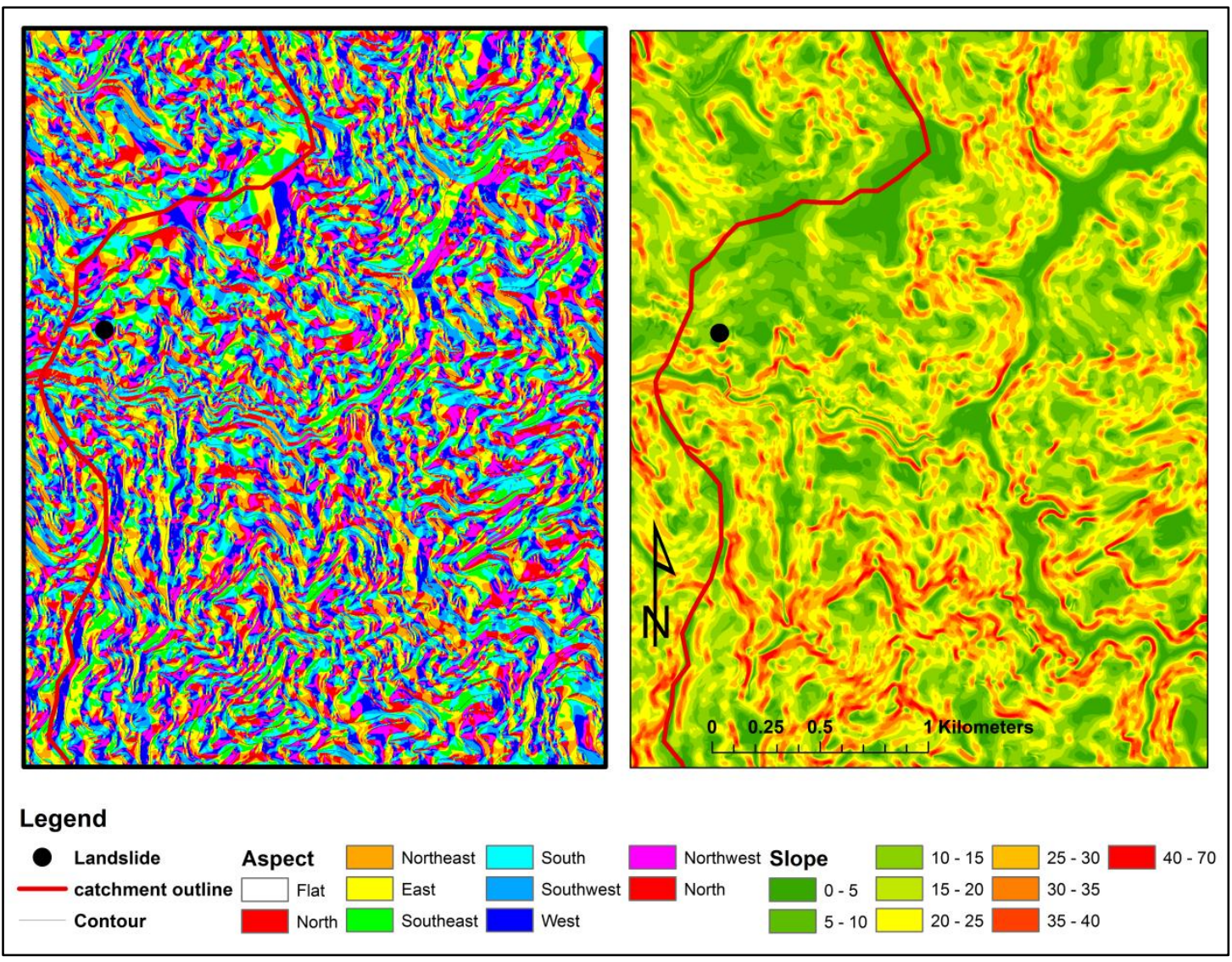




\section{Kopaatuaki}

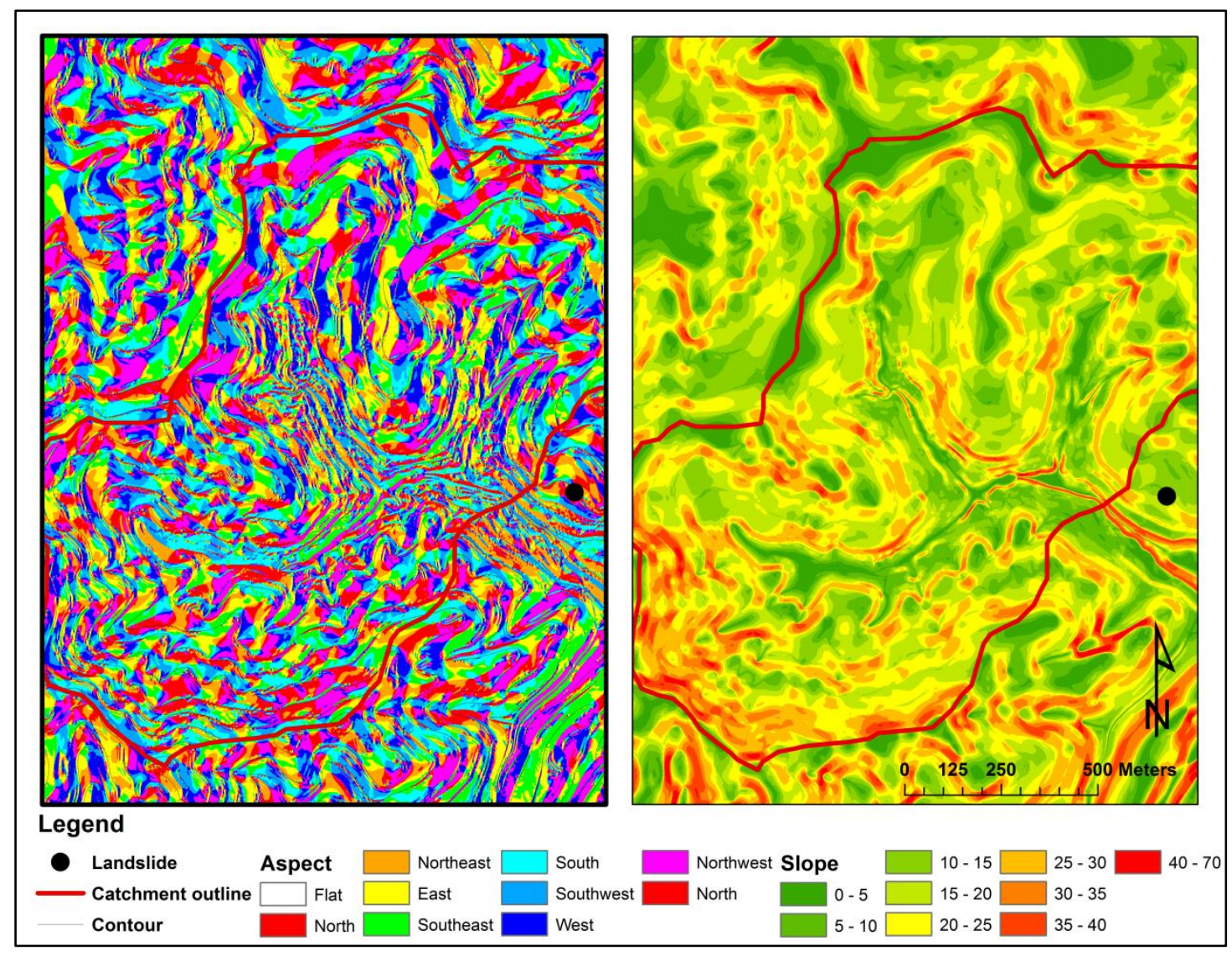




\section{Tangihau}

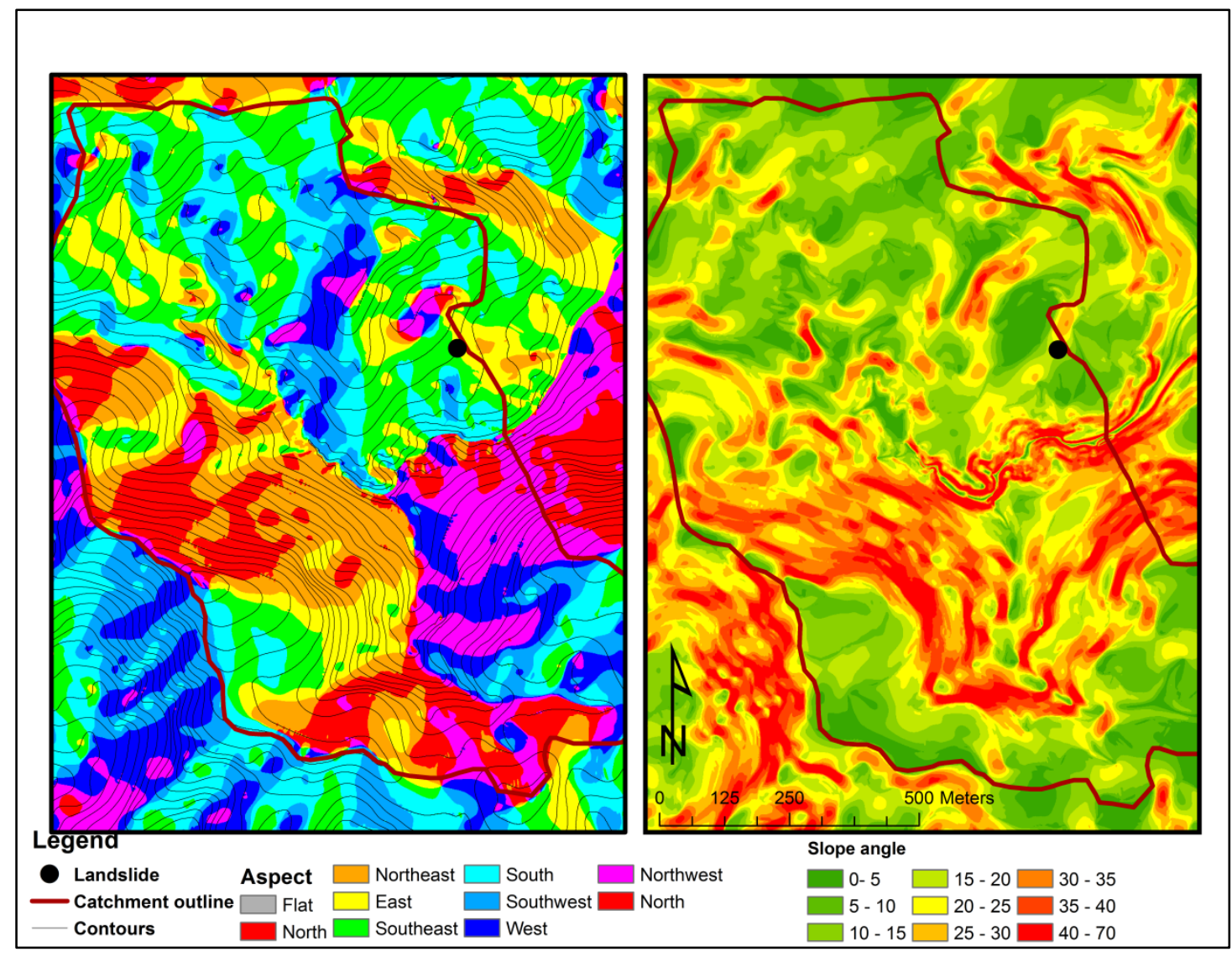




\section{Maungahurai}

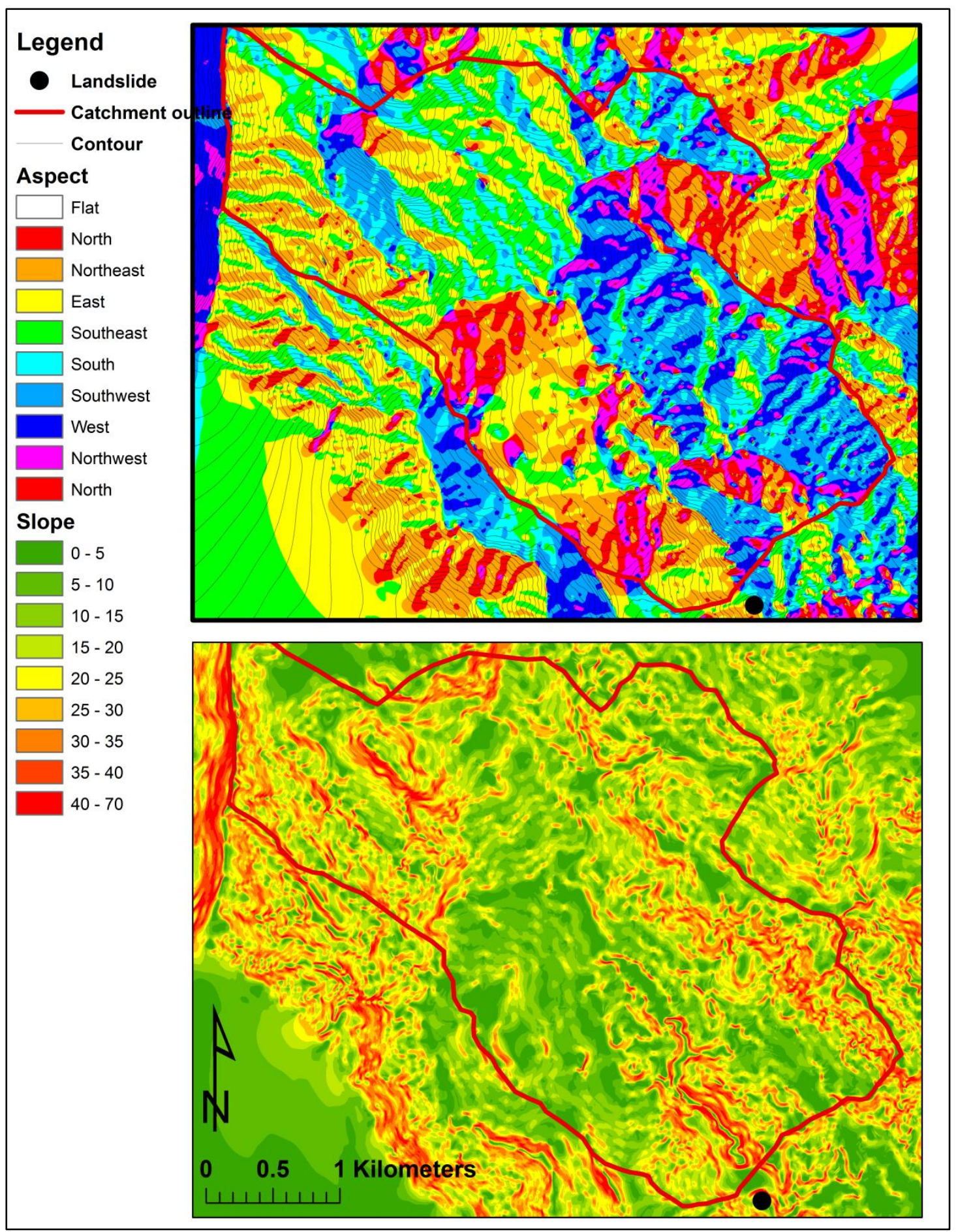




\section{Arai Matawai}

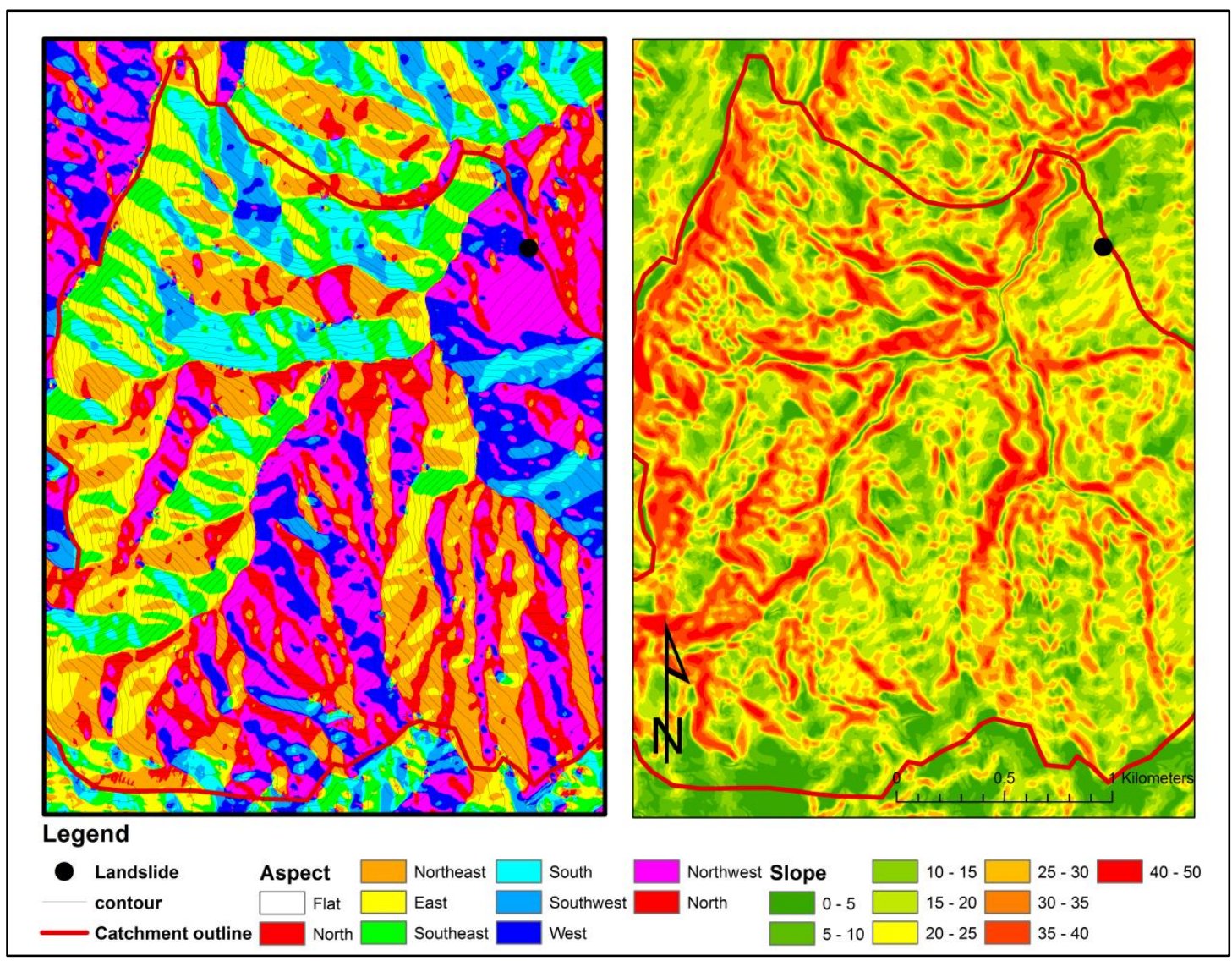




\section{Otara Station}

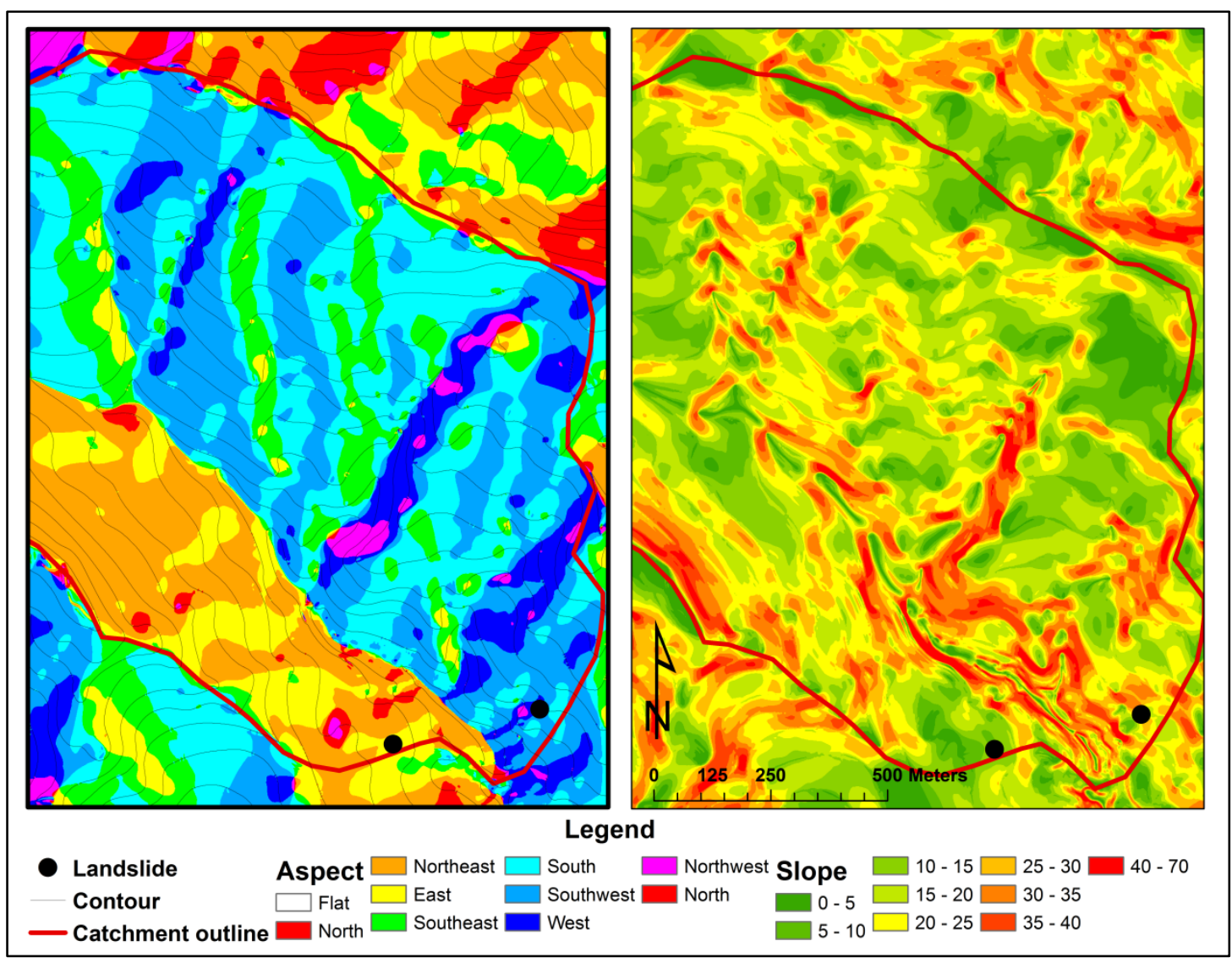


Appendix D 


\section{Mangakiore Core}
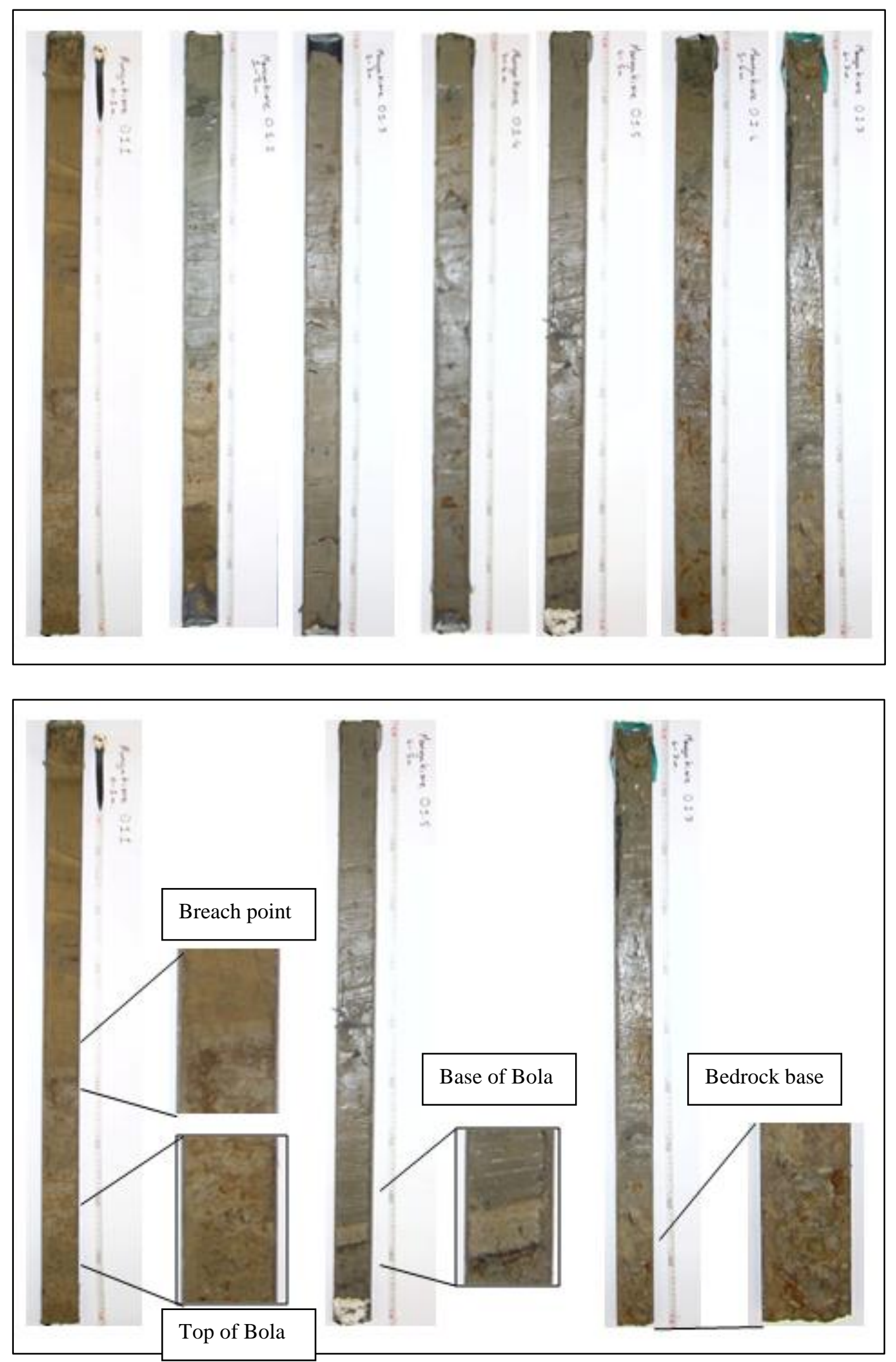
Kopaatuaki Core
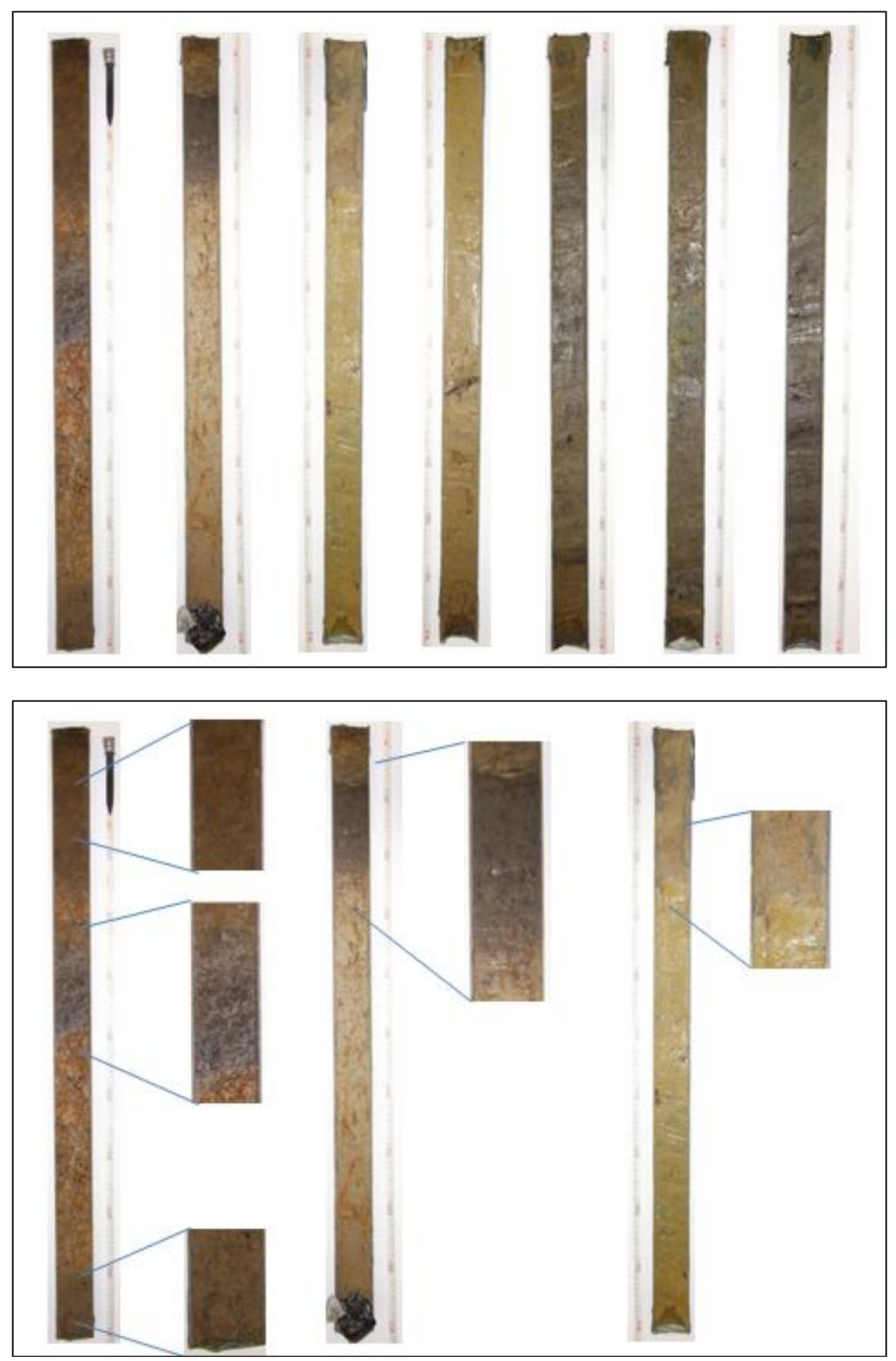

$217 \mid \mathrm{P}$ a g e 


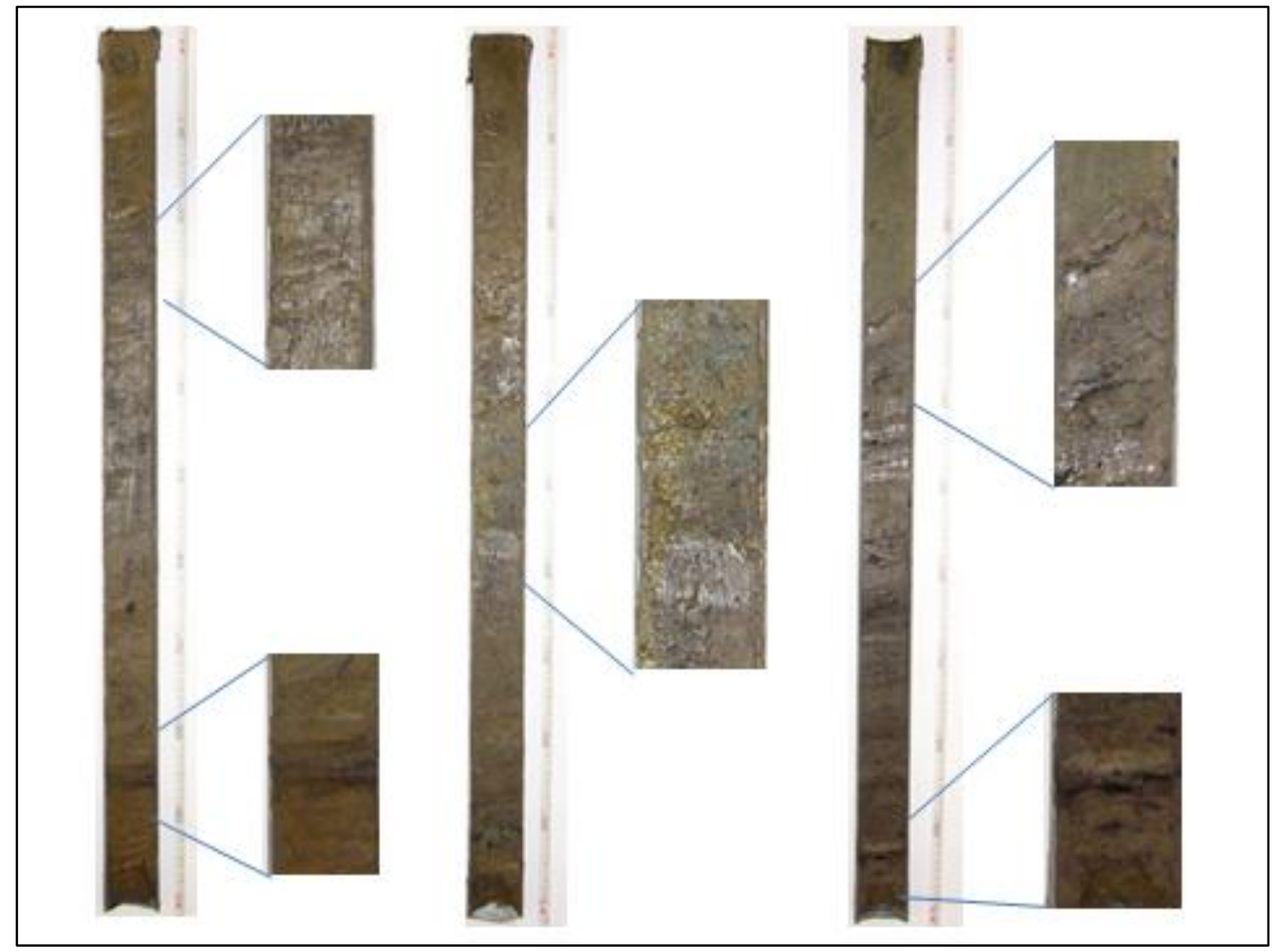

$\underline{\text { Tangihau Core }}$

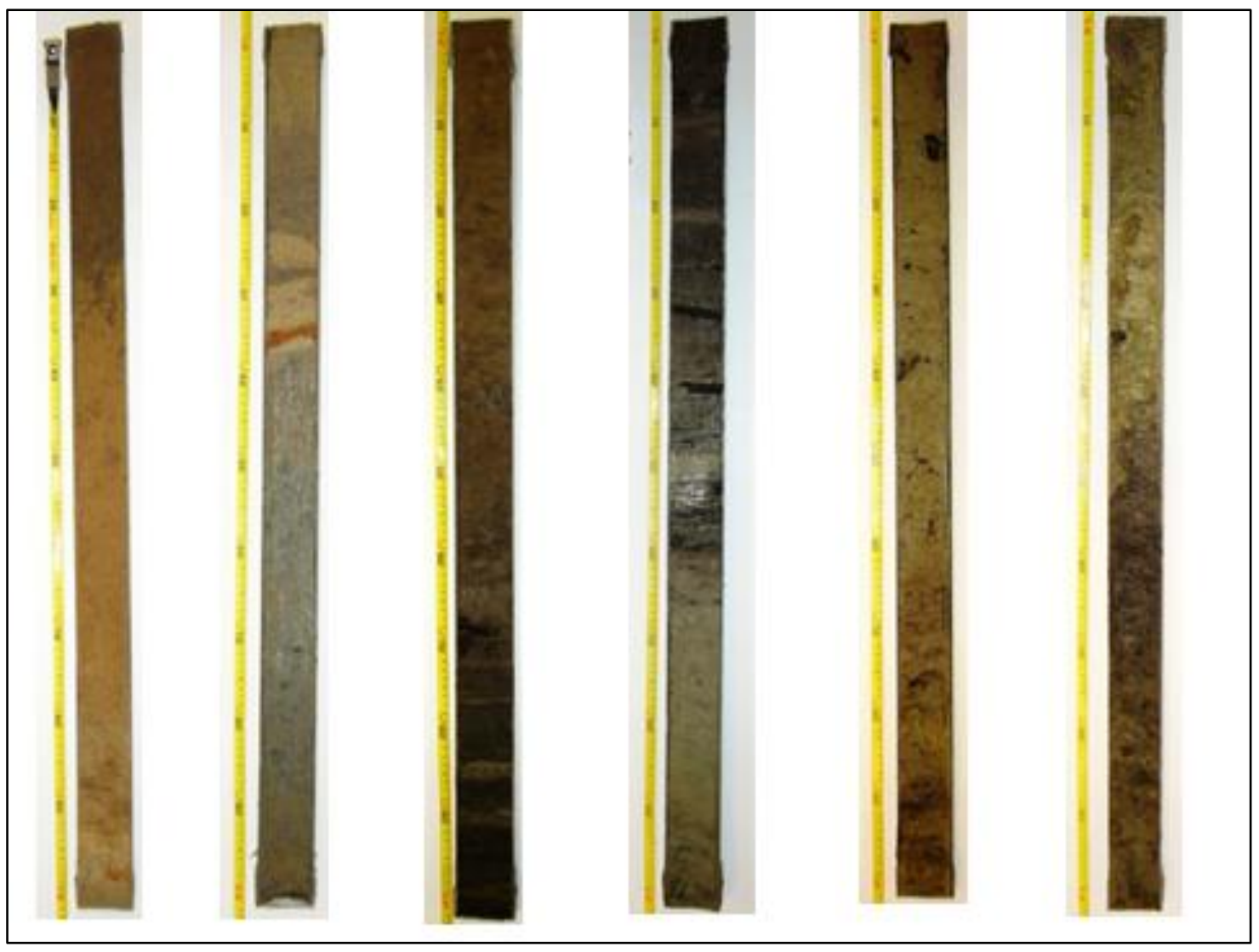

$218 \mid \mathrm{P}$ a g e 

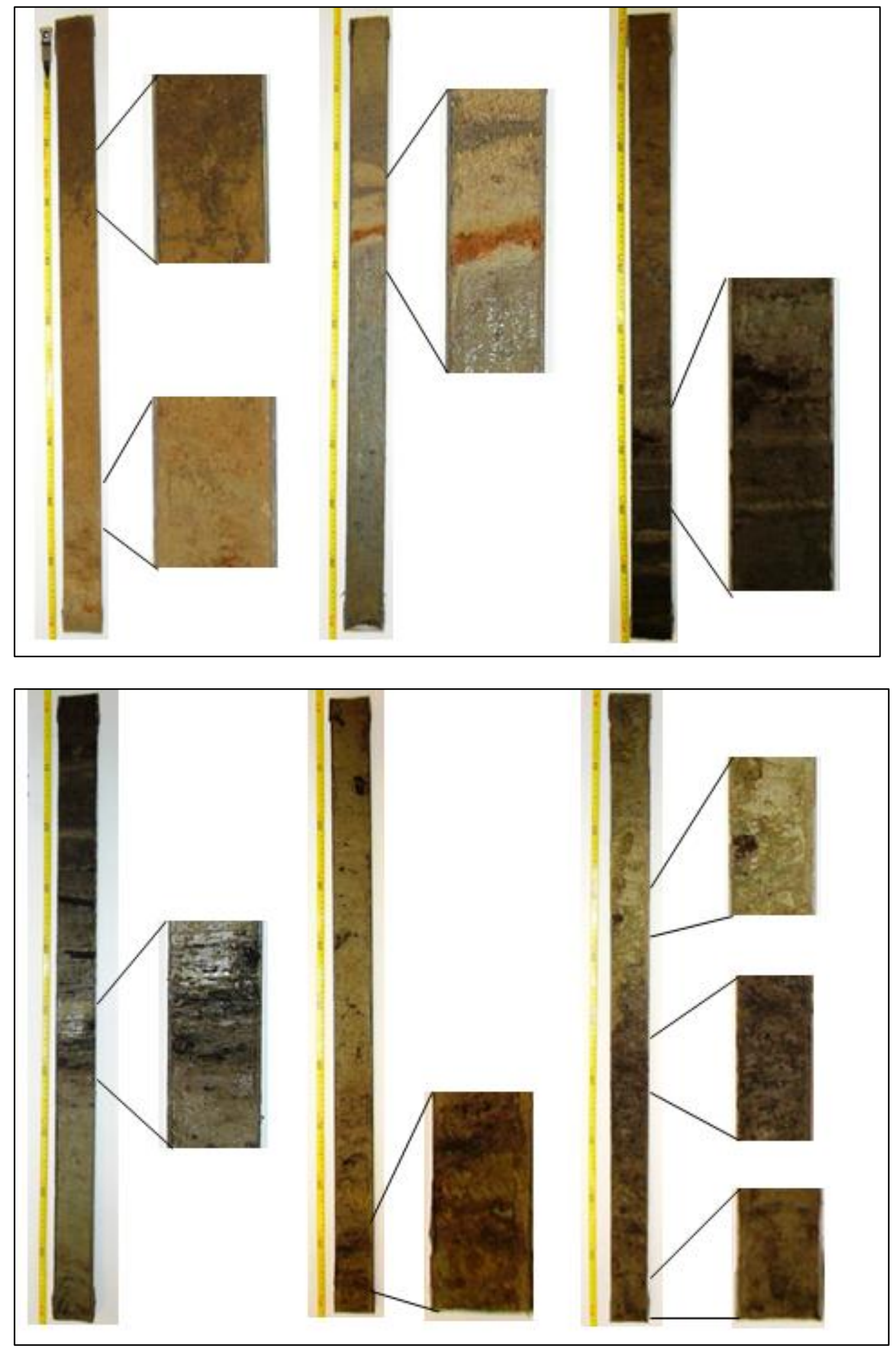

219 |P a g e 
Monck Road
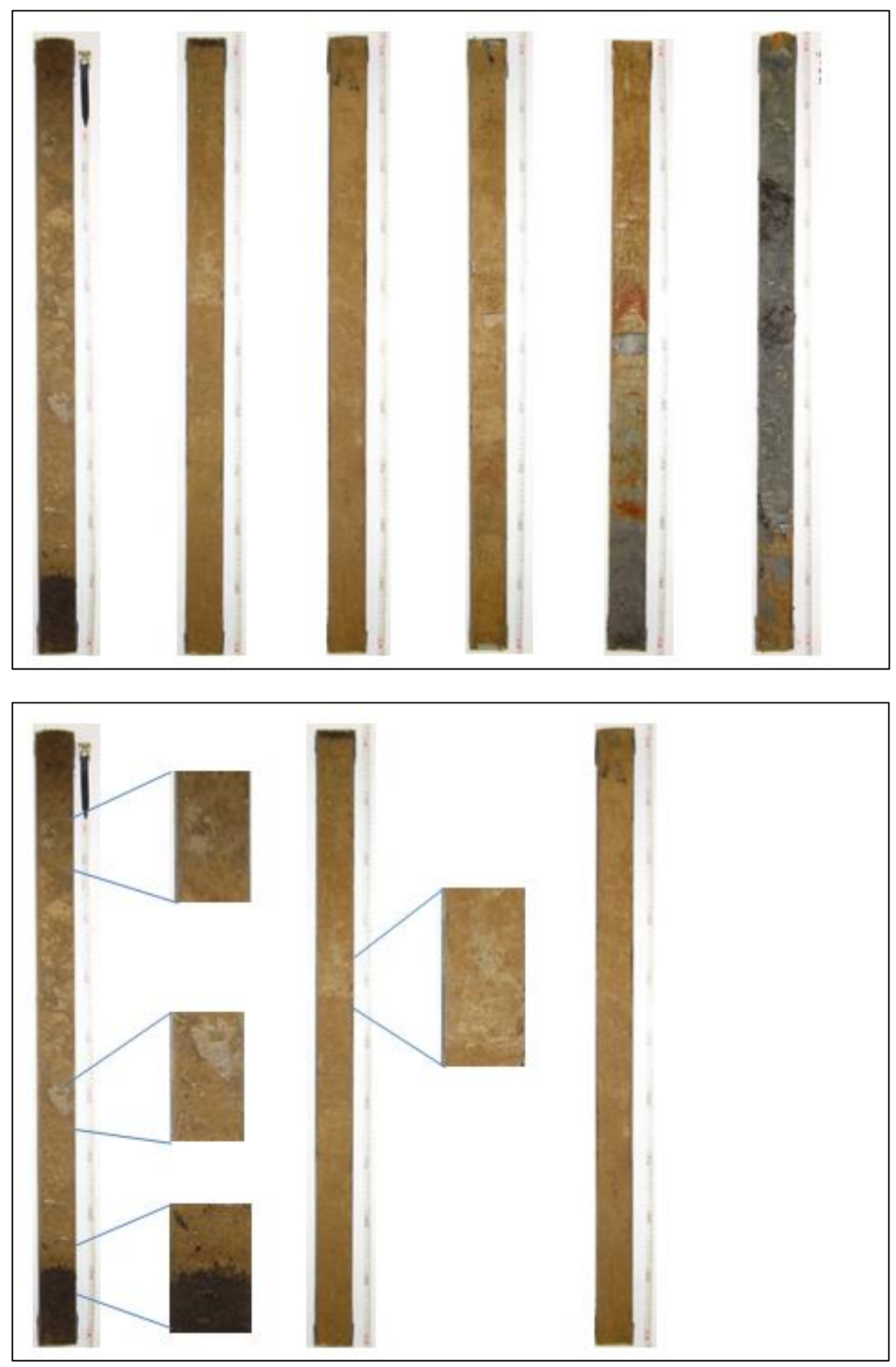

$220 \mid \mathrm{P}$ a g e 


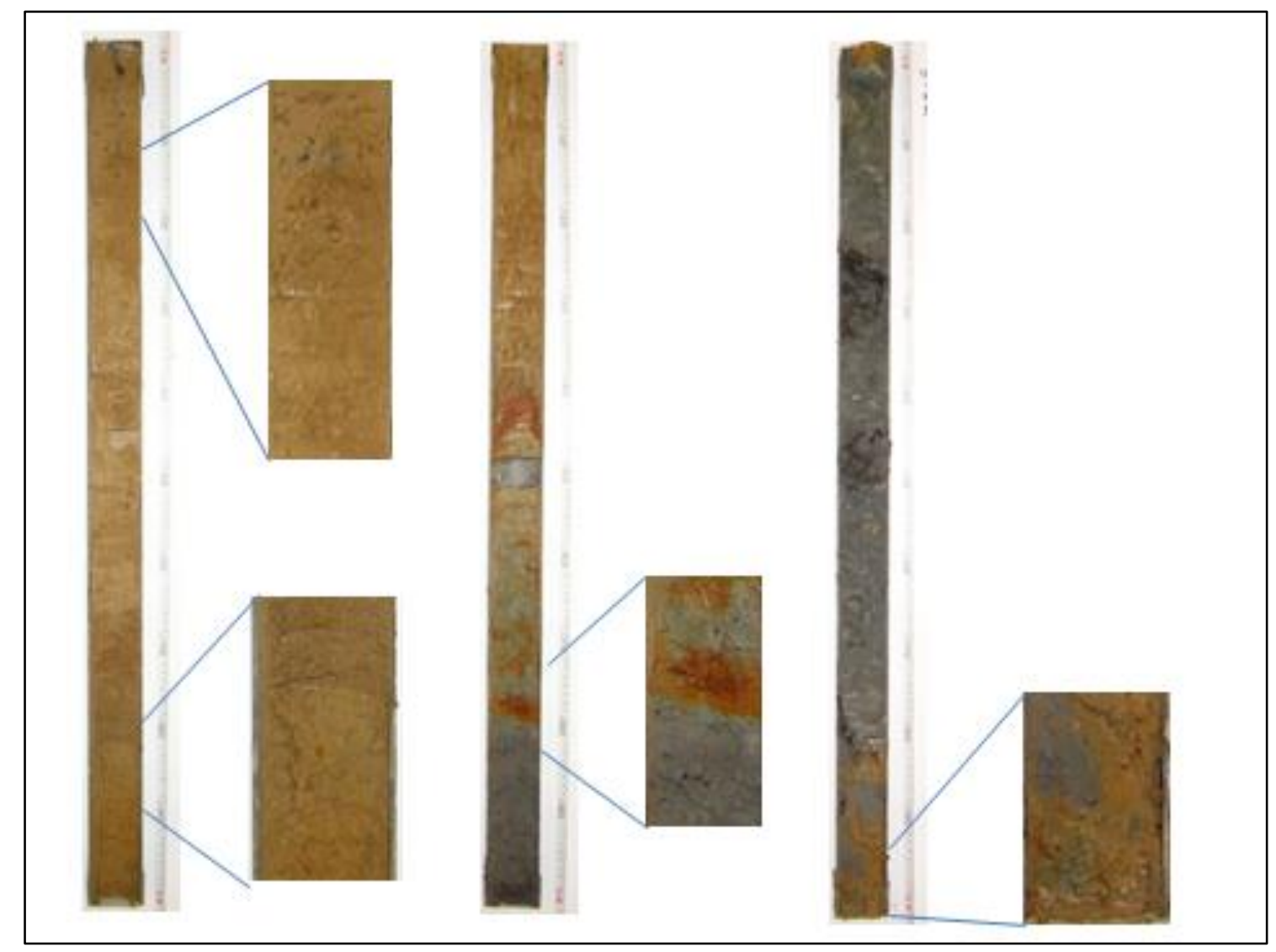

$221 \mid \mathrm{P}$ a g e 
Appendix E 
APPENDIX E

\begin{tabular}{|c|c|c|c|c|c|c|}
\hline & Probe Mount & & $\mathrm{SiO}_{2}$ & $\mathrm{Al}_{2} \mathrm{O}_{3}$ & $\mathrm{TiO}_{2}$ & $\mathrm{FeO}$ \\
\hline \multirow[t]{15}{*}{ WT1-T1 } & 10-11_11 & 6 & 78.55 & 12.35 & 0.13 & 0.95 \\
\hline & 10-11_12 & 7 & 78.42 & 12.35 & 0.11 & 0.87 \\
\hline & 10-11_13 & 8 & 75.55 & 13.68 & 0.26 & 1.88 \\
\hline & 10-11_14 & 9 & 76.50 & 13.30 & 0.17 & 1.76 \\
\hline & $10-11 \_15$ & 10 & 76.65 & 12.99 & 0.19 & 1.77 \\
\hline & 10-11_16 & 11 & 78.48 & 12.39 & 0.09 & 0.83 \\
\hline & 10-11_1 7 & 12 & 76.54 & 13.16 & 0.21 & 1.74 \\
\hline & 10-11_18 & 13 & 76.10 & 13.41 & 0.25 & 1.80 \\
\hline & 10-11_19 & 14 & 76.45 & 13.23 & 0.19 & 1.85 \\
\hline & 10-11_1 10 & 15 & 76.33 & 13.23 & 0.18 & 1.82 \\
\hline & 10-11_111 & 16 & 76.38 & 13.09 & 0.19 & 1.78 \\
\hline & 10-11_1 12 & 17 & 76.22 & 13.11 & 0.27 & 1.95 \\
\hline & $10-11 \_13$ & 18 & 76.38 & 13.19 & 0.20 & 1.79 \\
\hline & 10-11_1 14 & 19 & 76.83 & 13.09 & 0.16 & 1.78 \\
\hline & 10-11_1 15 & 20 & 76.16 & 13.39 & 0.24 & 1.91 \\
\hline \multirow[t]{15}{*}{ WT1-T2 } & 10-11_21 & 22 & 75.86 & 13.54 & 0.23 & 1.92 \\
\hline & 10-11_2 2 & 23 & 76.13 & 13.38 & 0.21 & 1.82 \\
\hline & 10-11_23 & 24 & 75.84 & 13.38 & 0.24 & 1.91 \\
\hline & $10-11 \_24$ & 25 & 75.71 & 13.45 & 0.25 & 1.91 \\
\hline & 10-11_25 & 26 & 75.88 & 13.52 & 0.20 & 1.95 \\
\hline & 10-11_26 & 27 & 75.45 & 13.63 & 0.22 & 2.01 \\
\hline & 10-11_27 & 28 & 76.03 & 13.36 & 0.23 & 1.86 \\
\hline & 10-11_28 & 29 & 75.88 & 13.35 & 0.24 & 1.96 \\
\hline & 10-11_29 & 30 & 75.69 & 13.49 & 0.21 & 1.96 \\
\hline & 10-11_2 10 & 31 & 75.62 & 13.52 & 0.25 & 1.99 \\
\hline & 10-11_2 11 & 32 & 75.59 & 13.54 & 0.25 & 1.89 \\
\hline & 10-11_2 12 & 33 & 75.76 & 13.50 & 0.25 & 1.88 \\
\hline & $10-11 \overline{2} 213$ & 34 & 75.55 & 13.58 & 0.23 & 1.98 \\
\hline & 10-11_2 14 & 35 & 75.88 & 13.45 & 0.23 & 1.94 \\
\hline & 10-11_2 15 & 36 & 75.74 & 13.50 & 0.24 & 1.92 \\
\hline \multirow[t]{6}{*}{ WT1-T3 } & 10-11_31 & 42 & 76.37 & 13.18 & 0.19 & 1.8 \\
\hline & $10-11 \_32$ & 43 & 76.18 & 13.28 & 0.20 & 1.78 \\
\hline & 10-11_33 & 44 & 78.31 & 12.50 & 0.09 & 0.84 \\
\hline & $10-11 \_34$ & 45 & 76.82 & 13.05 & 0.20 & 1.78 \\
\hline & $10-11 \_35$ & 46 & 78.53 & 12.31 & 0.08 & 0.8 \\
\hline & $10-11 \_36$ & 47 & 76.14 & 13.29 & 0.20 & \\
\hline
\end{tabular}

